Published in final edited form as:

Cochrane Database Syst Rev. ; 4: CD008712. doi:10.1002/14651858.CD008712.pub2.

\title{
Cognitive behavioural therapy versus other psychosocial treatments for schizophrenia
}

\author{
Christopher Jones ${ }^{1}$, David Hacker ${ }^{2}$, Irene Cormac ${ }^{3}$, Alan Meaden ${ }^{2}$, and Claire B Irving ${ }^{4}$ \\ ${ }^{1}$ School of Psychology, University of Birmingham, Birmingham, UK \\ ${ }^{2}$ Birmingham and Solihull Mental Health Foundation NHS Trust, Birmingham, UK \\ ${ }^{3}$ Fleming House, Rampton Hospital, Retford, UK \\ ${ }^{4}$ Cochrane Schizophrenia Group, The University of Nottingham, Nottingham, UK
}

\begin{abstract}
Background-Cognitive behavioural therapy (CBT) is now a recommended treatment for people with schizophrenia. This approach helps to link the person's distress and problem behaviours to underlying patterns of thinking.
\end{abstract}

Objectives-To review the effects of CBT for people with schizophrenia when compared with other psychological therapies.

Search methods-We searched the Cochrane Schizophrenia Group Trials Register (March 2010) which is based on regular searches of CINAHL, EMBASE, MEDLINE and PsycINFO. We inspected all references of the selected articles for further relevant trials, and, where appropriate, contacted authors.

Selection criteria-All relevant randomised controlled trials (RCTs) of CBT for people with schizophrenia-like illnesses.

Data collection and analysis-Studies were reliably selected and assessed for methodological quality. Two review authors, working independently, extracted data. We analysed dichotomous data on an intention-to-treat basis and continuous data with $65 \%$ completion rate are presented.

Copyright $\odot 2014$ The Cochrane Collaboration. Published by John Wiley \& Sons, Ltd

Contact address: Christopher Jones, School of Psychology, University of Birmingham, Edgbaston, Birmingham, B15 2TT, UK. c.a.jones@bham.ac.uk.

Editorial group: Cochrane Schizophrenia Group.

Publication status and date: Edited (no change to conclusions), published in Issue 3, 2014.

Review content assessed as up-to-date: 8 March 2010.

CONTRIBUTIONS OF AUTHORS

Chris Jones - protocol formulation, searching, trial selection, data extraction, report writing.

David Hacker - protocol formulation, searching, trial selection, data extraction, report writing.

Irene Cormac - protocol formulation, searching, trial selection, data extraction, report writing.

Alan Meaden - protocol formulation, searching, trial selection, data extraction, report writing.

Claire Irving - protocol formulation, searching, trial selection, data extraction, report writing.

DECLARATIONS OF INTEREST

Chris Jones is a Clinical Psychologist who specialises in neuropsychology.

David Hacker is a Clinical Psychologist who specialises in neuropsychology.

Alan Meaden is a Clinical Psychologist who works with persons with psychosis.

Irene Cormac is a Forensic Psychiatrist - no declarations of interest.

Claire Irving - no declarations of interest. 
Where possible, for dichotomous outcomes, we estimated a risk ratio (RR) with the $95 \%$ confidence interval (CI) along with the number needed to treat/harm.

Main results-Thirty one papers described 20 trials. Trials were often small and of limited quality. When CBT was compared with other psychosocial therapies, no difference was found for outcomes relevant to adverse effect/events ( 2 RCTs, $n=202$, RR death $0.57 \mathrm{CI} 0.12$ to 2.60). Relapse was not reduced over any time period ( 5 RCTs, $n=183$, RR long-term 0.91 CI 0.63 to 1.32) nor was rehospitalisation ( $5 \mathrm{RCTs}, \mathrm{n}=294$, $\mathrm{RR}$ in longer term $0.86 \mathrm{CI} 0.62$ to 1.21 ). Various global mental state measures failed to show difference (4 RCTs, $n=244$, RR no important change in mental state $0.84 \mathrm{CI} 0.64$ to 1.09 ). More specific measures of mental state failed to show differential effects on positive or negative symptoms of schizophrenia but there may be some longer term effect for affective symptoms ( 2 RCTs, $\mathrm{n}=105$, mean difference (MD) Beck Depression Inventory (BDI) $-6.21 \mathrm{CI}-10.81$ to -1.61 ). Few trials report on social functioning or quality of life. Findings do not convincingly favour either of the interventions ( 2 RCTs, $n=103$, MD Social Functioning Scale(SFS) 1.32 CI -4.90 to 7.54 ; $n=37$, MD EuroQOL -1.86 CI -19.20 to 15.48). For the outcome of leaving the study early, we found no significant advantage when CBT was compared with either non-active control therapies (4 RCTs, $n=433$, RR 0.88 CI 0.63 to 1.23 ) or active therapies (6 RCTs, $\mathrm{n}=339$, RR 0.75 CI 0.40 to 1.43 )

Authors' conclusions-Trial-based evidence suggests no clear and convincing advantage for cognitive behavioural therapy over other - and sometime much less sophisticated - therapies for people with schizophrenia.

\section{Medical Subject Headings (MeSH)}

Cognitive Therapy [*methods]; Schizophrenia [*therapy]

\section{MeSH check words}

Adult; Humans; Middle Aged

\section{BACKGROUND}

\section{Description of the condition}

Schizophrenia is a serious mental illness affecting one per cent of the population, irrespective of culture, class or race. The illness varies in its severity and in the variety of its symptoms. Every year one person per 10,000 begins to fall ill with schizophrenia, making it about twice as common as epilepsy (APA 1995). The first episode of schizophrenia often occurs when a person is in their early twenties (WHO 1973) and the course of the illness is variable. Many people experience considerable disability and there is a substantial increase in mortality (Drake 1986). Some people have difficulties with their thoughts, making illogical associations and developing false and sometimes bizarre explanations (i.e., delusions) for their experiences or symptoms. Problems with false perceptions may occur, for example, hearing voices or seeing visions (hallucinations). Difficulties with concentration, attention and motivation may also lead to poor social and occupational functioning. The range of emotional expression, capacity to think and act may be reduced, together with an inability to experience pleasure. It is customary to view the symptoms of 
schizophrenia as falling into two broad categories: (i) 'positive' symptoms, which are unusual by their presence (for example, hearing voices); and (ii) 'negative' symptoms, which are unusual by their absence (for example, restricted range and intensity of emotional expression).

\section{Description of the intervention}

Medication is the mainstay of treatment for schizophrenia but 5\% to $25 \%$ of people continue to experience symptoms in spite of medication (Christison 1991; Davis 1977; Meltzer 1992) and may experience side effects that are unwanted and unpleasant.

Talking therapies may also be used in addition to medication. In cognitive behaviour therapy (CBT), links are made between the person's feelings and patterns of thinking which underpin their distress. The participant is encouraged to take an active part by using the following techniques.

1. Challenging the habitual patterns of thinking.

2. Examining the evidence for and against the distressing beliefs.

3. Using reasoning abilities and personal experience to develop rational and personally acceptable alternative explanations and interpretations (Alford 1994) and to test these alternative explanations in real world situations. Tarrier 1993 has stressed the beneficial effects of enhancing coping strategies and general problemsolving skills. At present, a variety of interventions have been labelled as CBT and it is difficult to provide a single, unambiguous definition. In recognition, the review authors have constructed criteria that are felt to be both workable and to capture the elements of good practice in CBT.

Cognitive behavioural therapy is becoming increasingly available for people with schizophrenia, with recent recommendations of national treatment guidelines suggesting that CBT should be more widely available for people with schizophrenia (NICE 2009). This 2009 update of NICE 2002 is more directive in its support of the use of CBT for people with schizophrenia than the earlier version. In addition, many of the trials of CBT for psychosis have incorporated additional active therapeutic elements (e.g., psychoeducation and relapse prevention, etc) that would be considered adjunctive to techniques which are specifically targeted at eliciting belief change (e.g., guided discovery or behavioural experiments).

\section{How the intervention might work}

Cognitive behavioural therapy aims to remediate distressing emotional experiences or dysfunctional behaviour by changing the way in which the individual interprets and evaluates the experience or cognates on its consequence and meaning. Cognitive behavioural therapy encourages the person to identify and challenge biased interpretations of experiences that may be maintaining symptoms. Many of the CBT programmes (e.g. Garety 2008) are based upon a stress-vulnerability model of symptom onset and relapse. The empirical evidence for the stress-vulnerability model has been questioned (McKenna 2007).

In a recent theoretical review of the potential change processes that CBT for psychosis might possess, Birchwood 2006 distinguishes between "quasi-neuroleptic" effects of CBT 
upon psychotic symptoms (e.g., hallucination) and the emotional and behavioural consequences of such experiences or their treatment. Accordingly, Birchwood 2006 distinguishes between emotional/behavioural distress and psychotic symptomatology and advocates the former as an appropriate target for CBT interventions. Specifically, Birchwood 2006 suggests that CBT might focus upon the following.

1. Distress reduction or the reduction of depression and problem behaviour associated with beliefs about psychotic symptomatology.

2. The emotional and interpersonal difficulty in individuals at high risk of developing psychosis.

3. Relapse prodromes to prevent relapse in psychosis.

4. 'Comorbid' depression and social anxiety, including the patient's appraisal of the diagnosis and its stigmatising consequences.

5. General stress reactivity, thereby increasing resilience to life stress and preventing psychotic relapse.

6. Increasing self-esteem and social confidence in people with psychosis.

However, many of the current trials of CBT for psychosis have defined their outcomes in terms of psychotic symptomatology (e.g., hallucinatory and delusional experience) rather than distress, problem behaviour or stigma and self esteem.

\section{Why it is important to do this review}

Despite national treatment guidelines recommending CBT as an adjunct therapy for serious mental illness (NICE 2009), it is still not as widely available for people with schizophrenia as it is for people with other disorders (for example, depression and panic disorder).

The first case report of CBT for delusional beliefs in 1952, reported by Beck 2005, did not lead to widespread development of CBT for schizophrenia or its symptoms. Psychological interventions have become more widely accepted over the past two decades and are now seen as part of a comprehensive set of routine interventions in the treatment and management of schizophrenia (NICE 2009; Turkington 2004). However, the availability of CBT and other evidence-based therapies on the NHS is extremely limited, despite government efforts to improve access. Waiting times of more than a year are commonplace (Bird 2006). The delivery of CBT to people with schizophrenia also depends upon having a commitment from health service managers to support and facilitate training and supervision (Turkington 2004).

Since the publication of the original Cochrane review of 'Cognitive behavioural therapy for schizophrenia' (Jones 2004) there has been a substantial increase in the number of published and relevant clinical trials, and a refinement in the definition and working models of CBT. In addition, there has also been a diversification of research, with trials not only assessing overall effectiveness but investigating more specific aspects of CBT. Updating and splitting the original review of CBT to create a family of CBT reviews (see Jones 2009a and Jones 2009b) to incorporate and address this new more diverse data is necessary. This particular 
review will provide information about CBT's relative effectiveness compared with other similar adjunct psychosocial therapies.

\section{OBJECTIVES}

To assess the effectiveness of adjunct CBT for people with schizophrenia compared with other adjunct psychosocial interventions.

\section{METHODS}

\section{Criteria for considering studies for this review}

Types of studies-All relevant randomised controlled trials (RCTs). We excluded quasirandomised trials, such as those where allocation is undertaken on surname. If a trial was described as double-blind, but it was implied it had been randomised, we included these trials in a sensitivity analysis. We included randomised cross-over studies but only data up to the point of first cross-over because of the instability of the problem behaviours and the likely carry-over effects of all treatments.

As CBT requires the person to actively engage and participate in the therapy, it may not be possible to blind the participant to condition (that is, it may not be possible to provide a placebo control condition to reduce the effects of anticipated outcome on behalf of the participant). However, it is possible and desirable to blind the trialist to condition (that is, the trialist collecting outcome data is unaware of the allocation of the individual participant). Accordingly, single-blind trials are considered of appropriate methodological quality for the assessment of this type of intervention.

We compared the outcomes of trials that described a single-blind procedure with trials that did not describe any blinding procedure. If there was no substantive difference within primary outcomes (see Types of outcome measures) when these non-blinded studies were added, then we did not include them in the final analysis. If there was a substantive difference, we only used only singleblinded randomised trials and the results of the sensitivity analysis are described in the text.

Types of participants-People with a current diagnosis of schizophrenia, diagnosed by any criteria, irrespective of gender or race. We did not include participants who had very late onset of illness (onset after the age of 60 years) or those with other psychotic disorders such as bipolar affective disorder, substance-induced psychosis, significant physical or sensory difficulties or people with coexisting developmental disorders and/or learning disabilities. If studies randomised people with schizophrenia and those with the above disorders, we only included trials where more than $50 \%$ of the participants had a diagnosis of schizophrenia.

This review did not include trials that report outcomes from participants deemed to be "atrisk" of developing schizophrenia in the future. 


\section{Types of interventions}

1. Cognitive behavioural therapy (CBT): The label cognitive behavioural therapy has been applied to a variety of interventions, accordingly, is difficult to provide a single, unambiguous definition. Recognising this, the review authors constructed criteria that were felt to be both workable and to capture the elements of good practice in CBT.

In order to be classified as 'well-defined' the intervention must clearly demonstrate the following components:

- a discrete psychological intervention, which is in addition to, and separate from, other therapeutic interventions (for example, behavioural family therapy) and

- recipients establish links between their symptoms, thoughts and beliefs, and consequent distress or problem behaviour and

- the re-evaluation of their perceptions, beliefs or reasoning relating to the target symptoms; this may include the reevaluation of specific "inferential" beliefs or more global "evaluative" beliefs.

All therapies that did not meet these criteria (or that provided insufficient information) but were labelled as 'CBT' or 'Cognitive Therapy' were included as 'less-well-defined CBT'. We conducted a sensitivity analysis on the primary outcomes of this review (see Types of outcome measures) in order to investigate whether a 'well-defined' implementation of this therapy presents with differential outcomes.

In addition, we undertook a sensitivity analysis between studies that employed qualified CBT therapists compared with relatively unqualified CBT therapists. Qualified CBT therapists may be defined as:

- persons possessing appropriate professional qualifications for the provision of CBT (e.g., British Association of Behavioural and Cognitive Psychotherapy (BABCP) accreditation, Diploma in CBT, or other professionally accredited qualifications involving CBT as major part of training (e.g. Clinical or Counselling Psychologist)) or

- in situations where the qualifications of the therapist are unclear but they appear to have received training in CBT or specific training for the trial and there is a thorough adherence protocol.

Unqualified CBT therapists may be defined as persons not possessing appropriate professional qualifications or no report of training and adherence protocols.

2. Other psychosocial interventions: Where standard care has been supplemented by additional psychological or social interventions, or both, such as supportive therapy, psychoeducation, family therapy and other 'talking therapies'. This review distinguishes between trials that described 'active' psychosocial interventions (e.g., family therapy) aimed at a meaningful symptom reduction and those trials which have used 'non-active' psychosocial interventions (e.g., unstructured conversations) which act as merely a control for the nonspecific effects of therapy (e.g., time spent with therapist). Outcomes are presented 
separately for active and non-active psychosocial interventions and the pooled effect of these trials is also presented.

Types of outcome measures-Outcomes can be categorised as being of short-, medium- or long-duration. A short-term outcome is defined as occurring within the period typically associated with active treatment. The National Institute for Clinical Excellence (NICE) asserts that "for it to make a difference, [the patient] should have CBT treatment for more than 6 months, meeting for more than ten treatment sessions" (NICE 2009).

Accordingly, in this review, we have grouped outcomes into those measured in the shortterm (within 24 weeks of the onset of therapy), medium-term (within 24 to 52 weeks of the onset of therapy) and long-term (over 52 weeks since the onset of therapy).

Outcomes can also be grouped into broad areas (Table 1).

\section{Primary outcomes}

1. Death: 1.1 Any cause and sudden, unexpected death or suicide.

2. Mental state: 2.1 No clinically important response as defined by the individual studies (for example global impression less than much improved, or less than $50 \%$ reduction on a specified rating scale) - short-, medium- and long-term.

\section{Secondary outcomes}

\section{Mental state}

2.2 No change in general mental state.

2.3 Average endpoint general mental state score.

2.4 Average change in general mental state scores.

2.5 No clinically important change in specific symptoms.

2.6 Not any change in specific symptoms.

2.7 Average endpoint specific symptom score.

2.8 Average change in specific symptom scores.

\section{Adverse effects}

3.1 Not any general adverse effects.

3.2 Average endpoint general adverse effect score.

3.3 Average change in general adverse effect scores.

3.4 No clinically important change in specific adverse effects.

3.5 Not any change in specific adverse effects.

3.6 Average endpoint specific adverse effects.

3.7 Average change in specific adverse effects. 


\section{Engagement with services}

4.1 No clinically important engagement.

4.2 Not any engagement.

4.3 Average endpoint engagement score.

4.4 Average change in engagement scores.

4.5 Compliance with medication/treatment.

\section{Global state}

\subsection{Relapse.}

5.2 Hospitalisation.

5.3 Average endpoint general functioning score.

5.4 Average change in general functioning scores.

5.5 No clinically important change in specific aspects of functioning, such as social or life skills.

5.6 Not any change in specific aspects of functioning, such as social or life skills.

5.7 Average endpoint specific aspects of functioning, such as social or life skills.

5.8 Average change in specific aspects of functioning, such as social or life skills.

\section{Quality of life}

6.1 No clinically important change in quality of life.

6.2 Not any change in quality of life.

6.3 Average endpoint quality of life score.

6.4 Average change in quality of life scores.

6.5 No clinically important change in specific aspects of quality of life.

6.6 Not any change in specific aspects of quality of life.

6.7 Average endpoint specific aspects of quality of life.

6.8 Average change in specific aspects of quality of life.

\section{Satisfaction with treatment}

7.1 Leaving the study early: specific reason

7.2 Recipient of care not satisfied with treatment.

7.3 Recipient of care average satisfaction score.

7.4 Recipient of care average change in satisfaction scores.

7.6 Carer not satisfied with treatment. 
7.7 Carer average satisfaction score.

7.8 Carer average change in satisfaction scores.

\section{Economic}

\subsection{Direct costs.}

8.2 Indirect costs.

\section{Search methods for identification of studies \\ Electronic searches}

\section{Electronic searches}

1.1 The Cochrane Schizophrenia Group's Register (March 2010): This was searched by the Trial Search Co-ordinator of the Cochrane Schizophrenia Group, Samantha Roberts, using the phrase:

$\left\{\left[\left({ }^{*}\right.\right.\right.$ cogniti* AND $(*$ behavio* or therap*)) OR $(*$ cogniti* and $(*$ technique* or *restructur* or *challeng*)) OR (*self* and (*instruct* or *management* or *attribution*)) OR (*ational* and *emotiv*) in title, abstract, index terms of REFERENCE] or [Cognitive* in interventions of STUDY]\}

This register is compiled by systematic searches of major databases, handsearches and conference proceedings (see group module).

2. Details of previous searches for previous CBT review: For search details used in Jones 2004 Please see Appendix 1.

\section{Searching other resources}

1. Reference lists: We searched all references of included articles for further relevant trials.

2. Authors: When appropriate, we contacted the first author of each of the included papers and requested additional published and unpublished materials.

\section{Data collection and analysis}

Selection of studies-Three review authors (AM, DH \& CAJ) independently inspected all identified citations. When disputes arose as to which category a citation should be allocated, resolution was attempted by discussion. When this was not possible, we acquired the full article. Two review authors (DH, CAJ) independently inspected all articles identified in this way. When disputes arose as to whether an article was indeed relevant to this review, we attempted resolution by discussion. When this was not possible, we asked another review authors (CI) to read the article and decide. IR, AM and CI reviewed 30\% of the citations and articles, included and excluded by DH and CAJ, to check the use of inclusion criteria.

\section{Data extraction and management}

1. Extraction: Review authors DH and CAJ extracted data from all included studies. In addition, to ensure reliability, $\mathrm{CI}$ independently extracted data from a random sample of 
these studies, comprising $10 \%$ of the total. We resolved disputes by discussion and adjudication from the other review authors (AM, CI and IC) if necessary. When it was not possible to extract data or if further information was needed, we attempted to contact the authors. We extracted data presented only in graphs and figures whenever possible, but the data were included only if two review authors independently had the same result. We attempted to contact authors through an open-ended request in order to obtain missing information or for clarification whenever necessary. Where possible, we extracted data relevant to each component centre of multi-centre studies separately.

\section{Management}

2.1 Forms: We extracted data onto standard, simple forms.

2.2 Scale-derived data: We included continuous data from rating scales only if: a. the psychometric properties of the measuring instrument had been described in a peer-reviewed journal (Marshall 2000); and b. the measuring instrument was not written or modified by one of the trialists for that particular trial; and c. the measuring instrument was either i. a self-report or ii. completed by an independent rater or relative (not the therapist).

2.3 Endpoint versus change data: There are advantages of both endpoint and change data. Change data can remove a component of between-person variability from the analysis. On the other hand, calculation of change needs two assessments (baseline and endpoint) which can be difficult in unstable and difficult to measure conditions such as schizophrenia. We decided to primarily use endpoint data and only use change data if the former were not available. We combined endpoint and change data in the analysis as we used mean differences rather than standardised mean differences throughout (Higgins 2009).

2.4 Skewed data: Continuous data on clinical and social outcomes are often not normally distributed. To avoid the pitfall of applying parametric tests to non-parametric data, we aimed to apply the following standards to all data before inclusion: a) standard deviations and means are reported in the paper or obtainable from the authors; b) when a scale starts from the finite number zero, the standard deviation (SD), when multiplied by two, is less than the mean (as otherwise the mean is unlikely to be an appropriate measure of the centre of the distribution, (Altman 1996); c) if a scale started from a positive value (such as Positive and Negative Syndrome Scale (PANSS) which can have values from 30 to 210), the calculation described above was modified to take the scale starting point into account. In these cases skew is present if $2 \mathrm{SD}>(\mathrm{S}-\mathrm{S} \mathrm{min})$, where $\mathrm{S}$ is the mean score and $\mathrm{S}$ min is the minimum score. Endpoint scores on scales often have a finite start and end point and these rules can be applied. When continuous data are presented on a scale that includes a possibility of negative values (such as change data), it is difficult to tell whether data are skewed or not. We planned to enter skewed data from studies of less than 200 participants in additional tables rather than into an analysis. Skewed data pose less of a problem when looking at means if the sample size is large and such data were entered into syntheses. 
2.5 Common measure: To facilitate comparison between trials, we intended to convert variables that can be reported in different metrics, such as days in hospital (mean days per year, per week or per month) to a common metric (e.g. mean days per month).

2.6 Conversion of continuous to binary: Where possible, efforts were made to convert outcome measures to dichotomous data. This could be done by identifying cut-off points on rating scales and dividing participants accordingly into 'clinically improved' or 'not clinically improved'. It was generally assumed that if there had been a 50\% reduction in a scale-derived score such as the Brief Psychiatric Rating Scale (BPRS, Overall 1962) or the PANSS (Kay 1987), this could be considered as a clinically significant response (Leucht 2005a; Leucht 2005b). If data based on these thresholds were not available, we used the primary cut-off presented by the original authors.

2.7 Direction of graphs: Where possible, we entered data in such a way that the area to the left of the line of no effect indicates a favourable outcome for CBT.

2.8 Summary of findings table: We anticipated including the following short- or mediumterm outcomes in a 'Summary of findings' table.

\subsection{Relapse}

1.2 Re-hospitalisation

1.3 Healthy days

2.1 Improved to an important extent

3.1 Any adverse event

\subsection{Employed}

5.1 Not improved to an important extent

Assessment of risk of bias in included studies-Two review authors (DH and CAJ) assessed risk of bias using the tool described in the Cochrane Handbook for Systematic Reviews of Interventions (Higgins 2009). This tool encourages consideration of how the randomisation sequence was generated, how allocation was concealed, the integrity of blinding at outcome measurement, the completeness of outcome data, selective reporting and other biases. We excluded studies where sequence generation was at a high risk of bias or where allocation was clearly not concealed. If disputes arose as to the correct category for a trial, this was resolved through discussion and adjudication by the other review authors (AM, CI and IC) if necessary. If this was not possible because further information was necessary, we intended not to enter the data but to allocate the trial to the list of those awaiting assessment. Review authors were not blinded to the names of the authors, institutions, journal of publication, or results of the trials.

Measures of treatment effect-We adopted $\mathrm{P}=0.05$ as the conventional level of statistical significance but we were especially cautious where results were only slightly below this, and we reported $95 \%$ confidence intervals $(\mathrm{CI})$ in preference to $\mathrm{P}$ values. 
1. Binary data: For binary outcomes, we calculated a standard estimation of the risk ratio (RR) and its 95\% CI. It has been shown that RR is more intuitive (Boissel 1999) than odds ratios (OR) and that (OR) tend to be interpreted as RR by clinicians (Deeks 2000). For statistically significant results, we had planned to calculate the number needed to treat to provide benefit/to induce harm statistic (NNTB/H), and its 95\% CI using Visual Rx (http:// www.nntonline.net/) taking account of the event rate in the control group, but this has been superseded by the Summary of findings for the main comparison.

2. Continuous data: For continuous outcomes, we estimated mean difference (MD) between groups. We preferred not to calculate effect size measures (standardised mean difference SMD). However, had scales of very considerable similarity been used, we would have presumed there was a small difference in measurement, and we would have calculated effect size and transformed the effect back to the units of one or more of the specific instruments.

\section{Unit of analysis issues}

1. Cluster trials: Studies increasingly employ 'cluster randomisation' (such as randomisation by clinician or practice) but analysis and pooling of clustered data poses problems. Firstly, authors often fail to account for intra-class correlation in clustered studies, leading to a 'unit of analysis' error (Divine 1992) whereby P values are spuriously low, CIs unduly narrow and statistical significance overestimated. This causes type I errors (Bland 1997; Gulliford 1999).

Where clustering was not accounted for in primary studies, we had planned to present data in a table, with a $\left(^{*}\right)$ symbol to indicate the presence of a probable unit of analysis error. In subsequent versions of this review we will seek to contact first authors of studies to obtain intra-class correlation coefficients for their clustered data and to adjust for this by using accepted methods (Gulliford 1999). Where clustering has been incorporated into the analysis of primary studies, we will present these data as if from a non-cluster randomised study, but adjust for the clustering effect.

We have sought statistical advice and been advised that the binary data presented in a report should be divided by a 'design effect'. This is calculated using the mean number of participants per cluster $(\mathrm{m})$ and the intra-class correlation coefficient $($ ICC) $[$ Design effect $=$ $1+(\mathrm{m}-1) * \mathrm{ICC}]$ (Donner 2002). If the ICC is not reported it is assumed to be 0.1

(Ukoumunne 1999).

If cluster studies had been appropriately analysed taking into account ICCs and relevant data documented in the report, synthesis with other studies would have been possible using the generic inverse variance technique.

2. Cross-over trials: A major concern of cross-over trials is the carry-over effect. It occurs if an effect (e.g. pharmacological, physiological or psychological) of the treatment in the first phase is carried over to the second phase. As a consequence, on entry to the second phase, the participants can differ systematically from their initial state despite a wash-out phase. For the same reason cross-over trials are not appropriate if the condition of interest is 
unstable (Elbourne 2002). As both effects are very likely in severe mental illness, had we found any cross-over trials, we planned to use only the data from the first phase of the study.

3. Studies with multiple treatment groups: Where a study involved more than two treatment arms, if relevant, we presented the additional treatment arms in the comparisons. Where the additional treatment arms were not relevant, we did not report these data.

\section{Dealing with missing data}

1. Overall loss of credibility: At some degree of loss of follow-up, the findings of a trial must lose credibility (Xia 2009). We were forced to make a judgment where this was for the very short-term trials likely to be included in this review. We decided that if more than $40 \%$ of data were unaccounted for at eight weeks, we would not reproduce these data or use them within analyses.

2. Binary: If attrition for a binary outcome was between $0 \%$ and $40 \%$ and outcomes of these people were described, we included these data as reported. Where these data were not clearly described for the primary outcome, we assumed the worst for each person who was lost, and for adverse effects, we assumed rates similar to those among patients who did continue to have their data recorded.

\section{Continuous}

3.1 Attrition: In the case where attrition for a continuous outcome was between $0 \%$ and $40 \%$ and completer-only data were reported, we have reproduced these.

3.2 Standard deviations: We first tried to obtain the missing values from the authors. If not available, where there were missing measures of variance for continuous data but an exact standard error (SE) and CI were available for group means, and either ' $\mathrm{P}$ ' value or ' $\mathrm{t}$ ' value were available for differences in mean, we noted these, and in future versions of this review we will calculate them according to the rules described in the Cochrane Handbook for Systematic Reviews of Interventions (Higgins 2009): When only the SE is reported, standard deviations (SDs) can be calculated by the formula $\mathrm{SD}=\mathrm{SE} *$ square root (n). Chapters 7.7.3 and 16.1.3 of the Cochrane Handbook for Systematic Reviews of Interventions (Higgins 2009) present detailed formula for estimating SDs from P values, t or F values, CIs, ranges or other statistics. If these formula do not apply, we, in the future will calculate SDs according to a validated imputation method which is based on the SDs of the other included studies (Furukawa 2006). Some of these imputation strategies can introduce error. The alternative would be to exclude a given study's outcome and thus to lose information. We will examine the validity of the imputations in a sensitivity analysis excluding imputed values.

3.3 Last observation carried forward: We anticipated that in some studies the method of Last Observation Carried Forward (LOCF) would be employed within the study report. As with all methods of imputation to deal with missing data, LOCF introduces uncertainty about the reliability of the results. Therefore, where LOCF data have been used in the trial, if 
less than $40 \%$ of the data had been assumed, we reproduced these data and indicated that they are the product of LOCF assumptions.

\section{Assessment of heterogeneity}

1. Clinical heterogeneity: We considered all included studies initially, without seeing comparison data, to judge clinical heterogeneity. We simply inspected all studies for clearly outlying situations or people which we had not predicted would arise. When such situations or participant groups arose, these were fully discussed.

2. Methodological heterogeneity: We considered all included studies initially, without seeing comparison data, to judge methodological heterogeneity. We simply inspected all studies for clearly outlying methods which we had not predicted would arise. When such methodological outliers arose these were fully discussed.

\section{Statistical heterogeneity}

3.1 Visual inspection: We visually inspected graphs to investigate the possibility of statistical heterogeneity.

3.2 Employing the $\mathbf{I}^{2}$ statistic: Heterogeneity between studies was investigated by considering the $\mathrm{I}^{2}$ method alongside the $\mathrm{Chi}^{2}$ ' $\mathrm{P}$ ' value. The $\mathrm{I}^{2}$ provides an estimate of the percentage of inconsistency thought to be due to chance (Higgins 2003). The importance of the observed value of $\mathrm{I}^{2}$ depends on i. magnitude and direction of effects and ii. strength of evidence for heterogeneity (e.g. ' $\mathrm{P}$ ' value from $\mathrm{Chi}^{2}$ test, or a CI for $\mathrm{I}^{2}$ ). We interpreted an $\mathrm{I}^{2}$ estimate greater than or equal to $75 \%$ accompanied by a statistically significant $\mathrm{Chi}^{2}$ statistic as evidence of substantial levels of heterogeneity (Higgins 2009). When substantial levels of heterogeneity were found in the primary outcome, we explored reasons for heterogeneity (Subgroup analysis and investigation of heterogeneity).

Assessment of reporting biases-Reporting biases arise when the dissemination of research findings is influenced by the nature and direction of results (Egger 1997). These are described in section 10.1 of the Cochrane Handbook for Systematic Reviews of Interventions (Higgins 2009). We are aware that funnel plots may be useful in investigating reporting biases but are of limited power to detect small-study effects. We did not use funnel plots for outcomes where there were 10 or fewer studies, or where all studies were of similar sizes. In other cases, where funnel plots were possible, we sought statistical advice in their interpretation.

Data synthesis-We understand that there is no closed argument for preference for use of fixed-effect or random-effects models. The random-effects method incorporates an assumption that the different studies are estimating different, yet related, intervention effects. The random-effects model takes into account differences between studies, even if there is no statistically significant heterogeneity. There is, however, a disadvantage to the random-effects model. It puts added weight onto small studies which often are the most biased ones. Depending on the direction of effect, these studies can either inflate or deflate the effect size. 


\section{Subgroup analysis and investigation of heterogeneity}

1. Subgroup analyses: We anticipated sub-group analyses to test the hypothesis that CBT may be highlighted to have different effects when compared with:

1.1 Active versus non-active control therapies: Active psychological treatments as opposed to inactive ones.

1.2 Rigorous criteria for diagnosing schizophrenia as opposed to more loose criteria: We defined 'rigorous' as involving operational criteria.

1.3 Rigorous criteria for describing CBT as opposed to a more loose description: We defined 'rigorous' as outlined this in Types of interventions.

1.4 People in first episode of illness versus those at a later stage of illness: For each of the above subgroups, we aimed to undertake the analysis for only the primary outcomes of this review or the nearest we could find to them (see Types of outcome measures) and if data were available discussed the findings in the Effects of interventions..

2. Investigation of heterogeneity: If inconsistency was high, this was reported. First, we investigated whether data had been entered correctly. Second, if data were correct, we visually inspected the graph and studies outside of the company of the rest were successively removed to see if heterogeneity was restored. When this occurred with no more than $10 \%$ of the data being excluded, we presented the data. If not, we did not pool data and discussed the issues.

Where unanticipated clinical or methodological heterogeneity were obvious, we simply stated hypotheses regarding these for future reviews or versions of this review. We did not anticipate undertaking analyses relating to these.

\section{Sensitivity analysis}

1. Implication of randomisation: We aimed to include trials in a sensitivity analysis if they were described in some way as to imply randomisation. For the primary outcomes, we included these studies and if there was no substantive difference when the implied randomised studies were added to those with better description of randomisation, then we used all the data from these studies.

2. Blinding: We aimed to include trials in a sensitivity analysis if they were described in some way that suggested they blinded for assessment of outcome as opposed to not blinding at all. For the primary outcomes, we compared findings of blinded and non-blinded studies.

3. Well-defined CBT versus less-well-defined CBT: We aimed to include trials in a sensitivity analysis if they meet the criteria for 'well-defined' CBT as opposed to those studies that labelled the therapy as CBT but either did not contain the 'inferential' and 'evaluative' component or who did not provide enough information for this discrimination to be made (see Types of interventions). For the primary outcomes, we compared findings of well-defined CBT and less-well-defined CBT. 


\section{RESULTS}

\section{Description of studies}

Results of the search-Electronic searched identified 2279 references (Figure 1). Two hundred and ninety papers were relevant and all were obtained and scrutinised. Seventy-four of these reports (62 studies) did not meet the inclusion criteria (see Characteristics of excluded studies). One reference was not printed in English and is awaiting translation (Wu Ningqiang 2008) and one reference (NCT00980252) related to an early report of a trial for which we are awaiting outcome data.

Included studies-Thirty one references describing 20 RCTs met the inclusion criteria for this review (see Characteristics of included studies). Lewis 2002 involved three different centres (Lewis 2002 - Liverpool; Lewis 2002 - Manchester; Lewis 2002 - Nottingham).

1. Duration: This ranged between eight weeks (Bechdolf 2004) and five years (Drury 2000, Sensky 2000), but the average duration was about 20 months.

2. Participants: People in these studies were aged between 18 and 65. Participants were selected from in-patient and out-patient populations, at varying phases of illness (from acute phase to relatively stable but with treatment resistant symptoms), and with a range of typical co-morbidities. However, many trials excluded people with co-morbid substance misuse, evidence of organic brain disorder, learning disability or marked thought disorder and/or conceptual disorganisation.

All 20 trials focused on people with psychosis, whether schizophrenia, delusional disorder or schizoaffective disorder, and all employed operational criteria for diagnoses (DSM III-R, DSM IV, DSM-IV TR or ICD-10). Many people were reported to have comorbid mental disorders, such as depression or anxiety disorder. The 20 trials included participants with a representative range of duration of illness. For example, Jackson 2008 reports outcomes from participants with approximately two years length of illness whereas Durham 2003 and Cather 2005 included participants with an average duration of illness in excess of 10 years.

All participants received standard care in addition to CBT or other adjunctive therapies. Standard care would typically include antipsychotic medication. For example, Cather 2005 only included participants treated with olanzapine for at least six months, whereas Pinto 1999 intentionally selected people with medication-resistant symptoms.

\section{Interventions}

3.1 Cognitive behavioural therapy arm: In addition to cognitive restructuring, hypothesis testing and behavioural experiments, most CBT interventions commonly included other therapeutic activities such as psychoeducation, relapse prevention, coping strategy enhancement, problem-solving strategies or relaxation training. Some CBT interventions were administered on a group basis (Bechdolf 2004; Levine 1998; Penn 2009) whereas others utilised individual therapy (Lewis 2002; Jackson 2008; Valmaggia 2005). Drury 2000 employed a combination of both group and individual therapy. 
The CBT interventions varied with regard to both the target of the therapy and the degree of specificity of the focus of the intervention. For example, Kemp 1998 and O'Donnell 2003 used a CBT intervention focused specifically on medication compliance, whereas the CBT intervention described by Bechdolf 2004 had a wider focus incorporating auditory hallucinations and delusions, anxiety, depression, relapse prevention and enhancing medication compliance. Most trials targeted positive symptoms of psychosis, some with an explicit focus on auditory hallucinations (Bechdolf 2004; Haddock 2009; Jackson 2008; Penn 2009; Valmaggia 2005) and/or delusions (Garety 2008 a; Haddock 2009; Jackson 2008; Valmaggia 2005). It was less common for the CBT intervention to target negative symptoms of psychosis (Klingberg 2009). Strategies for relapse prevention were a common component in the CBT intervention and a specific focus in some trials (e.g., Garety 2008 a). Emotional distress (Bechdolf 2004; Sensky 2000) and self-esteem (Bechdolf 2004; Penn 2009), either in general or specifically related to the experience of psychosis, was a target in some trials that also targeted other symptoms. Finally, one trial, Haddock 2009, focused specifically on psychotic symptoms and anger relating to aggression and violence.

3.1.1 CBT arm does not include other active therapies: In 17 trials (85\%), the CBT arm was not 'contaminated' by other contemporaneous active psychological therapies which would not normally be a standard component of CBT for psychosis. However, Buchkremer 1997 reported a CBT intervention which variously included medication management training or key-person counselling, or both. The differential effects of the CBT and the medication management training or key-person counselling were not evaluated. Drury 2000 reported a CBT intervention that consisted of both individual and group cognitive therapy as well as family engagement (aimed at developing familial coping strategies). In addition, it included a structured activity programme (cooking, creative therapy and discussion groups) for an average of five hours per week. Thus, in Drury 2000 the intervention incorporates CBT within a broader rehabilitation framework. The differential effects of the CBT and the rehabilitation were not evaluated. Finally, Pinto 1999 includes social skills training in the CBT arm of the trial and also includes psychoeducation in the control arm of the trial. Accordingly, the differential effects of these interventions cannot be evaluated.

3.1.2 Well-defined CBT: All studies employed a cognitive behavioural intervention in addition to standard care. In order to be classified as 'well-defined' the intervention had to clearly demonstrate the components outlined above (Types of interventions). Only 11 trials (55\%) met our criteria for 'well-defined CBT' (Bechdolf 2004; Cather 2005; Drury 2000; Garety 2008 a; Haddock 1999; Haddock 2009; Lewis 2002; Pinto 1999; Turkington 2000; Valmaggia 2005) in that they clearly reported a therapeutic focus on belief change or reevaluating the subjective meaning of symptoms.

Durham 2003 and Buchkremer 1997 describe their intervention as CBT and for this reason are included in this review. However, the therapeutic focus appears to be on problemsolving skills and the development of coping strategies rather than the re-evaluation of the subjective symptoms. Klingberg 2009 was unique in having a specific focus on negative symptoms, however, reflecting this focus, the intervention incorporated goal setting, initiation, planning and increasing activity levels. Accordingly, the re-evaluation of the subjective symptoms was not clearly a focus in this intervention. Penn 2009 focused on CBT 
for auditory hallucinations based on Wykes 2004 treatment protocol. The authors, however, acknowledge that their intervention in the CBT arm emphasised the development of coping skills and de-emphasised cognitive restructuring.

3.1.3 CBT provided by qualified therapists: We defined qualified CBT therapists as:

- persons possessing appropriate professional qualifications for the provision of CBT (for example, BABCP accreditation, Diploma in CBT, or other professionally accredited qualifications involving CBT as major part of training (for example, Clinical or Counselling Psychologist)); or

- in situations were the qualifications of the therapist are unclear but they appear to have received training in $\mathrm{CBT}$ or specific training for the trial and there is a thorough adherence to the protocol.

According to these criteria 13 trials $(65 \%)$ met the criteria for qualified CBT therapists, with the remaining studies not providing sufficient information to assess this. There was wide variation in the way in which trials fulfilled this criterion with some having a clearly specified a priori protocol to which adherence was assessed in a structured fashion, whilst others appear to have only a broad CBT-based agenda and to assess compliance by audiotaping samples of sessions (Turkington 2000) or by ensuring regular supervision.

3.2 Comparison therapy arm: In all trials the non-CBT arm of the trial was in addition to treatment as usual or standard care. The comparison arm of the trials employed a variety of interventions. Interventions aimed at meaningful symptom or distress reduction were characterised as 'active' comparison therapy whereas psychosocial interventions which act as merely a control for the non-specific effects of therapy (for example, time spent with therapist) were characterised as 'non-active' comparison therapy. Some interventions such as supportive psychotherapy or counselling varied in the degree to which they were used as an active and structured therapy. In such cases, allocation to the active or non-active conditions was dependent upon whether the authors had made reference to the intervention as a control for the non-specific effects of therapy. Table 2 describes the interventions in each trial in more detail than is possible in Characteristics of included studies.

Nine trials compared CBT with non-active control therapies (Drury 2000; Haddock 2009; Jackson 2008; Kemp 1998; Lewis 2002; O’Donnell 2003; Sensky 2000; Turkington 2000; Valmaggia 2005). Eleven trials described active comparison therapies (Bechdolf 2004; Buchkremer 1997; Cather 2005; Durham 2003; Garety 2008 a; Haddock 1999; Klingberg 2009; Levine 1998; Penn 2009; Pinto 1999; Tarrier 1999 a), the most common being psychoeducation and supportive therapy or counselling. Notably, two trials used particularly well-defined non-CBT interventions. Garety 2008 a reported outcomes compared with family therapy and Klingberg 2009 reported outcomes compared with cognitive remediation therapy.

4. Outcomes: All studies, with the exception of Kemp 1998 and O'Donnell 2003, evaluated the effects of CBT on symptoms of psychosis. Kemp 1998 and O'Donnell 2003, however, reported trials in which CBT was focused on improving compliance with medication. 
4.1 Adverse effects or events: Mortality was only reported in two trials (Durham 2003; Lewis 2002) with Lewis 2002 reporting outcome specifically related to suicide.

Klingberg 2009 reported rates for 'No adverse effects'. Ten trials reported 'leaving the study early' (Drury 2000; Durham 2003; Garety 2008 a; Haddock 1999; Kemp 1998; Levine 1998; Lewis 2002; Pinto 1999; Sensky 2000; Tarrier 1999 a).

4.2 Global outcomes: Relapse data were reported in six trials (Bechdolf 2004; Drury 2000, Garety 2008 a, Haddock 1999, Lewis 2002, Tarrier 1999 a). However, different studies used varied criteria for relapse. For example, Garety 2008 a defined relapse as "the re-emergence of, or significant deterioration in, positive psychotic symptoms of at least moderate degree persisting for at least 2 weeks" whereas Bechdolf 2004 defined relapse as "a rating of at least 5 and a 2-point increase compared with the previous assessment in at least one of the items of the Positive Syndrome Subscale of the PANSS". Five trials reported data relating to re-hospitalisation (Bechdolf 2004; Buchkremer 1997; Drury 2000; Jackson 2008; Penn 2009). Two continuous measure of global state were reported. The Global Assessment of Functioning (GAF) scale is used by mental health professionals to rate social, occupational, and psychological functioning. Three trials used this scale (Durham 2003; Haddock 2009; Kemp 1998). The Global Assessment Scale (GAS) (Endicott 1976) rates people from zero to 100 on a continuum from psychological or psychiatric sickness to health (high $=$ good). Outcomes on this scale were reported by Durham 2003.

4.3 Mental state outcomes: Seven trials reported important or reliable change in mental health (Bechdolf 2004; Cather 2005; Drury 2000; Durham 2003; Garety 2008 a; Sensky 2000; Tarrier 1999 a). The definitions of important or reliable change varied between the trials. For example, Bechdolf 2004 defined clinically significant change as greater than two standard deviations on PANSS global score and a statistically significant Reliable Change Index, Cather 2005 defined important or reliable change as a clinically significant reduction of positive symptoms which is a $20 \%$ reduction in PANSS positive factor score, and Garety 2008 a defined important or reliable change as partial or full remission of symptoms without further episode. Sensky 2000 defined reliable change as greater than 50\% improvement and reported outcomes at 18 months from the CPRS (CBT 29/46, Befreinding 17/44), MADRS (CBT 31/46, Befriending 22/44) and the SANS (CBT 23/46, Befriending 23/44) .For the purpose of this review the frequency of reliable change was averaged across these three outcome measures.

It was common for trialists to report continuous measure of mental health outcomes.

\subsubsection{Mental state scales used in this review: a. Brief Psychiatric Rating Scale - BPRS} (Overall 1962)

The Brief Psychiatric Rating Scale is a brief rating scale used to assess the severity of a range of psychiatric symptoms, including psychotic symptoms. The most commonly used version of the scale has 18 items which are rated from one if not present to seven with high scores indicating poorer functioning, Each item can be defined on a seven-point scale varying from 'not present' to 'extremely severe'. There was variation between trials in the 
manner in which BPRS scores were reported. Haddock 1999, Jackson 2008, Kemp 1998 and Pinto 1999 provided data for the BPRS. Unfortunately, Jackson 2008 reported only the positive symptoms subscale of the BPRS and these data could not be combined with the data reported in the other studies.

b.Comprehensive Psychiatric Rating Scale - CPRS (Asberg 1978) The Comprehensive Psychiatric Rating Scale is a general psychiatric rating scale. Sensky 2000 reported outcomes for this measure.

c. Psychotic Symptom Rating Scale - PSYRATS (Haddock 1999b)

This scale is used to assess dimensions of hallucinations and delusions. PSYRATS consists of two scales designed to rate auditory hallucinations and delusions. The items are rated on a five-point ordinal scale (zero to four). The auditory hallucinations are on an 11-item scale. Items include frequency, duration, severity and intensity of distress, controllability, loudness, location, beliefs about origin of voices. This scale was used by Cather 2005, Durham 2003, Haddock 2009, Lewis 2002, Penn 2009 and Valmaggia 2005. The delusions subscale is a six-item scale which assesses dimensions of delusions. The items include preoccupation, distress, duration, conviction, intensity of distress and disruption. This scale was used by Cather 2005, Durham 2003, Haddock 2009, Lewis 2002, Penn 2009 and Valmaggia 2005.

\section{d. Positive and Negative Syndrome Scale (PANSS) (Kay 1987)}

This scale is designed to assess the positive symptoms (i.e., delusions, conceptual disorganisation, hallucinations, hyperactivity, grandiosity, suspiciousness/persecution and hostility), negative symptoms (i.e., blunted affect, emotional withdrawal, poor rapport, passive/apathetic social withdrawal, difficulty in abstract thinking, lack of spontaneity and flow of conversation, stereotyped thinking) and general psychopathology (i.e., somatic concern, anxiety, depression, guilt, tension, mannerisms and posture, motor retardation, uncooperativeness, unusual thought content, disorientation, attentional problems, lack of judgement and insight, disturbance of volition, poor impulse control, preoccupation and active social avoidance). This scale was used by Bechdolf 2004, Cather 2005, Haddock 2009, Levine 1998, Lewis 2002, Penn 2009, Valmaggia 2005 and Garety 2008 a.

\section{e. Beliefs about Voices Questionnaire - Revised (Chadwick 2000)}

This scale measures beliefs about voices including rating benevolence, malevolence, and omnipotence (i.e., power). It also measures the negative affective response to voices as well as attempts to resist the voice (resistance) and the positive affective response to voices as well as willing engagement or compliance with the voice (engagement). Penn 2009 reported outcomes relating to this scale.

f. Scale for the Assessment of Negative Symptoms (SANS) (Andreasen 1984)

The Scale for the Assessment of Negative Symptoms is designed to assess the negative symptoms of schizophrenia. This six-point scale gives a global rating of the following 
negative symptoms: alogia, affective blunting, avolition-apathy, anhedonia-asociality and attention impairment. Higher scores indicate more symptoms. Jackson 2008, Pinto 1999, Sensky 2000 and Tarrier 1999 a provide outcomes on this scale.

g. Montgomery-Asberg Depression Rating Scale (MADRS) (Montgomery 1979)

This depression rating scale is designed to be sensitive to change. It was developed using a 65-item comprehensive psychopathology scale to identify the 17 most commonly occurring symptoms in primary depressive illness. Ratings on 10 items, with higher score indicating poor outcome. Maximum score is 30. Sensky 2000 reported data from this scale.

\section{h. Beck Depression Inventory (BDI) (Beck 1961)}

This is a 21-item, self-report questionnaire which measures the intensity of depressive symptoms. Garety 2008 a and Penn 2009 used this scale.

i. Beck Anxiety Inventory (BDI) (Beck 1988)

This is a 21-item, self-report questionnaire which measures the intensity of depressive symptoms. Garety 2008 a and Penn 2009 used this scale.

j. Beck Cognitive Insight Scale (Beck 2004)

This is a 15-item, self-report measure of self-reflectiveness and over confidence in the interpretation of experiences. Penn 2009 reported outcomes on this scale.

k. Rosenberg Self-Esteem Scale (Rosenberg 1965)

This is a 10-item, self-rated measure of self-esteem. Penn 2009 reported outcomes on this scale.

l. Novaco Anger Scale (Novaco 2003)

This is a 48-item, self-report questionnaire measuring cognitive, behaviour and arousal aspects of anger. Haddock 2009 reported outcomes from this scale.

m. Novaco Provocation Inventory (Novaco 2003)

This is a 25-item, self-report questionnaire measuring triggers or provocations to anger. Haddock 2009 reported outcomes from this scale.

n. Ward Anger Rating Scale (Haddock 2009)

Part A consists of 18 dichotomous, weekly ratings regarding verbal and physical behaviours associated with anger and aggression. Part B consists of seven items regarding affectivebehavioural attributes related to anger. Haddock 2009 reported outcomes from this scale.

o. Historical Clinical Risk Management-20 ( Webster 1997 ) 
This 20-item, clinician-rated scale consists of three subscales (i.e., historical factors; clinical factors; and risk factors in relation to the future) relating to risk of violence. Haddock 2009 reported outcomes from this scale.

4.4 Social functioning outcome: These important outcomes were not reported in binary form (able to look after self, able to hold employment). Scales were employed by a few trials.

\subsubsection{Social functioning scales used in this review: a. Social Functioning Scale (SFS)} (Birchwood 1990)

This scale measures social role and behavioural functioning across seven basic areas of community functioning: social engagement, interpersonal behaviour, prosocial activities, recreation, independence, employment. Penn 2009 reported outcomes on this scale.

b. Social and Occupational Functioning Assessment Scale (Brambilla 2000).

This is a clinician-rated measure of social and occupational functioning on a continuum from excellent to grossly impaired functioning. Jackson 2008 and Garety 2008 a reported outcomes on this measure.

4.5 Quality of life outcomes: Only Garety 2008 a reported on this important outcome.

4.5.1 Quality of life scales used in this review: a. European Quality of Life Questionnaire (Brazier 1993).

This is also known as the EuroQoL or the EQ-5D. This is a self-rated measure of five dimension of health relate quality of life (mobility, self care, usual activities, pain/ discomfort, anxiety/depression).

Excluded studies: We excluded 62 studies (74 reports) from this review.

1. Issues relating to methods: We excluded most studies because they were not randomised controlled trials (Arlow 1997; Bechdolf 2005b; Bouchaud 1996; Buchanan 1992; Chadwick 1994; Garety 1994; Hartman 1983; Hodel 1994; Hogarty 1991; Jackson 1998; Kemp 1996b; Kingdon 1991; Kuipers 1996; May 1984; Perris 1992; Shon 2002; Spaulding 1992).

2. Issues relating to participants: Two studies reported outcome on individuals at-risk of psychosis (McGorry 2002; Morrison 2002) and were therefore excluded as they do not apply directly to people with a diagnosis of schizophrenia.

3. Issues relating to comparison: A large number of papers reported CBT compared with treatment as usual (Barrowclough 2001; Barrowclough 2006; Bradshaw 2000; Castle 2002; Daniels 1998; England 2007; Garety 1998; Granholm 2005; Gumley 2003; Jackson 2001; Kuipers 2004; Lysaker 2009; Rector 2003; Sellwood 2001; Startup 1998; Startup 2006; Turkington 2002; Turkington 2006; Wykes 2003) and were therefore excluded from this review as they do not involve an adjunctive comparison therapy. 
4. Issues relating to intervention: Several studies reported CBT interventions as part of a broader treatment package where is was not possible to identify the effect of the CBT elements (Edwards 2003; Evins 2001; Haldun 2002; Hayward 1995; Hertz 2000). In particular, Anzai 2002 reported comparisons of different types of services (community reentry model versus occupational rehabilitation) in which CBT had greater or lesser involvement.

Several studies employed therapeutic strategies which did not meet our criteria for CBT (Bach 2002; Bellucci 2002; Bradshaw 1993; Claghorn 1974; Drake 1993; Fritze 1988; Gaudiano 2006; Hogarty 1997; Hogarty 2004; MacPherson 1996; Olbrich 1990; Roder 2002; Tarrier 1993 b; Van Der Gaag 2003; Velligan 2002; Wykes 2002). Notably, Tarrier 1993 b employed coping strategy enhancement which, although a commonly used component of CBT, would not in itself meet our criteria for CBT. The same applied to acceptance and commitment therapy (Bach 2002; Gaudiano 2006), which, like CBT, has a focus on cognitions. It, however, aims to help patients respond differently to their thoughts rather than directly challenge or test out their validity. Patients are encouraged to accept and experience their internal events non-judgmentally. Accordingly, this treatment would not meet our criteria for CBT. Personal therapy (Hogarty 1997), like CBT, aims to prevent relapse and promote personal and social adjustment. However, personal therapy differs from CBT in that it consists of psychoeducation awareness of early signs, supportive therapy techniques, social skills training, the teaching of coping strategies, without an explicit focus on beliefs and cognitive restructuring. Accordingly, this treatment would not meet our criteria for CBT. Several papers (Bellucci 2002; Fritze 1988; Hogarty 2004; Olbrich 1990; Van Der Gaag 2003; Velligan 2002; Wykes 2002) report the use of therapeutic strategies designed to on overcoming intellectual and memory deficits associated with schizophrenia rather than psychotic symptoms, beliefs or cognitive distortions.

\section{Risk of bias in included studies}

For graphical representation please see Figure 2 and Figure 3.

Allocation-All of the 20 included trials reported some form of randomisation. Ten trials reported adequate sequence generation, whist the remaining trial provided insufficient information to rate this particular bias. Allocation was concealed in 11 studies, with the remaining studies not providing enough information to rate this bias.

Blinding-None of the included trials were able to use double blinding as a technique due to the inherent difficulties involved in disguising psychosocial interventions. Sixteen trials (80\%) attempted to reduce any bias by employing raters who were naïve to allocation (Bechdolf 2004; Cather 2005; Durham 2003; Garety 2008 a; Haddock 1999; Haddock 2009; Jackson 2008; Klingberg 2009; Levine 1998; Lewis 2002; O'Donnell 2003; Penn 2009; Sensky 2000; Tarrier 1999 a; Turkington 2000; Valmaggia 2005).

Incomplete outcome data-Overall, data were adequately reported. Some data were lost due to studies failing to report appropriate measures of central tendency and deviation; presenting findings in graphs; presenting outcomes in aggregated statistical form; or by 
inexact P values. Buchkremer 1997 did not report standard deviations, rendering these data unusable. We were unable to use the PAS used by Drury 2000 as the data were only reported in graphical form. Finally, the measure of compliance reported in Kemp 1998 was not peer reviewed and therefore could not be included.

Selective reporting-Turkington 2000 reported many continuous outcomes without standard deviations and it was therefore problematic to analyse these particular data. Klingberg 2009 is an ongoing trial that has yet to publish outcomes with respect to negative symptoms which is the main focus of their therapeutic intervention. Buchkremer 1997 failed to report a large number, but not all, of their outcomes by individual group and data were aggregated in a manner which rendered it unsuitable for meta-analysis.

Other potential sources of bias-Haddock 2009 is one of the few trials to report outcome data with regard to problem behaviours. However, a potential source of bias in these data may result from the inclusion of a mixed sample of in-patients and out-patients, with a greater opportunity to observe and record aggressive behaviour in the in-patient sample. Levine 1998 contained only six participants in each of the two arms of the trial. Such a small trial could not guarantee that randomisation would be adequate to control for idiosyncratic participant characteristics.

\section{Effects of interventions}

See: Summary of findings for the main comparison Cognitive behavioural therapy compared with other psychosocial therapies for schizophrenia

\section{Comparison 1: CBT versus all other psychological therapies}

\subsection{Adverse effect/event}

1.1.1 Death: Durham 2003 and Lewis 2002 reported six deaths during the trials, with Lewis 2002 specifically reporting suicides. There were two deaths in the CBT intervention group and four in the other psychological therapies ( 2 RCTs, $n=202$, risk ratio (RR) 0.57 confidence interval (CI) 0.12 to 2.60; Analysis 1.1). Lewis 2002 employed supportive counselling as the non-active control therapy and Durham 2003 employed a more active procedure of supportive counselling.

1.1.2 Adverse Effects: Klingberg 2009 reported the presence or absence of adverse outcomes. There were no significant differences in adverse outcome between CBT and Cognitive Remediation Training in the long-term $(n=198, R R$ any adverse effect $2.00 \mathrm{CI}$ 0.71 to 5.64; Analysis 1.2).

\subsection{Mental state}

1.2.1 General symptoms: Four outcomes were reported as indicators of general mental state; no important or reliable change, the British Psychiatric Rating Scale, the Total Score of the Positive and Negative Symptom Scale (PANSS), and the General Symptom Score of the PANSS. 
1.2.1.1 No important or reliable change: No advantage was observed for $\mathrm{CBT}$ in the shortterm ( 2 RCTs, $\mathrm{n}=99$, RR 0.84 CI 0.40 to 1.75 ), medium-term ( 3 RCTs $\mathrm{n}=162 \mathrm{RR} 0.78 \mathrm{CI}$ 0.61 to 1.00 ) or long-term (4 RCTs, $\mathrm{n}=244$, RR $0.91 \mathrm{CI} 0.77$ to 1.08 ) (Analysis 1.3 ).

\subsubsection{Total score on the Brief Psychiatric Rating Scale (BPRS), the Positive and Negative Symptoms Scale (PANSS) and the Comprehensive Psychiartic Rating Scale}

(CPRS): Three trials reported endpoint data on the BPRS in the short- and medium-term. No advantage was observed in the short-term ( 2 RCTs, $\mathrm{n}=94$, MD 0.07 CI $1.15-2.83$ to 5.14). However, a small advantage, favouring CBT, was observed in the medium-term (1 RCT, $\mathrm{n}=$ 37, MD -7.60 CI -14.30 to -0.90; Analysis 1.4). This effect was observed from a single small trial (Pinto 1999) which compared CBT to an active therapy (supportive counselling).

Six trials reported endpoint data on the Total Score of the PANSS in the short-, mediumand long-term (Analysis 1.4). A significant advantage favouring CBT was observed in the short-term (4 RCTs, $\mathrm{n}=303$, MD $-11.26 \mathrm{CI}-13.83$ to -8.69$)$ and medium-term ( $2 \mathrm{RCTs}, \mathrm{n}$ $=110, \mathrm{MD}-8.09 \mathrm{CI}-10.66$ to -5.52$)$. However, these data showed significant heterogeneity for short-term outcomes $\left(\mathrm{Chi}^{2}=105.73, \mathrm{df}=3(\mathrm{P}<0.001) \mathrm{I}^{2}=97 \%\right)$. In addition, this positive result appears to be largely attributable to one small trial (Levine 1998). When this trial is removed homogeneity is restored and the effect is no longer statistically significant ( 3 RCTs, $\mathrm{n}=291, \mathrm{MD}-2.27 \mathrm{CI}-5.37$ to $0.84 ; \mathrm{Chi}^{2}=2.63$, df $=2(\mathrm{P}$ $=0.27) ; \mathrm{I}^{2}=24 \%$ ). There was no clear effect was observed for CBT in the longer term (5 RCTs, $\mathrm{n}=378, \mathrm{MD}-2.58 \mathrm{CI}-5.26$ to 0.10 ).

One trial (Sensky 2000) reported outcomes on the CPRS. No significant effect was observed in either the medium term ( $1 \mathrm{RCT}, \mathrm{n}=90, \mathrm{MD}-4.30 \mathrm{CI}-9.26$ to 0.66$)$ or the longer term (1 $\mathrm{RCT}, \mathrm{n}=59, \mathrm{MD}-4.60 \mathrm{CI}-11.22$ to 2.02 ).

1.2.2 Specific symptoms: Studies reported specific symptoms relating positive symptom (e.g., hallucinations and delusions), negative symptoms, psychological distress (e.g., depression, anxiety, self esteem and anger) and problem behaviours.

1.2.2.1 Positive symptoms (outcomes 1.7 through 1.11): Eight trials reported endpoint outcomes on the positive symptom subscale of the PANSS (Analysis 1.5). No significant advantage was observed in the short-term ( 7 RCTs, $n=477$, MD $-0.67 \mathrm{CI}-1.46$ to 0.13 ) or medium-term (4 RCTs, $\mathrm{n}=239$, MD $-0.99 \mathrm{CI}-2.09$ to 0.11 ). However, a small advantage favouring CBT was observed in the long-term ( 7 RCTs, $n=380$, MD $-0.90 \mathrm{CI}-1.74$ to -0.06). Only Penn 2009 evidenced a significant effect and this employed a variant of CBT which was explicitly focused on the management of auditory hallucinations.

Five trials reported outcomes of the hallucinations subscale of the PSRS (Analysis 1.6). No effect was observed in the short-term (4 RCTs, $\mathrm{n}=258$, MD $-0.92 \mathrm{CI}-3.33$ to 1.49), medium-term ( 2 RCTs, $\mathrm{n}=105$, MD $-0.57 \mathrm{CI}-3.95$ to 2.80 ) or the long-term (6 RCTs, $\mathrm{n}=$ 267, MD $-1.30 \mathrm{CI}-4.01$ to 1.41 ).

Five trials reported outcomes on the delusions subscale of the PSRS (Analysis 1.7). There was a significant advantage favouring CBT in the short-term (4 RCTS, $n=311, M D-1.62$ CI -3.16 to -0.07 ) which was not maintained at medium-term ( 2 RCTs, $n=106$, MD -0.59 
CI -3.03 to 1.86 ) or long-term ( $6 \mathrm{RCTs}, \mathrm{n}=329, \mathrm{MD}-0.89 \mathrm{CI}-2.34$ to 0.55 ). Only

Haddock 2009 evidenced a significant effect in the short-term and it should be noted that this study's intervention was targeted at anger and aggression rather than delusional beliefs. When Haddock 2009 was removed from these data the effect in the short-term was no longer statistically significant ( $3 \mathrm{RCTs}, \mathrm{n}=233$, MD $-0.09 \mathrm{CI}-1.73$ to 1.91 ).

1.2.2.2 Negative symptoms (outcomes 1.12 through 1.13): Eight trials reported outcomes on the Negative Symptom subscale of the PANSS. No significant advantage was observed in the short-term (6 RCTs, $\mathrm{n}=328, \mathrm{MD}-0.25 \mathrm{CI}-1.09$ to 0.59 ), medium-term (4 RCTs, $\mathrm{n}=$ 239 , MD $-0.27 \mathrm{CI}-1.28$ to 0.74 ) or long-term ( 7 RCTs, $n=380$, MD $-0.43 \mathrm{CI}-1.38$ to 0.51; Analysis 1.10). Four trials (Jackson 2008; Pinto 1999; Sensky 2000; Tarrier 1999 a) reported outcomes on the Scale for the Assessment of Negative Symptoms (SANS). No significant advantage was observed in the short-term ( 3 RCTs, $n=195$, MD -0.92 CI -3.42 to 1.59 ), medium-term ( $3 \mathrm{RCTs}, \mathrm{n}=171, \mathrm{MD}-0.68 \mathrm{CI}-3.13$ to 1.76 ) or long-term ( 3 RCTs, $\mathrm{n}=161$, MD $0.95 \mathrm{CI}-1.56$ to 3.46; Analysis 1.11).

1.2.2.3 Psychological distress (outcomes 1.14 through 1.20): Seven trials reported outcomes on the General Symptom Score of the PANSS. They observed no clear effect in the short-term (4 RCTs, $\mathrm{n}=288$, MD $-0.06 \mathrm{CI}-1.61$ to 1.50), medium-term (5 RCTs, $\mathrm{n}=$ $280, \mathrm{MD}-1.01-2.66$ to 0.63 ) or long-term ( $8 \mathrm{RCTs}, \mathrm{n}=549$, MD $-1.03-2.36$ to 0.29 ; Analysis 1.12).

Two trials reported outcomes on the Beck Depression Scale (BDI) when CBT was compared with family therapy (Garety 2008 a) and enhanced supportive therapy (Penn 2009). No significant advantage was observed in the short-term (1 RCT, $\mathrm{n}=65$, MD $-1.20 \mathrm{CI}-5.56$ to 3.16) and medium-term ( 2 RCTs, $n=108, \mathrm{MD}-3.09 \mathrm{CI}-7.18$ to 0.99 ) although all studies report outcomes favouring the CBT condition. However, in the long-term there was a statistically significant effect ( 2 RCTs, $n=105$, MD $-6.21 \mathrm{CI}-10.81$ to -1.61 ) with Garety 2008 a and Penn 2009 both reporting significant advantages for CBT $\left(\mathrm{Chi}^{2}=0.01, \mathrm{df}=1(\mathrm{P}\right.$ $=0.91) ; \mathrm{I}^{2}=0 \%$; Analysis 1.13).

Similarly, when depressive symptomatology was measured using the Montgomery-Asberg Depression Rating Scale (MADRS), and was compared against a non-active control therapy (Sensky 2000), there was no significant advantage in the medium-term (1 RCT, $\mathrm{n}=90$, MD $--2.50 \mathrm{CI}-4.19$ to -0.81$)$. However, a no significant effect was observed in the long-term (1 $\mathrm{RCT}, \mathrm{n}=90, \mathrm{MD}-1.50 \mathrm{CI}-3.78$ to 0.78 ; Analysis 1.18 ).

No significant advantage was observed for a series of other scores - Rosenberg Self Esteem Scale (RSES) (Analysis 1.15), the Beck Anxiety Inventory (BAI) (Analysis 1.16), the Beck Cognitive Insight Scale (Analysis 1.17) or the Novaco Anger Scale (Analysis 1.14).

1.2.2.4 Problem behaviours: No significant advantage was observed in a series of rating scale scores: the Novaco Provocation Inventory in the short-term (1 RCT, n = 77, MD 4.12 CI -3.93 to 12.17) or long-term (1 RCT, $\mathrm{n}=77$, MD 3.33 CI -3.70 to 10.36; Analysis 1.19); Ward Anger Rating Scale (WARS) in the short-term (1 RCT, $\mathrm{n}=77$, MD $-2.33 \mathrm{CI}-4.84$ to 0.18 ) or long-term ( $1 \mathrm{RCT}, \mathrm{n}=77, \mathrm{MD}-2.10 \mathrm{CI}-5.01$ to 0.81 ; Analysis 1.20$)$; Historical Clinical Risk Management-20 scale (HCR-20) Risk Management subscale (1 RCT, $\mathrm{n}=77$, 
MD $-0.23 \mathrm{CI}-1.77$ to 1.31; Analysis 1.21) or the Clinical subscale (1 RCT, $\mathrm{n}=77$, MD $-0.46 \mathrm{CI}-1.62$ to 0.70 ; Analysis 1.22 ).

1.3 Global state: Four outcomes were reported as indicators of global state; relapse, rehospitalisation, the Global Assessment of Functioning (GAF) Scale, and the Global Assessment Scale (GAS).

1.3.1 Relapse and rehospitalisation: Six trials reported data relating to relapse in the shortterm (Bechdolf 2004), medium-term (Tarrier 1999 a) and the long-term (Drury 2000; Garety 2008 a; Haddock 1999; Lewis 2002; Tarrier 1999 a). No significant reduction in relapse was reported in either the short-term ( $1 \mathrm{RCT}, \mathrm{n}=71$, RR $0.65 \mathrm{CI} 0.21$ to 1.95 ), medium-term (1 $\mathrm{RCT}, \mathrm{n}=59$, RR 0.63 CI 0.19 to 2.11) or the long-term (5 RCTs, $\mathrm{n}=350$, RR $0.91 \mathrm{CI} 0.63$ to 1.32; Analysis 1.23). Only one of the six trials reported a significant reduction in relapse favouring CBT. This study, Lewis 2002, employed a non-active control therapy and was targeted at "positive symptoms of delusions and hallucinations, identifying precipitating and alleviating factors and reducing associated distress" (Lewis 2002, p92). This study, contributing $28 \%$ of weight to the final result also was responsible for the high heterogeneity $\left(\mathrm{Tau}^{2}=0.10 ; \mathrm{Chi}^{2}=10.71, \mathrm{df}=4(\mathrm{P}=0.03) ; \mathrm{I}^{2}=63 \%\right)$.

Five trials reported data relating to re-hospitalisation in the shortterm (Bechdolf 2004; Penn 2009), medium-term (Buchkremer 1997; Penn 2009) and long-term (Bechdolf 2004; Buchkremer 1997; Drury 2000; Jackson 2008; Penn 2009). No significant reduction in rehospitalisation was reported in either the shortterm ( 2 RCTs, $n=136$, RR 0.36 CI 0.11 to 1.13), mediumterm ( 2 RCTs, $\mathrm{n}=132$, RR 0.59 CI 0.27 to 1.30 ) or the long-term (5 RCTs, $n$ $=294$, RR 0.86 CI 0.62 to 1.21; Analysis 1.24). None of the individual trials evidenced a significant reduction in re-hospitalisation $\left(\mathrm{Chi}^{2}=2.36, \mathrm{df}=4(\mathrm{P}=0.67) ; \mathrm{I}^{2}=0 \%\right)$.

1.3.2 Global Assessment of Function (GAF) and Global Assessment Scale (GAS): One trial (Durham 2003), employing an active control therapy of supportive counselling, reported outcomes on the GAS. No significant differences in treatments were observed in the mediumterm ( $1 \mathrm{RCT}, \mathrm{n}=38, \mathrm{MD}-0.60 \mathrm{CI}-4.93$ to 3.73 ) or the long-term ( $3 \mathrm{RCT}, \mathrm{n}=$ 155, mean difference (MD) $4.20 \mathrm{CI}-0.63$ to 9.03 ; Analysis 1.24).

Durham 2003, Haddock 2009 and Kemp 1998 reported outcomes on the GAFscale. A consistent positive effect favouring CBT was observed in the short-term ( 2 RCTs, $n=147$, MD 9.02 CI 4.29 to $\left.13.75 ; \mathrm{Chi}^{2}=0.04, \mathrm{df}=1(\mathrm{P}=0.84) ; \mathrm{I}^{2}=0 \%\right)$. The trials contributing to this effect employed both active (Haddock 2009) and non-active (Kemp 1998) control therapies. However, this effect was not statistically significant in the long-term ( 3 RCTs, $n=$ 155, MD 4.20 CI -0.63 to 9.03; Analysis 1.24).

\subsubsection{Social Functioning Scale (SFS) and Social and Occupational Functioning} Assessment Scale (SOFAS): No significant advantage was observed on the SFS when CBT was compared with enhanced supportive therapy (Penn 2009) in the short-term ( $\mathrm{n}=65$, MD 5.40 CI -5.18 to 15.98$)$, medium-term ( $\mathrm{n}=65$, MD $7.20 \mathrm{CI}-3.46$ to 17.86$)$ or the long-term ( $\mathrm{n}=65$, MD $8.80 \mathrm{CI}-4.07$ to 21.67; Analysis 1.25). Garety $2008 \mathrm{a}$ and Jackson 2008 reported outcomes on the SOFAS. An advantage favouring CBT was observed in the short- 
term (1 RCT, $\mathrm{n}=62$, MD 9.09 CI 2.79 to 15.39$)$ when compared with a non-active control therapy (befriending). This advantage was not observed in the medium-term (1 RCT, $\mathrm{n}=45$, MD 5.33 CI -2.57 to 13.23 ) and the long-term (2 RCTs, $n=103$, MD 1.32 CI -4.90 to 7.54; Analysis 1.26).

\subsection{Quality of life}

1.4.1 EuroQol: Only Garety 2008 a reported outcomes with regard to changes in quality of life. There was no significant differences in EuroQOL scores between CBT and family therapy in the long-term ( $\mathrm{n}=37, \mathrm{MD}-1.86 \mathrm{CI}-19.20$ to 15.48 ; Analysis 1.27 ).

\subsection{Satisfaction with treatment}

1.5.1 Attitude to medication: One study rated attitude to medication and, using two measures, found significantly in favour of the CBT groups (Analysis 1.28).

1.5.2 Leaving the study early: Ten trials reported data on participants leaving the trial early (Analysis 1.29). There was no significant advantage when CBT was compared with either non-active control therapies (4 RCTs, $\mathrm{n}=433$, RR $0.88 \mathrm{CI} 0.63$ to 1.23 ; Analysis 2.22) or active therapies (6 RCTs, $\mathrm{n}=339$, RR 0.75 CI 0.40 to 1.43; Analysis 3.23).

2. Missing outcomes-We found no usable data on direct or indirect costs.

\section{Sensitivity analyses}

3.1 Adverse event: Only two studies reported outcomes relating to death (Durham 2003; Lewis 2002). Accordingly, no sensitivity analysis could be performed

3.2 Mental state: No important or reliable change: No advantage was observed for CBT in the short-term, mediumterm or long-term across seven trial (Bechdolf 2004; Cather 2005; Durham 2003; Drury 2000; Garety 2008 a; Sensky 2000; Tarrier 1999 a). When trials showing inadequate or suspect blinding (Drury 2000; Sensky 2000) were removed then was no advantage for $\mathrm{CBT}$ in the medium-term $(\mathrm{Z}=1.57, \mathrm{P}=0.12)$ or long-term $(\mathrm{Z}=0.67, \mathrm{P}=$ 0.50 ). When trials showing inadequate or suspect randomisation (Drury 2000; Sensky 2000) were removed then no advantage for $\mathrm{CBT}$ was observed in the medium-term $(\mathrm{Z}=1.57, \mathrm{P}=$ $0.12)$ or long-term $(Z=0.67, P=0.50)$.

When only well-defined CBT trials were considered there was a significant advantage for $\mathrm{CBT}$ in the medium term ( 2 RCTs, $\mathrm{n}=121$, MD $0.70 \mathrm{CI} 0.53$ to 0.93 ). However, this advantage was not evident in the three well-defined CBT trials contributing long-term outcomes (3 RCTs, $\mathrm{n}=154$, MD 0.94 CI 0.79 to 1.13 ).

\subsection{Global state}

3.3.1 Relapse: Of the six trials reported data relating to relapse in the short-term (Bechdolf 2004), medium-term (Tarrier 1999 a) and the long-term (Drury 2000; Garety 2008 a; Haddock 1999; Lewis 2002; Tarrier 1999 a). 
When trials showing inadequate or suspect blinding (Drury 2000) were removed from the long-term data then no advantage for CBT was observed (Test for overall effect: $\mathrm{Z}=0.53, \mathrm{P}$ $=0.60$ ). Similarly, when trials showing inadequate or suspect randomisation (Drury 2000; Haddock 1999) were removed from the long-term data then no advantage for CBT was observed (Test for overall effect: $\mathrm{Z}=0.10, \mathrm{P}=0.92$ ).

When only well-defined CBT trials (Drury 2000; Garety 2008 a; Haddock 1999; Lewis 2002) were considered there was no advantage for CBT in the long-term ( 4 RCTs, $n=350$, MD 0.91 CI 0.63 to 1.32 ).

3.3.2 Hospitalisation: Five trials reported data relating to re-hospitalisation in the shortterm (Bechdolf 2004; Penn 2009), medium-term (Buchkremer 1997; Penn 2009) and longterm (Bechdolf 2004; Buchkremer 1997; Drury 2000; Jackson 2008; Penn 2009).

When trials showing inadequate or suspect blinding (Drury 2000) were removed from the long-term data then no advantage for CBT was observed (Test for overall effect: $\mathrm{Z}=0.53, \mathrm{P}$ $=0.60$ ). Similarly, when trials showing inadequate or suspect randomisation (Penn 2009, Drury 2000,) were removed from the long-term data then no advantage for CBT was observed (Test for overall effect: $\mathrm{Z}=0.62, \mathrm{P}=0.54$ ).

When only well-defined CBT trials (Buchkremer 1997, Drury 2000) were considered there was no advantage for CBT in the long-term ( 2 RCTs, $n=129$, MD 0.86 CI 0.51 to 1.44).

\section{DISCUSSION}

\section{Summary of main results}

\section{Comparison 1. CBT versus all other psychological therapies}

1.1 Adverse effect/event: Overall numbers were very small (3\%), but CBT did not show an advantage with respect to avoidance of death by natural causes or suicide.

For 'general adverse effects' no advantage was found for cognitive therapy. One trial (Klingberg 2009), reported no difference in adverse outcomes between CBT and Cognitive Remediation Training in the long-term. Many of these studies do not report adverse effects of this theoretically potent talking therapy. If such treatment is potentially to be recommended for wide adoption routine recording and reporting of adverse effects should be expected within evaluative studies.

1.2 Mental state: We found no consistent advantage for CBT over other therapies with respect to clinically reliable or important changes in general psychiatric symptoms.

Of the seven trials, only Drury 2000 and Sensky 2000 showed a positive effect for CBT and this was in comparison to non-active therapies designed to control for non-specific aspects of therapy. With respect to global psychiatric symptoms based on the BPRS, no effect was found in the short- or long-term but a small advantage for CBT was found in the mediumterm. This was observed in only a single small trial (Pinto 1999) which compared CBT to an active therapy (supportive counselling). Global psychiatric symptoms as measured by the 
Total Score of the PANSS showed a significant advantage for CBT in the short- and medium-term, but not over longer periods. There was significant variation in the trial results in the short-term and the positive result was entirely attributable to Levine 1998 which targeted medication compliance. We found no effect in the short-, medium- or long-term on the general symptom scale of the PANSS.

Much of the CBT-based interventions for psychosis focus on specific symptoms. With respect to positive symptoms on the PANSS, no significant advantage was found for CBT in the short- or medium-term. There was a small effect in the long-term in favour of CBT, but this seems to be accounted for by a single trial (Penn 2009) which employed a variant of CBT explicitly focused on the management of auditory hallucinations. When a more specific measure of dimensions of voice hearing (the PSRS or Beliefs About Voices Questionnaire) was used, no advantage was found for CBT at any duration of treatment outcome.

With respect to delusions as measured by the Delusions subscale of the PSRS across five trials, a significant advantage was found for CBT in the short-term which was not maintained at longer durations, and the effect in the short-term is attributable to the impact of one trial that was not targeted at treatment of delusions (Haddock 2009). No effect was found for the differential impact of CBT on negative symptoms at any treatment duration.

A significant advantage was found for CBT in comparison to both Family Therapy (Garety 2008 a) and Enhanced Supportive Therapy (Penn 2009) in terms of reducing depressive symptoms as measured by the BDI but only in longer term outcomes. At shorter durations there was a consistent but non-significant trend in favour of CBT. This pattern of longerterm benefits was demonstrated on a second measure of depression in a further trial (Sensky 2000). This finding supports the Birchwood 2006 assertion that CBT targets the emotional/ behavioural distress rather than psychotic symptomatology.

No advantage for CBT was found at any duration of outcome for anxiety, self-esteem, insight, anger or problem behaviours in the form of violence.

1.3 Global state: There was no consistent advantage for CBT over other therapies with respect to rate of relapse or rehospitalisation. No differential effect of CBT was observed on global functioning as measured by the Global Assessment Scale. In contrast, there was a consistent positive effect on global functioning (as measured by the DSM-IV GAF measure) which favoured CBT; this effect, however, was only observed in the short-term and was not present over longer periods and may be a chance finding. However, notably, the studies contributing to this short-term effect involved a focus on anger and psychotic symptoms relating to problem behaviour (Haddock 2009) and medication compliance (Kemp 1998).

The findings with respect to social functioning were equivocal and dependent on the measure used. No significant advantage was observed on the SFS when CBT was compared with Enhance supportive therapy (Penn 2009) at any duration of outcome. In contrast, using the SOFAS, Garety 2008 a and Jackson 2008 reported an advantage favouring CBT in the short-term when compared with a non-active control therapy (befriending) but this was not maintained at subsequent follow-up. This important outcome is not often measured but there 
is no indication that the addition of CBT to standard care has any convincing generalised effect.

1.4 Quality of life: It is surprising that only one trial of less than 40 participants (Garety 2008 a) reported a measure of quality of life. No differential effect of CBT was found at any duration of outcome.

1.5 Satisfaction with care: Cognitive behavioural therapy did not seem to keep people in care any more than other therapies. About $20 \%$ of both groups left the studies. However, this rate of attrition this is better than is seen in many drug trials.

\section{Overall completeness and applicability of evidence}

1. Completeness-This review contains data on the primary outcomes (adverse event, mental state - no clinically important response, relapse, hospitalisation). Even the most replete of the outcomes contains less than 300 participants,. Trials are small, often undertaken by pioneers of CBT, and numbers of events in any one group are few. There is a poverty of measurement of some outcomes and none on others. For example, there are few studies that attempt to report on adverse effects, and none that measures engagement with services,

\section{Applicability}

2.1 Participants: The included studies involved people with serious mental illnesses (as derived from recognised diagnostic criteria) from a wide range of settings, including both inpatients and out-patients. The results of this review could be said to be valid for people with a diagnosis of a psychotic disorder whose illness has taken a chronic course whether treated on an in-patient or out-patient basis. The exclusion criteria were such that this review is of less relevance to persons with other psychotic disorders such as bipolar disorder, substanceinduced psychosis, significant physical or sensory difficulties or people with acquired brain injury or coexisting developmental learning disabilities.

2.2 Interventions: Eleven trials meet our criteria for 'well-defined CBT'. The period of active therapy varied between studies. Bechdolf 2004 provided up to eight weeks of individual CBT, whilst Drury 2000 gave both individual and group cognitive therapy over the course of recovery (which did not exceed nine months) as well as family engagement, aimed at developing familial coping strategies and a structured activity programme (for an average of five hours per week) including cooking, creative therapy and discussion groups. On the other hand, Kemp 1998, reported that their intervention consisted of four to six sessions of therapy aimed at increasing medication compliance.

The CBT interventions varied with regard to both the target of the therapy and the degree of specificity of the focus of the intervention. For example, Kemp 1998 and O'Donnell 2003 used a CBT intervention focused specifically on medication compliance, whereas the CBT intervention described by Bechdolf 2004 had a wider focus incorporating auditory hallucinations and delusions, anxiety, depression, relapse prevention and enhancing medication compliance. Most trials targeted positive symptoms of psychosis, some with an 
explicit focus on auditory hallucinations (Bechdolf 2004; Haddock 2009; Jackson 2008; Penn 2009; Valmaggia 2005) and/or delusions (Garety 2008 a; Haddock 2009; Jackson 2008; Valmaggia 2005). It was less common for the CBT intervention to target negative symptoms of psychosis (Klingberg 2009). Strategies for relapse prevention were a common component in the CBT intervention and a specific focus in some trials (e.g., Garety 2008 a). Emotional distress (Bechdolf 2004; Sensky 2000) and self-esteem (Bechdolf 2004; Penn 2009), either in general or specifically related to the experience of psychosis, was a target in some trials that also targeted other symptoms. Finally, Haddock 2009 focused specifically on psychotic symptoms and anger relating to aggression and violence.

The present review differed from previous reviews in that we adopted a tiered definition of CBT. Cognitive behavioural therapy in clinical practice typically includes a number of components: cognitive restructuring, hypothesis testing, behavioural experiments, psychoeducation, relapse prevention, coping strategy enhancement, problem-solving strategies, with or without, relaxation training. In this respect, many of the current trials reflect common clinical practice. However, this multi-component approach is not necessarily helpful in identifying the active components of CBT as control arms to the trials are often not balanced in terms of component therapies. Trials generally include a range of interventions in the same treatment arm and in many the intervention is described as "CBT" without a clear and explicit indication that the active element of therapy involves explicit manipulation of belief. In addition, cognitive therapy for psychosis, as reflected in current trials, has become increasingly distanced from its basis in CBT for non-psychotic mood disorders where the focus is on the emotional and behavioural consequences of dysfunctional thinking patterns and the intervention is clearly designed to address cognitions and beliefs. This point has been identified by Birchwood 2006 who has noted that CBT for psychosis has often been treated as if it were a 'quasi-neuroleptic' where the focus of outcome measurement has been on global symptoms with the expectation that CBT should reduce psychotic symptoms directly as opposed to eliciting emotional and behavioural changes. More recent trials of CBT in relation to treatment as usual are more clearly based on theoretical models of psychotic symptoms (e.g. Trower 2004). Such trials have a clear focus on the specificity of the beliefs addressed (e.g. power beliefs about voices) and outcome measures which are sensitive to belief change as the mediator of emotional and behavioural change.

Overall, interventions did vary considerably but findings were consistent. When wellimplemented CBT is given, for long or short periods, with various foci of treatment, there is no convincing difference between CBT and other psychosocial interventions in relation to psychotic symptomatology and broad measures of functioning (Summary of findings for the main comparison). However, there are some promising preliminary findings with respect to the effect of CBT on symptoms of depression. At present, it remains unclear but it is interesting to speculate as to the relative benefits for CBT for psychosis compared with CBT which is specifically focused upon depression in this group of patients. 


\section{Quality of the evidence}

This is an attempt to quantitatively summarise the effects of cognitive behavioural therapy for schizophrenia. This has not been an easy task and the review authors will be pleased to hear from readers in order to improve this work for future issues of The Cochrane Library. The methodological quality of the included studies is summarised in Figure 2. There still are too few trials. Studies are too small. Outcomes are often reported in such a way that leaves presentation in a systematic review, difficult or impossible. In addition, scales are often used to measure outcomes that are not directly relevant to psychological therapy.

There has, however, been a general improvement in methodological rigor of the more recent trials. Several trials had relatively large sample sizes (Buchkremer 1997; Garety 2008 a; Klingberg 2009; Lewis 2002 all exceeded 100 people). All 20 included studies report some form of randomisation, with 10 describing adequate sequence generation. Allocation was concealed in 11 studies and 16 of the 20 trials (80\%) employed raters blinded to the treatment condition.

One of the key issues which is a limiting factor in interpreting current trial data is the wide variation in the targets of treatment and there is little agreement on how these targets and key outcomes should be operationalised. Studies frequently measure different outcomes or measure the same outcome using different measures. The differences in the psychometric properties of these measures make it difficult to interpret the variability of the outcomes reported in the trials. It would be invaluable to future trialists to receive direction regarding a common consensus on the most reliable, valid and clinically relevant outcome measures for $\mathrm{CBT}$ for psychosis. In the view of the authors this is likely to require the design and validation of new outcome measures both for specific aspects of positive symptoms (e.g. beliefs, preoccupation and conviction) as well as key emotional and behavioural outcomes including anxiety, depression and more specific symptom-related distress. For example, current state-of-the-art measures of these dimensions are not fully adequate to assess the efficacy of CBT. The PSYRATS, for example, includes only a single four-point measure of delusional or voice-related distress and the Beliefs About Voices Questionnaire includes measures of emotional response to voices which are not clearly delineated from other variables, such as the person's behaviour in relation to the voice. In addition, the ultimate aim of clinical intervention is to improve functioning and trials should include primary outcomes relating to this including, return to work, social functioning and quality of life. It would seem important to also report on some economic outcomes.

Finally, a welcome addition to some of the newer trials is the introduction of protocols to assess adherence to CBT methods, though there remains a lack of consensus across trials as to how this is implemented. In addition, a recent government focus in the UK on making psychological therapies more widely available is likely to mean that a broader range of expertise is employed in the delivery of CBT for psychosis. At present the experience of therapists in trials is not always clearly described and this renders it difficult to undertake a sensitivity analysis of the effect of therapist expertise. 


\section{Potential biases in the review process}

One of the review authors (AM) is actively engaged in the evaluation of the efficacy of CBT for psychosis.

\section{Agreements and disagreements with other studies or reviews}

There are few reviews of CBT compared with other psychological therapies. However, in a meta-analysis of eight trials with 528 patients, Pilling 2002 reported that CBT did not show an advantage over other active therapies (i.e., supportive counselling, and a problem solving group) although positive effects of CBT were reported relative to standard care.

\section{AUTHORS' CONCLUSIONS}

\section{Implications for practice}

1. For people with schizophrenia-The use of CBT has been associated with some reduction in symptoms, especially the positive symptoms of schizophrenia. However, there is considerable variability in the findings of the various studies and, at present, it is not possible to assert any substantial benefit for cognitive behavioural therapy over other psychological therapies.

2. For clinicians-Presently, CBT is a scarce commodity, often provided by highly skilled and experienced therapists. These data are not convincing of clear benefit over other - and sometimes less sophisticated - therapies for people with schizophrenia. There is some indication that CBT may help the affective problems associated with having such a serious illness as schizophrenia.

3. For policy makers-Cognitive behavioural therapy held promise of providing a useful adjunct to traditional treatment of people with psychotic disturbance. The Included randomised controlled trials of CBT and their small sample sizes demand caution until such time as data from larger, more methodologically coherent randomised controlled trials are available to supplement these initial findings.

A cost/benefit analysis would enable clinicians and purchasers to manage service provision and make best use of resources.

4. For funders of research-More, large, generally applicable, clinically meaningful trials are needed. More comparisons of CBT with supportive approaches would seem of particular interest. Further research should address the issue of the use of CBT in specific settings and contexts (e.g., tertiary psychiatric services, long-stay institutions, day hospitals).

The present data provides little indication of how effective CBT procedures might be when they are applied by less experienced practitioners. It would be useful to know whether the effects of CBT are sustained after the therapy course has finished, whether booster sessions are beneficial, or whether continued (long-term) therapy is required to sustain the treatment effect. 


\section{Implications for research}

\section{General}

1.1 Presentation of data: If all of the trials within this review had conformed to the suggestions within the CONSORT statement on trials reporting (Begg 1996; Moher 2001) much more may be known on the effect of CBT for people with schizophrenia. Cognitive behavioural therapy trials are difficult to undertake so data should not be wasted. Unfortunately, trialists often did not present clear measures of association between intervention and outcome, for example, risk ratios, odds ratios, risk or means difference, as well as the raw data. Wherever possible, binary outcomes should be reported in preference to continuous scale derived data as they are easier to interpret and clinically relevant. If $\mathrm{P}$ values are used, the exact value should be reported.

1.2 Randomisation: Allocation concealment is a fundamental part of trial methodology. If readers are to be reassured that selection bias was minimised then the randomisation process should be clearly described.

1.3 Blinding: Double-blind evaluation of the outcomes of a psychosocial intervention is extremely difficult, and probably impossible. Trialists should, however, take every precaution to minimise the effect of biases by using blinded or independent raters (quoting inter-rater reliability and measuring their blindness) and, probably more importantly, using 'harder' outcomes such as relapse, self-harm, and relapse or admission rather than scale data.

1.4 Withdrawals: Intention-to-treat analysis is preferable. If possible, trialists should describe from which groups withdrawals came, why they occurred and what was their outcome.

\section{Specific to cognitive behavioural therapy trials}

2.1 The issue of practitioners: Cognitive behavioural therapy holds the promise of providing a valuable adjunct to traditional treatments for people with psychotic disturbances. Despite the fact that it may be an effective therapy, it is currently inaccessible to most of those with schizophrenia even within well-resourced care services. This situation will remain until either i. the basic skills of cognitive behavioural therapy can be generalised to other healthcare professionals; or ii. there can be increased availability of specialists specifically practising CBT for those with schizophrenia.

2.2 Power: Estimates of statistical power based on data obtained from this review indicates that using data from within this review for the outcome of 'no important improvement', estimates of statistical power indicate that about 70 people per group are required to show a statistically significant difference in the outcome over a period of at least six months (alpha 0.05 , beta 0.8 ). This computation assumes that the difference in proportions is -0.29 (specifically, 0.58 versus 0.87 ). Given an attrition rate of approximately $30 \%$, researchers should aim for a minimal sample size of 100 persons per intervention. 
2.3 Outcomes measured: Outcomes should be clear and clinically useful but if authors are to persist in using continuous scale-derived data these tools should be standardised, and peer reviewed (Marshall 2000). Concrete outcomes of disturbance such as 'disturbed episode', 'use of detention order', 'use of special nursing observation' or, for those in the community, 'avoiding hospitalisation' would be of interest. Data on quality of life, social functioning, occupational status, general impression of carer/other, unwanted effects, such as anxiety, depression and dependence on the relationship with the therapist, staff fatigue and economic outcomes would be very welcome.

\section{Acknowledgments}

Clive Adams, for invaluable editorial support and encouragement.

\section{SOURCES OF SUPPORT}

Internal sources

- $\quad$ South Warwickshire Mental Health Trust, UK.

- University of Birmingham, UK.

- Nottinghamshire Healthcare NHS Trust, UK.

External sources

- $\quad$ No sources of support supplied

\section{Appendix 1. Previous searches}

1. Detail of searches used in original CBT review (Jones 2004)

1. Electronic searches for update

1.1 The Cochrane Schizophrenia Group's Register (January 2004) was searched using the phrase: $\left\{\left[\left({ }^{*}\right.\right.\right.$ cogniti* AND $(*$ behavio* or therap* $\left.)\right)$ OR $(*$ cogniti* and $(*$ technique* or *restructur* or *challeng*)) OR (*self* and (*instruct* or *management* or *attribution*)) OR (*rational* and *emotiv*) in title, abstract, index terms of REFERENCE] or [Cognitive* in interventions of STUDY]\}

The Schizophrenia Groups trials register is based on regular searches of BIOSIS Inside; CENTRAL; CINAHL; EMBASE; MEDLINE and PsycINFO; the hand searching of relevant journals and conference proceedings, and searches of several key grey literature sources.

A full description is given in the Group's module.

2. Details of previous searches:

2.1 Biological Abstracts (January 1980 - January 1998) was searched using the Cochrane Schizophrenia Groups search for randomised controlled trials and schizophrenia (please see Cochrane Schizophrenia Group Module) combined with: [and (COGNITIV* and BEHAVIO* and THERAP*) or (COGNITI* and (TECHNIQUE* or THERAP* or RESTRUCTUR* or CHALLENG*)) or (ATTRIBUTION* or (SELF and (INSTRUCT* or MANAGEMENT* or ATTRIBUTION*))) or (RET or (RATIONAL and $\left.\mathrm{EMOTIV}^{*}\right)$ )] 
2.2 CINAHL (January 1982 - January 1998) was searched using the Cochrane Schizophrenia Group's search for randomised controlled trials and schizophrenia (please see Cochrane Schizophrenia Group Module) combined with: [and (COGNITIV* and BEHAVIO* and THERAP*) or (COGNITI* and (TECHNIQUE* or THERAP* or RESTRUCTUR* or CHALLENG*)) or (ATTRIBUTION* or (SELF and (INSTRUCT* or MANAGEMENT* or ATTRIBUTION*))) or (RET or (RATIONAL and EMOTIV*)) or "COGNITIVE-THERAPY"/ all topical subheadings / all age subheadings]

2.3 The Cochrane Library (Issue 2, 1998) CENTRAL Register was searched using the phrase: [ $<$ me> COGNITIVE THERAPY or <me> PSYCHOTHERAPY RATIONAL EMOTIVE or (COGNITI* and (TECHNIQUE* or THERAP* or RESTRUCTUR* or CHALLENG*)) or (SELF and (INSTRUCT* or MANAGEMENT* or ATTRIBUTION*)) or ATTRIBUTION* or (COGNITIV* and BEHAVIO* and THERAP*) or RET or (RATIONAL and EMOTIV*)]

2.4 The Cochrane Schizophrenia Group's Register of Trials (August 1998) was searched using the phrase: [(COGNITIV* and BEHAVIO* and THERAP*) or (COGNITI* and (TECHNIQUE* or THERAP* or RESTRUCTUR* or CHALLENG*)) or (ATTRIBUTION* or (SELF and (INSTRUCT* or MANAGEMENT* or ATTRIBUTION*))) or (RET or (RATIONAL and EMOTIV*)) or \#42=142]

2.5 The Cochrane Schizophrenia Groups' Register of Trials (January 2001) was searched using the phrase: [(COGNITIV* and BEHAVIO* and THERAP*) or (COGNITI* and (TECHNIQUE* or THERAP* or RESTRUCTUR* or CHALLENG*)) or (ATTRIBUTION* or (SELF and (INSTRUCT* or MANAGEMENT* or ATTRIBUTION*))) or (RET or (RATIONAL and EMOTIV*))]

This register now encompasses all other of the databases and many more (see Group Module).

2.6 EMBASE (1980 - January 1998) was searched using the Cochrane Schizophrenia Group's search for randomised controlled trials and schizophrenia (please see Cochrane Schizophrenia Group Module) combined with: [and (COGNITIV* and BEHAVIO* and THERAP*) or (COGNITI* and (TECHNIQUE* or THERAP* or RESTRUCTUR* or CHALLENG*)) or (ATTRIBUTION* or (SELF and (INSTRUCT* or MANAGEMENT* or ATTRIBUTION*))) or (RET or (RATIONAL and EMOTIV*)) or "COGNITIVE-THERAPY"/all subheadings]

2.7 MEDLINE (1966 - January 1998) was searched using the Cochrane Schizophrenia Group's search for randomised controlled trials and schizophrenia (please see Cochrane Schizophrenia Group Module) combined with: [and (COGNITIV* and BEHAVIO* and THERAP*) or (COGNITI* and (TECHNIQUE* or THERAP* or RESTRUCTUR* or CHALLENG*)) or (ATTRIBUTION* or (SELF and (INSTRUCT* or MANAGEMENT* or ATTRIBUTION*)) ) or (RET or (RATIONAL and EMOTIV*)) or "COGNITIVE-THERAPY"/all subheadings]

2.8 PsycLIT (1887 January 1998) was searched using the Cochrane Schizophrenia Group's search for randomised controlled trials and schizophrenia (please see Cochrane 
Schizophrenia Group Module) combined with: [and (COGNITIV* and BEHAVIO* and THERAP*) or explode "COGNITIVE-TECHNIQUES" or (COGNITI* and (TECHNIQUE* or THERAP* or RESTRUCTUR* or CHALLENG*)) or (ATTRIBUTION* or (SELF and (INSTRUCT* or MANAGEMENT* or ATTRIBUTION*))) or (RET or (RATIONAL near2 EMOTIV*)) or explode "RATIONAL-EMOTIVE-THERAPY" or explode "SELF-HELP-TECHNIQUES" or explode "INDIVIDUALIZED-INSTRUCTION" or explode "SELFINSTRUCTIONAL-TRAINING”]

2.9 SIGLE (1990 - January 1998) was searched using the Cochrane Schizophrenia Group's search for randomised controlled trials and schizophrenia (please see Cochrane Schizophrenia Group Module) combined with: [and (COGNITIV* and BEHAVIO* and THERAP*) or (COGNITI* and (TECHNIQUE* or THERAP* or RESTRUCTUR* or CHALLENG*)) or (ATTRIBUTION* or (SELF and (INSTRUCT* or MANAGEMENT* or ATTRIBUTION*))) or (RET or (RATIONAL and EMOTIV*))]

2.10 Sociofile (1980 - January 2001) was searched using the Cochrane Schizophrenia Group's search for randomised controlled trials and schizophrenia (please see Cochrane Schizophrenia Group Module) combined with: [and (COGNITIV* and BEHAVIO* and THERAP*) or (COGNITI* and (TECHNIQUE* or THERAP* ${ }^{*}$ or RESTRUCTUR* or CHALLENG*)) or (ATTRIBUTION* or (SELF and (INSTRUCT* or MANAGEMENT* or ATTRIBUTION*))) or (RET or (RATIONAL and EMOTIV*)) or explode "PSYCHOTHERAPY"]

\section{Searching other resources}

1. Reference Lists

All references of included articles were searched for further relevant trials.

2. Authors

When appropriate, the first author of each of the included papers was contacted and additional published and unpublished materials were requested.

\section{CHARACTERISTICS OF STUDIES}

\section{Characteristics of included studies [ordered by study ID]}

Bechdolf 2004

\begin{tabular}{ll}
\hline Methods & Allocation: randomised. \\
& Blinding: blind assessments carried out by independent raters not involved in treatment. \\
& Duration: 8 weeks, 6 months and 24 months. \\
\hline Participants & Diagnosis: schizophrenia or related disorder (ICD 10). \\
& $\mathrm{N}=88$. \\
& Sex: 40 male 48 female. \\
& Age: mean $~ 32$ years (SD 10). \\
& History: patients with a primary diagnosis of drug or alcohol dependence, organic brain disease, \\
& learning disability or hearing impairment was excluded \\
\hline
\end{tabular}


Interventions

1 Group cognitive behavioural therapy: treatment based on approach by Tarrier $1993 \mathrm{~b}$ (used coping strategy enhancement, problem solving \& relapse prevention), focused on treatment of auditory hallucinations \& delusions, associated symptoms \& problem (e.g. anxiety, depression), relapse prevention \& associated problems \& enhancing medication compliance. $\mathrm{N}=40$

2 Group psychoeducational programme: included eight weekly 60-90 min sessions, sessions followed semi-structured format, covering symptoms and models of psychosis, effects of medication, maintenance medication, early symptoms of relapse, relapse prevention; approach primarily didactic, included formulation, guided discovery and motivational interviewing. $\mathrm{N}=48$

\begin{tabular}{|c|c|c|}
\hline Outcomes & \multicolumn{2}{|c|}{$\begin{array}{l}\text { Global state: clinically significant change ( }>2 \text { SD on PANSS global score + RCI exceeds } 1.96 \text { ); } \\
\text { relapse (rating }>5 \text { also } 2 \text {-point increase on previous assessment in }>1 \text { item of positive syndrome } \\
\text { subscale of PANSS); re-hospitalisation ( } 36 \text {-hour full hospitalisation or } 5 \text {-day partial hospitalisation } \\
\text { because of exacerbation of acute psychotic symptoms) }\end{array}$} \\
\hline \multicolumn{3}{|l|}{ Notes } \\
\hline \multicolumn{3}{|l|}{ Risk of bias } \\
\hline Bias & Authors' judgement & Support for judgement \\
\hline $\begin{array}{l}\text { Random } \\
\text { sequence } \\
\text { generation } \\
\text { (selection bias) }\end{array}$ & Low risk & Computer-generated random numbers, blocks of 8 . \\
\hline $\begin{array}{l}\text { Allocation } \\
\text { concealment } \\
\text { (selection bias) }\end{array}$ & Low risk & $\begin{array}{l}\text { Allocation in sealed envelopes and opened at time of } \\
\text { treatment allocation }\end{array}$ \\
\hline $\begin{array}{l}\text { Blinding } \\
\text { (performance } \\
\text { bias and } \\
\text { detection bias) } \\
\text { All outcomes }\end{array}$ & Low risk & $\begin{array}{l}\text { Single - most assessments by independent raters not } \\
\text { involved in treatment }\end{array}$ \\
\hline $\begin{array}{l}\text { Incomplete } \\
\text { outcome data } \\
\text { (attrition bias) } \\
\text { All outcomes }\end{array}$ & Low risk & $\begin{array}{l}\text { Investigated by comparing sociodemo-graphic data, } \\
\text { psychopathology and compliance ratings at } \\
\text { pretreatment stage for group whose ratings were } \\
\text { missing at post-treatment or follow-up with the } \\
\text { remaining participants for whom scores existed. } \\
\text { Intention to treat analysis undertaken }\end{array}$ \\
\hline $\begin{array}{l}\text { Selective } \\
\text { reporting } \\
\text { (reporting bias) }\end{array}$ & Low risk & $\begin{array}{l}\text { We did not have the study protocol but see no } \\
\text { indication of selective reporting }\end{array}$ \\
\hline Other bias & Low risk & No clear indication of other bias. \\
\hline
\end{tabular}

Buchkremer 1997

\begin{tabular}{ll}
\hline Methods & Allocation: randomised. \\
& Blinding: none. \\
& Duration: 2 years. \\
\hline Participants & Diagnosis: schizophrenia (DSM-III-R). \\
& N = 191. \\
& Age: mean $\sim 31$ years, SD $\sim 7$. \\
& History: not schizoaffective, no comorbidity with substance abuse \\
\hline
\end{tabular}

Interventions $\quad 1$ Cognitive behavioural therapy: psychoeducational medication management training + cognitive therapy + standard care. $\mathrm{N}=34$

2 Cognitive behavioural therapy: psychoeducational medication management training + cognitive therapy + key person counselling + standard care. $\mathrm{N}=33$

3 Psychoeducational medication training + leisure time group + standard care. $\mathrm{N}=32$

4 Psychoeducational medication training + leisure time group + key person counselling + standard care. $\mathrm{N}=35$ 
$5 \quad$ Structured free-time activity + standard care. $\mathrm{N}=57$.

\begin{tabular}{|c|c|c|}
\hline Outcomes & \multicolumn{2}{|c|}{$\begin{array}{l}\text { General state: hospitalisation. } \\
\text { Unable to use - Mental state: BPRS, SANS (data not reported by individual groups), IRA (data not } \\
\text { reported by individual groups). } \\
\text { Prognosis: SCPI, MPS (data not reported by individual groups). } \\
\text { Global impression: GAS (data not reported by individual groups). } \\
\text { Satisfaction with treatment: Leaving the study early (data not reported by individual groups) }\end{array}$} \\
\hline Notes & \multicolumn{2}{|c|}{$\begin{array}{l}\text { Psychoeducational medication training (PMT) - individualized information about schizophrenia and } \\
\text { its treatment, patients trained to recognize and react to early signs of relapse } \\
\text { Cognitive psychotherapy - designed to mediate problem-solving skills and to improve coping } \\
\text { strategies. Structured coping with stress situations (definition of a problem, setting of goals and } \\
\text { systematic selection of steps towards attainment of goals) and more adequate coping with everyday } \\
\text { stress were to be learned as a means of reducing general stress levels Key-person counselling (KC) - } \\
\text { targeted at relatives/care-givers - given information about schizophrenia and its treatment, and } \\
\text { recognition of impending relapses discussed, together with coping strategies, dealing with day-to- } \\
\text { day problems involved in living with schizophrenia, aimed to transfer to self-help group }\end{array}$} \\
\hline \multicolumn{3}{|l|}{ Risk of bias } \\
\hline Bias & Authors' judgement & Support for judgement \\
\hline $\begin{array}{l}\text { Random } \\
\text { sequence } \\
\text { generation } \\
\text { (selection bias) }\end{array}$ & Low risk & $\begin{array}{l}\text { Randomisation carried out by an independent } \\
\text { institution. }\end{array}$ \\
\hline $\begin{array}{l}\text { Allocation } \\
\text { concealment } \\
\text { (selection bias) }\end{array}$ & Low risk & $\begin{array}{l}\text { Randomisation carried out by an independent } \\
\text { institution. }\end{array}$ \\
\hline $\begin{array}{l}\text { Blinding } \\
\text { (performance } \\
\text { bias and } \\
\text { detection bias) } \\
\text { All outcomes }\end{array}$ & High risk & $\begin{array}{l}\text { Data recorded by trained project staff who were not } \\
\text { blind with respect to the group of allocation }\end{array}$ \\
\hline $\begin{array}{l}\text { Incomplete } \\
\text { outcome data } \\
\text { (attrition bias) } \\
\text { All outcomes }\end{array}$ & Low risk & $\begin{array}{l}\text { Modified intention-to-treat approach all who } \\
\text { attended }>1 \text { group session included in main } \\
\text { analysis }\end{array}$ \\
\hline $\begin{array}{l}\text { Selective } \\
\text { reporting } \\
\text { (reporting bias) }\end{array}$ & High risk & $\begin{array}{l}\text { Data for BPRS, SANS, GAS and others were } \\
\text { reported by individual groups only }\end{array}$ \\
\hline Other bias & Unclear risk & No clear indication of other bias. \\
\hline
\end{tabular}

Cather 2005

\begin{tabular}{|c|c|}
\hline Methods & $\begin{array}{l}\text { Allocation: randomised - stratified by severity of symptoms (PANNS < 63) and gender. } \\
\text { Blinding: single - assessments blind to treatment condition. } \\
\text { Duration: } 16 \text { weeks. }\end{array}$ \\
\hline Participants & $\begin{array}{l}\text { Diagnosis: schizophrenia (61\%) or schizoaffective disorder (39\%). } \\
\mathrm{N}=30 \text {. } \\
\text { Age: average } 40 \text { years (SD 12). } \\
\text { Duration Ill: average } 18 \text { years (SD 13). } \\
\text { History: doses of olanzapine ranged from } 5 \text { to } 40 \mathrm{mg} \text {, with a mean daily dose of } 19.7 \text { (8.6) mg; } 33 \% \\
\text { of sample was taking another antipsychotic in addition to olanzapine. } \\
\text { Inclusion criteria: } 18-65 \text { years of age, English speaking, treated with olanzapine for > } 6 \text { months and } \\
\text { at stable dose > } 30 \text { days, and exhibiting residual psychotic symptoms. } \\
\text { Excluded: evidence of organic brain disorder, recent substance use disorder, a conceptual } \\
\text { disorganization rating on the PANSS of moderate or higher, or previous exposure to CBT }\end{array}$ \\
\hline Interventions & $\begin{array}{l}\text { Cognitive behavioural therapy: inclusive of cognitive restructuring, goal setting and } \\
\text { coping strategy enhancement, with focus on addressing specific functional goals in } \\
\text { relation to social and occupational functioning, weekly 1-hour individual sessions for } 16 \\
\text { weeks. } \mathrm{N}=15\end{array}$ \\
\hline
\end{tabular}

Cochrane Database Syst Rev. Author manuscript; available in PMC 2014 September 15. 
2 Psychoeducation: supportive elements of therapy and psycho-education in a manualised intervention delivered by experienced therapists, weekly 1 -hour individual sessions for 16 weeks. $\mathrm{N}=13$

\begin{tabular}{|c|c|c|}
\hline Outcomes & \multicolumn{2}{|c|}{$\begin{array}{l}\text { Mental state: clinically significant improvement, PSRS, PANSS. } \\
\text { Social functioning: SFS.* }\end{array}$} \\
\hline Notes & \multicolumn{2}{|c|}{$\begin{array}{l}\text { * SFS is designed to assess functioning over the past } 3 \text { months. In this study it was used to assess } \\
\text { functioning over a one week period. Accordingly, this non-standard use of the SFS invalidates } \\
\text { comparison with other studies }\end{array}$} \\
\hline \multicolumn{3}{|l|}{ Risk of bias } \\
\hline Bias & Authors' judgement & Support for judgement \\
\hline $\begin{array}{l}\text { Random } \\
\text { sequence } \\
\text { generation } \\
\text { (selection bias) }\end{array}$ & Low risk & $\begin{array}{l}\text { Randomised - stratified by severity of symptoms } \\
\text { (PANNS < 63) and gender - no further details }\end{array}$ \\
\hline $\begin{array}{l}\text { Allocation } \\
\text { concealment } \\
\text { (selection bias) }\end{array}$ & High risk & $\begin{array}{l}\text { Allocation carried out by an "independent rater" (not } \\
\text { blinded) }\end{array}$ \\
\hline $\begin{array}{l}\text { Blinding } \\
\text { (performance } \\
\text { bias and } \\
\text { detection bias) } \\
\text { All outcomes }\end{array}$ & Low risk & Rater blind to allocation. \\
\hline $\begin{array}{l}\text { Incomplete } \\
\text { outcome data } \\
\text { (attrition bias) } \\
\text { All outcomes }\end{array}$ & High risk & No intention-to-treat analysis. \\
\hline $\begin{array}{l}\text { Selective } \\
\text { reporting } \\
\text { (reporting bias) }\end{array}$ & Low risk & $\begin{array}{l}\text { We did not have the study protocol but see no } \\
\text { indication of selective reporting }\end{array}$ \\
\hline Other bias & Low risk & No clear indication of other bias. \\
\hline
\end{tabular}

Drury 2000

\begin{tabular}{|c|c|}
\hline Methods & $\begin{array}{l}\text { Allocation: random allocation, using stratified sampling technique. } \\
\text { Blinding: none. } \\
\text { Duration: } 5 \text { years. }\end{array}$ \\
\hline Participants & $\begin{array}{l}\text { Diagnosis: schizophrenia, schizoaffective, or delusional disorder (DSM-IV). } \\
\mathrm{N}=62 \text {. } \\
\text { Age: mean } \sim 30 \text { years, SD } \sim 9 \text {, range } \sim 20-55 \text {. } \\
\text { Sex: } 25 \mathrm{M}, 15 \mathrm{~F} \text {, unknown } 22 \text {. } \\
\text { History: mean duration of illness } \sim 6 \text { years, number of episodes } \sim 3\end{array}$ \\
\hline \multirow[t]{2}{*}{ Interventions } & $\begin{array}{l}1 \text { Cognitive behavioural therapy:individual, challenging and testing key beliefs, group } \\
\text { cognitive therapy, coping strategy enhancement + standard care. } \mathrm{N}=30\end{array}$ \\
\hline & $\begin{array}{l}2 \text { Control: recreation and support: leisure and social activities away from ward + } \\
\text { standard care. } \mathrm{N}=32\end{array}$ \\
\hline Outcomes & $\begin{array}{l}\text { General state: relapse. } \\
\text { Mental state: important improvement (PQ), specific symptom clusters (PAS). } \\
\text { Satisfaction with treatment: Leaving the study early. } \\
\text { Unable to use - } \\
\text { Mental state: PAS (reported only as graphs, no extractable data) Average use of antipsychotic } \\
\text { medication (data skewed). }\end{array}$ \\
\hline Notes & $\begin{array}{l}\text { Reviewers considered recreation and support to be an non-active therapy. Authors contacted for } \\
\text { further data }\end{array}$ \\
\hline Risk of bias & \\
\hline
\end{tabular}

Cochrane Database Syst Rev. Author manuscript; available in PMC 2014 September 15. 


\begin{tabular}{|c|c|c|}
\hline Bias & Authors' judgement & Support for judgement \\
\hline $\begin{array}{l}\text { Random sequence } \\
\text { generation } \\
\text { (selection bias) }\end{array}$ & Unclear risk & $\begin{array}{l}\text { Random allocation, using stratified sampling } \\
\text { technique. }\end{array}$ \\
\hline $\begin{array}{l}\text { Allocation } \\
\text { concealment } \\
\text { (selection bias) }\end{array}$ & Unclear risk & Insufficient information. \\
\hline $\begin{array}{l}\text { Blinding } \\
\text { (performance bias } \\
\text { and detection } \\
\text { bias) } \\
\text { All outcomes }\end{array}$ & High risk & $\begin{array}{l}\text { All participants were rated by first author with a } \\
\text { subset rated blindly by two other authors }\end{array}$ \\
\hline $\begin{array}{l}\text { Incomplete } \\
\text { outcome data } \\
\text { (attrition bias) } \\
\text { All outcomes }\end{array}$ & Low risk & $\begin{array}{l}\text { Completer analysis of outcomes. No intention to } \\
\text { treat analysis of people who left early }\end{array}$ \\
\hline $\begin{array}{l}\text { Selective } \\
\text { reporting } \\
\text { (reporting bias) }\end{array}$ & Low risk & $\begin{array}{l}\text { We did not have the study protocol but see no } \\
\text { indication of selective reporting }\end{array}$ \\
\hline Other bias & Low risk & No clear indication of other bias. \\
\hline
\end{tabular}

Durham 2003

\begin{tabular}{|c|c|c|}
\hline Methods & \multicolumn{2}{|l|}{$\begin{array}{l}\text { Allocation: randomised. } \\
\text { Blinding: outcome only. } \\
\text { Duration: } 12 \text { months. }\end{array}$} \\
\hline Participants & \multicolumn{2}{|c|}{$\begin{array}{l}\text { Diagnosis: schizophrenia, schizoaffective and delusional disorder (ICD-10 and DSM -IV). } \\
\mathrm{N}=66 . \\
\text { History: duration of illness } \sim 13 \text { years, mean age } \sim 36 \text { years. } \\
\text { Sex: } 45 \mathrm{M}, 21 \mathrm{~F} \text {. }\end{array}$} \\
\hline \multirow[t]{3}{*}{ Interventions } & Cognitive & ehavioural therapy: individual CBT + standard care. $\mathrm{N}=22$ \\
\hline & $2 \quad$ Supportive & psychotherapy: individual psychotherapy + standard care. $\mathrm{N}=23$ \\
\hline & $3 \quad$ Standard c & re: routine care, case management $\&$ medication. $\mathrm{N}=21$ \\
\hline Outcomes & \multicolumn{2}{|c|}{$\begin{array}{l}\text { Adverse effect/event: Death. } \\
\text { Mental state: GAS, PANSS, PSYRATS. } \\
\text { Global state: No important improvement. } \\
\text { Satisfaction with treatment: Leaving the study early. }\end{array}$} \\
\hline \multicolumn{3}{|l|}{ Notes } \\
\hline \multicolumn{3}{|l|}{ Risk of bias } \\
\hline Bias & Authors' judgement & Support for judgement \\
\hline $\begin{array}{l}\text { Random sequence } \\
\text { generation (selection } \\
\text { bias) }\end{array}$ & Low risk & $\begin{array}{l}\text { Randomisation procedure (sealed envelope technique) devised by the } \\
\text { project statistician, carried out separately within each treatment } \\
\text { centre using randomised permuted blocking }\end{array}$ \\
\hline $\begin{array}{l}\text { Allocation } \\
\text { concealment } \\
\text { (selection bias) }\end{array}$ & Low risk & Administered centrally by the non-clinical project coordinator \\
\hline $\begin{array}{l}\text { Blinding (performance } \\
\text { bias and detection } \\
\text { bias) } \\
\text { All outcomes }\end{array}$ & Low risk & Independent raters. \\
\hline $\begin{array}{l}\text { Incomplete outcome } \\
\text { data (attrition bias) } \\
\text { All outcomes }\end{array}$ & Low risk & $\begin{array}{l}\text { Analyses repeated with missing values replaced either with previous } \\
\text { values carried forward or with group means, and the same pattern of } \\
\text { significance was found }\end{array}$ \\
\hline
\end{tabular}

Cochrane Database Syst Rev. Author manuscript; available in PMC 2014 September 15. 


\begin{tabular}{lll}
$\begin{array}{l}\text { Selective reporting } \\
\text { (reporting bias) }\end{array}$ & Low risk & $\begin{array}{l}\text { We did not have the study protocol but see no indication of selective } \\
\text { reporting }\end{array}$ \\
\hline Other bias & Low risk & No clear indication of other bias. \\
\hline
\end{tabular}

Garety 2008 a

\begin{tabular}{|c|c|c|c|}
\hline Methods & \multicolumn{3}{|c|}{$\begin{array}{l}\text { Allocation: randomised. } \\
\text { Blinding: single. } \\
\text { Duration: } 24 \text { months. }\end{array}$} \\
\hline Participants & \multicolumn{3}{|c|}{$\begin{array}{l}\text { Diagnosis: non-affective psychosis (ICD-10 and DSM-IV) with at least one positive symptom of } \\
\text { moderate severity on the PANSS. } \\
\mathrm{N}=301 \text {. } \\
\text { Age: } 18-65 \text { years. } \\
\text { Sex: not reported. } \\
\text { History:(a) ICD non-affective psychosis ; a second or subsequent psychotic episode; positive } \\
\text { symptoms, no alcohol or substance dependency, }\end{array}$} \\
\hline \multirow[t]{3}{*}{ Interventions } & 1 & \multicolumn{2}{|c|}{$\begin{array}{l}\text { Cognitive behavioural therapy: targeted at relapse prevention, done by exploring } \\
\text { people's understanding of triggers and risks of relapse and by developing new model of } \\
\text { disorder emphasising alternatives to delusional thinking, targets often included } \\
\text { persistent negative beliefs about self and others, characteristic reasoning styles such as } \\
\text { jumping to conclusions and distressing emotional reactions to events and anomalous } \\
\text { experiences; administered by skilled practitioners (doctorial level clinical psychologists) } \\
\text { and treatment fidelity assessed using the Cognitive Therapy for Psychosis Adherence } \\
\text { Scale. } \mathrm{N}=96\end{array}$} \\
\hline & 2 & \multicolumn{2}{|c|}{$\begin{array}{l}\text { Family intervention: emphasis on improving communication, offering discussion of up- } \\
\text { to-date information about psychosis, problem-solving, reducing criticism and conflict, } \\
\text { improving activity, and emotional processing of grief, loss and anger. } \mathrm{N}=28\end{array}$} \\
\hline & 3 & \multicolumn{2}{|c|}{ Treatment as usual. $\mathrm{N}=177$} \\
\hline Outcomes & \multicolumn{3}{|c|}{$\begin{array}{l}\text { General state: relapse (evidence of re-emergence of, or significant deterioration in, positive } \\
\text { psychotic symptoms of at least moderate degree persisting for }>2 \text { weeks), hospitalisation. } \\
\text { Mental state: no significant or meaningful change, PANSS, PSYRATS, BDI, BAI. } \\
\text { Social and occupational functioning: SOFAS. } \\
\text { Satisfaction with treatment: Leaving the study early. }\end{array}$} \\
\hline \multicolumn{4}{|l|}{ Notes } \\
\hline \multicolumn{4}{|l|}{ Risk of bias } \\
\hline Bias & \multicolumn{2}{|c|}{ Authors' judgement } & Support for judgement \\
\hline $\begin{array}{l}\text { Random } \\
\text { sequence } \\
\text { generation } \\
\text { (selection bias) }\end{array}$ & \multicolumn{2}{|l|}{ Low risk } & $\begin{array}{l}\text { Randomisation - stratified within each of five } \\
\text { participating centres and within in-patient or out- } \\
\text { patient status at the time of relapse }\end{array}$ \\
\hline $\begin{array}{l}\text { Allocation } \\
\text { concealment } \\
\text { (selection bias) }\end{array}$ & \multicolumn{2}{|l|}{ Low risk } & $\begin{array}{l}\text { Randomisation schedules independently generated by } \\
\text { a trial randomisation service in a separate location } \\
\text { from all trial centres (accessed by telephone) }\end{array}$ \\
\hline $\begin{array}{l}\text { Blinding } \\
\text { (performance } \\
\text { bias and } \\
\text { detection bias) } \\
\text { All outcomes }\end{array}$ & \multicolumn{2}{|l|}{ Low risk } & $\begin{array}{l}\text { Primary outcome (relapse) was masked. } \\
88 \% \text { of secondary outcomes were completed masked } \\
\text { (i.e. the allocation of the patient had not been } \\
\text { revealed to the assessor) }\end{array}$ \\
\hline $\begin{array}{l}\text { Incomplete } \\
\text { outcome data } \\
\text { (attrition bias) } \\
\text { All outcomes }\end{array}$ & \multicolumn{2}{|l|}{ Low risk } & Intention-to-treat analysis was undertaken. \\
\hline $\begin{array}{l}\text { Selective } \\
\text { reporting } \\
\text { (reporting bias) }\end{array}$ & \multicolumn{2}{|l|}{ Low risk } & $\begin{array}{l}\text { We did not have the study protocol but see no } \\
\text { indication of selective reporting }\end{array}$ \\
\hline Other bias & \multicolumn{2}{|l|}{ Low risk } & No clear indication of other bias. \\
\hline
\end{tabular}

Cochrane Database Syst Rev. Author manuscript; available in PMC 2014 September 15. 
Haddock 1999

\begin{tabular}{|c|c|c|}
\hline Methods & \multicolumn{2}{|l|}{$\begin{array}{l}\text { Allocation: randomised. } \\
\text { Blinding: outcome only. } \\
\text { Duration: } 2 \text { years. }\end{array}$} \\
\hline Participants & \multicolumn{2}{|c|}{$\begin{array}{l}\text { Diagnosis: schizophrenia, schizoaffective. } \\
\mathrm{N}=21 . \\
\text { History: duration of illness }<5 \text { years. } \\
\text { Age: mean }-28 \text { years, } \mathrm{SD}-7 \text {. } \\
\text { Sex: } 19 \text { men, } 2 \text { women. }\end{array}$} \\
\hline \multirow[t]{2}{*}{ Interventions } & $\begin{array}{ll}1 \quad \text { Cognitive } \\
=10\end{array}$ & ehavioural therapy:short-term individual CBT + standard care. $\mathrm{N}$ \\
\hline & $2 \quad$ Control: su & portive counselling and psychoeducation + standard care. $\mathrm{N}=11$ \\
\hline Outcomes & \multicolumn{2}{|c|}{$\begin{array}{l}\text { General state: relapse. } \\
\text { Mental state: BPRS. } \\
\text { Satisfaction with treatment: leaving the study early. }\end{array}$} \\
\hline \multicolumn{3}{|l|}{ Notes } \\
\hline \multicolumn{3}{|l|}{ Risk of bias } \\
\hline Bias & Authors' judgement & Support for judgement \\
\hline $\begin{array}{l}\text { Random sequence } \\
\text { generation (selection bias) }\end{array}$ & Unclear risk & Randomised - no further details. \\
\hline $\begin{array}{l}\text { Allocation concealment } \\
\text { (selection bias) }\end{array}$ & Unclear risk & Insufficient information. \\
\hline $\begin{array}{l}\text { Blinding (performance } \\
\text { bias and detection bias) } \\
\text { All outcomes }\end{array}$ & Low risk & At outcome - no further details. \\
\hline $\begin{array}{l}\text { Incomplete outcome data } \\
\text { (attrition bias) } \\
\text { All outcomes }\end{array}$ & High risk & Completer data (less than 5\% drop out). \\
\hline $\begin{array}{l}\text { Selective reporting } \\
\text { (reporting bias) }\end{array}$ & Low risk & $\begin{array}{l}\text { We did not have the study protocol but see no indication of } \\
\text { selective reporting }\end{array}$ \\
\hline Other bias & Low risk & No clear indication of other bias. \\
\hline
\end{tabular}

Haddock 2009

\begin{tabular}{|c|c|c|}
\hline Methods & \multicolumn{2}{|c|}{$\begin{array}{l}\text { Allocation: randomised - stratified by gender, substance misuse, anger related difficulties, } \\
\text { violence within the last } 12 \text { months, and facility (inpatient versus outpatient). } \\
\text { Blinding: single - raters blind to allocation. } \\
\text { Duration: } 12 \text { months. }\end{array}$} \\
\hline Participants & \multicolumn{2}{|c|}{$\begin{array}{l}\text { Diagnosis: schizophrenia or schizoaffective disorder (DSM-IV). } \\
\mathrm{N}=77 \text {. } \\
\text { Age: not reported. } \\
\text { Sex: } 66 \text { male; } 11 \text { female. } \\
\text { History: violent behaviour, experiencing persistent hallucinations and/or delusions ( } 24 \text { PANSS } \\
\text { sub-scales P1 and P3), receiving antipsychotic medication (dose between } 400 \mathrm{mg} \text { and } 1000 \mathrm{mg} \\
\text { chlorpromazine or equivalent). } \\
\text { Setting: } 19 \text { outpatients, } 58 \text { inpatients. }\end{array}$} \\
\hline \multirow[t]{2}{*}{ Interventions } & 1 & $\begin{array}{l}\text { Cognitive behavioural therapy: motivational strategies to aid engagement, to reduce } \\
\text { severity and distress of psychotic symptoms and severity of anger linked to aggression } \\
\text { and violence. } N=38\end{array}$ \\
\hline & 2 & Social Activities Therapy: helping identify and carry out enjoyable activities. $\mathrm{N}=39$ \\
\hline
\end{tabular}

Cochrane Database Syst Rev. Author manuscript; available in PMC 2014 September 15. 
Mental state: PANSS, PSYRATS, NAS-PI, aggression and violence, WARS, HCR-20

\begin{tabular}{|c|c|c|}
\hline Notes & $\begin{array}{l}\text { Therapy manual devel } \\
\text { Audio tapes of session } \\
\text { SAT tapes also rated to } \\
\text { standards }\end{array}$ & $\begin{array}{l}\text { ped for each treatment. } \\
\text { assessed by supervisors using the Cognitive Therapy Scale for Psychosis, } \\
\text { ensure no CBT used by presence of non-specific therapeutic quality }\end{array}$ \\
\hline \multicolumn{3}{|l|}{ Risk of bias } \\
\hline Bias & Authors' judgement & Support for judgement \\
\hline $\begin{array}{l}\text { Random sequence } \\
\text { generation } \\
\text { (selection bias) }\end{array}$ & Low risk & Randomised with computer-generated sequences. \\
\hline $\begin{array}{l}\text { Allocation } \\
\text { concealment } \\
\text { (selection bias) }\end{array}$ & Low risk & "Independent allocation”. \\
\hline $\begin{array}{l}\text { Blinding } \\
\text { (performance bias } \\
\text { and detection } \\
\text { bias) } \\
\text { All outcomes }\end{array}$ & Low risk & $\begin{array}{l}\text { Masking maintained by ensuring therapists and assessors were housed in } \\
\text { separate accommodation, therapy files were kept separately from data } \\
\text { and clinical staff was repeatedly instructed not to disclose any knowledge } \\
\text { of therapy group to assessors }\end{array}$ \\
\hline $\begin{array}{l}\text { Incomplete } \\
\text { outcome data } \\
\text { (attrition bias) } \\
\text { All outcomes }\end{array}$ & Low risk & Intention-to-treat analysis undertaken. \\
\hline $\begin{array}{l}\text { Selective } \\
\text { reporting } \\
\text { (reporting bias) }\end{array}$ & Low risk & $\begin{array}{l}\text { We did not have the study protocol but see no indication of selective } \\
\text { reporting }\end{array}$ \\
\hline Other bias & High risk & $\begin{array}{l}\text { Different samples (i.e. inpatient and outpatient) and therefore } \\
\text { opportunities to observe base rates of violent behaviour will vary as a } \\
\text { function of sample }\end{array}$ \\
\hline
\end{tabular}

Jackson 2008

\begin{tabular}{|c|c|}
\hline Methods & $\begin{array}{l}\text { Allocation: randomised. } \\
\text { Blinding: single. } \\
\text { Duration: } 14 \text { weeks. }\end{array}$ \\
\hline Participants & $\begin{array}{l}\text { Diagnosis: people experiencing a first episode of psychosis. } \\
\mathrm{N}=62 \text {. } \\
\text { Age: mean } ~ 22 \text { years (SD } ~ 3-4) \text {. } \\
\text { Sex: } 45 \text { men, } 17 \text { women. } \\
\text { Duration ill: CBT = } 83 \text { (untreated) days, befriending = median } 107 \text { (untreated) days. } \\
\text { Excluded: before randomisation if unable to speak English, IQ <70, psychosis due to medical } \\
\text { condition, change to non-psychotic diagnosis, treatment from private psychiatrist/ psychologist, } \\
\text { participating in first-episode mania trial, exhibiting violent behaviour, or being incarcerated }\end{array}$ \\
\hline \multirow[t]{2}{*}{ Interventions } & $\begin{array}{l}1 \text { Cognitive behavioural therapy: manualised - assessment and formulation of } \\
\text { relationship between psychotic and non-psychotic complaints and participants' life } \\
\text { history, treatment prioritised in order of the following; risk, distressing positive } \\
\text { symptoms, comorbidity, negative symptoms, issues of identity and relapse prevention, } \\
\text { a maximum of } 20 \times 45 \text { minute sessions over } 14 \text { weeks. } \mathrm{N}=31\end{array}$ \\
\hline & $\begin{array}{l}2 \text { Befriending: based on Sensky } 2000 \text { - a non-active therapist contact control, } \\
\text { "befriending aims to control for time in therapy, participant expectations and positive } \\
\text { experiences of therapy". } \mathrm{N}=31\end{array}$ \\
\hline Outcomes & $\begin{array}{l}\text { Gobal state: hospitalisation. } \\
\text { Mental state: psychotic subscale of BPRS, SANS. } \\
\text { Social functioning: SOFAS. }\end{array}$ \\
\hline \multicolumn{2}{|l|}{ Notes } \\
\hline Risk of bias & \\
\hline
\end{tabular}

Cochrane Database Syst Rev. Author manuscript; available in PMC 2014 September 15. 


\begin{tabular}{|c|c|c|}
\hline Bias & Authors' judgement & Support for judgement \\
\hline $\begin{array}{l}\text { Random } \\
\text { sequence } \\
\text { generation } \\
\text { (selection bias) }\end{array}$ & Low risk & $\begin{array}{l}\text { Randomised - stratified according to affective and non- } \\
\text { affective psychotic diagnosis }\end{array}$ \\
\hline $\begin{array}{l}\text { Allocation } \\
\text { concealment } \\
\text { (selection bias) }\end{array}$ & Low risk & Allocation was conducted by independent statistician. \\
\hline $\begin{array}{l}\text { Blinding } \\
\text { (performance } \\
\text { bias and } \\
\text { detection bias) } \\
\text { All outcomes }\end{array}$ & Low risk & Single - raters blind to allocated treatment. \\
\hline $\begin{array}{l}\text { Incomplete } \\
\text { outcome data } \\
\text { (attrition bias) } \\
\text { All outcomes }\end{array}$ & Low risk & $\begin{array}{l}\text { Missing values in each of the outcome measures for } \\
\text { any individual at time points subsequent to baseline } \\
\text { were assumed to have occurred at random, given } \\
\text { observed pre-treatment scores. Multiple Imputation } \\
\text { was used to compensate for missing data }\end{array}$ \\
\hline $\begin{array}{l}\text { Selective } \\
\text { reporting } \\
\text { (reporting bias) }\end{array}$ & Low risk & $\begin{array}{l}\text { We did not have the study protocol but see no } \\
\text { indication of selective reporting }\end{array}$ \\
\hline Other bias & High risk & $\begin{array}{l}\text { The participant group contained fewer patients with } \\
\text { schizophreniform disorder }(40.3 \%) \text { than expected by } \\
\text { chance (refusers }=62.7 \%) \text {. There were also } \\
\text { significantly more patients with schizoaffective } \\
\text { disorder in the participant group }(11.3 \%) \text { than in the } \\
\text { refuser group }(1.6 \%)\end{array}$ \\
\hline
\end{tabular}

Kemp 1998

\begin{tabular}{|c|c|c|}
\hline Methods & \multicolumn{2}{|l|}{$\begin{array}{l}\text { Allocation: randomised. } \\
\text { Blinding: none. } \\
\text { Duration: } 18 \text { months. }\end{array}$} \\
\hline Participants & \multicolumn{2}{|c|}{$\begin{array}{l}\text { Diagnosis: schizophrenia, schizoaffective, delusional disorder (DSM III-R). } \\
\mathrm{N}=74 \text {. } \\
\text { Age: range } 18-65 \text { years. } \\
\text { Sex: Not reported Excluded: non-English speakers, Learning disability, deaf or organic } \\
\text { brain disease }\end{array}$} \\
\hline \multirow[t]{2}{*}{ Interventions } & \multicolumn{2}{|c|}{$\begin{array}{l}\text { Cognitive behavioural therapy:psychoeducation + compliance therapy + } \\
\text { standard care. } \mathrm{N}=39\end{array}$} \\
\hline & Control: $\mathrm{n}$ & Control: non-specific counselling + standard care. $\mathrm{N}=35$ \\
\hline Outcomes & \multicolumn{2}{|c|}{$\begin{array}{l}\text { Mental state: BPRS, GAF, SAI, DAI, AMQ. } \\
\text { Satisfaction with treatment: leaving the study early. } \\
\text { Unable to use - } \\
\text { Compliance measure (scale not peer reviewed). }\end{array}$} \\
\hline Notes & \multicolumn{2}{|c|}{ The main focus of the intervention was on medication compliance } \\
\hline \multicolumn{3}{|l|}{ Risk of bias } \\
\hline Bias & \multicolumn{2}{|c|}{ Authors' judgement Support for judgement } \\
\hline $\begin{array}{l}\text { Random sequence } \\
\text { generation (selection } \\
\text { bias) }\end{array}$ & \multicolumn{2}{|r|}{ Reports random allocation - no detail provided. } \\
\hline $\begin{array}{l}\text { Allocation concealment } \\
\text { (selection bias) }\end{array}$ & \multicolumn{2}{|r|}{ No information reported. } \\
\hline $\begin{array}{l}\text { Blinding (performance } \\
\text { bias and detection bias) }\end{array}$ & \multicolumn{2}{|l|}{ High risk } \\
\hline
\end{tabular}

Cochrane Database Syst Rev. Author manuscript; available in PMC 2014 September 15. 
All outcomes

\begin{tabular}{lll}
\hline $\begin{array}{l}\text { Incomplete outcome } \\
\text { data (attrition bias) }\end{array}$ & High risk & Completer data. \\
\hline $\begin{array}{l}\text { All outcomes } \\
\begin{array}{l}\text { Selective reporting } \\
\text { (reporting bias) }\end{array}\end{array}$ & Low risk & $\begin{array}{l}\text { We did not have the study protocol but see no indication of } \\
\text { selective reporting }\end{array}$ \\
\hline Other bias & Low risk & No clear indication of other bias. \\
\hline
\end{tabular}

Klingberg 2009

\begin{tabular}{|c|c|c|}
\hline Methods & \multicolumn{2}{|l|}{$\begin{array}{l}\text { Allocation: randomised. } \\
\text { Blinding: single. } \\
\text { Duration: } 9 \text { months. }\end{array}$} \\
\hline Participants & \multicolumn{2}{|c|}{$\begin{array}{l}\text { Diagnosis: schizophrenia (DSM-IV). } \\
\mathrm{N}=198 \text {. } \\
\text { Age: average } 37 \text { years (SD 10). } \\
\text { Sex: } 56 \% \text { male. }\end{array}$} \\
\hline \multirow[t]{2}{*}{ Interventions } & \multicolumn{2}{|c|}{$\begin{array}{l}\text { Cognitive behavioural therapy: strategies designed specifically to reduce negative } \\
\text { symptoms, involved case formulation, goal setting, homework assignments, role } \\
\text { play, focus on initiative and planning, social activity, emotional participation and } \\
\text { expression and speech activity. } \mathrm{N}=99\end{array}$} \\
\hline & \multicolumn{2}{|c|}{$\begin{array}{l}\text { Cognitive remediation training: treatment protocol not described - reported that it } \\
\text { "might ameliorate negative symptoms to a certain extend as this is a partially active } \\
\text { treatment". } \mathrm{N}=99\end{array}$} \\
\hline Outcomes & \multicolumn{2}{|l|}{ Adverse effects. } \\
\hline Notes & \multicolumn{2}{|c|}{ Trial is ongoing and outcome with regard to negative symptoms has yet to be reported } \\
\hline \multicolumn{3}{|l|}{ Risk of bias } \\
\hline Bias & Authors' judgement & Support for judgement \\
\hline $\begin{array}{l}\text { Random sequence } \\
\text { generation } \\
\text { (selection bias) }\end{array}$ & Unclear risk & Insufficient detail. \\
\hline $\begin{array}{l}\text { Allocation } \\
\text { concealment } \\
\text { (selection bias) }\end{array}$ & Unclear risk & Insufficient detail. \\
\hline $\begin{array}{l}\text { Blinding } \\
\text { (performance bias } \\
\text { and detection bias) } \\
\text { All outcomes }\end{array}$ & Low risk & Raters blind to allocation. \\
\hline $\begin{array}{l}\text { Incomplete } \\
\text { outcome data } \\
\text { (attrition bias) } \\
\text { All outcomes }\end{array}$ & High risk & Completer data reported. \\
\hline $\begin{array}{l}\text { Selective reporting } \\
\text { (reporting bias) }\end{array}$ & High risk & $\begin{array}{l}\text { Trial is ongoing and outcome with regard to } \\
\text { negative symptoms has yet to be reported }\end{array}$ \\
\hline Other bias & Low risk & No clear indication of other bias. \\
\hline
\end{tabular}

Levine 1998

\begin{tabular}{ll}
\hline Methods & Allocation: randomised. \\
& Blinding: none.
\end{tabular}

Cochrane Database Syst Rev. Author manuscript; available in PMC 2014 September 15. 
Duration: 10 weeks.

\begin{tabular}{|c|c|c|}
\hline Participants & \multicolumn{2}{|c|}{$\begin{array}{l}\text { Diagnosis: paranoid schizophrenia. } \\
\mathrm{N}=12 \text {. } \\
\text { History: ill }>5 \text { years, not comorbid substance misuse, nor chronic physical condition or } \\
\text { orthodox religious conviction. } \\
\text { Age: range } 20-45 \text { years. }\end{array}$} \\
\hline \multirow[t]{2}{*}{ Interventions } & $\begin{array}{l}1 \quad \text { Cognitive } \\
\mathrm{N}=6 \text {. }\end{array}$ & Iral therapy: group based, six weekly sessions + standard care. \\
\hline & Supportiv & : group based, six weekly sessions + standard care. $N=6$ \\
\hline Outcomes & \multicolumn{2}{|c|}{$\begin{array}{l}\text { Mental state: PANSS - positive, negative, general, thought disturbance and total scores. } \\
\text { Satisfaction with treatment: leaving the study early. }\end{array}$} \\
\hline \multicolumn{3}{|l|}{ Notes } \\
\hline \multicolumn{3}{|l|}{ Risk of bias } \\
\hline Bias & Authors' judgement & Support for judgement \\
\hline $\begin{array}{l}\text { Random sequence } \\
\text { generation (selection } \\
\text { bias) }\end{array}$ & Unclear risk & Reports random allocation - no detail provided. \\
\hline $\begin{array}{l}\text { Allocation } \\
\text { concealment (selection } \\
\text { bias) }\end{array}$ & Unclear risk & Insufficient details provided. \\
\hline $\begin{array}{l}\text { Blinding (performance } \\
\text { bias and detection } \\
\text { bias) } \\
\text { All outcomes }\end{array}$ & Low risk & Raters unaware of allocation. \\
\hline $\begin{array}{l}\text { Incomplete outcome } \\
\text { data (attrition bias) } \\
\text { All outcomes }\end{array}$ & High risk & Completer analysis only. \\
\hline $\begin{array}{l}\text { Selective reporting } \\
\text { (reporting bias) }\end{array}$ & Low risk & $\begin{array}{l}\text { We did not have the study protocol but see no indication of } \\
\text { selective reporting }\end{array}$ \\
\hline Other bias & High risk & Sample size of only 6 participants per group. \\
\hline
\end{tabular}

Lewis 2002

\begin{tabular}{|c|c|}
\hline Methods & $\begin{array}{l}\text { Allocation: randomised. } \\
\text { Blinding: single. } \\
\text { Duration: } 18 \text { months. }\end{array}$ \\
\hline Participants & $\begin{array}{l}\text { Diagnosis: schizophrenia (DSM IV). } \\
\mathrm{N}=315 \text {. } \\
* \text { History: in acute phase, first or second acute admission. } \\
\text { Age: median }-27 \text { years. }\end{array}$ \\
\hline \multirow[t]{3}{*}{ Interventions } & 1 Cognitive behavioural therapy: 5 week session + routine care. $N=101$ \\
\hline & 2 Supportive counselling + routine care. $\mathrm{N}=106$. \\
\hline & $3 \quad$ Routine care. $\mathrm{N}=102$ \\
\hline Outcomes & $\begin{array}{l}\text { Global state: hospital admission. } \\
\text { Adverse effect/event: death. } \\
\text { Mental state: PANSS, PSYRATS (delusional scale). } \\
\text { Satisfaction with treatment: leaving the study early. }\end{array}$ \\
\hline Notes & * Six people excluded after randomisation. \\
\hline \multicolumn{2}{|l|}{ Risk of bias } \\
\hline Bias & Authors' judgement Support for judgement \\
\hline
\end{tabular}

Cochrane Database Syst Rev. Author manuscript; available in PMC 2014 September 15. 


\begin{tabular}{lll}
$\begin{array}{l}\text { Random sequence } \\
\text { generation (selection } \\
\text { bias) }\end{array}$ & Low risk & "Independent, concealed randomisation". \\
\hline $\begin{array}{l}\text { Allocation } \\
\text { concealment } \\
\text { (selection bias) }\end{array}$ & Low risk & Described as "concealed". \\
\hline $\begin{array}{l}\text { Blinding } \\
\text { (performance bias and } \\
\text { detection bias) }\end{array}$ & Low risk & Raters blind to treatment allocation. \\
\hline $\begin{array}{l}\text { All outcomes } \\
\text { data (attrition bias) }\end{array}$ & Low risk & \\
$\begin{array}{l}\text { All outcomes } \\
\text { Selective reporting } \\
\text { (reporting bias) }\end{array}$ & Low risk & Intention-to-treat regressional analysis. \\
\hline \begin{tabular}{l} 
Other bias \\
\hline
\end{tabular} & Low risk & $\begin{array}{l}\text { We did not have the study protocol but see no indication of selective } \\
\text { reporting }\end{array}$ \\
\hline
\end{tabular}

Lewis 2002 - Liverpool

\begin{tabular}{|c|c|c|}
\hline Methods & \multicolumn{2}{|c|}{$\begin{array}{l}\text { Allocation: randomised. } \\
\text { Blinding: raters blind to treatment allocation. } \\
\text { Duration: } 18 \text { months. }\end{array}$} \\
\hline Participants & \multicolumn{2}{|c|}{$\begin{array}{l}\text { Diagnosis: schizophrenia (DSM IV). } \\
\mathrm{N}=114 \text {. }\end{array}$} \\
\hline \multirow[t]{3}{*}{ Interventions } & 1 Cognitive & ehavioural therapy: 5 week session + routine care \\
\hline & Supportive & counselling + routine care. \\
\hline & $3 \quad$ Rountine & \\
\hline Outcomes & \multicolumn{2}{|c|}{$\begin{array}{l}\text { Global state: hospital admission. } \\
\text { Adverse effect/event: death. } \\
\text { Mental state: PANSS, PSYRATS (delusional scale). } \\
\text { Satisfaction with treatment: leaving the study early. }\end{array}$} \\
\hline Notes & \multicolumn{2}{|c|}{ This is one centre in the Lewis $2002 \mathrm{a}$ study. } \\
\hline \multicolumn{3}{|l|}{ Risk of bias } \\
\hline Bias & \multicolumn{2}{|c|}{ Authors' judgement Support for judgement } \\
\hline $\begin{array}{l}\text { Random sequence } \\
\text { generation (selection } \\
\text { bias) }\end{array}$ & \multicolumn{2}{|c|}{ Low risk "Independent, concealed randomisation". } \\
\hline $\begin{array}{l}\text { Allocation } \\
\text { concealment (selection } \\
\text { bias) }\end{array}$ & Low risk & Described as "concealed". \\
\hline $\begin{array}{l}\text { Blinding (performance } \\
\text { bias and detection bias) } \\
\text { All outcomes }\end{array}$ & Low risk & Raters blind to treatment allocation. \\
\hline $\begin{array}{l}\text { Incomplete outcome } \\
\text { data (attrition bias) } \\
\text { All outcomes }\end{array}$ & Low risk & Intention-to-treat regressional analysis. \\
\hline $\begin{array}{l}\text { Selective reporting } \\
\text { (reporting bias) }\end{array}$ & Low risk & $\begin{array}{l}\text { We did not have the study protocol but see no indication of selective } \\
\text { reporting }\end{array}$ \\
\hline Other bias & Low risk & No clear indication of other bias. \\
\hline
\end{tabular}

\section{Lewis 2002 - Manchester}

Cochrane Database Syst Rev. Author manuscript; available in PMC 2014 September 15. 


\begin{tabular}{|c|c|c|}
\hline Methods & \multicolumn{2}{|c|}{$\begin{array}{l}\text { Allocation: randomised. } \\
\text { Blinding: raters blind to treatment allocation. } \\
\text { Duration: } 18 \text { months. }\end{array}$} \\
\hline Participants & \multicolumn{2}{|c|}{$\begin{array}{l}\text { Diagnosis: schizophrenia (DSM IV). } \\
\mathrm{N}=112 \text {. }\end{array}$} \\
\hline \multirow[t]{3}{*}{ Interventions } & Cognitive & ehavioural therapy: 5 week session + routine care \\
\hline & Supportive & counselling + routine care. \\
\hline & $3 \quad$ Routine ca & \\
\hline Outcomes & \multicolumn{2}{|c|}{$\begin{array}{l}\text { Global state: hospital admission. } \\
\text { Adverse effect/event: death. } \\
\text { Mental state: PANSS, PSYRATS (delusional scale). } \\
\text { Satisfaction with treatment: leaving the study early. }\end{array}$} \\
\hline Notes & \multicolumn{2}{|c|}{ This is one centre in the Lewis $2002 \mathrm{a}$ study. } \\
\hline \multicolumn{3}{|l|}{ Risk of bias } \\
\hline Bias & \multicolumn{2}{|c|}{ Authors' judgement Support for judgement } \\
\hline $\begin{array}{l}\text { Random sequence } \\
\text { generation (selection } \\
\text { bias) }\end{array}$ & \multicolumn{2}{|c|}{ Low risk "Independent, concealed randomisation". } \\
\hline $\begin{array}{l}\text { Allocation } \\
\text { concealment (selection } \\
\text { bias) }\end{array}$ & Low risk & Described as "concealed". \\
\hline $\begin{array}{l}\text { Blinding (performance } \\
\text { bias and detection bias) } \\
\text { All outcomes }\end{array}$ & Low risk & Raters blind to treatment allocation. \\
\hline $\begin{array}{l}\text { Incomplete outcome } \\
\text { data (attrition bias) } \\
\text { All outcomes }\end{array}$ & Low risk & Intention-to-treat regressional analysis. \\
\hline $\begin{array}{l}\text { Selective reporting } \\
\text { (reporting bias) }\end{array}$ & Low risk & $\begin{array}{l}\text { We did not have the study protocol but see no indication of selective } \\
\text { reporting }\end{array}$ \\
\hline Other bias & Low risk & No clear indication of other bias. \\
\hline
\end{tabular}

Lewis 2002 - Nottingham

\begin{tabular}{ll}
\hline Methods & $\begin{array}{l}\text { Allocation: randomised. } \\
\text { Blinding: raters blind to treatment allocation. } \\
\text { Duration: } 18 \text { months. }\end{array}$ \\
\hline Participants & $\begin{array}{l}\text { Diagnosis: schizophrenia (DSM IV). } \\
\mathrm{N}=83 .\end{array}$ \\
\hline Interventions & $\mathbf{1} \quad$ Cognitive behavioural therapy: 5 week session + routine care \\
& $\mathbf{2} \quad$ Supportive counselling + routine care. \\
& $\mathbf{3} \quad$ Routine care. \\
\hline Outcomes & Global state: hospital admission. \\
& $\begin{array}{l}\text { Adverse effect/event: death. } \\
\text { Mental state: PANSS, PSYRATS (delusional scale). }\end{array}$ \\
\hline Satisfaction with treatment: leaving the study early.
\end{tabular}

Cochrane Database Syst Rev. Author manuscript; available in PMC 2014 September 15. 


\begin{tabular}{|c|c|c|}
\hline Bias & Authors' judgement & Support for judgement \\
\hline $\begin{array}{l}\text { Random sequence } \\
\text { generation (selection } \\
\text { bias) }\end{array}$ & Low risk & "Independent, concealed randomisation". \\
\hline $\begin{array}{l}\text { Allocation } \\
\text { concealment (selection } \\
\text { bias) }\end{array}$ & Low risk & Described as "concealed". \\
\hline $\begin{array}{l}\text { Blinding (performance } \\
\text { bias and detection bias) } \\
\text { All outcomes }\end{array}$ & Low risk & Raters blind to treatment allocation. \\
\hline $\begin{array}{l}\text { Incomplete outcome } \\
\text { data (attrition bias) } \\
\text { All outcomes }\end{array}$ & Low risk & Intention-to-treat regressional analysis. \\
\hline $\begin{array}{l}\text { Selective reporting } \\
\text { (reporting bias) }\end{array}$ & Low risk & $\begin{array}{l}\text { We did not have the study protocol but see no indication of selective } \\
\text { reporting }\end{array}$ \\
\hline Other bias & Low risk & No clear indication of other bias. \\
\hline
\end{tabular}

O'Donnell 2003

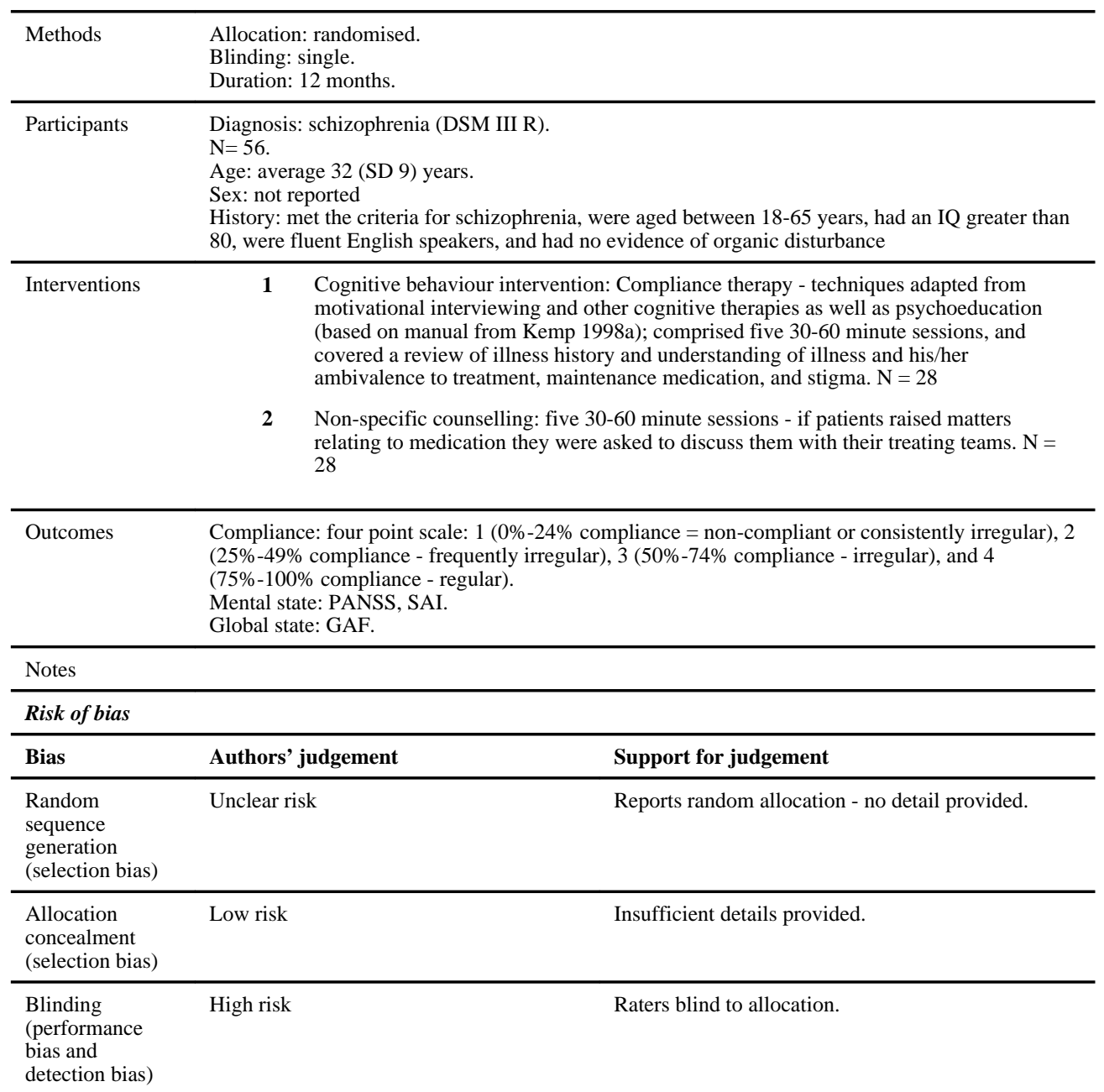

Cochrane Database Syst Rev. Author manuscript; available in PMC 2014 September 15. 
All outcomes

\begin{tabular}{|c|c|c|}
\hline $\begin{array}{l}\text { Incomplete } \\
\text { outcome data } \\
\text { (attrition bias) } \\
\text { All outcomes }\end{array}$ & Low risk & Completer data reported. \\
\hline $\begin{array}{l}\text { Selective } \\
\text { reporting } \\
\text { (reporting bias) }\end{array}$ & Low risk & $\begin{array}{l}\text { We did not have the study protocol but see no } \\
\text { indication of selective reporting }\end{array}$ \\
\hline Other bias & Unclear risk & No clear indication of other bias. \\
\hline
\end{tabular}

Penn 2009

\begin{tabular}{|c|c|c|}
\hline Methods & \multicolumn{2}{|l|}{$\begin{array}{l}\text { Allocation: randomised. } \\
\text { Blinding: single. } \\
\text { Duration: } 64 \text { weeks. }\end{array}$} \\
\hline Participants & \multicolumn{2}{|c|}{$\begin{array}{l}\text { Participants: schizophrenia, schizoaffective disorder. } \\
\mathrm{N}=65 \text {. } \\
\text { Age: } 18-65 \text { years. } \\
\text { History: auditory hallucinations of at least moderate severity. } \\
\text { Setting: out patient department. } \\
\text { Excluded: learning disability, substance dependency. }\end{array}$} \\
\hline \multirow[t]{2}{*}{ Interventions } & $\begin{array}{l}\text { Cognitive be } \\
\text { auditory hall } \\
\text { emphasizing } \\
\text { esteem work }\end{array}$ & $\begin{array}{l}\text { ased upon New Reference protocols, focused on } \\
\text { behavioral analysis, and coping strategies) - more } \\
\text { than cognitive restructuring; and de-emphasizing self- } \\
\mathrm{N}=32\end{array}$ \\
\hline & $\begin{array}{l}\text { Enhanced su } \\
\text { alliance, ii. a } \\
\text { on social int } \\
\text { approach to } \\
\text { members (ur } \\
\text { problems, an }\end{array}$ & $\begin{array}{l}\text { ided into } 3 \text { phases: i. establishing therapeutic } \\
\text { onal goals (for each group member); and iii. focusing } \\
\text { ing steps to achieve those interpersonal goals) - direct } \\
\text { ying on advice from therapists and other group } \\
\text { ders provided direct advice for client questions/ } \\
\text { d suggestions from group members). } \mathrm{N}=33\end{array}$ \\
\hline Outcomes & \multicolumn{2}{|c|}{$\begin{array}{l}\text { Global state: hospitalisation. } \\
\text { Mental state: PANSS, PSYRATS, BAVQ, BCIS, BDI, RSES. } \\
\text { Social functioning: SFS. } \\
\text { Satisfaction with treatment: leaving the study early }\end{array}$} \\
\hline \multicolumn{3}{|l|}{ Notes } \\
\hline \multicolumn{3}{|l|}{ Risk of bias } \\
\hline Bias & Authors' judgement & Support for judgement \\
\hline $\begin{array}{l}\text { Random } \\
\text { sequence } \\
\text { generation } \\
\text { (selection bias) }\end{array}$ & Unclear risk & $\begin{array}{l}\text { Randomised - computer generated - stratified by } \\
\text { sex. }\end{array}$ \\
\hline $\begin{array}{l}\text { Allocation } \\
\text { concealment } \\
\text { (selection bias) }\end{array}$ & Unclear risk & $\begin{array}{l}\text { Randomisation conducted by Research Assistant } \\
\text { blind to correspondence between random number } \\
\text { and treatment group }\end{array}$ \\
\hline $\begin{array}{l}\text { Blinding } \\
\text { (performance } \\
\text { bias and } \\
\text { detection bias) } \\
\text { All outcomes }\end{array}$ & Low risk & Raters blind to allocation. \\
\hline $\begin{array}{l}\text { Incomplete } \\
\text { outcome data } \\
\text { (attrition bias) } \\
\text { All outcomes }\end{array}$ & Low risk & Intention-to-treat analysis. \\
\hline
\end{tabular}

Cochrane Database Syst Rev. Author manuscript; available in PMC 2014 September 15. 


\begin{tabular}{lll}
$\begin{array}{l}\text { Selective } \\
\text { reporting } \\
\text { (reporting bias) }\end{array}$ & Low risk & $\begin{array}{l}\text { We did not have the study protocol but see no } \\
\text { indication of selective reporting }\end{array}$ \\
\hline Other bias & Low risk & No clear indication of other bias. \\
\hline
\end{tabular}

Pinto 1999

\begin{tabular}{|c|c|c|}
\hline Methods & \multicolumn{2}{|l|}{$\begin{array}{l}\text { Allocation: randomised. } \\
\text { Blinding: none. } \\
\text { Duration: } 6 \text { months. }\end{array}$} \\
\hline Participants & \multicolumn{2}{|c|}{$\begin{array}{l}\text { Diagnosis: schizophrenia (DSM IV). } \\
\mathrm{N}=41 \text {. } \\
\text { History: treatment refractory to medication, no current substance misuse or organic pathology, } \\
\text { all receiving clozapine. } \\
\text { Age: mean } 35 \text { years. }\end{array}$} \\
\hline \multirow[t]{2}{*}{ Interventions } & \multirow{2}{*}{\multicolumn{2}{|c|}{$\begin{array}{l}\text { CBT: individual cognitive behaviour therapy }+ \text { social skills training }+ \text { standard care } \\
\mathrm{N}=20 \\
\text { Supportive counselling: included psychoeducation about nature and treatment of } \\
\text { schizophrenia, active listening, empathy and reassurance, health promotion, crisis } \\
\text { management, advocacy }+ \text { standard care. } \mathrm{N}=21\end{array}$}} \\
\hline & & \\
\hline Outcomes & \multicolumn{2}{|c|}{$\begin{array}{l}\text { Mental state: BPRS, SAPS,SANS. } \\
\text { Satisfaction with treatment: leaving the study early. }\end{array}$} \\
\hline \multicolumn{3}{|l|}{ Notes } \\
\hline \multicolumn{3}{|l|}{ Risk of bias } \\
\hline Bias & Authors' judgement & Support for judgement \\
\hline $\begin{array}{l}\text { Random sequence } \\
\text { generation } \\
\text { (selection bias) }\end{array}$ & Unclear risk & Reports random allocation - no detail provided. \\
\hline $\begin{array}{l}\text { Allocation } \\
\text { concealment } \\
\text { (selection bias) }\end{array}$ & Unclear risk & Insufficient details provided. \\
\hline $\begin{array}{l}\text { Blinding } \\
\text { (performance bias } \\
\text { and detection bias) } \\
\text { All outcomes }\end{array}$ & High risk & No report of blinding raters to allocation. \\
\hline $\begin{array}{l}\text { Incomplete outcome } \\
\text { data (attrition bias) } \\
\text { All outcomes }\end{array}$ & Unclear risk & Insufficient details provided. \\
\hline $\begin{array}{l}\text { Selective reporting } \\
\text { (reporting bias) }\end{array}$ & Low risk & $\begin{array}{l}\text { We did not have the study protocol but see no } \\
\text { indication of selective reporting }\end{array}$ \\
\hline Other bias & Low risk & No clear indication of other bias. \\
\hline
\end{tabular}

Sensky 2000

\begin{tabular}{ll}
\hline Methods & Allocation: randomised. \\
& Blinding: raters blind to treatment condition. \\
& Duration: participants were followed up immediately post therapy (9 months) and at 5 years \\
\hline Participants & Diagnosis: schizophrenia (ICD-10 \& DSM IV). \\
& N = 90. \\
& History: distressing symptoms of $>6$ months duration, medication resistant, not comorbid \\
& substance misuse, not exclusively negative symptoms.
\end{tabular}

Cochrane Database Syst Rev. Author manuscript; available in PMC 2014 September 15. 
Age: range 16-60 years.

\begin{tabular}{|c|c|c|}
\hline Interventions & $\begin{array}{ll}1 & \text { CBT: } \operatorname{cog} r \\
2 & \text { Befriendin } \\
& \text { care. } \mathrm{N}=\end{array}$ & $\begin{array}{l}\text { Befriending: non-active therapist contact, focus is upon leisure activity }+ \text { standard } \\
\text { care. } \mathrm{N}=44\end{array}$ \\
\hline Outcomes & \multicolumn{2}{|c|}{$\begin{array}{l}\text { Mental state: CPRS, MADRS, SANS, no significant improvement. } \\
\text { Satisfaction with treatment: leaving the study early. }\end{array}$} \\
\hline \multicolumn{3}{|l|}{ Notes } \\
\hline \multicolumn{3}{|l|}{ Risk of bias } \\
\hline Bias & Authors' judgement & Support for judgement \\
\hline $\begin{array}{l}\text { Random sequence } \\
\text { generation } \\
\text { (selection bias) }\end{array}$ & Unclear risk & Reports random allocation - no detail provided. \\
\hline $\begin{array}{l}\text { Allocation } \\
\text { concealment } \\
\text { (selection bias) }\end{array}$ & Unclear risk & No detail provided. \\
\hline $\begin{array}{l}\text { Blinding } \\
\text { (performance bias } \\
\text { and detection bias) } \\
\text { All outcomes }\end{array}$ & Low risk & Raters blind to treatment condition. \\
\hline $\begin{array}{l}\text { Incomplete } \\
\text { outcome data } \\
\text { (attrition bias) } \\
\text { All outcomes }\end{array}$ & Low risk & Intention-to-treat analysis undertaken. \\
\hline $\begin{array}{l}\text { Selective } \\
\text { reporting } \\
\text { (reporting bias) }\end{array}$ & Low risk & $\begin{array}{l}\text { We did not have the study protocol but see no indication } \\
\text { of selective reporting }\end{array}$ \\
\hline Other bias & Low risk & No clear indication of other bias. \\
\hline
\end{tabular}

Tarrier 1999 a

\begin{tabular}{|c|c|c|}
\hline Methods & \multicolumn{2}{|c|}{$\begin{array}{l}\text { Allocation: random allocation, stratified sample technique. } \\
\text { Blinding: raters blind to treatment condition. } \\
\text { Duration: } 24 \text { months. }\end{array}$} \\
\hline Participants & \multicolumn{2}{|c|}{$\begin{array}{l}\text { Diagnosis: schizophrenia, schizoaffective psychosis, delusional disorder (DSM III R). } \\
\mathrm{N}=87 . \\
\text { History: median duration of illness } 11 \mathrm{yrs} \text {, persistent positive symptoms. } \\
\text { Age: mean }-39 \text { yrs, SD }-11 \text {. } \\
\text { Sex: } 69 \mathrm{M}, 18 \mathrm{~F} \text {. }\end{array}$} \\
\hline \multirow[t]{3}{*}{ Interventions } & 1 & $\begin{array}{l}\text { CBT: coping strategy enhancement, training in problem solving, strategies to reduce } \\
\text { relapse + standard care. } N=33\end{array}$ \\
\hline & 2 & $\begin{array}{l}\text { Supportive counselling: emotional support, unconditional regard, general counselling } \\
+ \text { standard care. } \mathrm{N}=26\end{array}$ \\
\hline & 3 & $\begin{array}{l}\text { Standard care: standard psychiatric management with medication, monitoring out } \\
\text { patient follow-up \& care programme approach. } \mathrm{N}=28\end{array}$ \\
\hline Outcomes & \multicolumn{2}{|c|}{$\begin{array}{l}\text { General state: relapse. } \\
\text { Mental state: no important improvement, BPRS. } \\
\text { Satisfaction with treatment: leaving the study early. } \\
\text { Unable to use - } \\
\text { Mental state: positive symptoms, calculated by combining PSE and BPRS scores (data not } \\
\text { reported) }\end{array}$} \\
\hline \multicolumn{3}{|l|}{ Notes } \\
\hline$k$ of bias & & \\
\hline
\end{tabular}

Cochrane Database Syst Rev. Author manuscript; available in PMC 2014 September 15. 


\begin{tabular}{|c|c|c|}
\hline Bias & Authors' judgement & Support for judgement \\
\hline $\begin{array}{l}\text { Random sequence } \\
\text { generation } \\
\text { (selection bias) }\end{array}$ & Low risk & Stratified block randomisation procedure. \\
\hline $\begin{array}{l}\text { Allocation } \\
\text { concealment } \\
\text { (selection bias) }\end{array}$ & Low risk & $\begin{array}{l}\text { Allocation contained in sealed envelopes - } \\
\text { undertaken by independent third party }\end{array}$ \\
\hline $\begin{array}{l}\text { Blinding } \\
\text { (performance bias } \\
\text { and detection bias) } \\
\text { All outcomes }\end{array}$ & Low risk & Raters blind to treatment condition. \\
\hline $\begin{array}{l}\text { Incomplete } \\
\text { outcome data } \\
\text { (attrition bias) } \\
\text { All outcomes }\end{array}$ & High risk & Completer data reported. \\
\hline $\begin{array}{l}\text { Selective reporting } \\
\text { (reporting bias) }\end{array}$ & Low risk & $\begin{array}{l}\text { We did not have the study protocol but see no } \\
\text { indication of selective reporting }\end{array}$ \\
\hline Other bias & Low risk & No clear indication of other bias. \\
\hline
\end{tabular}

Turkington 2000

\begin{tabular}{|c|c|c|}
\hline Methods & \multicolumn{2}{|c|}{$\begin{array}{l}\text { Allocation: randomised. } \\
\text { Blinding: raters blind to treatment condition. } \\
\text { Duration: } 6 \text { months. }\end{array}$} \\
\hline Participants & \multicolumn{2}{|c|}{$\begin{array}{l}\text { Diagnosis: schizophrenia (ICD-10 \& DSM III-R). } \\
\mathrm{N}=18 \text {. } \\
\text { History: treatment resistant. } \\
\text { Age: range } 16-65 \text { years. }\end{array}$} \\
\hline \multirow[t]{2}{*}{ Interventions } & CBT: $\operatorname{cog} n$ & ive behavioural therapy + standard care. $\mathrm{N}=12$ \\
\hline & $\begin{array}{l}2 \quad \text { Befriendin } \\
=6\end{array}$ & non-directive discussion around neutral topics + standard care. $\mathrm{N}$ \\
\hline Outcomes & \multicolumn{2}{|c|}{$\begin{array}{l}\text { Mental state: CPRS. } \\
\text { Unable to use - } \\
\text { Mental state: MADRS (no SD). } \\
\text { Length of time in hospital (no SD). }\end{array}$} \\
\hline \multicolumn{3}{|l|}{ Notes } \\
\hline \multicolumn{3}{|l|}{ Risk of bias } \\
\hline Bias & \multicolumn{2}{|c|}{ Authors' judgement Support for judgement } \\
\hline $\begin{array}{l}\text { Random sequence } \\
\text { generation (selection } \\
\text { bias) }\end{array}$ & \multicolumn{2}{|c|}{ Low risk $\quad$ Reports random allocation - no detail provided. } \\
\hline $\begin{array}{l}\text { Allocation concealment } \\
\text { (selection bias) }\end{array}$ & Low risk & Reports allocation concealment. \\
\hline $\begin{array}{l}\text { Blinding (performance } \\
\text { bias and detection bias) } \\
\text { All outcomes }\end{array}$ & Low risk & Raters blind to treatment condition. \\
\hline $\begin{array}{l}\text { Incomplete outcome } \\
\text { data (attrition bias) } \\
\text { All outcomes }\end{array}$ & Unclear risk & No detail provided. \\
\hline $\begin{array}{l}\text { Selective reporting } \\
\text { (reporting bias) }\end{array}$ & Low risk & $\begin{array}{l}\text { We did not have the study protocol but see no indication of } \\
\text { selective reporting }\end{array}$ \\
\hline Other bias & Low risk & No clear indication of other bias. \\
\hline
\end{tabular}

Cochrane Database Syst Rev. Author manuscript; available in PMC 2014 September 15. 
Valmaggia 2005

\begin{tabular}{|c|c|c|c|}
\hline Methods & \multicolumn{3}{|c|}{$\begin{array}{l}\text { Allocation: randomised with allocation concealment. } \\
\text { Blinding: raters blind to allocation. } \\
\text { Duration } 6 \text { months. }\end{array}$} \\
\hline Participants & \multicolumn{3}{|c|}{$\begin{array}{l}\text { Diagnosis: schizophrenia (DSM-IV). } \\
\mathrm{N}=72 . \\
\text { Setting: in hospital. } \\
\text { Age: } 18-70 \text { years. } \\
\text { Sex: CBT } 27 / 36 \text { male SC } 14 / 36 \text { male. } \\
\text { History: residual delusions or auditory hallucinations experienced for at least } 3 \text { months, stable } \\
\text { medication regimen (last medication change more than } 6 \text { weeks prior to recruitment), no previous } \\
\text { exposure to CBT }\end{array}$} \\
\hline \multirow[t]{2}{*}{ Interventions } & 1 & \multirow{2}{*}{\multicolumn{2}{|c|}{$\begin{array}{l}\text { Cognitive behavioural therapy: manualised, therapy begins with engagement phase } \\
\text { emphasising collaboration, focuses on delusional distress; second phase - shared case } \\
\text { formulation is identified, specific techniques used for symptom and distress reduction. } \\
\text { With auditory hallucinations aim is to change beliefs about origin, power and } \\
\text { dangerousness of voices. In delusions, focus is on challenging dysfunctional beliefs and } \\
\text { learning to make more balanced conclusions; last phase - treatment focuses on relapse } \\
\text { prevention strategies. } \mathrm{N}=36 . * \\
\text { Supportive counselling: conventional method previously used in other studies (e.g., } \\
\text { Lewis 2002a). } \mathrm{N}=36 \text {. }\end{array}$}} \\
\hline & 2 & & \\
\hline Outcomes & \multicolumn{3}{|c|}{ Mental state: PANSS. } \\
\hline Notes & \multicolumn{3}{|c|}{$\begin{array}{l}\text { * The therapist shows non-critical acceptance, warmth, genuineness and empathy. Focus of } \\
\text { intervention was preferably identified by patient, however if patient experiences difficulties } \\
\text { identifying therapeutic targets then therapist could ask questions about current living circumstances, } \\
\text { illness and current problems, daily routine, social contacts, family, and personal history. In addition, } \\
\text { intervention offered patients psycho-education about schizophrenia. The authors state that "To } \\
\text { control for non-specific therapy and therapist effects, cognitive-behavioural therapy was compared } \\
\text { with supportive counselling plus psycho-education". Accordingly, this use of supportive counselling } \\
\text { was considered as an non-active therapy }\end{array}$} \\
\hline \multicolumn{4}{|l|}{ Risk of bias } \\
\hline Bias & \multicolumn{2}{|c|}{ Authors' judgement } & Support for judgement \\
\hline $\begin{array}{l}\text { Random } \\
\text { sequence } \\
\text { generation } \\
\text { (selection bias) }\end{array}$ & \multicolumn{2}{|c|}{ Unclear risk } & Randomisation not described. \\
\hline $\begin{array}{l}\text { Allocation } \\
\text { concealment } \\
\text { (selection bias) }\end{array}$ & \multicolumn{2}{|l|}{ Low risk } & $\begin{array}{l}\text { To ensure the anonymity of participants, each individual } \\
\text { was given a code, and coordinator used form to } \\
\text { communicate results of random assignment to local } \\
\text { therapist }\end{array}$ \\
\hline $\begin{array}{l}\text { Blinding } \\
\text { (performance } \\
\text { bias and } \\
\text { detection bias) } \\
\text { All outcomes }\end{array}$ & \multicolumn{2}{|l|}{ Low risk } & Raters blind to allocation. \\
\hline $\begin{array}{l}\text { Incomplete } \\
\text { outcome data } \\
\text { (attrition bias) } \\
\text { All outcomes } \\
\end{array}$ & \multicolumn{2}{|l|}{ Low risk } & Intention-to-treat analysis undertaken. \\
\hline $\begin{array}{l}\text { Selective } \\
\text { reporting } \\
\text { (reporting bias) }\end{array}$ & \multicolumn{2}{|l|}{ Low risk } & $\begin{array}{l}\text { We did not have the study protocol but see no indication } \\
\text { of selective reporting }\end{array}$ \\
\hline Other bias & \multicolumn{2}{|l|}{ Low risk } & No clear indication of other bias. \\
\hline
\end{tabular}

BAI: Beck Anxiety Inventory; BDI: Beck Depression Inventory; BPRS: Brief Psychiatric Rating Scale; CBT: Cognitive behavioural therapy; GAF: Global Assessment of Functioning; GAS: Global Assessment Scale; KC: Key-person counselling; MADRS:Montgomery-Asberg Depression Rating Scale; PANSS: Positive and Negative Syndrome Scale; PAS: Psychiatric Assessment Scale; PMT:Psychoeducational medication training; PSRS: Psychotic Symptom Rating Scale; RSES: Rosenberg Self-Esteem Scale; SANS: Scale for the Assessment of Negative Symptoms; SFS: Social Functioning Scale; SOFAS: Social and occupational functioning; WARS: Ward Anger Rating Scale. 


\section{Characteristics of excluded studies [ordered by study ID]}

\begin{tabular}{|c|c|}
\hline Study & Reason for exclusion \\
\hline Anzai 2002 & $\begin{array}{l}\text { Allocation: randomised. } \\
\text { Participants: people with schizophrenia. } \\
\text { Intervention: community re-entry model versus conventional occupational rehabilitation } \\
\text { program, not CBT }\end{array}$ \\
\hline Arlow 1997 & Allocation: not randomised, case series. \\
\hline Bach 2002 & $\begin{array}{l}\text { Allocation: randomised. } \\
\text { Participants: people with schizophrenia. } \\
\text { Intervention: Acceptance and Commitment Therapy compared with treatment as usual; no other } \\
\text { psychological therapy }\end{array}$ \\
\hline Barrowclough 2001 & $\begin{array}{l}\text { Allocation: randomised. } \\
\text { Participants: people with schizophrenia. } \\
\text { Intervention: CBT compared with treatment as usual; no other psychological therapy }\end{array}$ \\
\hline Barrowclough 2006 & $\begin{array}{l}\text { Allocation: randomised. } \\
\text { Participants: people with schizophrenia. } \\
\text { Intervention: CBT compared with treatment as usual; no other psychological therapy }\end{array}$ \\
\hline Bechdolf 2005b & Allocation: uncontrolled prospective design with pre- and post-treatment measures \\
\hline Bellucci 2002 & $\begin{array}{l}\text { Allocation: randomised. } \\
\text { Participants: people with schizophrenia. } \\
\text { Intervention: computer assisted cognitive rehabilitation versus a 'wait-list' control group, not } \\
\text { CBT }\end{array}$ \\
\hline Bouchaud 1996 & Allocation: not randomised, review. \\
\hline Bradshaw 1993 & $\begin{array}{l}\text { Allocation: randomised. } \\
\text { Participants: those with schizophrenia. } \\
\text { Intervention: coping-skills training versus problem-solving approach, not CBT }\end{array}$ \\
\hline Bradshaw 2000 & $\begin{array}{l}\text { Allocation: randomised. } \\
\text { Participants: people with schizophrenia. } \\
\text { Intervention: Day Treatment Program plus CBT versus Day Treatment Program } \\
\text { The Day Treatment Program incorporated active psychological treatments (e.g., social skills } \\
\text { training, independent living skills groups, goal groups, occupational and recreational therapy, } \\
\text { prevocational employment training and medication management). However, these active } \\
\text { treatments in the comparison condition were also mirrored in the CBT condition, such that the } \\
\text { study did not provide a differential test of CBT versus other psychological therapies }\end{array}$ \\
\hline Buchanan 1992 & Allocation: not randomised, case series. \\
\hline Castle 2002 & $\begin{array}{l}\text { Allocation: randomised. } \\
\text { Participants: persons with schizophrenia. } \\
\text { Intervention: group CBT versus waiting list controls. }\end{array}$ \\
\hline Chadwick 1994 & Allocation: not randomised, case series and review. \\
\hline Claghorn 1974 & $\begin{array}{l}\text { Allocation: randomised. } \\
\text { Participants: people with schizophrenia. } \\
\text { Interventions: group dynamic therapy + chlorpromazine or thiothixene versus chlorpromazine or } \\
\text { thiothixene - not described as cognitive therapy }\end{array}$ \\
\hline Daniels 1998 & $\begin{array}{l}\text { Allocation: randomised. } \\
\text { Participants: people with schizophrenia. } \\
\text { Intervention: CBT compared with treatment as usual; no other psychological therapy }\end{array}$ \\
\hline Drake 1993 & $\begin{array}{l}\text { Allocation: not randomised; review article. } \\
\text { Participants: mixed diagnostic categories. } \\
\text { Intervention: social network treatment versus treatment as usual, not CBT }\end{array}$ \\
\hline Edwards 2003 & $\begin{array}{l}\text { Allocation: randomised. } \\
\text { Participants: people with schizophrenia. } \\
\text { Intervention: CBT }+ \text { thioridazine versus clozapine. }\end{array}$ \\
\hline England 2007 & $\begin{array}{l}\text { Allocation: randomised. } \\
\text { Participants: people with schizophrenia. } \\
\text { Intervention: CBT compared with treatment as usual; no other psychological therapy }\end{array}$ \\
\hline Evins 2001 & $\begin{array}{l}\text { Allocation: randomised. } \\
\text { Participants: people with schizophrenia. }\end{array}$ \\
\hline
\end{tabular}

Cochrane Database Syst Rev. Author manuscript; available in PMC 2014 September 15. 


\begin{tabular}{|c|c|}
\hline Study & Reason for exclusion \\
\hline & Interventions: $\mathrm{CBT}+$ bupropion versus CBT. \\
\hline Fritze 1988 & $\begin{array}{l}\text { Allocation: randomised. } \\
\text { Participants: those with schizophrenia. } \\
\text { Interventions: rehabilitation of intellectual disabilities versus standard care, not CBT }\end{array}$ \\
\hline Garety 1994 & Allocation: not randomised. \\
\hline Garety 1998 & $\begin{array}{l}\text { Allocation: randomised. } \\
\text { Participants: people with schizophrenia. } \\
\text { Intervention: CBT compared with treatment as usual; no other psychological therapy }\end{array}$ \\
\hline Gaudiano 2006 & $\begin{array}{l}\text { Allocation: randomised. } \\
\text { Participants: people with schizophrenia. } \\
\text { Intervention: Acceptance and Commitment Therapy compared with treatment as usual; no other } \\
\text { psychological therapy }\end{array}$ \\
\hline Granholm 2005 & $\begin{array}{l}\text { Allocation: randomised. } \\
\text { Participants: people with schizophrenia. } \\
\text { Intervention: CBT compared with treatment as usual; no other psychological therapy }\end{array}$ \\
\hline Gumley 2003 & $\begin{array}{l}\text { Allocation: randomised. } \\
\text { Participants: people with schizophrenia. } \\
\text { Intervention: CBT compared with treatment as usual; no other psychological therapy }\end{array}$ \\
\hline Haldun 2002 & $\begin{array}{l}\text { Allocation: randomised. } \\
\text { Participants: persons with schizophrenia } \\
\text { Intervention: } \mathrm{CBT}+\text { family therapy + case management }+ \text { education }+ \text { medication versus } \\
\text { medication + education }\end{array}$ \\
\hline Hartman 1983 & Allocation: not randomised. \\
\hline Hayward 1995 & $\begin{array}{l}\text { Allocation: randomised. } \\
\text { Participants: people with schizophrenia. } \\
\text { Intervention: medication self-management using motivational interviewing versus standard care. } \\
\text { Not CBT }\end{array}$ \\
\hline Hertz 2000 & $\begin{array}{l}\text { Allocation: randomised } \\
\text { Participants: outpatients with schizophrenia } \\
\text { Intervention: program for relapse prevention (PRP) is more effective than treatment as usual } \\
\text { (TAU). Not CBT }\end{array}$ \\
\hline Hodel 1994 & Allocation: not randomised. \\
\hline Hogarty 1991 & Allocation: not randomised. \\
\hline Hogarty 1997 & $\begin{array}{l}\text { Allocation: randomised. } \\
\text { Participants: persons with schizophrenia. } \\
\text { Intervention: Personal Therapy, not CBT. }\end{array}$ \\
\hline Hogarty 2004 & $\begin{array}{l}\text { Allocation: randomised. } \\
\text { Participants: persons with schizophrenia. } \\
\text { Intervention: cognitive remediation for cognitive (intellectual) deficits, not CBT }\end{array}$ \\
\hline Jackson 1998 & Allocation: not randomised. \\
\hline Jackson 2001 & $\begin{array}{l}\text { Allocation: randomised. } \\
\text { Participants: persons with schizophrenia. } \\
\text { Intervention: cognitive therapy versus treatment as usual. }\end{array}$ \\
\hline Kemp $1996 b$ & Allocation: not randomised, case series. \\
\hline Kingdon 1991 & Allocation: not randomised, case series. \\
\hline Kuipers 1996 & Allocation: not randomised, review. \\
\hline Kuipers 2004 & $\begin{array}{l}\text { Allocation: randomised. } \\
\text { Participants: people with schizophrenia. } \\
\text { Intervention: CBT compared with treatment as usual; no other psychological therapy }\end{array}$ \\
\hline Lecompte 1996 & $\begin{array}{l}\text { Allocation: randomised. } \\
\text { Participants: those with schizophrenia. } \\
\text { Intervention: medication compliance versus unstructured conversations. } \\
\text { Outcomes: no usable data. }\end{array}$ \\
\hline Lysaker 2009 & $\begin{array}{l}\text { Allocation: randomised. } \\
\text { Participants: those with schizophrenia. }\end{array}$ \\
\hline
\end{tabular}

Cochrane Database Syst Rev. Author manuscript; available in PMC 2014 September 15. 


\begin{tabular}{|c|c|}
\hline Study & Reason for exclusion \\
\hline & Intervention: CBT compared with treatment as usual; no other psychological therapy \\
\hline MacPherson 1996 & $\begin{array}{l}\text { Allocation: randomised. } \\
\text { Participants: those with schizophrenia. } \\
\text { Intervention: education programme based on bibliotherapy versus standard care, not cognitive } \\
\text { behavioural therapy }\end{array}$ \\
\hline May 1984 & Allocation: not randomised, review. \\
\hline McGorry 2002 & $\begin{array}{l}\text { Allocation: randomised. } \\
\text { Participants: people at risk of developing schizophrenia. } \\
\text { Intervention: needs based intervention with no antipsychotic versus specific intervention of CBT } \\
\text { + risperidone, not CBT alone }\end{array}$ \\
\hline Morrison 2002 & $\begin{array}{l}\text { Allocation: randomised. } \\
\text { Participants: people at incipient risk of psychosis, not schizophrenia }\end{array}$ \\
\hline Olbrich 1990 & $\begin{array}{l}\text { Allocation: randomised. } \\
\text { Participants: those with schizophrenia. } \\
\text { Intervention: skills training aimed at cognitive deficits versus standard care, not cognitive } \\
\text { behavioural therapy }\end{array}$ \\
\hline Perris 1992 & Allocation: not randomised, case series. \\
\hline Rector 2003 & $\begin{array}{l}\text { Allocation: randomised. } \\
\text { Participants: people with schizophrenia. } \\
\text { Intervention: CBT compared with treatment as usual; no other psychological therapy }\end{array}$ \\
\hline Roder 2002 & $\begin{array}{l}\text { Allocation: not randomised. } \\
\text { Participants: mixed schizophrenia and schizoaffective disorder Intervention: residential social } \\
\text { skills training versus vocational social skills training versus recreational social skills training } \\
\text { versus general social skills training, not CBT }\end{array}$ \\
\hline Sellwood 2001 & $\begin{array}{l}\text { Allocation: randomised. } \\
\text { Participants: people with schizophrenia. } \\
\text { Intervention: CBT compared with treatment as usual; no other psychological therapy }\end{array}$ \\
\hline Shon 2002 & Allocation: not randomised, ABA design. \\
\hline Spaulding 1992 & Allocation: not randomised, case series. \\
\hline Startup 1998 & $\begin{array}{l}\text { Allocation: randomised. } \\
\text { Participants: people with schizophrenia. } \\
\text { Intervention: CBT compared with treatment as usual; no other psychological therapy }\end{array}$ \\
\hline Startup 2006 & $\begin{array}{l}\text { Allocation: randomised. } \\
\text { Participants: people with schizophrenia. } \\
\text { Intervention: CBT compared with treatment as usual; no other psychological therapy }\end{array}$ \\
\hline Tarrier $1993 \mathrm{~b}$ & $\begin{array}{l}\text { Allocation: randomised. } \\
\text { Participants: people with schizophrenia. } \\
\text { Interventions: problem solving (CBT focusing on social disability + daily living difficulties) + } \\
\text { standard care versus coping strategy enhancement (CBT focusing on positive symptoms) + } \\
\text { standard care; in addition, also allocated within group to waiting list or not. No Control arm. } \\
\text { Outcomes: leaving the study early, mental state (BPRS, PAS), self perception, completer data } \\
\text { only - numbers initially allocated to each group not reported. Authors are being contacted }\end{array}$ \\
\hline Turkington 2002 & $\begin{array}{l}\text { Allocation: randomised. } \\
\text { Participants: people with schizophrenia. } \\
\text { Intervention: CBT compared with treatment as usual; no other psychological therapy }\end{array}$ \\
\hline Turkington 2006 & $\begin{array}{l}\text { Allocation: randomised. } \\
\text { Participants: people with schizophrenia. } \\
\text { Intervention: CBT compared with treatment as usual; no other psychological therapy }\end{array}$ \\
\hline Van Der Gaag 2003 & $\begin{array}{l}\text { Allocation: randomised. } \\
\text { Participants: people with schizophrenia. } \\
\text { Intervention: cognitive remediations program versus participation in a leisure program, not CBT }\end{array}$ \\
\hline Velligan 2002 & $\begin{array}{l}\text { Allocation: randomised. } \\
\text { Participants: persons with schizophrenia. } \\
\text { Intervention: cognitive adaption training versus, patient environmental changes versus treatment } \\
\text { as usual, not CBT }\end{array}$ \\
\hline Wirshing 1992 & $\begin{array}{l}\text { Allocation: randomised. } \\
\text { Participants: people with schizophrenia. }\end{array}$ \\
\hline
\end{tabular}

Cochrane Database Syst Rev. Author manuscript; available in PMC 2014 September 15. 


\begin{tabular}{ll}
\hline Study & Reason for exclusion \\
\hline & $\begin{array}{l}\text { Interventions: CBT + standard care (cognitive restructuring, behavioral rehearsal / role play, } \\
\text { coping strategy enhancement, problem solving) versus group psychotherapy + standard care } \\
\text { (insight oriented psychotherapy group + education re schizophrenia). } \\
\text { Outcomes: leaving the study early, mental state (BPRS, SANS). - data presented for 41 people } \\
\text { who completed } 12 \text { months - numbers initially allocated to each group not reported }\end{array}$ \\
\hline Wykes 2002 & $\begin{array}{l}\text { Allocation: randomised. } \\
\text { Participants: persons with schizophrenia. } \\
\text { Intervention: rehabilitation of intellectual disabilities, not cognitive behavioural therapy }\end{array}$ \\
\hline Wykes 2003 & $\begin{array}{l}\text { Allocation: randomised. } \\
\text { Participants: people with schizophrenia. } \\
\text { Intervention: group CBT versus standard care, not other psychological therapy }\end{array}$ \\
\hline
\end{tabular}

BPRS: Brief Psychiatric Rating Scale; CBT: Cognitive behavioural therapy; PAS: Premorbid Adjustment Scale; PRP: program for relapse prevention; SANS: Scale for the Assessment of Negative Symptoms; TAU: treatment as usual.

\section{Characteristics of studies awaiting assessment [ordered by study ID]}

$$
\text { NCT00980252 }
$$

\begin{tabular}{|c|c|}
\hline Methods & $\begin{array}{l}\text { Allocation: randomised. } \\
\text { Blinding: not reported. } \\
\text { Duration: not reported }\end{array}$ \\
\hline Participants & $\begin{array}{l}\text { Diagnosis: clinical diagnosis of schizophreniform disorder, schizophrenia, or schizoaffective disorder } \\
\text { in last } 6 \text { months } \\
\mathrm{N}=\text { not reported. } \\
\text { History: not reported. } \\
\text { Age: range } 16-45 \text { years. }\end{array}$ \\
\hline \multirow[t]{2}{*}{ Interventions } & 1 CBT: cognitive behavioural therapy + standard care. \\
\hline & 2 Psychoeducation + standard care. \\
\hline Outcomes & $\begin{array}{l}\text { Acceptance of therapeutic intervention as measured by number of sessions attended. Difference in } \\
\text { adherence behavior as measured by duration of antipsychotic treatment during follow-up. Differences } \\
\text { in adherence attitudes }\end{array}$ \\
\hline Notes & \\
\hline
\end{tabular}

Wu Ningqiang 2008

\begin{tabular}{ll}
\hline Methods & Awaiting translation \\
\hline Participants & Awaiting translation \\
\hline Interventions & Awaiting translation \\
\hline Outcomes & Awaiting translation \\
\hline Notes & Awaiting translation \\
\hline CBT: Cognitive behavioural therapy
\end{tabular}


DATA AND ANALYSES

\section{Comparison 1 \\ CBT versus ALL OTHER PSYCHOLOGICAL THERAPIES}

\begin{tabular}{|c|c|c|c|c|}
\hline Outcome or subgroup title & No. of studies & No. of participants & Statistical method & Effect size \\
\hline 1 Adverse effect/event: 1 . Death & 2 & 202 & $\begin{array}{l}\text { Risk Ratio (M-H, } \\
\text { Fixed, 95\% CI) }\end{array}$ & $0.57[0.12,2.60]$ \\
\hline $\begin{array}{l}2 \text { Adverse effect/event: } 2 \text {. Adverse } \\
\text { effects - any - medium-term only }\end{array}$ & 1 & 198 & $\begin{array}{l}\text { Risk Ratio (M-H, } \\
\text { Fixed, 95\% CI) }\end{array}$ & $2.0[0.71,5.64]$ \\
\hline $\begin{array}{l}3 \text { Mental state: } 1 \text {. General - no } \\
\text { important or reliable change }\end{array}$ & 7 & & $\begin{array}{l}\text { Risk Ratio (M-H, } \\
\text { Random, 95\% CI) }\end{array}$ & Subtotals only \\
\hline 3.1 short-term & 2 & 99 & $\begin{array}{l}\text { Risk Ratio (M-H, } \\
\text { Random, 95\% CI) }\end{array}$ & $0.84[0.40,1.75]$ \\
\hline 3.2 medium-term & 3 & 162 & $\begin{array}{l}\text { Risk Ratio (M-H, } \\
\text { Random, 95\% CI) }\end{array}$ & $0.78[0.61,1.00]$ \\
\hline 3.3 long-term & 4 & 244 & $\begin{array}{l}\text { Risk Ratio (M-H, } \\
\text { Random, 95\% CI) }\end{array}$ & $0.91[0.77,1.08]$ \\
\hline $\begin{array}{l}4 \text { Mental state: } 2 . \text { Average scale } \\
\text { score - total }\end{array}$ & 13 & & $\begin{array}{l}\text { Mean Difference } \\
\text { (IV, Fixed, } 95 \% \\
\text { CI) }\end{array}$ & Subtotals only \\
\hline $\begin{array}{l}4.1 \text { short-term - BPRS (high = } \\
\text { poor) }\end{array}$ & 2 & 94 & $\begin{array}{l}\text { Mean Difference } \\
\text { (IV, Fixed, } 95 \% \\
\text { CI) }\end{array}$ & $1.15[-2.83,5.14]$ \\
\hline $\begin{aligned} & 4.2 \text { medium-term - (BPRS, high } \\
= & \text { poor })\end{aligned}$ & 1 & 37 & $\begin{array}{l}\text { Mean Difference } \\
\text { (IV, Fixed, } 95 \% \\
\text { CI) }\end{array}$ & $-7.60[-14.30,-0.90]$ \\
\hline $\begin{array}{l}4.3 \text { short-term - (PANSS, } \\
\text { endpoint data, high = poor) }\end{array}$ & 4 & 303 & $\begin{array}{l}\text { Mean Difference } \\
\text { (IV, Fixed, } 95 \% \\
\text { CI) }\end{array}$ & $\begin{array}{l}-11.26[-13.83,-8 . \\
69]\end{array}$ \\
\hline $\begin{array}{l}4.4 \text { medium-term - (PANSS, } \\
\text { endpoint data, high = poor) }\end{array}$ & 2 & 110 & $\begin{array}{l}\text { Mean Difference } \\
\text { (IV, Fixed, } 95 \% \\
\text { CI) }\end{array}$ & $-6.47[-10.84,-2.11]$ \\
\hline $\begin{array}{l}4.5 \text { long-term - PANSS } \\
\text { (endpoint data, high = poor) }\end{array}$ & 7 & 378 & $\begin{array}{l}\text { Mean Difference } \\
\text { (IV, Fixed, } 95 \% \\
\text { CI) }\end{array}$ & $-2.58[-5.26,0.10]$ \\
\hline $\begin{array}{c}4.6 \text { medium term - CPRS } \\
\text { (endpoint data, high = poor) }\end{array}$ & 1 & 90 & $\begin{array}{l}\text { Mean Difference } \\
\text { (IV, Fixed, } 95 \% \\
\text { CI) }\end{array}$ & $-4.30[-9.26,0.66]$ \\
\hline $\begin{array}{l}4.7 \text { long-term - CPRS (endpoint } \\
\text { data, high = poor) }\end{array}$ & 1 & 59 & $\begin{array}{l}\text { Mean Difference } \\
\text { (IV, Fixed, } 95 \% \\
\text { CI) }\end{array}$ & $-4.60[-11.22,2.02]$ \\
\hline $\begin{array}{l}5 \text { Mental state: } 3 \mathrm{a} \text {. Specific - } \\
\text { average score - positive symptoms } \\
\text { - overall (PANSS, endpoint data, } \\
\text { high = poor) }\end{array}$ & 11 & & $\begin{array}{l}\text { Mean Difference } \\
\text { (IV, Fixed, } 95 \% \\
\text { CI) }\end{array}$ & Subtotals only \\
\hline 5.1 short-term & 7 & 477 & $\begin{array}{l}\text { Mean Difference } \\
\text { (IV, Fixed, } 95 \% \\
\text { CI) }\end{array}$ & $-0.67[-1.46,0.13]$ \\
\hline 5.2 medium-term & 4 & 239 & $\begin{array}{l}\text { Mean Difference } \\
\text { (IV, Fixed, } 95 \% \\
\text { CI) }\end{array}$ & $-0.99[-2.09,0.11]$ \\
\hline 5.3 long-term & 7 & 380 & $\begin{array}{l}\text { Mean Difference } \\
\text { (IV, Fixed, } 95 \% \\
\text { CI) }\end{array}$ & $-0.90[-1.74,-0.06]$ \\
\hline $\begin{array}{l}6 \text { Mental state: } 3 b \text {. Specific - } \\
\text { average score - positive symptoms } \\
\text { - hallucinations (Psychotic }\end{array}$ & 8 & & $\begin{array}{l}\text { Mean Difference } \\
\text { (IV, Fixed, } 95 \% \\
\text { CI) }\end{array}$ & Subtotals only \\
\hline
\end{tabular}




\begin{tabular}{|c|c|c|c|c|}
\hline Outcome or subgroup title & No. of studies & No. of participants & Statistical method & Effect size \\
\hline \multicolumn{5}{|l|}{$\begin{array}{l}\text { Symptom Rating Scale, high = } \\
\text { poor) }\end{array}$} \\
\hline 6.1 short-term & 4 & 258 & $\begin{array}{l}\text { Mean Difference } \\
\text { (IV, Fixed, 95\% } \\
\text { CI) }\end{array}$ & $-0.92[-3.33,1.49]$ \\
\hline 6.2 medium-term & 2 & 105 & $\begin{array}{l}\text { Mean Difference } \\
\text { (IV, Fixed, 95\% } \\
\text { CI) }\end{array}$ & $-0.57[-3.95,2.80]$ \\
\hline 6.3 long-term & 6 & 267 & $\begin{array}{l}\text { Mean Difference } \\
\text { (IV, Fixed, 95\% } \\
\text { CI) }\end{array}$ & $-1.30[-4.01,1.41]$ \\
\hline $\begin{array}{l}7 \text { Mental state: } 3 \mathrm{c} \text {. Specific - } \\
\text { average score - positive symptoms } \\
\text { - delusions (Psychotic Symptom } \\
\text { Rating Scale, high = poor) }\end{array}$ & 8 & & $\begin{array}{l}\text { Mean Difference } \\
\text { (IV, Fixed, 95\% } \\
\text { CI) }\end{array}$ & Subtotals only \\
\hline 7.1 short-term & 4 & 311 & $\begin{array}{l}\text { Mean Difference } \\
\text { (IV, Fixed, 95\% } \\
\text { CI) }\end{array}$ & $-1.62[-3.16,-0.07]$ \\
\hline 7.2 medium-term & 2 & 106 & $\begin{array}{l}\text { Mean Difference } \\
\text { (IV, Fixed, 95\% } \\
\text { CI) }\end{array}$ & $-0.59[-3.03,1.86]$ \\
\hline 7.3 long-term & 6 & 329 & $\begin{array}{l}\text { Mean Difference } \\
\text { (IV, Fixed, 95\% } \\
\text { CI) }\end{array}$ & $-0.89[-2.34,0.55]$ \\
\hline $\begin{array}{l}8 \text { Mental state: } 3 \mathrm{~d} \text {. Specific - } \\
\text { average score - positive symptoms } \\
\text { - delusions cognitive characteristics } \\
\text { (psychotic symptom rating scale, } \\
\text { high = poor) }\end{array}$ & 1 & & $\begin{array}{l}\text { Mean Difference } \\
\text { (IV, Fixed, 95\% } \\
\text { CI) }\end{array}$ & Subtotals only \\
\hline 8.1 medium-term & 1 & 58 & $\begin{array}{l}\text { Mean Difference } \\
\text { (IV, Fixed, 95\% } \\
\text { CI) }\end{array}$ & $-0.26[-2.58,2.06]$ \\
\hline 8.2 long-term & 1 & 58 & $\begin{array}{l}\text { Mean Difference } \\
\text { (IV, Fixed, 95\% } \\
\text { CI) }\end{array}$ & $0.39[-2.13,2.91]$ \\
\hline $\begin{array}{l}9 \text { Mental state: } 3 \text { e. Specific - } \\
\text { average score - positive symptoms } \\
\text { - delusions emotional } \\
\text { characteristics (psychotic symptom } \\
\text { rating scale, high = poor) }\end{array}$ & 1 & & $\begin{array}{l}\text { Mean Difference } \\
\text { (IV, Fixed, 95\% } \\
\text { CI) }\end{array}$ & Subtotals only \\
\hline 9.1 medium-term & 1 & 58 & $\begin{array}{l}\text { Mean Difference } \\
\text { (IV, Fixed, 95\% } \\
\text { CI) }\end{array}$ & $0.66[-0.75,2.07]$ \\
\hline 9.2 long-term & 1 & 58 & $\begin{array}{l}\text { Mean Difference } \\
\text { (IV, Fixed, 95\% } \\
\text { CI) }\end{array}$ & $0.11[-1.39,1.61]$ \\
\hline $\begin{array}{l}10 \text { Mental state: } 4 \text { a. Specific - } \\
\text { average score - negative symptoms } \\
\text { - overall (PANSS, endpoint data, } \\
\text { high = poor) }\end{array}$ & 10 & & $\begin{array}{l}\text { Mean Difference } \\
\text { (IV, Fixed, 95\% } \\
\text { CI) }\end{array}$ & Subtotals only \\
\hline 10.1 short-term & 6 & 328 & $\begin{array}{l}\text { Mean Difference } \\
\text { (IV, Fixed, 95\% } \\
\text { CI) }\end{array}$ & $-0.25[-1.09,0.59]$ \\
\hline 10.2 medium-term & 4 & 239 & $\begin{array}{l}\text { Mean Difference } \\
\text { (IV, Fixed, 95\% } \\
\text { CI) }\end{array}$ & $-0.27[-1.28,0.74]$ \\
\hline 10.3 long-term & 7 & 380 & $\begin{array}{l}\text { Mean Difference } \\
\text { (IV, Fixed, 95\% } \\
\text { CI) }\end{array}$ & $-0.43[-1.38,0.51]$ \\
\hline
\end{tabular}




\begin{tabular}{|c|c|c|c|c|}
\hline Outcome or subgroup title & No. of studies & No. of participants & Statistical method & Effect size \\
\hline $\begin{array}{l}11 \text { Mental state: } 4 \mathrm{~b} \text {. Specific - } \\
\text { average score - negative symptoms } \\
\text { - overall (SANS, high }=\text { good) }\end{array}$ & 4 & & $\begin{array}{l}\text { Mean Difference } \\
\text { (IV, Fixed, } 95 \% \\
\text { CI) }\end{array}$ & Subtotals only \\
\hline 11.1 short-term & 2 & 107 & $\begin{array}{l}\text { Mean Difference } \\
\text { (IV, Fixed, 95\% } \\
\text { CI) }\end{array}$ & $-1.29[-3.88,1.29]$ \\
\hline 11.2 medium-term & 3 & 171 & $\begin{array}{l}\text { Mean Difference } \\
\text { (IV, Fixed, 95\% } \\
\text { CI) }\end{array}$ & $-0.68[-3.13,1.76]$ \\
\hline 11.3 long-term & 3 & 161 & $\begin{array}{l}\text { Mean Difference } \\
\text { (IV, Fixed, 95\% } \\
\text { CI) }\end{array}$ & $0.95[-1.56,3.46]$ \\
\hline $\begin{array}{l}12 \text { Mental state: } 5 \text { a. Specific - } \\
\text { average score - affective symptoms } \\
\text { (PANSS General symptoms, } \\
\text { endpoint data, high = poor) }\end{array}$ & 9 & & $\begin{array}{l}\text { Mean Difference } \\
\text { (IV, Fixed, } 95 \% \\
\text { CI) }\end{array}$ & Subtotals only \\
\hline 12.1 short-term & 4 & 288 & $\begin{array}{l}\text { Mean Difference } \\
\text { (IV, Fixed, 95\% } \\
\text { CI) }\end{array}$ & $-0.06[-1.61,1.50]$ \\
\hline 12.2 medium-term & 5 & 280 & $\begin{array}{l}\text { Mean Difference } \\
\text { (IV, Fixed, 95\% } \\
\text { CI) }\end{array}$ & $-1.01[-2.66,0.63]$ \\
\hline 12.3 long-term & 8 & 549 & $\begin{array}{l}\text { Mean Difference } \\
\text { (IV, Fixed, 95\% } \\
\text { CI) }\end{array}$ & $-1.03[-2.36,0.29]$ \\
\hline $\begin{array}{l}13 \text { Mental state: } 5 \text { b. Specific - } \\
\text { average score - affective symptoms } \\
\text { - depression (Beck Depression } \\
\text { Inventory, high = poor) }\end{array}$ & 2 & & $\begin{array}{l}\text { Mean Difference } \\
\text { (IV, Fixed, } 95 \% \\
\text { CI) }\end{array}$ & Subtotals only \\
\hline 13.1 short-term & 1 & 65 & $\begin{array}{l}\text { Mean Difference } \\
\text { (IV, Fixed, 95\% } \\
\text { CI) }\end{array}$ & $-1.20[-5.56,3.16]$ \\
\hline 13.2 medium-term & 2 & 108 & $\begin{array}{l}\text { Mean Difference } \\
\text { (IV, Fixed, 95\% } \\
\text { CI) }\end{array}$ & $-3.09[-7.18,0.99]$ \\
\hline 13.3 long-term & 2 & 105 & $\begin{array}{l}\text { Mean Difference } \\
\text { (IV, Fixed, 95\% } \\
\text { CI) }\end{array}$ & $-6.21[-10.81,-1.61]$ \\
\hline $\begin{array}{l}14 \text { Mental state: } 5 \mathrm{~g} \text {. Specific - } \\
\text { average score - affective symptoms } \\
\text { - Anger/aggression (Novaco Anger } \\
\text { Scale (high }=\text { poor)) }\end{array}$ & 1 & & $\begin{array}{l}\text { Mean Difference } \\
\text { (IV, Fixed, 95\% } \\
\text { CI) }\end{array}$ & Subtotals only \\
\hline 14.1 short-term & 1 & 77 & $\begin{array}{l}\text { Mean Difference } \\
\text { (IV, Fixed, 95\% } \\
\text { CI) }\end{array}$ & $2.10[-5.70,9.90]$ \\
\hline 14.2 long-term & 1 & 77 & $\begin{array}{l}\text { Mean Difference } \\
\text { (IV, Fixed, 95\% } \\
\text { CI) }\end{array}$ & $-1.05[-9.47,7.37]$ \\
\hline $\begin{array}{l}15 \text { Mental state: } 5 \text { d. Specific - } \\
\text { average score - affective symptoms } \\
\text { - self esteem (Rosenberg Self } \\
\text { Esteem Scale (high }=\text { good)) }\end{array}$ & 1 & & $\begin{array}{l}\text { Mean Difference } \\
\text { (IV, Fixed, } 95 \% \\
\text { CI) }\end{array}$ & Subtotals only \\
\hline 15.1 short-term & 1 & 65 & $\begin{array}{l}\text { Mean Difference } \\
\text { (IV, Fixed, 95\% } \\
\text { CI) }\end{array}$ & $1.60[-0.93,4.13]$ \\
\hline 15.2 medium-term & 1 & 65 & $\begin{array}{l}\text { Mean Difference } \\
\text { (IV, Fixed, 95\% } \\
\text { CI) }\end{array}$ & $0.80[-2.17,3.77]$ \\
\hline
\end{tabular}




\begin{tabular}{|c|c|c|c|c|}
\hline Outcome or subgroup title & No. of studies & No. of participants & Statistical method & Effect size \\
\hline 15.3 long-term & 1 & 65 & $\begin{array}{l}\text { Mean Difference } \\
\text { (IV, Fixed, 95\% } \\
\text { CI) }\end{array}$ & $1.70[-1.79,5.19]$ \\
\hline $\begin{array}{l}16 \text { Mental state: } 5 \text { e. Specific - } \\
\text { average score - affective symptoms } \\
\text { - anxiety (Beck anxiety Inventory } \\
(\text { high = poor) }\end{array}$ & 1 & & $\begin{array}{l}\text { Mean Difference } \\
\text { (IV, Fixed, 95\% } \\
\text { CI) }\end{array}$ & Subtotals only \\
\hline 16.1 medium-term & 1 & 41 & $\begin{array}{l}\text { Mean Difference } \\
\text { (IV, Fixed, 95\% } \\
\text { CI) }\end{array}$ & $-0.79[-9.30,7.72]$ \\
\hline 16.2 long-term & 1 & 40 & $\begin{array}{l}\text { Mean Difference } \\
\text { (IV, Fixed, 95\% } \\
\text { CI) }\end{array}$ & $-0.59[-9.10,7.92]$ \\
\hline $\begin{array}{l}17 \text { Mental state: } 5 \text { f. Specific - } \\
\text { average score - affective symptoms } \\
\text { - insight }(\text { Beck Cognitive Insight } \\
\text { Scale }(\text { high = good)) }\end{array}$ & 1 & & $\begin{array}{l}\text { Mean Difference } \\
\text { (IV, Fixed, 95\% } \\
\text { CI) }\end{array}$ & Subtotals only \\
\hline 17.1 short-term & 1 & 65 & $\begin{array}{l}\text { Mean Difference } \\
\text { (IV, Fixed, 95\% } \\
\text { CI) }\end{array}$ & $0.70[-2.25,3.65]$ \\
\hline 17.2 medium-term & 1 & 65 & $\begin{array}{l}\text { Mean Difference } \\
\text { (IV, Fixed, 95\% } \\
\text { CI) }\end{array}$ & $-0.5[-3.44,2.44]$ \\
\hline 17.3 long-term & 1 & 65 & $\begin{array}{l}\text { Mean Difference } \\
\text { (IV, Fixed, 95\% } \\
\text { CI) }\end{array}$ & $0.70[-1.75,3.15]$ \\
\hline $\begin{array}{l}18 \text { Mental state: } 5 \mathrm{c} \text {. Specific - } \\
\text { average score - affective symptoms } \\
\text { - depression (Montgomery-Asberg } \\
\text { Depression Rating Scale, high = } \\
\text { poor) }\end{array}$ & 1 & & $\begin{array}{l}\text { Mean Difference } \\
\text { (IV, Fixed, 95\% } \\
\text { CI) }\end{array}$ & Subtotals only \\
\hline 18.1 medium-term & 1 & 90 & $\begin{array}{l}\text { Mean Difference } \\
\text { (IV, Fixed, 95\% } \\
\text { CI) }\end{array}$ & $-2.5[-4.19,-0.81]$ \\
\hline 18.2 long-term & 1 & 59 & $\begin{array}{l}\text { Mean Difference } \\
\text { (IV, Fixed, 95\% } \\
\text { CI) }\end{array}$ & $-1.5[-3.78,0.78]$ \\
\hline $\begin{array}{l}19 \text { Mental state: } 6 \text { a. Specific - } \\
\text { average score - problem behaviours } \\
\text { (Novaco Provocation Inventory, } \\
\text { high = poor) }\end{array}$ & 1 & & $\begin{array}{l}\text { Mean Difference } \\
\text { (IV, Fixed, 95\% } \\
\text { CI) }\end{array}$ & Subtotals only \\
\hline 19.1 short-term & 1 & 77 & $\begin{array}{l}\text { Mean Difference } \\
\text { (IV, Fixed, 95\% } \\
\text { CI) }\end{array}$ & $4.12[-3.93,12.17]$ \\
\hline 19.2 long-term & 1 & 77 & $\begin{array}{l}\text { Mean Difference } \\
\text { (IV, Fixed, 95\% } \\
\text { CI) }\end{array}$ & $3.33[-3.70,10.36]$ \\
\hline $\begin{array}{l}20 \text { Mental state: } 6 \mathrm{~b} \text {. Specific - } \\
\text { average score - problem behaviours } \\
\text { (Ward Anger Rating Scale, high = } \\
\text { poor) }\end{array}$ & 1 & & $\begin{array}{l}\text { Mean Difference } \\
\text { (IV, Fixed, } 95 \% \\
\text { CI) }\end{array}$ & Subtotals only \\
\hline 20.1 short-term & 1 & 77 & $\begin{array}{l}\text { Mean Difference } \\
\text { (IV, Fixed, 95\% } \\
\text { CI) }\end{array}$ & $-2.33[-4.84,0.18]$ \\
\hline 20.2 long-term & 1 & 77 & $\begin{array}{l}\text { Mean Difference } \\
\text { (IV, Fixed, 95\% } \\
\text { CI) }\end{array}$ & $-2.10[-5.01,0.81]$ \\
\hline
\end{tabular}




\begin{tabular}{|c|c|c|c|c|}
\hline Outcome or subgroup title & No. of studies & No. of participants & Statistical method & Effect size \\
\hline $\begin{array}{l}21 \text { Mental state: } 6 c . \text { Specific - } \\
\text { average score - problem behaviours } \\
\text { (HCR-20 risk management, high } \\
\text { poor) - long-term only }\end{array}$ & 1 & 77 & $\begin{array}{l}\text { Mean Difference } \\
\text { (IV, Fixed, 95\% } \\
\text { CI) }\end{array}$ & $-0.23[-1.77,1.31]$ \\
\hline $\begin{array}{l}22 \text { Mental state: } 6 \mathrm{~d} \text {. Specific - } \\
\text { average score - problem behaviour } \\
(\mathrm{HCR}-20 \text { clinical scale, high }= \\
\text { poor) - long-term only }\end{array}$ & 1 & 77 & $\begin{array}{l}\text { Mean Difference } \\
\text { (IV, Fixed, 95\% } \\
\text { CI) }\end{array}$ & $-0.46[-1.62,0.70]$ \\
\hline $\begin{array}{l}23 \text { Global state: } 1 \text {. Relapse/ } \\
\text { rehospitalisation }\end{array}$ & 9 & & $\begin{array}{l}\text { Risk Ratio (M-H, } \\
\text { Random, 95\% CI) }\end{array}$ & Subtotals only \\
\hline 23.1 relapse - short-term & 1 & 71 & $\begin{array}{l}\text { Risk Ratio (M-H, } \\
\text { Random, } 95 \% \text { CI) }\end{array}$ & $0.65[0.21,1.95]$ \\
\hline 23.2 relapse - medium-term & 1 & 59 & $\begin{array}{l}\text { Risk Ratio (M-H, } \\
\text { Random, 95\% CI) }\end{array}$ & $0.63[0.19,2.11]$ \\
\hline 23.3 relapse - long-term & 5 & 350 & $\begin{array}{l}\text { Risk Ratio (M-H, } \\
\text { Random, 95\% CI) }\end{array}$ & $0.91[0.63,1.32]$ \\
\hline 23.4 rehospitalisation -short-term & 2 & 136 & $\begin{array}{l}\text { Risk Ratio (M-H, } \\
\text { Random, 95\% CI) }\end{array}$ & $0.36[0.11,1.13]$ \\
\hline $\begin{array}{l}23.5 \text { rehospitalisation - medium- } \\
\text { term }\end{array}$ & 2 & 132 & $\begin{array}{l}\text { Risk Ratio (M-H, } \\
\text { Random, 95\% CI) }\end{array}$ & $0.59[0.27,1.30]$ \\
\hline $\begin{array}{l}23.6 \text { rehospitalisation - long- } \\
\text { term }\end{array}$ & 5 & 294 & $\begin{array}{l}\text { Risk Ratio (M-H, } \\
\text { Random, 95\% CI) }\end{array}$ & $0.86[0.61,1.20]$ \\
\hline $\begin{array}{l}24 \text { Global state: } 2 \text {. Various } \\
\text { outcomes }\end{array}$ & 3 & & $\begin{array}{l}\text { Mean Difference } \\
\text { (IV, Fixed, 95\% } \\
\text { CI) }\end{array}$ & Subtotals only \\
\hline $\begin{array}{l}24.1 \text { medium-term - average } \\
\text { score }(\mathrm{GAS}, \text { endpoint data, high }= \\
\text { good) }\end{array}$ & 1 & 38 & $\begin{array}{l}\text { Mean Difference } \\
\text { (IV, Fixed, 95\% } \\
\text { CI) }\end{array}$ & $-0.60[-4.93,3.73]$ \\
\hline $\begin{array}{l}24.2 \text { long-term - average score } \\
\text { (GAS, endpoint data, high = good) }\end{array}$ & 1 & 30 & $\begin{array}{l}\text { Mean Difference } \\
\text { (IV, Fixed, 95\% } \\
\text { CI) }\end{array}$ & $-0.5[-7.63,6.63]$ \\
\hline $\begin{array}{l}24.3 \text { short-term - average score } \\
(\mathrm{GAF}, \text { high }=\text { good })\end{array}$ & 2 & 147 & $\begin{array}{l}\text { Mean Difference } \\
\text { (IV, Fixed, } 95 \% \\
\text { CI) }\end{array}$ & $9.02[4.29,13.75]$ \\
\hline $\begin{array}{l}24.4 \text { long-term - average score } \\
(\mathrm{GAF}, \text { high }=\text { good })\end{array}$ & 3 & 155 & $\begin{array}{l}\text { Mean Difference } \\
\text { (IV, Fixed, } 95 \% \\
\text { CI) }\end{array}$ & $4.20[-0.63,9.03]$ \\
\hline $\begin{array}{l}25 \text { Global state: } 3 \text { a. Social } \\
\text { functioning - average scores } \\
\text { (Social Functioning Scale, high }= \\
\text { good) }\end{array}$ & 1 & & $\begin{array}{l}\text { Mean Difference } \\
\text { (IV, Fixed, 95\% } \\
\text { CI) }\end{array}$ & Subtotals only \\
\hline 25.1 short-term & 1 & 65 & $\begin{array}{l}\text { Mean Difference } \\
\text { (IV, Fixed, 95\% } \\
\text { CI) }\end{array}$ & $5.40[-5.18,15.98]$ \\
\hline 25.2 medium-term & 1 & 65 & $\begin{array}{l}\text { Mean Difference } \\
\text { (IV, Fixed, 95\% } \\
\text { CI) }\end{array}$ & $7.20[-3.46,17.86]$ \\
\hline 25.3 long-term & 1 & 65 & $\begin{array}{l}\text { Mean Difference } \\
\text { (IV, Fixed, } 95 \% \\
\text { CI) }\end{array}$ & $8.80[-4.07,21.67]$ \\
\hline $\begin{array}{l}26 \text { Global state: } 3 \mathrm{~b} \text {. Social } \\
\text { functioning - average scores } \\
\text { (Social and Occupational } \\
\text { Functioning Assessment Scale, } \\
\text { high = good) }\end{array}$ & 2 & & $\begin{array}{l}\text { Mean Difference } \\
\text { (IV, Fixed, 95\% } \\
\text { CI) }\end{array}$ & Subtotals only \\
\hline 26.1 short-term & 1 & 62 & $\begin{array}{l}\text { Mean Difference } \\
\text { (IV, Fixed, 95\% } \\
\text { CI) }\end{array}$ & $9.09[2.79,15.39]$ \\
\hline
\end{tabular}




\begin{tabular}{|c|c|c|c|c|}
\hline Outcome or subgroup title & No. of studies & No. of participants & Statistical method & Effect size \\
\hline 26.2 medium-term & 1 & 45 & $\begin{array}{l}\text { Mean Difference } \\
\text { (IV, Fixed, } 95 \% \\
\text { CI) }\end{array}$ & $5.33[-2.57,13.23]$ \\
\hline 26.3 long-term & 2 & 103 & $\begin{array}{l}\text { Mean Difference } \\
\text { (IV, Fixed, } 95 \% \\
\text { CI) }\end{array}$ & $1.32[-4.90,7.54]$ \\
\hline $\begin{array}{l}27 \text { Quality of life: Average score } \\
\text { (EuroQOL, high = good) - long- } \\
\text { term only }\end{array}$ & 1 & 37 & $\begin{array}{l}\text { Mean Difference } \\
\text { (IV, Fixed, } 95 \% \\
\text { CI) }\end{array}$ & $\begin{array}{l}-1.86[-19.20,15 \\
48]\end{array}$ \\
\hline $\begin{array}{l}28 \text { Satisfaction with treatment: } 1 \text {. } \\
\text { Attitude to medication - average } \\
\text { score - short-term }\end{array}$ & 1 & & $\begin{array}{l}\text { Mean Difference } \\
\text { (IV, Fixed, } 95 \% \\
\text { CI) }\end{array}$ & Subtotals only \\
\hline $\begin{array}{l}\text { 28.1 Attitude to Medication } \\
\text { Questionnaire (high = good) }\end{array}$ & 1 & 74 & $\begin{array}{l}\text { Mean Difference } \\
\text { (IV, Fixed, } 95 \% \\
\text { CI) }\end{array}$ & $4.50[2.17,6.83]$ \\
\hline $\begin{array}{l}28.2 \text { Drug Attitude Inventory } \\
\text { (high = good) }\end{array}$ & 1 & 63 & $\begin{array}{l}\text { Mean Difference } \\
\text { (IV, Fixed, } 95 \% \\
\text { CI) }\end{array}$ & $5.70[2.05,9.35]$ \\
\hline $\begin{array}{l}29 \text { Satisfaction with treatment: } 2 \text {. } \\
\text { Leaving the study early }\end{array}$ & 10 & 772 & $\begin{array}{l}\text { Risk Ratio (M-H, } \\
\text { Random, 95\% CI) }\end{array}$ & $0.85[0.63,1.14]$ \\
\hline
\end{tabular}

Comparison 2

SUBGROUP 1: CBT versus "NON-ACTIVE"

THERAPIES

\begin{tabular}{|c|c|c|c|c|}
\hline $\begin{array}{l}\text { Outcome or subgroup } \\
\text { title }\end{array}$ & No. of studies & No. of participants & Statistical method & Effect size \\
\hline $\begin{array}{l}1 \text { Adverse effect/event: } \\
\text { Death }\end{array}$ & 1 & 157 & $\begin{array}{l}\text { Risk Ratio (M-H, } \\
\text { Fixed, 95\% CI) }\end{array}$ & $0.68[0.12,3.93]$ \\
\hline $\begin{array}{l}2 \text { Mental state: } 1 \text {. General } \\
\text { - no important or reliable } \\
\text { change }\end{array}$ & 2 & & $\begin{array}{l}\text { Risk Ratio (M-H, } \\
\text { Random, 95\% CI) }\end{array}$ & Subtotals only \\
\hline 2.1 medium-term & 1 & 62 & $\begin{array}{l}\text { Risk Ratio (M-H, } \\
\text { Random, 95\% CI) }\end{array}$ & $0.59[0.40,0.87]$ \\
\hline 2.2 long-term & 1 & 90 & $\begin{array}{l}\text { Risk Ratio (M-H, } \\
\text { Random, 95\% CI) }\end{array}$ & $0.75[0.47,1.18]$ \\
\hline $\begin{array}{l}3 \text { Mental state: } 2 \mathrm{a} \text {. } \\
\text { General - average score - } \\
\text { total (BPRS, high = poor) }\end{array}$ & 1 & & $\begin{array}{l}\text { Mean Difference (IV, } \\
\text { Fixed, 95\% CI) }\end{array}$ & Subtotals only \\
\hline 3.1 short-term & 1 & 74 & $\begin{array}{l}\text { Mean Difference (IV, } \\
\text { Fixed, 95\% CI) }\end{array}$ & $0.20[-4.04,4.44]$ \\
\hline $\begin{array}{l}4 \text { Mental state: } 2 \mathrm{~b} \text {. } \\
\text { General - average score - } \\
\text { total (PANSS, endpoint } \\
\text { data, high = poor) }\end{array}$ & 5 & & $\begin{array}{l}\text { Mean Difference (IV, } \\
\text { Fixed, 95\% CI) }\end{array}$ & Subtotals only \\
\hline 4.1 short-term & 1 & 149 & $\begin{array}{l}\text { Mean Difference (IV, } \\
\text { Fixed, 95\% CI) }\end{array}$ & $1.77[-4.03,7.57]$ \\
\hline 4.2 long-term & 4 & 231 & $\begin{array}{l}\text { Mean Difference (IV, } \\
\text { Fixed, 95\% CI) }\end{array}$ & $-1.11[-4.53,2.32]$ \\
\hline $\begin{array}{l}5 \text { Mental state: } 3 \mathrm{a} \text {. } \\
\text { Specific - average score - } \\
\text { positive symptoms - } \\
\text { overall (PANSS, endpoint } \\
\text { data, high = poor) }\end{array}$ & 6 & & $\begin{array}{l}\text { Mean Difference (IV, } \\
\text { Fixed, 95\% CI) }\end{array}$ & Subtotals only \\
\hline
\end{tabular}




\begin{tabular}{|c|c|c|c|c|}
\hline $\begin{array}{l}\text { Outcome or subgroup } \\
\text { title }\end{array}$ & No. of studies & No. of participants & Statistical method & Effect size \\
\hline 5.1 short-term & 3 & 284 & $\begin{array}{l}\text { Mean Difference (IV, } \\
\text { Fixed, 95\% CI) }\end{array}$ & $-0.32[-1.45,0.80]$ \\
\hline 5.2 medium-term & 1 & 58 & $\begin{array}{l}\text { Mean Difference (IV, } \\
\text { Fixed, 95\% CI) }\end{array}$ & $-0.80[-2.82,1.22]$ \\
\hline 5.3 long-term & 4 & 231 & $\begin{array}{l}\text { Mean Difference (IV, } \\
\text { Fixed, 95\% CI) }\end{array}$ & $-0.36[-1.40,0.68]$ \\
\hline $\begin{array}{l}6 \text { Mental state: } 3 \text { b. } \\
\text { Specific - average score - } \\
\text { positive symptoms - } \\
\text { hallucinations (Psychotic } \\
\text { Symptom Rating Scale, } \\
\text { high = poor) }\end{array}$ & 5 & & $\begin{array}{l}\text { Mean Difference (IV, } \\
\text { Fixed, 95\% CI) }\end{array}$ & Subtotals only \\
\hline 6.1 short-term & 2 & 165 & $\begin{array}{l}\text { Mean Difference (IV, } \\
\text { Fixed, 95\% CI) }\end{array}$ & $-0.69[-4.33,2.94]$ \\
\hline 6.2 long-term & 4 & 163 & $\begin{array}{l}\text { Mean Difference (IV, } \\
\text { Fixed, 95\% CI) }\end{array}$ & $-2.43[-6.06,1.19]$ \\
\hline $\begin{array}{l}7 \text { Mental state: } 3 \mathrm{c} \text {. } \\
\text { Specific - average score - } \\
\text { positive symptoms - } \\
\text { delusions (Psychotic } \\
\text { Symptom Rating Scale, } \\
\text { high = poor) }\end{array}$ & 5 & & $\begin{array}{l}\text { Mean Difference (IV, } \\
\text { Fixed, 95\% CI) }\end{array}$ & Subtotals only \\
\hline 7.1 short-term & 2 & 218 & $\begin{array}{l}\text { Mean Difference (IV, } \\
\text { Fixed, 95\% CI) }\end{array}$ & $-1.96[-3.84,-0.09]$ \\
\hline 7.2 long-term & 4 & 224 & $\begin{array}{l}\text { Mean Difference (IV, } \\
\text { Fixed, 95\% CI) }\end{array}$ & $-1.08[-2.86,0.70]$ \\
\hline $\begin{array}{l}8 \text { Mental state: } 4 \mathrm{a} \text {. } \\
\text { Specific - average score - } \\
\text { negative symptoms - } \\
\text { overall (PANSS, endpoint } \\
\text { data, high = poor) }\end{array}$ & 5 & & $\begin{array}{l}\text { Mean Difference (IV, } \\
\text { Fixed, 95\% CI) }\end{array}$ & Subtotals only \\
\hline 8.1 short-term & 2 & 135 & $\begin{array}{l}\text { Mean Difference (IV, } \\
\text { Fixed, 95\% CI) }\end{array}$ & $0.04[-1.27,1.34]$ \\
\hline 8.2 medium-term & 1 & 58 & $\begin{array}{l}\text { Mean Difference (IV, } \\
\text { Fixed, 95\% CI) }\end{array}$ & $0.04[-1.52,1.60]$ \\
\hline 8.3 long-term & 4 & 231 & $\begin{array}{l}\text { Mean Difference (IV, } \\
\text { Fixed, 95\% CI) }\end{array}$ & $-0.40[-1.54,0.74]$ \\
\hline $\begin{array}{l}9 \text { Mental state: } 4 \mathrm{~b} \text {. } \\
\text { Specific - average score - } \\
\text { negative symptoms - } \\
\text { overall (SANS, high = } \\
\text { good) }\end{array}$ & 2 & & $\begin{array}{l}\text { Mean Difference (IV, } \\
\text { Fixed, 95\% CI) }\end{array}$ & Subtotals only \\
\hline 9.1 short-term & 1 & 62 & $\begin{array}{l}\text { Mean Difference (IV, } \\
\text { Fixed, 95\% CI) }\end{array}$ & $-5.21[-10.99,0.57]$ \\
\hline 9.2 medium-term & 1 & 90 & $\begin{array}{l}\text { Mean Difference (IV, } \\
\text { Fixed, 95\% CI) }\end{array}$ & $0.0[-6.92,6.92]$ \\
\hline 9.3 long-term & 2 & 121 & $\begin{array}{l}\text { Mean Difference (IV, } \\
\text { Fixed, 95\% CI) }\end{array}$ & $-6.53[-11.93,-1.13]$ \\
\hline $\begin{array}{l}10 \text { Mental state: } 5 \text { a. } \\
\text { Specific - average score - } \\
\text { affective symptoms } \\
\text { (PANSS General } \\
\text { symptoms, endpoint data, } \\
\text { high = poor) }\end{array}$ & 5 & & $\begin{array}{l}\text { Mean Difference (IV, } \\
\text { Fixed, 95\% CI) }\end{array}$ & Subtotals only \\
\hline 10.1 short-term & 2 & 135 & $\begin{array}{l}\text { Mean Difference (IV, } \\
\text { Fixed, 95\% CI) }\end{array}$ & $-0.13[-2.42,2.16]$ \\
\hline 10.2 medium-term & 1 & 58 & $\begin{array}{l}\text { Mean Difference (IV, } \\
\text { Fixed, 95\% CI) }\end{array}$ & $0.12[-2.71,2.95]$ \\
\hline
\end{tabular}




\begin{tabular}{|c|c|c|c|c|}
\hline $\begin{array}{l}\text { Outcome or subgroup } \\
\text { title }\end{array}$ & No. of studies & No. of participants & Statistical method & Effect size \\
\hline 10.3 long-term & 4 & 231 & $\begin{array}{l}\text { Mean Difference (IV, } \\
\text { Fixed, } 95 \% \text { CI) }\end{array}$ & $-0.44[-2.21,1.34]$ \\
\hline $\begin{array}{l}11 \text { Mental state: } 5 \text { b. } \\
\text { Specific - average score - } \\
\text { affective symptoms - } \\
\text { depression (Montgomery- } \\
\text { Asberg Depression Rating } \\
\text { Scale, high = poor) }\end{array}$ & 1 & & $\begin{array}{l}\text { Mean Difference (IV, } \\
\text { Fixed, 95\% CI) }\end{array}$ & Subtotals only \\
\hline 11.1 medium-term & 1 & 90 & $\begin{array}{l}\text { Mean Difference (IV, } \\
\text { Fixed, 95\% CI) }\end{array}$ & $-2.5[-4.19,-0.81]$ \\
\hline 11.2 long-term & 1 & 59 & $\begin{array}{l}\text { Mean Difference (IV, } \\
\text { Fixed, 95\% CI) }\end{array}$ & $-1.5[-3.78,0.78]$ \\
\hline $\begin{array}{l}12 \text { Mental state: } 5 \mathrm{c} \text {. } \\
\text { Specific - average score - } \\
\text { affective symptoms - } \\
\text { Anger/aggression } \\
\text { (Novaco Anger Scale, } \\
\text { high = poor) }\end{array}$ & 1 & & $\begin{array}{l}\text { Mean Difference (IV, } \\
\text { Fixed, 95\% CI) }\end{array}$ & Subtotals only \\
\hline 12.1 short-term & 1 & 77 & $\begin{array}{l}\text { Mean Difference (IV, } \\
\text { Fixed, 95\% CI) }\end{array}$ & $2.10[-5.70,9.90]$ \\
\hline 12.2 long-term & 1 & 77 & $\begin{array}{l}\text { Mean Difference (IV, } \\
\text { Fixed, 95\% CI) }\end{array}$ & $-1.05[-9.47,7.37]$ \\
\hline $\begin{array}{l}13 \text { Mental state: } 6 \text { a. } \\
\text { Specific - average score - } \\
\text { problem behaviours } \\
\text { (Novaco Provocation } \\
\text { Inventory, high = poor) }\end{array}$ & 1 & & $\begin{array}{l}\text { Mean Difference (IV, } \\
\text { Fixed, 95\% CI) }\end{array}$ & Subtotals only \\
\hline 13.1 short-term & 1 & 77 & $\begin{array}{l}\text { Mean Difference (IV, } \\
\text { Fixed, 95\% CI) }\end{array}$ & $4.12[-3.93,12.17]$ \\
\hline 13.2 long-term & 1 & 77 & $\begin{array}{l}\text { Mean Difference (IV, } \\
\text { Fixed, 95\% CI) }\end{array}$ & $3.33[-3.70,10.36]$ \\
\hline $\begin{array}{l}14 \text { Mental state: } 6 \mathrm{c} \text {. } \\
\text { Specific - average score - } \\
\text { problem behaviours } \\
\text { (Ward Anger Rating } \\
\text { Scale, high = poor) }\end{array}$ & 1 & & $\begin{array}{l}\text { Mean Difference (IV, } \\
\text { Fixed, 95\% CI) }\end{array}$ & Subtotals only \\
\hline 14.1 short-term & 1 & 77 & $\begin{array}{l}\text { Mean Difference (IV, } \\
\text { Fixed, 95\% CI) }\end{array}$ & $-2.33[-4.84,0.18]$ \\
\hline 14.2 long-term & 1 & 77 & $\begin{array}{l}\text { Mean Difference (IV, } \\
\text { Fixed, 95\% CI) }\end{array}$ & $-2.10[-5.01,0.81]$ \\
\hline $\begin{array}{l}15 \text { Mental state: } 6 \mathrm{~d} \text {. } \\
\text { Specific - average score - } \\
\text { problem behaviour }(\mathrm{HCR} \\
-20 \text { clinical scale, high = } \\
\text { poor) - long-term only }\end{array}$ & 1 & 77 & $\begin{array}{l}\text { Mean Difference (IV, } \\
\text { Fixed, 95\% CI) }\end{array}$ & $-0.46[-1.62,0.70]$ \\
\hline $\begin{array}{l}16 \text { Mental state: } 6 \mathrm{e} \text {. } \\
\text { Specific - average score - } \\
\text { problem behaviours } \\
\text { (HCR-20 risk } \\
\text { management, high poor) - } \\
\text { long-term only }\end{array}$ & 1 & 77 & $\begin{array}{l}\text { Mean Difference (IV, } \\
\text { Fixed, 95\% CI) }\end{array}$ & $-0.23[-1.77,1.31]$ \\
\hline $\begin{array}{l}17 \text { Global state: } 1 . \\
\text { Relapse - long-term only }\end{array}$ & 3 & 275 & $\begin{array}{l}\text { Risk Ratio (M-H, } \\
\text { Random, 95\% CI) }\end{array}$ & $0.95[0.56,1.61]$ \\
\hline $\begin{array}{l}18 \text { Global state: } 2 . \\
\text { Rehospitalisation - long- } \\
\text { term only }\end{array}$ & 2 & 119 & $\begin{array}{l}\text { Risk Ratio (M-H, } \\
\text { Fixed, } 95 \% \mathrm{CI})\end{array}$ & $1.02[0.63,1.64]$ \\
\hline $\begin{array}{l}19 \text { Global state: } 3 \text {. } \\
\text { Average score (GAF, high } \\
=\text { good) }\end{array}$ & 3 & & $\begin{array}{l}\text { Mean Difference (IV, } \\
\text { Fixed, 95\% CI) }\end{array}$ & Subtotals only \\
\hline
\end{tabular}




\begin{tabular}{|c|c|c|c|c|}
\hline $\begin{array}{l}\text { Outcome or subgroup } \\
\text { title }\end{array}$ & No. of studies & No. of participants & Statistical method & Effect size \\
\hline 19.1 short-term & 2 & 147 & $\begin{array}{l}\text { Mean Difference (IV, } \\
\text { Fixed, 95\% CI) }\end{array}$ & $9.02[4.29,13.75]$ \\
\hline 19.2 long-term & 3 & 155 & $\begin{array}{l}\text { Mean Difference (IV, } \\
\text { Fixed, 95\% CI) }\end{array}$ & $4.20[-0.63,9.03]$ \\
\hline $\begin{array}{l}20 \text { Global state: } 4 \text {. Social } \\
\text { functioning - average } \\
\text { scores (Social and } \\
\text { Occupational Functioning } \\
\text { Assessment Scale, high = } \\
\text { good) }\end{array}$ & 1 & & $\begin{array}{l}\text { Mean Difference (IV, } \\
\text { Fixed, 95\% CI) }\end{array}$ & Subtotals only \\
\hline 20.1 short-term & 1 & 62 & $\begin{array}{l}\text { Mean Difference (IV, } \\
\text { Fixed, 95\% CI) }\end{array}$ & $9.09[2.79,15.39]$ \\
\hline 20.2 long-term & 1 & 62 & $\begin{array}{l}\text { Mean Difference (IV, } \\
\text { Fixed, 95\% CI) }\end{array}$ & $1.30[-6.26,8.86]$ \\
\hline $\begin{array}{l}21 \text { Satisfaction with } \\
\text { treatment: } 1 \text {. Attitude to } \\
\text { medication - average } \\
\text { score - short-term }\end{array}$ & 1 & & $\begin{array}{l}\text { Mean Difference (IV, } \\
\text { Fixed, 95\% CI) }\end{array}$ & Subtotals only \\
\hline $\begin{array}{l}21.1 \text { Attitude to } \\
\text { Medication Questionnaire } \\
\text { (high = good) }\end{array}$ & 1 & 74 & $\begin{array}{l}\text { Mean Difference (IV, } \\
\text { Fixed, 95\% CI) }\end{array}$ & $4.50[2.17,6.83]$ \\
\hline $\begin{array}{l}21.2 \text { Drug Attitude } \\
\text { Inventory (high = good) }\end{array}$ & 1 & 63 & $\begin{array}{l}\text { Mean Difference (IV, } \\
\text { Fixed, 95\% CI) }\end{array}$ & $5.70[2.05,9.35]$ \\
\hline $\begin{array}{l}22 \text { Satisfaction with } \\
\text { treatment: } 2 \text {. Leaving the } \\
\text { study early }\end{array}$ & 4 & 433 & $\begin{array}{l}\text { Risk Ratio (M-H, } \\
\text { Random, 95\% CI) }\end{array}$ & $0.88[0.63,1.23]$ \\
\hline
\end{tabular}

\section{Comparison 3 \\ SUBGROUP 2: CBT versus "ACTIVE" PSYCHOLOGICAL THERAPIES}

\begin{tabular}{|c|c|c|c|c|}
\hline $\begin{array}{l}\text { Outcome or subgroup } \\
\text { title }\end{array}$ & No. of studies & No. of participants & Statistical method & Effect size \\
\hline $\begin{array}{l}\text { 1 Adverse effect/event: } \\
\text { 1. Death }\end{array}$ & 1 & 45 & $\begin{array}{l}\text { Risk Ratio (M-H, Fixed, } \\
95 \% \text { CI) }\end{array}$ & $0.35[0.01,8.11]$ \\
\hline $\begin{array}{l}2 \text { Adverse effect/event: } \\
\text { 2. Adverse effects - any - } \\
\text { medium-term only }\end{array}$ & 1 & 198 & $\begin{array}{l}\text { Risk Ratio (M-H, Fixed, } \\
95 \% \text { CI) }\end{array}$ & $2.0[0.71,5.64]$ \\
\hline $\begin{array}{l}3 \text { Mental state: } 1 . \text { No } \\
\text { important or reliable } \\
\text { change }\end{array}$ & 5 & & $\begin{array}{l}\text { Risk Ratio (M-H, } \\
\text { Random, 95\% CI) }\end{array}$ & Subtotals only \\
\hline 3.1 short-term & 2 & 99 & $\begin{array}{l}\text { Risk Ratio (M-H, } \\
\text { Random, 95\% CI) }\end{array}$ & $0.84[0.40,1.75]$ \\
\hline 3.2 medium-term & 2 & 100 & $\begin{array}{l}\text { Risk Ratio (M-H, } \\
\text { Random, 95\% CI) }\end{array}$ & $0.86[0.71,1.04]$ \\
\hline 3.3 long-term & 3 & 154 & $\begin{array}{l}\text { Risk Ratio (M-H, } \\
\text { Random, 95\% CI) }\end{array}$ & $0.94[0.79,1.13]$ \\
\hline $\begin{array}{l}4 \text { Mental state: } 2 \mathrm{a} \text {. } \\
\text { General - average score - } \\
\text { total (BPRS, high = } \\
\text { poor) }\end{array}$ & 2 & 57 & $\begin{array}{l}\text { Mean Difference (IV, } \\
\text { Fixed, 95\% CI) }\end{array}$ & $-3.66[-9.48,2.16]$ \\
\hline 4.1 short-term & 1 & 20 & $\begin{array}{l}\text { Mean Difference (IV, } \\
\text { Fixed, 95\% CI) }\end{array}$ & $8.5[-3.26,20.26]$ \\
\hline
\end{tabular}




\begin{tabular}{|c|c|c|c|c|}
\hline $\begin{array}{l}\text { Outcome or subgroup } \\
\text { title }\end{array}$ & No. of studies & No. of participants & Statistical method & Effect size \\
\hline 4.2 medium-term & 1 & 37 & $\begin{array}{l}\text { Mean Difference (IV, } \\
\text { Fixed, 95\% CI) }\end{array}$ & $-7.60[-14.30,-0.90]$ \\
\hline $\begin{array}{l}5 \text { Mental state: } 2 \mathrm{~b} \text {. } \\
\text { General - average score - } \\
\text { total (PANSS, endpoint } \\
\text { data, high = poor) }\end{array}$ & 4 & & $\begin{array}{l}\text { Mean Difference (IV, } \\
\text { Fixed, 95\% CI) }\end{array}$ & Subtotals only \\
\hline 5.1 short-term & 2 & 77 & $\begin{array}{l}\text { Mean Difference (IV, } \\
\text { Fixed, } 95 \% \text { CI) }\end{array}$ & $-17.19[-20.39,-13$ \\
\hline 5.2 medium-term & 2 & 110 & $\begin{array}{l}\text { Mean Difference (IV, } \\
\text { Fixed, 95\% CI) }\end{array}$ & $\begin{array}{l}98]-6.47[-10.84 \\
-2.11]\end{array}$ \\
\hline 5.3 long-term & 3 & 147 & $\begin{array}{l}\text { Mean Difference (IV, } \\
\text { Fixed, 95\% CI) }\end{array}$ & $-4.89[-9.18,-0.60]$ \\
\hline $\begin{array}{l}6 \text { Mental state: } 3 \mathrm{a} . \\
\text { Specific - average score } \\
\text { - positive symptoms - } \\
\text { overall (PANSS, } \\
\text { endpoint data, high = } \\
\text { poor) }\end{array}$ & 9 & & $\begin{array}{l}\text { Mean Difference (IV, } \\
\text { Fixed, 95\% CI) }\end{array}$ & Subtotals only \\
\hline 6.1 short-term & 4 & 193 & $\begin{array}{l}\text { Mean Difference (IV, } \\
\text { Fixed, } 95 \% \text { CI) }\end{array}$ & $-1.01[-2.14,0.12]$ \\
\hline 6.2 medium-term & 3 & 181 & $\begin{array}{l}\text { Mean Difference (IV, } \\
\text { Fixed, } 95 \% \text { CI) }\end{array}$ & $-1.06[-2.37,0.25]$ \\
\hline 6.3 long-term & 7 & 380 & $\begin{array}{l}\text { Mean Difference (IV, } \\
\text { Fixed, 95\% CI) }\end{array}$ & $-0.90[-1.74,-0.06]$ \\
\hline $\begin{array}{l}7 \text { Mental state: } 3 \text { b. } \\
\text { Specific - average score } \\
\text { - positive symptoms - } \\
\text { hallucinations (Psychotic } \\
\text { Symptom Rating Scale, } \\
\text { high = poor) }\end{array}$ & 3 & 302 & $\begin{array}{l}\text { Mean Difference (IV, } \\
\text { Fixed, 95\% CI) }\end{array}$ & $-0.60[-2.63,1.42]$ \\
\hline 7.1 short-term & 2 & 93 & $\begin{array}{l}\text { Mean Difference (IV, } \\
\text { Fixed, } 95 \% \text { CI) }\end{array}$ & $-1.10[-4.32,2.13]$ \\
\hline 7.2 medium-term & 2 & 105 & $\begin{array}{l}\text { Mean Difference (IV, } \\
\text { Fixed, 95\% CI) }\end{array}$ & $-0.57[-3.95,2.80]$ \\
\hline 7.3 long-term & 2 & 104 & $\begin{array}{l}\text { Mean Difference (IV, } \\
\text { Fixed, 95\% CI) }\end{array}$ & $0.13[-3.94,4.21]$ \\
\hline $\begin{array}{l}8 \text { Mental state: } 3 \mathrm{c} \text {. } \\
\text { Specific - average acore } \\
\text { - positive symptoms - } \\
\text { delusions (Psychotic } \\
\text { Symptom Rating Scale, } \\
\text { high = poor) }\end{array}$ & 3 & 304 & $\begin{array}{l}\text { Mean Difference (IV, } \\
\text { Fixed, 95\% CI) }\end{array}$ & $-0.64[-2.11,0.83]$ \\
\hline 8.1 short-term & 2 & 93 & $\begin{array}{l}\text { Mean Difference (IV, } \\
\text { Fixed, 95\% CI) }\end{array}$ & $-0.86[-3.62,1.89]$ \\
\hline 8.2 medium-term & 2 & 106 & $\begin{array}{l}\text { Mean Difference (IV, } \\
\text { Fixed, 95\% CI) }\end{array}$ & $-0.59[-3.03,1.86]$ \\
\hline 8.3 long-term & 2 & 105 & $\begin{array}{l}\text { Mean Difference (IV, } \\
\text { Fixed, 95\% CI) }\end{array}$ & $-0.52[-3.00,1.97]$ \\
\hline $\begin{array}{l}9 \text { Mental state: } 4 \mathrm{a} . \\
\text { Specific - average score } \\
\text { - negative symptoms - } \\
\text { overall (PANSS, } \\
\text { endpoint data, high = } \\
\text { poor) }\end{array}$ & 5 & & $\begin{array}{l}\text { Mean Difference (IV, } \\
\text { Fixed, } 95 \% \text { CI) }\end{array}$ & Subtotals only \\
\hline 9.1 short-term & 4 & 193 & $\begin{array}{l}\text { Mean Difference (IV, } \\
\text { Fixed, 95\% CI) }\end{array}$ & $-0.46[-1.56,0.64]$ \\
\hline 9.2 medium-term & 3 & 181 & $\begin{array}{l}\text { Mean Difference (IV, } \\
\text { Fixed, } 95 \% \text { CI) }\end{array}$ & $-0.50[-1.82,0.83]$ \\
\hline
\end{tabular}




\begin{tabular}{|c|c|c|c|c|}
\hline $\begin{array}{l}\text { Outcome or subgroup } \\
\text { title }\end{array}$ & No. of studies & No. of participants & Statistical method & Effect size \\
\hline 9.3 long-term & 3 & 149 & $\begin{array}{l}\text { Mean Difference (IV, } \\
\text { Fixed, 95\% CI) }\end{array}$ & $-0.51[-2.22,1.20]$ \\
\hline $\begin{array}{l}10 \text { Mental state: } 4 \mathrm{~b} \text {. } \\
\text { Specific - average score } \\
\text { - negative symptoms - } \\
\text { overall (SANS, high = } \\
\text { good) }\end{array}$ & 2 & & $\begin{array}{l}\text { Mean Difference (IV, } \\
\text { Fixed, 95\% CI) }\end{array}$ & Subtotals only \\
\hline 10.1 short-term & 1 & 45 & $\begin{array}{l}\text { Mean Difference (IV, } \\
\text { Fixed, 95\% CI) }\end{array}$ & $-0.31[-3.20,2.58]$ \\
\hline 10.2 medium-term & 2 & 81 & $\begin{array}{l}\text { Mean Difference (IV, } \\
\text { Fixed, } 95 \% \text { CI) }\end{array}$ & $-0.78[-3.40,1.84]$ \\
\hline 10.3 long-term & 1 & 40 & $\begin{array}{l}\text { Mean Difference (IV, } \\
\text { Fixed, } 95 \% \text { CI) }\end{array}$ & $3.01[0.17,5.85]$ \\
\hline $\begin{array}{l}11 \text { Mental state: } 5 \mathrm{a} \text {. } \\
\text { Specific - average score } \\
\text { - affective symptoms } \\
\text { (PANSS General } \\
\text { symptoms, endpoint } \\
\text { data, high = poor) }\end{array}$ & 4 & & $\begin{array}{l}\text { Mean Difference (IV, } \\
\text { Fixed, 95\% CI) }\end{array}$ & Subtotals only \\
\hline 11.1 short-term & 2 & 153 & $\begin{array}{l}\text { Mean Difference (IV, } \\
\text { Fixed, } 95 \% \text { CI) }\end{array}$ & $0.01[-2.11,2.13]$ \\
\hline 11.2 medium-term & 4 & 222 & $\begin{array}{l}\text { Mean Difference (IV, } \\
\text { Fixed, } 95 \% \text { CI) }\end{array}$ & $-1.59[-3.61,0.43]$ \\
\hline 11.3 long-term & 4 & 318 & $\begin{array}{l}\text { Mean Difference (IV, } \\
\text { Fixed, } 95 \% \text { CI) }\end{array}$ & $-1.80[-3.80,0.21]$ \\
\hline $\begin{array}{l}12 \text { Mental state: } 5 \text { b. } \\
\text { Specific - average score } \\
\text { - affective symptoms - } \\
\text { depression (Beck } \\
\text { Depression Inventory, } \\
\text { high = poor) }\end{array}$ & 2 & 278 & $\begin{array}{l}\text { Mean Difference (IV, } \\
\text { Fixed, } 95 \% \text { CI) }\end{array}$ & $-3.39[-5.90,-0.89]$ \\
\hline 12.1 short-term & 1 & 65 & $\begin{array}{l}\text { Mean Difference (IV, } \\
\text { Fixed, 95\% CI) }\end{array}$ & $-1.20[-5.56,3.16]$ \\
\hline 12.2 medium-term & 2 & 108 & $\begin{array}{l}\text { Mean Difference (IV, } \\
\text { Fixed, } 95 \% \text { CI) }\end{array}$ & $-3.09[-7.18,0.99]$ \\
\hline 12.3 long-term & 2 & 105 & $\begin{array}{l}\text { Mean Difference (IV, } \\
\text { Fixed, } 95 \% \text { CI) }\end{array}$ & $-6.21[-10.81,-1.61]$ \\
\hline $\begin{array}{l}13 \text { Mental state: } 5 \mathrm{c} \text {. } \\
\text { Specific - average score } \\
\text { - affective symptoms - } \\
\text { self esteem (Rosenberg } \\
\text { Self Esteem Scale (high } \\
=\text { good)) }\end{array}$ & 1 & 195 & $\begin{array}{l}\text { Mean Difference (IV, } \\
\text { Fixed, 95\% CI) }\end{array}$ & $1.36[-0.32,3.05]$ \\
\hline 13.1 short-term & 1 & 65 & $\begin{array}{l}\text { Mean Difference (IV, } \\
\text { Fixed, 95\% CI) }\end{array}$ & $1.60[-0.93,4.13]$ \\
\hline 13.2 medium-term & 1 & 65 & $\begin{array}{l}\text { Mean Difference (IV, } \\
\text { Fixed, } 95 \% \text { CI) }\end{array}$ & $0.80[-2.17,3.77]$ \\
\hline 13.3 long-term & 1 & 65 & $\begin{array}{l}\text { Mean Difference (IV, } \\
\text { Fixed, } 95 \% \text { CI) }\end{array}$ & $1.70[-1.79,5.19]$ \\
\hline $\begin{array}{l}14 \text { Mental state: } 5 \mathrm{~d} \text {. } \\
\text { Specific - average score } \\
\text { - affective symptoms - } \\
\text { anxiety (Beck anxiety } \\
\text { Inventory (high = poor)) }\end{array}$ & 1 & 81 & $\begin{array}{l}\text { Mean Difference (IV, } \\
\text { Fixed, 95\% CI) }\end{array}$ & $-0.69[-6.71,5.33]$ \\
\hline 14.1 medium-term & 1 & 41 & $\begin{array}{l}\text { Mean Difference (IV, } \\
\text { Fixed, } 95 \% \text { CI) }\end{array}$ & $-0.79[-9.30,7.72]$ \\
\hline 14.2 long-term & 1 & 40 & $\begin{array}{l}\text { Mean Difference (IV, } \\
\text { Fixed, } 95 \% \text { CI) }\end{array}$ & $-0.59[-9.10,7.92]$ \\
\hline
\end{tabular}




\begin{tabular}{|c|c|c|c|c|}
\hline $\begin{array}{l}\text { Outcome or subgroup } \\
\text { title }\end{array}$ & No. of studies & No. of participants & Statistical method & Effect size \\
\hline $\begin{array}{l}15 \text { Mental State: } 5 \mathrm{e} \text {. } \\
\text { Specific - average score } \\
\text { - affective symptoms - } \\
\text { insight (Beck Cognitive } \\
\text { Insight Scale (high = } \\
\text { good)) }\end{array}$ & 1 & 195 & $\begin{array}{l}\text { Mean Difference (IV, } \\
\text { Fixed, 95\% CI) }\end{array}$ & $0.35[-1.24,1.94]$ \\
\hline 15.1 short-term & 1 & 65 & $\begin{array}{l}\text { Mean Difference (IV, } \\
\text { Fixed, 95\% CI) }\end{array}$ & $0.70[-2.25,3.65]$ \\
\hline 15.2 medium-term & 1 & 65 & $\begin{array}{l}\text { Mean Difference (IV, } \\
\text { Fixed, 95\% CI) }\end{array}$ & $-0.5[-3.44,2.44]$ \\
\hline 15.3 long-term & 1 & 65 & $\begin{array}{l}\text { Mean Difference (IV, } \\
\text { Fixed, 95\% CI) }\end{array}$ & $0.70[-1.75,3.15]$ \\
\hline $\begin{array}{l}\text { 16 Global state: } 1 . \\
\text { Relapse }\end{array}$ & 4 & & $\begin{array}{l}\text { Risk Ratio (M-H, } \\
\text { Random, 95\% CI) }\end{array}$ & Subtotals only \\
\hline 16.1 short-term & 1 & 71 & $\begin{array}{l}\text { Risk Ratio (M-H, } \\
\text { Random, 95\% CI) }\end{array}$ & $0.65[0.21,1.95]$ \\
\hline 16.2 medium-term & 1 & 59 & $\begin{array}{l}\text { Risk Ratio (M-H, } \\
\text { Random, } 95 \% \mathrm{CI} \text { ) }\end{array}$ & $0.63[0.19,2.11]$ \\
\hline 16.3 long-term & 3 & 137 & $\begin{array}{l}\text { Risk Ratio (M-H, } \\
\text { Random, 95\% CI) }\end{array}$ & $1.08[0.66,1.77]$ \\
\hline $\begin{array}{l}17 \text { Global state: } 2 . \\
\text { Rehospitalisation }\end{array}$ & 3 & & $\begin{array}{l}\text { Risk Ratio (M-H, Fixed, } \\
95 \% \text { CI) }\end{array}$ & Subtotals only \\
\hline 17.1 short-term & 2 & 136 & $\begin{array}{l}\text { Risk Ratio (M-H, Fixed, } \\
95 \% \text { CI) }\end{array}$ & $0.31[0.10,0.97]$ \\
\hline 17.2 medium-term & 2 & 132 & $\begin{array}{l}\text { Risk Ratio (M-H, Fixed, } \\
95 \% \mathrm{CI})\end{array}$ & $0.59[0.27,1.30]$ \\
\hline 17.3 long-term & 3 & 175 & $\begin{array}{l}\text { Risk Ratio (M-H, Fixed, } \\
95 \% \text { CI) }\end{array}$ & $0.74[0.46,1.20]$ \\
\hline $\begin{array}{l}18 \text { Global state: } 3 \mathrm{a} \text {. } \\
\text { Average score (GAS, } \\
\text { endpoint data, high = } \\
\text { good) }\end{array}$ & 1 & 68 & $\begin{array}{l}\text { Mean Difference (IV, } \\
\text { Fixed, 95\% CI) }\end{array}$ & $-0.57[-4.27,3.13]$ \\
\hline 18.1 medium-term & 1 & 38 & $\begin{array}{l}\text { Mean Difference (IV, } \\
\text { Fixed, 95\% CI) }\end{array}$ & $-0.60[-4.93,3.73]$ \\
\hline 18.2 long-term & 1 & 30 & $\begin{array}{l}\text { Mean Difference (IV, } \\
\text { Fixed, 95\% CI) }\end{array}$ & $-0.5[-7.63,6.63]$ \\
\hline $\begin{array}{l}19 \text { Global state: } 3 \mathrm{~b} \text {. } \\
\text { Average score (GAF, } \\
\text { high = good) }\end{array}$ & 2 & & $\begin{array}{l}\text { Mean Difference (IV, } \\
\text { Fixed, 95\% CI) }\end{array}$ & Subtotals only \\
\hline 19.1 short-term & 1 & 77 & $\begin{array}{l}\text { Mean Difference (IV, } \\
\text { Fixed, 95\% CI) }\end{array}$ & $8.52[1.75,15.29]$ \\
\hline 19.2 long-term & 1 & 30 & $\begin{array}{l}\text { Mean Difference (IV, } \\
\text { Fixed, 95\% CI) }\end{array}$ & $-0.5[-7.63,6.63]$ \\
\hline $\begin{array}{l}20 \text { Global state: } 4 \mathrm{a} \text {. } \\
\text { Social Functioning Scale } \\
\text { (high = good) }\end{array}$ & 1 & 195 & $\begin{array}{l}\text { Mean Difference (IV, } \\
\text { Fixed, 95\% CI) }\end{array}$ & $6.93[0.44,13.41]$ \\
\hline 20.1 short-term & 1 & 65 & $\begin{array}{l}\text { Mean Difference (IV, } \\
\text { Fixed, 95\% CI) }\end{array}$ & $5.40[-5.18,15.98]$ \\
\hline 20.2 medium-term & 1 & 65 & $\begin{array}{l}\text { Mean Difference (IV, } \\
\text { Fixed, 95\% CI) }\end{array}$ & $7.20[-3.46,17.86]$ \\
\hline 20.3 long-term & 1 & 65 & $\begin{array}{l}\text { Mean Difference (IV, } \\
\text { Fixed, 95\% CI) }\end{array}$ & $8.80[-4.07,21.67]$ \\
\hline $\begin{array}{l}21 \text { Global state } 4 \mathrm{~b} \text {. } \\
\text { Social and Occupational } \\
\text { Functioning Assessment } \\
\text { Scale (high = good) }\end{array}$ & 1 & & $\begin{array}{l}\text { Mean Difference (IV, } \\
\text { Fixed, 95\% CI) }\end{array}$ & Subtotals only \\
\hline
\end{tabular}




\begin{tabular}{|c|c|c|c|c|}
\hline $\begin{array}{l}\text { Outcome or subgroup } \\
\text { title }\end{array}$ & No. of studies & No. of participants & Statistical method & Effect size \\
\hline 21.1 medium-term & 1 & 45 & $\begin{array}{l}\text { Mean Difference (IV, } \\
\text { Fixed, 95\% CI) }\end{array}$ & $5.33[-2.57,13.23]$ \\
\hline 21.2 long-term & 1 & 41 & $\begin{array}{l}\text { Mean Difference (IV, } \\
\text { Fixed, 95\% CI) }\end{array}$ & $1.36[-9.59,12.31]$ \\
\hline $\begin{array}{l}22 \text { Quality of Life: } \\
\text { EuroQOL (high = good) }\end{array}$ & 1 & 37 & $\begin{array}{l}\text { Mean Difference (IV, } \\
\text { Fixed, 95\% CI) }\end{array}$ & $-1.86[-19.20,15.48]$ \\
\hline 22.1 long-term & 1 & 37 & $\begin{array}{l}\text { Mean Difference (IV, } \\
\text { Fixed, 95\% CI) }\end{array}$ & $-1.86[-19.20,15$ \\
\hline $\begin{array}{l}23 \text { Satisfaction with } \\
\text { treatment: } 1 . \text { Leaving the } \\
\text { study early }\end{array}$ & 6 & 339 & $\begin{array}{l}\text { Risk Ratio (M-H, } \\
\text { Random, 95\% CI) }\end{array}$ & $48] 0.75[0.40,1.43]$ \\
\hline
\end{tabular}

Analysis 1.1

Comparison 1 CBT versus ALL OTHER

PSYCHOLOGICAL THERAPIES, Outcome 1 Adverse effect/event: 1. Death

Review: Cognitive behavioural therapy versus other psychosocial treatments for schizophrenia

Comparison: 1 CBT versus ALL OTHER PSYCHOLOGICAL THERAPIES

Outcome: 1 Adverse effect/event: 1 . Death

\begin{tabular}{|c|c|c|c|c|c|}
\hline Study or subgroup & $\begin{array}{r}\text { Treatment } \\
\mathrm{n} / \mathrm{N}\end{array}$ & $\begin{array}{r}\text { Control } \\
\mathrm{n} / \mathrm{N}\end{array}$ & $\begin{array}{c}\text { Risk Ratio } \\
\text { M-H,Fixed,95\% CI }\end{array}$ & Weight & $\begin{array}{r}\text { Risk Ratio } \\
\text { M-H,Fixed,95\% CI }\end{array}$ \\
\hline Durham 2003 & $0 / 22$ & 1/23 & $\longrightarrow$ & $33.0 \%$ & $0.35[0.01,8.11]$ \\
\hline Lewis 2002 & 278 & $3 / 79$ & - & $67.0 \%$ & $0.68[0.12,3.93]$ \\
\hline Total $(95 \% \mathrm{CI})$ & 100 & 102 & - & $100.0 \%$ & $0.57[0.12,2.60]$ \\
\hline \multicolumn{6}{|c|}{ Total events: 2 (Treatment), 4 (Control) } \\
\hline \multicolumn{6}{|c|}{ Heterogeneity: $\mathrm{Chi}^{2}=0.13, \mathrm{df}=\mathrm{I}(\mathrm{P}=0.72) ; \mathrm{I}^{2}=0.0 \%$} \\
\hline \multicolumn{6}{|c|}{ Test for overal effect: $Z=0.73(P=0.47)$} \\
\hline \multicolumn{6}{|c|}{ Test for subgroup differences: Not applicable } \\
\hline & & & $\begin{array}{l}0.0010 .010 .1 \quad 10 \quad 100 \quad 1000 \\
\text { Favours treatment } \\
\text { Favours control }\end{array}$ & & \\
\hline
\end{tabular}


Analysis 1.2

Comparison 1 CBT versus ALL OTHER

PSYCHOLOGICAL THERAPIES, Outcome 2 Adverse

effect/event: 2. Adverse effects - any - medium-term

only

Review: Cognitive behavioural therapy versus other psychosocial treatments for schizophrenia

Comparison: 1 CBT versus ALL OTHER PSYCHOLOGICAL THERAPIES

Outcome: 2 Adverse effect/event: 2 . Adverse effects - any - medium-term only

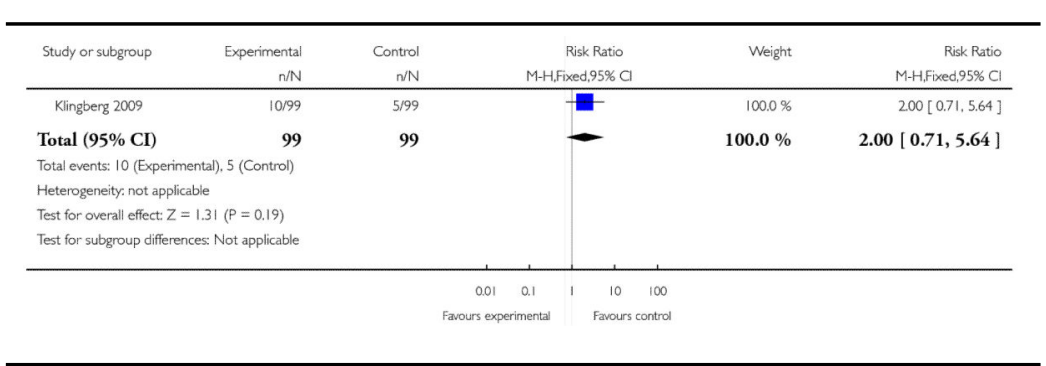


Analysis 1.3

Comparison 1 CBT versus ALL OTHER

PSYCHOLOGICAL THERAPIES, Outcome 3 Mental

state: 1. General - no important or reliable change

Review: Cognitive behavioural therapy versus other psychosocial treatments for schizophrenia

Comparison: 1 CBT versus ALL OTHER PSYCHOLOGICAL THERAPIES

Outcome: 3 Mental state: 1 . General - no important or reliable change

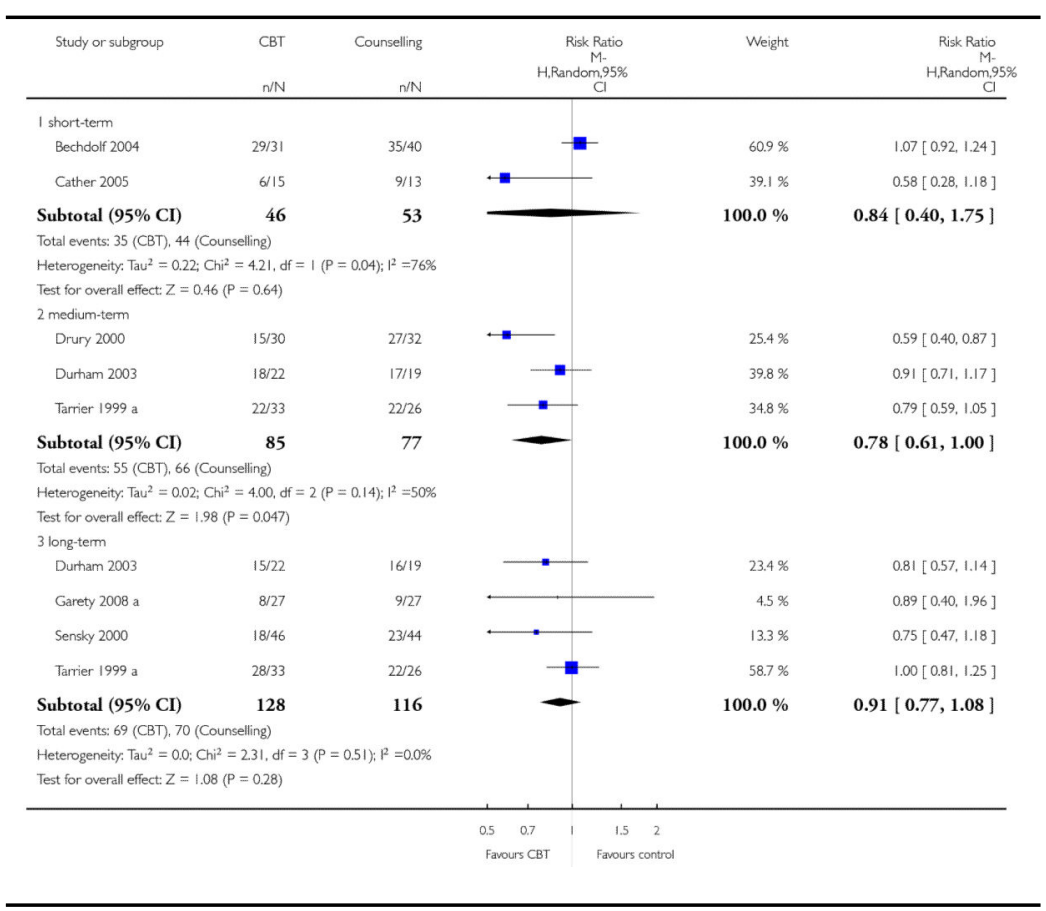


Analysis 1.4

Comparison 1 CBT versus ALL OTHER

PSYCHOLOGICAL THERAPIES, Outcome 4 Mental

state: 2. Average scale score - total

Review: Cognitive behavioural therapy versus other psychosocial treatments for schizophrenia

Comparison: 1 CBT versus ALL OTHER PSYCHOLOGICAL THERAPIES

Outcome: 4 Mental state: 2. Average scale score - total

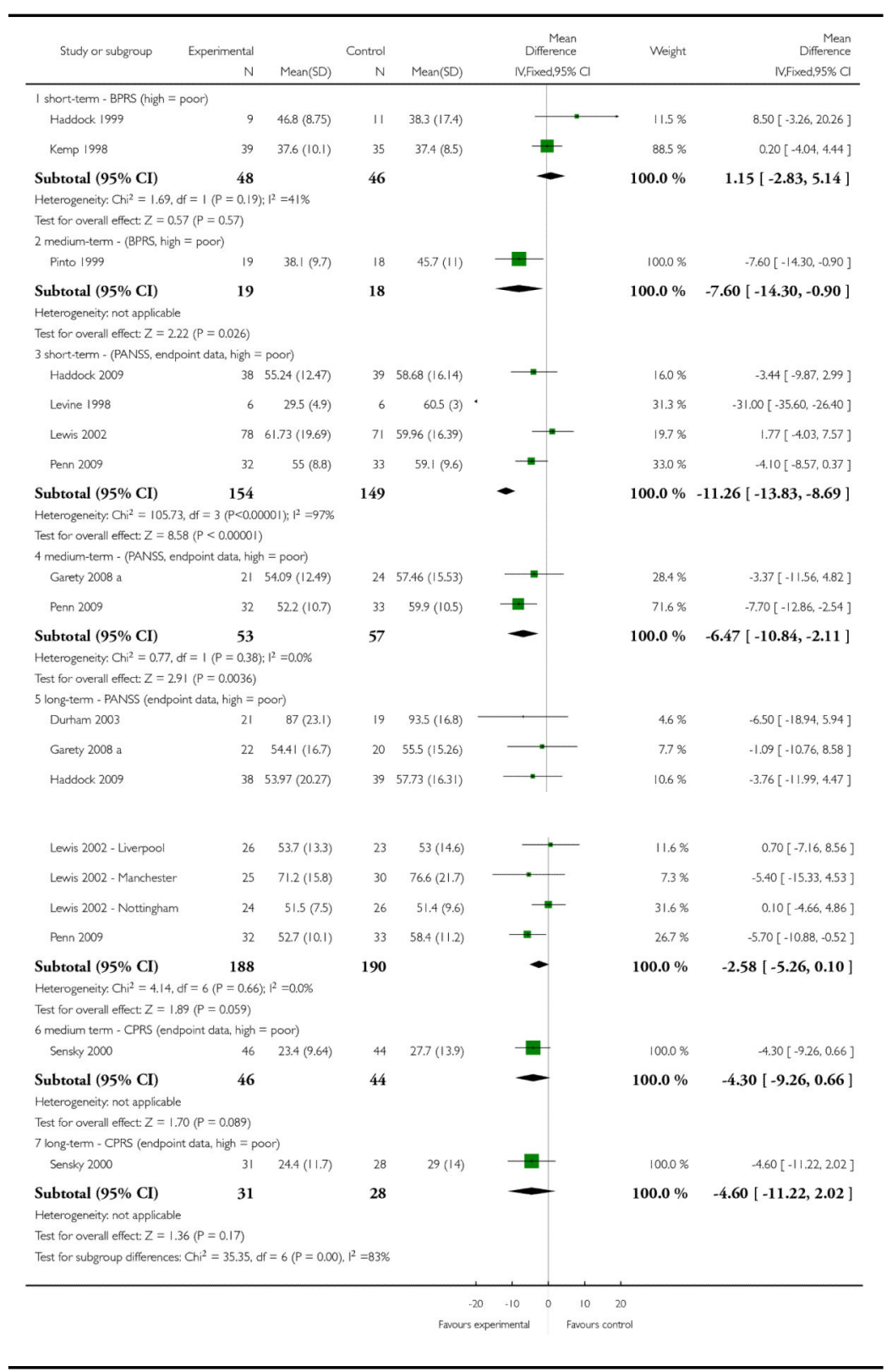


Analysis 1.5

Comparison 1 CBT versus ALL OTHER

PSYCHOLOGICAL THERAPIES, Outcome 5 Mental

state: 3a. Specific - average score - positive symptoms -

overall (PANSS, endpoint data, high = poor $)$

Review: Cognitive behavioural therapy versus other psychosocial treatments for schizophrenia

Comparison: 1 CBT versus ALL OTHER PSYCHOLOGICAL THERAPIES

Outcome: 5 Mental state: 3a. Specific - average score - positive symptoms - overall (PANSS, endpoint data, high $=$ poor $)$

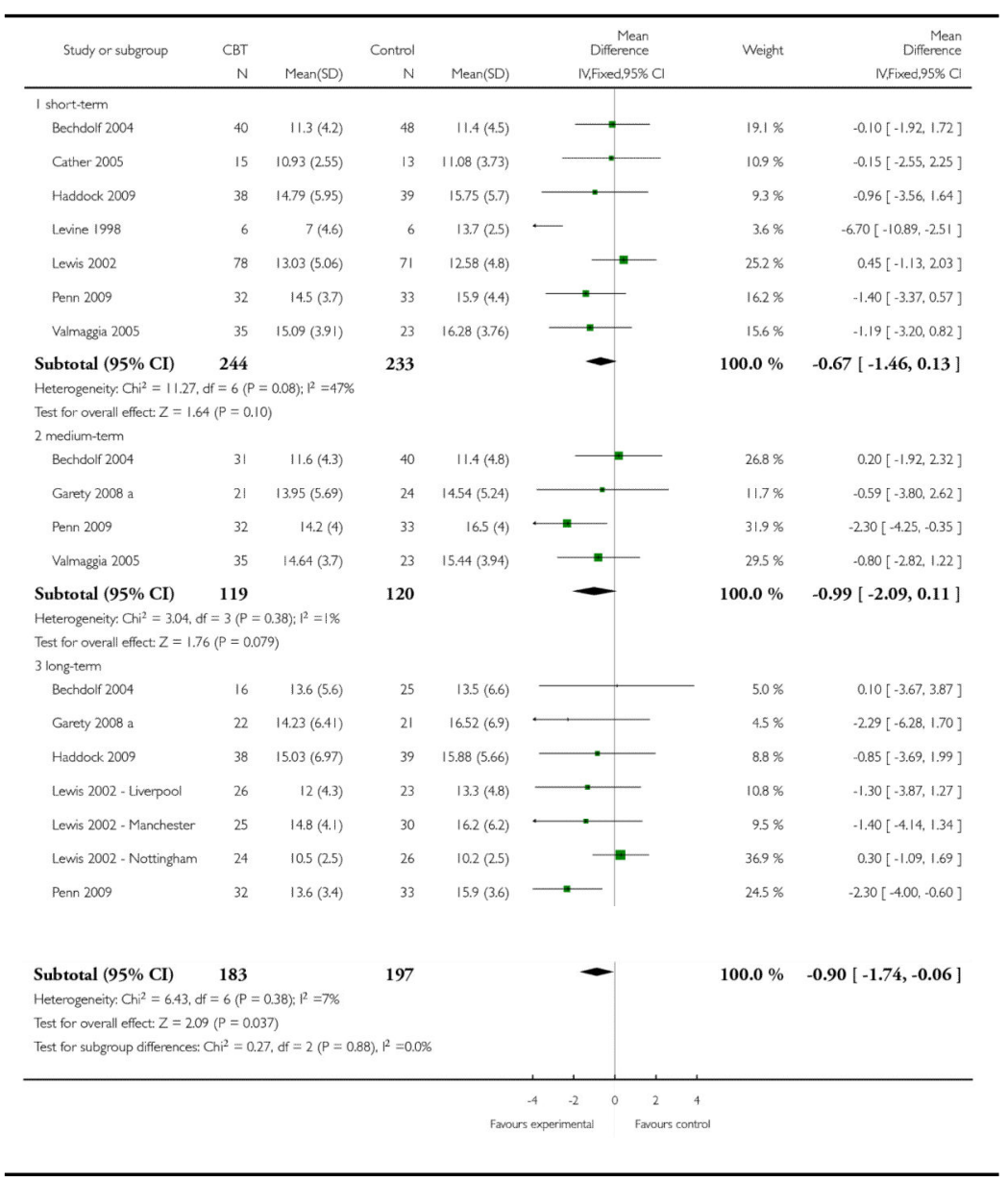


Analysis 1.6

Comparison 1 CBT versus ALL OTHER

PSYCHOLOGICAL THERAPIES, Outcome 6 Mental

state: $3 b$. Specific - average score - positive symptoms hallucinations (Psychotic Symptom Rating Scale, high = poor)

Review: Cognitive behavioural therapy versus other psychosocial treatments for schizophrenia

Comparison: 1 CBT versus ALL OTHER PSYCHOLOGICAL THERAPIES

Outcome: 6 Mental state: 3 b. Specific - average score - positive symptoms - hallucinations (Psychotic Symptom Rating Scale, high = poor)

\begin{tabular}{|c|c|c|c|c|c|c|c|c|}
\hline \multirow[t]{2}{*}{ Study or subgroup } & \multirow{2}{*}{$\begin{array}{r}\text { Experimental } \\
N\end{array}$} & \multicolumn{3}{|c|}{ Control } & \multirow{2}{*}{\multicolumn{2}{|c|}{ 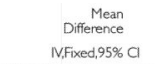 }} & \multirow[t]{2}{*}{ Weight } & \multirow{2}{*}{$\begin{array}{r}\text { Mean } \\
\text { Difference } \\
\text { IV.Fixed, } 95 \% \mathrm{Cl} \\
\end{array}$} \\
\hline & & $\operatorname{Mean}(\mathrm{SD})$ & $\mathrm{N}$ & $\operatorname{Mean}(\mathrm{SD})$ & & & & \\
\hline \multicolumn{9}{|l|}{ I short-term } \\
\hline Cather 2005 & 15 & $18.11(11.36)$ & 13 & $20.52(12.57)$ & $\rightarrow$ & & $7.3 \%$ & $-241[-11.34,6.52]$ \\
\hline Haddock 2009 & 38 & $9.74(13.92)$ & 39 & 11.38 (15.13) & - & - & $13.8 \%$ & $-1.64[-8.13,4.85]$ \\
\hline Lewis 2002 & 47 & $6.15(10.31)$ & 41 & $6.41(10.61)$ & 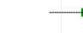 & - & $30.2 \%$ & $-0.26[-4.65,4.13]$ \\
\hline Penn 2009 & 32 & $25.4(7.4)$ & 33 & $26.3(6.8)$ & - & & $48.7 \%$ & $-0.90[-4.36,256]$ \\
\hline Subtotal $(95 \% \mathrm{CI})$ & 132 & & 126 & & & & $100.0 \%$ & $-0.92[-3.33,1.49]$ \\
\hline \multicolumn{9}{|c|}{ Heterogeneity: $C \mathrm{~h}^{2}=0.24$, of $=3(P=0.97) ; R^{2}=0.0 \%$} \\
\hline \multicolumn{9}{|c|}{ Test for overall effect: $Z=0.75(P=0.46)$} \\
\hline \multicolumn{9}{|l|}{2 medium-term } \\
\hline Durham 2003 & 21 & $17.9(13.2)$ & 19 & $20.6(12.3)$ & & & $18.2 \%$ & $-2.70[-10.60,5.20]$ \\
\hline Penn 2009 & 32 & $25.6(6.9)$ & 33 & $25.7(8.4)$ & & & $81.8 \%$ & $-0.10[-3.83,3.63]$ \\
\hline Subtotal $(95 \% \mathrm{CI})$ & 53 & & 52 & & & & $100.0 \%$ & $-0.57[-3.95,2.80]$ \\
\hline \multicolumn{9}{|c|}{ Heterogeneity. $C h i^{2}=0.34, d f=1 \quad(P=0.56) ; 1^{2}=0.0 \%$} \\
\hline \multicolumn{9}{|c|}{ Test for overall effect: $Z=0.33(P=0.74)$} \\
\hline \multicolumn{9}{|l|}{3 long-term } \\
\hline Durham 2003 & 20 & $18.5(12.8)$ & 19 & $18(12.2)$ & & & $11.9 \%$ & $0.50[-7.35,8.35]$ \\
\hline Haddock 2009 & 38 & $9.36(1272)$ & 39 & $10.38(16.63)$ & & & $16.8 \%$ & $-1.02[-7.62,5.58]$ \\
\hline Lewis 2002 - Liverpool & 11 & $0.0001(0.00001)$ & 11 & $9.5(14.4)$ & $*$ & & $10.1 \%$ & $-9.50[-18.01,-0.99]$ \\
\hline Lewis 2002 - Manchester & 15 & $7.1(12.5)$ & 20 & $14.2(16.2)^{-}$ & $\hookrightarrow$ & & $8.1 \%$ & $-7.10[-16.61,2.41]$ \\
\hline Lewis 2002 - Nottingham & 14 & $4.4(8.9)$ & 15 & $2.7(7.3)$ & & * & $20.7 \%$ & $1.70[-4.25,7.65]$ \\
\hline Penn 2009 & 32 & $23(9.6)$ & 33 & $23(10)$ & & & $32.3 \%$ & $0.0[-4.76,4.76]$ \\
\hline Subtotal $(95 \% \mathrm{CI})$ & 130 & & 137 & & & - & $100.0 \%$ & $-1.30[-4.01,1.41]$ \\
\hline \multirow{2}{*}{\multicolumn{9}{|c|}{$\begin{array}{l}\text { Heterogeneity, } \mathrm{Ch}^{2}=6.47, \mathrm{df}=5(P=0.26) ; P^{2}=23 \% \\
\text { Test for overal effect: } Z=0.94(P=0.35)\end{array}$}} \\
\hline \multirow{2}{*}{\multicolumn{9}{|c|}{ Test for subgroup differences: $C \mathrm{~h}^{2}=0.11$, df $=2(P=0.95), 1^{2}=0.0 \%$}} \\
\hline & & & & & & & & \\
\hline & & & & $\begin{aligned}-10 \\
\text { Favars e: }\end{aligned}$ & $\begin{array}{l}-10 \\
-10 \\
\text { sexperimental }\end{array}$ & $\begin{array}{l}0 \\
0 \\
\quad \text { Farours }\end{array}$ & 10 & \\
\hline
\end{tabular}


Analysis 1.7

Comparison 1 CBT versus ALL OTHER

PSYCHOLOGICAL THERAPIES, Outcome 7 Mental

state: 3c. Specific - average score - positive symptoms delusions (Psychotic Symptom Rating Scale, high = poor)

Review: Cognitive behavioural therapy versus other psychosocial treatments for schizophrenia

Comparison: 1 CBT versus ALL OTHER PSYCHOLOGICAL THERAPIES

Outcome: 7 Mental state: 3c. Specific - average score - positive symptoms - delusions (Psychotic Symptom Rating Scale, high = poor)

\begin{tabular}{|c|c|c|c|c|c|c|c|c|}
\hline \multirow[t]{2}{*}{ Study or subgroup } & \multirow{2}{*}{$\begin{array}{r}\text { Experimental } \\
\mathrm{N}\end{array}$} & \multicolumn{3}{|c|}{ Control } & \multirow{2}{*}{\multicolumn{2}{|c|}{$\begin{array}{c}\text { Mean } \\
\text { Difference } \\
\text { IV.Fixed,95\% CI }\end{array}$}} & \multirow[t]{2}{*}{ Weight } & \multirow{2}{*}{$\begin{array}{r}\text { Mean } \\
\text { Difference } \\
\text { IV,Fixed,95\% Cl }\end{array}$} \\
\hline & & $\operatorname{Mean}(\mathrm{SD})$ & $\mathrm{N}$ & $\operatorname{Mean}(\mathrm{SD})$ & & & & \\
\hline \multicolumn{9}{|l|}{ I short-term } \\
\hline Cather 2005 & 15 & $10.69(6.49)$ & 13 & $10.15(7.48)$ & & - & $8.8 \%$ & $0.54[-4.69,5.77]$ \\
\hline Haddock 2009 & 38 & $4.9(6.55)$ & 39 & $11.04(6.7)$ & $\leftarrow$ & & $27.4 \%$ & $-6.14[-9.10,-3.18]$ \\
\hline Lewis 2002 & 74 & $6.95(7.66)$ & 67 & $6.13(6.98)$ & & $=$ & $41.0 \%$ & $0.82[-1.60,3.24]$ \\
\hline Penn 2009 & 32 & $8.6(7)$ & 33 & $10(6.3)$ & $\longleftarrow$ & - & $22.8 \%$ & $-1.40[-4.64,1.84]$ \\
\hline Subtotal $(95 \% \mathrm{CI})$ & 159 & & 152 & & & & $100.0 \%$ & $-1.62[-3.16,-0.07]$ \\
\hline \multicolumn{9}{|c|}{ Heterogeneity: Chi $i^{2}=13.55$, of $=3(P=0.004) ;\left.\right|^{2}=78 \%$} \\
\hline \multicolumn{9}{|c|}{ Test for overal effect: $Z=2.05(P=0.041)$} \\
\hline \multicolumn{9}{|l|}{2 medium-term } \\
\hline Durham 2003 & 22 & $13.3(5.4)$ & 19 & $11.8(6.2)$ & & - & $46.5 \%$ & $1.50[-209.5 .09]$ \\
\hline Penn 2009 & 32 & $8(7.7)$ & 33 & $10.4(5.9)$ & 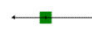 & - & $53.5 \%$ & $-2.40[-5.74,0.94]$ \\
\hline Subtotal $(95 \% \mathrm{CI})$ & 54 & & 52 & & & - & $100.0 \%$ & $-0.59[-3.03,1.86]$ \\
\hline \multicolumn{9}{|c|}{ Heterogeneity: $C \mathrm{i}^{2}=2.43, \mathrm{df}=1(\mathrm{P}=0.12): \mathrm{1}^{2}=59 \%$} \\
\hline \multicolumn{9}{|c|}{ Test for overal effect: $Z=0.47(P=0.64)$} \\
\hline \multicolumn{9}{|l|}{3 long term } \\
\hline Durham 2003 & 21 & $11.1(5.8)$ & 19 & $9.7(6,1)$ & & 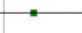 & $15.3 \%$ & $1.40[-2.30,5.10]$ \\
\hline Haddock 2009 & 38 & $7.6(8.25)$ & 39 & $8.38(8.03)$ & $m$ & & $15.8 \%$ & $-0.78[-4.42,2.86]$ \\
\hline Lewis 2002 - Liverpool & 24 & $3.5(6)$ & 23 & $5.9(7.3)$ & 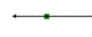 & - & $14.2 \%$ & $-2.40[-6.23,1.43]$ \\
\hline Lewis 2002 - Manchester & 25 & $8.9(6.9)$ & 27 & $9.2(8.1)$ & & & $12.5 \%$ & $-0.30[-4.38,3.78]$ \\
\hline Lewis 2002 - Nottingham & 23 & $5.5(5.3)$ & 25 & $6.4(5.2)$ & 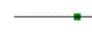 & & $23.6 \%$ & $-0.90[-3.87,2.07]$ \\
\hline Penn 2009 & 32 & $6.9(7)$ & 33 & $9(6.8)$ & $\longleftrightarrow$ & - & $18.5 \%$ & $-2.10[-5.46,1.26]$ \\
\hline Subtotal $(95 \% \mathrm{CI})$ & 163 & & 166 & & & & $100.0 \%$ & $-0.89[-2.34,0.55]$ \\
\hline \multicolumn{9}{|c|}{ Heterogeneity: $C \mathrm{Ci}^{2}=2.65, \mathrm{df}=5(\mathrm{P}=0.75): \mathrm{1}^{2}=0.0 \%$} \\
\hline \multicolumn{9}{|c|}{ Test for overall effect: $Z=1.21(P=0.23)$} \\
\hline \multicolumn{9}{|c|}{ Test for subgroup differences: $C \mathrm{~h}^{2}=0.67, \mathrm{df}=2(\mathrm{P}=0.71), \mathrm{I}^{2}=0.0 \%$} \\
\hline & & & & & $-4 \quad-2$ & $0 \quad 2$ & 4 & \\
\hline & & & & Favours & is experimental & Favours cor & & \\
\hline
\end{tabular}


Analysis 1.8

Comparison 1 CBT versus ALL OTHER

PSYCHOLOGICAL THERAPIES, Outcome 8 Mental

state: $3 d$. Specific - average score - positive symptoms -

delusions cognitive characteristics (psychotic symptom

rating scale, high $=$ poor)

Review: Cognitive behavioural therapy versus other psychosocial treatments for schizophrenia

Comparison: 1 CBT versus ALL OTHER PSYCHOLOGICAL THERAPIES

Outcome: 8 Mental state: $3 \mathrm{~d}$. Specific - average score - positive symptoms - delusions cognitive characteristics (psychotic symptom rating scale, high $=$ poor)

\begin{tabular}{|c|c|c|c|c|c|c|c|}
\hline Study or subgroup & Experimental & \multicolumn{3}{|c|}{ Control } & $\begin{array}{c}\text { Mean } \\
\text { Difference } \\
\text { IV.Fixed,95\% Cl }\end{array}$ & Weight & $\begin{array}{r}\text { Mean } \\
\text { Difference } \\
\text { IV,Fixed,95\% C }\end{array}$ \\
\hline \multicolumn{8}{|l|}{ I medium-term } \\
\hline Vaimaggia 2005 & 35 & $7(4.28)$ & 23 & $7.26(4.5)$ & + & $100.0 \%$ & $-0.26[-2.58,2.06]$ \\
\hline Subtotal $(95 \% \mathrm{CI})$ & 35 & & 23 & & 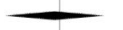 & $100.0 \%$ & $-0.26[-2.58,2.06]$ \\
\hline \multicolumn{8}{|c|}{ Heterogeneity: not applicable } \\
\hline \multicolumn{8}{|c|}{ Test for overal effect: $Z=0.22(P=0.83)$} \\
\hline \multicolumn{8}{|c|}{2 long-term } \\
\hline Valmaggia 2005 & 35 & $6.81(4.32)$ & 23 & $6.42(5.08)$ & 푤 & $100.0 \%$ & $0.39[-2.13,2.91]$ \\
\hline Subtotal $(95 \% \mathrm{CI})$ & 35 & & 23 & & & $100.0 \%$ & $0.39[-2.13,2.91]$ \\
\hline \multicolumn{8}{|c|}{ Heterogeneity: not applicable } \\
\hline \multicolumn{8}{|c|}{ Test for overall effect: $Z=0.30(P=0.76)$} \\
\hline \multicolumn{8}{|c|}{ Test for subgroup differences: $C h i^{2}=0.14$, df $=1(P=0.71), P^{2}=0.0 \%$} \\
\hline & & & & & $\begin{array}{cc}-2 & 0 \\
\text { itmental } & 2 \\
\text { Faxours }\end{array}$ & & \\
\hline
\end{tabular}


Analysis 1.9

Comparison 1 CBT versus ALL OTHER

PSYCHOLOGICAL THERAPIES, Outcome 9 Mental

state: 3e. Specific - average score - positive symptoms -

delusions emotional characteristics (psychotic symptom

rating scale, high $=$ poor $)$

Review: Cognitive behavioural therapy versus other psychosocial treatments for schizophrenia

Comparison: 1 CBT versus ALL OTHER PSYCHOLOGICAL THERAPIES

Outcome: 9 Mental state: 3e. Specific - average score - positive symptoms - delusions emotional characteristics (psychotic symptom rating scale, high $=$ poor)

\begin{tabular}{|c|c|c|c|c|c|c|c|}
\hline \multirow[t]{2}{*}{ Study or subgroup } & \multirow{2}{*}{$\begin{array}{r}\text { Experimental } \\
\mathrm{N}\end{array}$} & \multicolumn{3}{|c|}{ Control } & \multirow{2}{*}{$\begin{array}{c}\text { Mean } \\
\text { Difference } \\
\text { IV.Fixed,95\% Cl }\end{array}$} & \multirow[t]{2}{*}{ Weight } & \multirow{2}{*}{$\begin{array}{r}\text { Mean } \\
\text { Difference } \\
\text { IV,Fixed,95\% Cl }\end{array}$} \\
\hline & & $\operatorname{Mean}(\mathrm{SD})$ & $\mathrm{N}$ & $\operatorname{Mean}(\mathrm{SD})$ & & & \\
\hline \multicolumn{8}{|l|}{1 medium-term } \\
\hline Valmaggia 2005 & 35 & $4.02(28)$ & 23 & $3.36(2.61)$ & E- & $100.0 \%$ & $0.66[-0.75,2.07]$ \\
\hline Subtotal $(95 \% \mathrm{CI})$ & 35 & & 23 & & 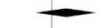 & $100.0 \%$ & $0.66[-0.75,2.07]$ \\
\hline \multicolumn{8}{|l|}{ Heterogeneity. not applicable } \\
\hline \multicolumn{8}{|c|}{ Test for overal effect: $Z=0.92(P=0.36)$} \\
\hline \multicolumn{8}{|c|}{2 long-term } \\
\hline Valmaggia 2005 & 35 & $3.28(2.74)$ & 23 & $3.17(2.92)$ & - & $100.0 \%$ & $0.11[-1.39,1.61]$ \\
\hline Subtotal $(95 \% \mathrm{CI})$ & 35 & & 23 & & & $100.0 \%$ & $0.11[-1.39,1.61]$ \\
\hline \multicolumn{8}{|c|}{ Heterogeneity not applicable } \\
\hline \multicolumn{8}{|c|}{ Test for overal effect: $Z=0.14(P=0.89)$} \\
\hline \multicolumn{8}{|c|}{ Test for subgroup differences: Chi $^{2}=0.27, \mathrm{df}=1(\mathrm{P}=0.60), \mathrm{l}^{2}=0.0 \%$} \\
\hline & & & & & -2 & & \\
\hline
\end{tabular}


Analysis 1.10

Comparison 1 CBT versus ALL OTHER

PSYCHOLOGICAL THERAPIES, Outcome 10 Mental

state: 4a. Specific - average score - negative symptoms -

overall (PANSS, endpoint data, high = poor $)$

Review: Cognitive behavioural therapy versus other psychosocial treatments for schizophrenia

Comparison: 1 CBT versus ALL OTHER PSYCHOLOGICAL THERAPIES

Outcome: 10 Mental state: 4a. Specific - average score - negative symptoms - overall (PANSS, endpoint data, high $=$ poor)

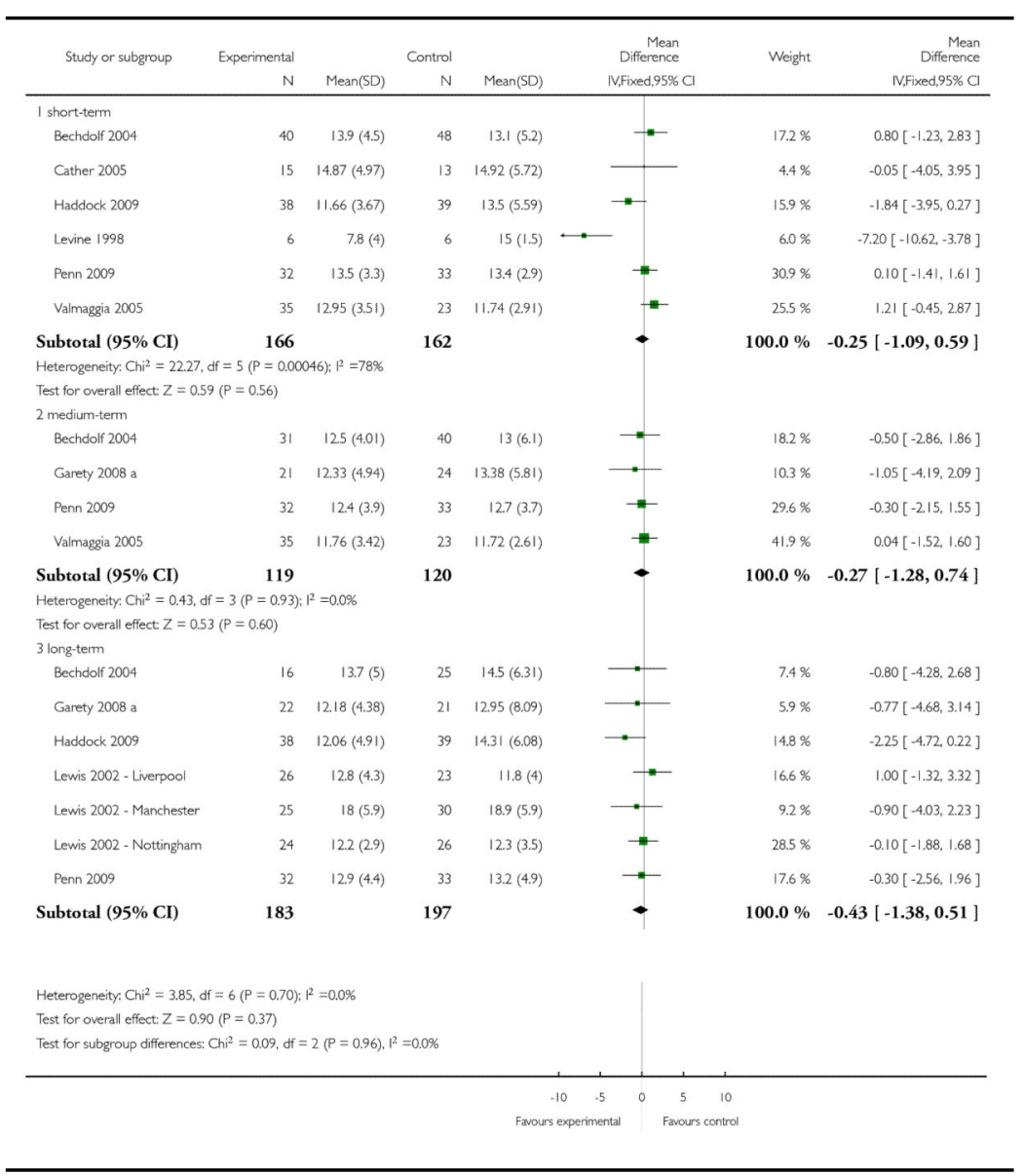


Analysis 1.11

Comparison 1 CBT versus ALL OTHER

PSYCHOLOGICAL THERAPIES, Outcome 11 Mental

state: $4 \mathrm{~b}$. Specific - average score - negative symptoms -

overall $($ SANS, high $=$ good $)$

Review: Cognitive behavioural therapy versus other psychosocial treatments for schizophrenia

Comparison: 1 CBT versus ALL OTHER PSYCHOLOGICAL THERAPIES

Outcome: 11 Mental state: 4b. Specific - average score - negative symptoms - overall

$($ SANS, high $=$ good $)$

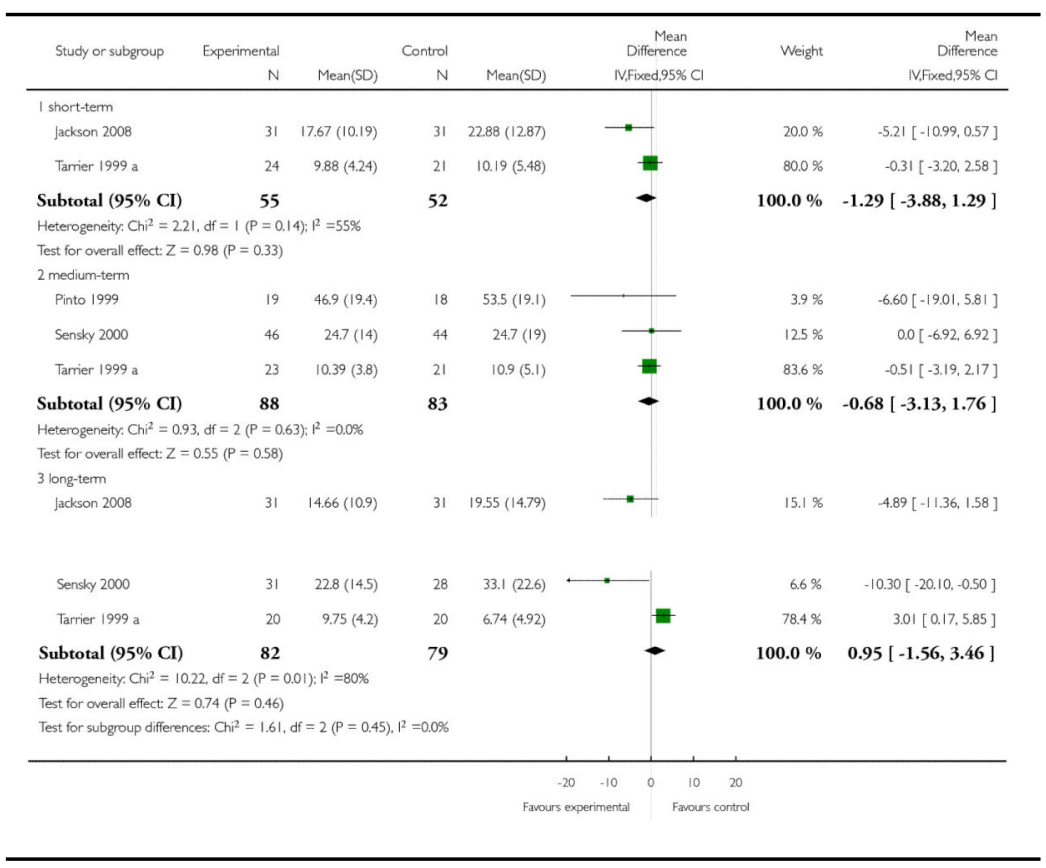


Analysis 1.12

Comparison 1 CBT versus ALL OTHER

PSYCHOLOGICAL THERAPIES, Outcome 12 Mental

state: 5a. Specific - average score - affective symptoms

(PANSS General symptoms, endpoint data, high = poor)

Review: Cognitive behavioural therapy versus other psychosocial treatments for schizophrenia

Comparison: 1 CBT versus ALL OTHER PSYCHOLOGICAL THERAPIES

Outcome: 12 Mental state: 5a. Specific - average score - affective symptoms (PANSS

General symptoms, endpoint data, high = poor)

\begin{tabular}{|c|c|c|c|c|c|c|c|}
\hline \multirow[t]{2}{*}{ Study or subgroup } & \multirow{2}{*}{$\begin{array}{r}\text { Experimental } \\
\mathrm{N}\end{array}$} & \multicolumn{3}{|c|}{ Control } & \multirow{2}{*}{$\begin{array}{c}\text { Mean } \\
\text { Difference } \\
\text { IN,Fixed,95\% Cl }\end{array}$} & \multirow[t]{2}{*}{ Weight } & \multirow{2}{*}{ 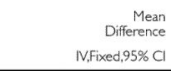 } \\
\hline & & $\operatorname{Mean}(S D)$ & N & $\operatorname{Mean}(S D)$ & & & \\
\hline \multicolumn{8}{|l|}{ I short-term } \\
\hline Bechdolf 2004 & 40 & $28(9.2)$ & 48 & $25(6.2)$ & 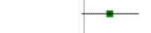 & $21.6 \%$ & $3.00[-0.35,6.35]$ \\
\hline Haddock 2009 & 38 & $28.45(6.52)$ & 39 & $29.5(7.84)$ & $\because$ & $23.4 \%$ & $-1.05[-4.27,2.17]$ \\
\hline Penn 2009 & 32 & $27(4.9)$ & 33 & $29(6.3)$ & $=$ & $32.3 \%$ & $-2.00[-4.74,0.74]$ \\
\hline Valmaggia 2005 & 35 & $30.4(6.28)$ & 23 & $29.58(6.16)$ & $=$ & $22.7 \%$ & $0.82[-245,4.09]$ \\
\hline Subtotal $(95 \% \mathrm{CI})$ & 145 & & 143 & & 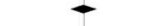 & $100.0 \%$ & $-0.06[-1.61,1.50]$ \\
\hline \multicolumn{8}{|c|}{ Heterogeneity. $C h^{2}=5.78, d f=3(P=0.12): 1^{2}=48 \%$} \\
\hline \multirow{2}{*}{\multicolumn{8}{|c|}{ Test for overall effect: $Z=0.07(P=0.94)$}} \\
\hline \multicolumn{6}{|l|}{2 medium-term } & & \\
\hline Bechdolf 2004 & 31 & $28.5(8.8)$ & 40 & $26(6.9)$ & * & $19.1 \%$ & $2.50[-1.26,6.26]$ \\
\hline Durharn 2003 & 22 & $96.2(17.7)$ & 19 & $95.2(16.2)$ & & $2.5 \%$ & $1.00[-9.38,11.38]$ \\
\hline Garety 2008 a & 21 & $27.81(6.76)$ & 24 & $29.54(7.6)$ & $\longrightarrow$ & $15.4 \%$ & $-1.73[-5.93,247]$ \\
\hline Fenn 2009 & 32 & $25.6(5.3)$ & 33 & $30(7.1)$ & $\because$ & $29.3 \%$ & $-4.40[-7.44,-1.36]$ \\
\hline Valmaggia 2005 & 35 & $29.74(6.34)$ & 23 & $29.62(4.65)$ & & $33.7 \%$ & $0.12[-2.71,295]$ \\
\hline Subtotal $(95 \% \mathrm{CI})$ & 141 & & 139 & & - & $100.0 \%$ & $-1.01[-2.66,0.63]$ \\
\hline \multicolumn{8}{|c|}{ Heterogeneity. $C h^{2}=8.99, d f=4(P=0.06) ; 1^{2}=55 \%$} \\
\hline \multicolumn{8}{|c|}{ Test for overall effect: $Z=1.21(P=0.23)$} \\
\hline \multicolumn{8}{|l|}{3 long-term } \\
\hline Bechdolf 2004 & 16 & $28.1(6.3)$ & 25 & $26.4(6.9)$ & 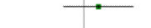 & $10.5 \%$ & $1.70[-2.40,5.80]$ \\
\hline Durham 2003 & 21 & $87(23.1)$ & 149 & $93.5(16.8)$ & - & $1.7 \%$ & $-6.50[-16.74,3.74]$ \\
\hline Garety 2008 a & 22 & $28(8.42)$ & 20 & $28.25(6.56)$ & - & $8.5 \%$ & $-0.25[-4.79,4.29]$ \\
\hline Haddock 2009 & 38 & $26.88(10.46)$ & 39 & $28.81(9.56)$ & - & $8.8 \%$ & $-1.93[-6.41,2.55]$ \\
\hline Lewis 2002 - Liverpool & 26 & $28.9(6.9)$ & 23 & $27.9(7.4)$ & $\sqrt{3}$ & $10.9 \%$ & $1.00[-3.02,5.02]$ \\
\hline Lewis 2002 - Manchester & 25 & $38.3(10.8)$ & 30 & $41.5(12.2)$ & - & $4.8 \%$ & $-3.20[-9.28,2.88]$ \\
\hline Lewis 2002 - Nottingham & 24 & $28.8(3.8)$ & 26 & $28.9(4.7)$ & $\rightarrow-$ & $31.6 \%$ & $-0.10[-2.46,2.26]$ \\
\hline Penn 2009 & 32 & $26(5.1)$ & 33 & $29.6(6.2)$ & - & $23.2 \%$ & $-3.60[-6.36,-0.84]$ \\
\hline Subtotal $(95 \% \mathrm{CI})$ & 204 & & 345 & & - & $100.0 \%$ & $-1.03[-2.36,0.29]$ \\
\hline \multicolumn{8}{|c|}{ Heterogeneity. $C \mathrm{hi}^{2}=8.47, \mathrm{df}=7(\mathrm{P}=0.29) ; 1^{2}=17 \%$} \\
\hline \multicolumn{8}{|c|}{$\begin{array}{l}\text { Test for overall effect: } Z=1.52(P=0.13) \\
\text { Test for subgroup differences: } C \mathrm{~h}^{2}=1.03 \text {, df }=2(P=0.60), 1^{2}=0.0 \%\end{array}$} \\
\hline \multicolumn{8}{|c|}{ Test for subgroup differences: $C \mathrm{Ch}^{2}=1.03$, df $=2(P=0.60), 1^{2}=0.0 \%$} \\
\hline & & & & & -50 & 0 & \\
\hline & & & & & erimental & & \\
\hline
\end{tabular}


Analysis 1.13

Comparison 1 CBT versus ALL OTHER

PSYCHOLOGICAL THERAPIES, Outcome 13 Mental

state: $5 \mathrm{~b}$. Specific - average score - affective symptoms depression (Beck Depression Inventory, high = poor)

Review: Cognitive behavioural therapy versus other psychosocial treatments for schizophrenia

Comparison: 1 CBT versus ALL OTHER PSYCHOLOGICAL THERAPIES

Outcome: 13 Mental state: 5 b. Specific - average score - affective symptoms - depression (Beck Depression Inventory, high = poor)

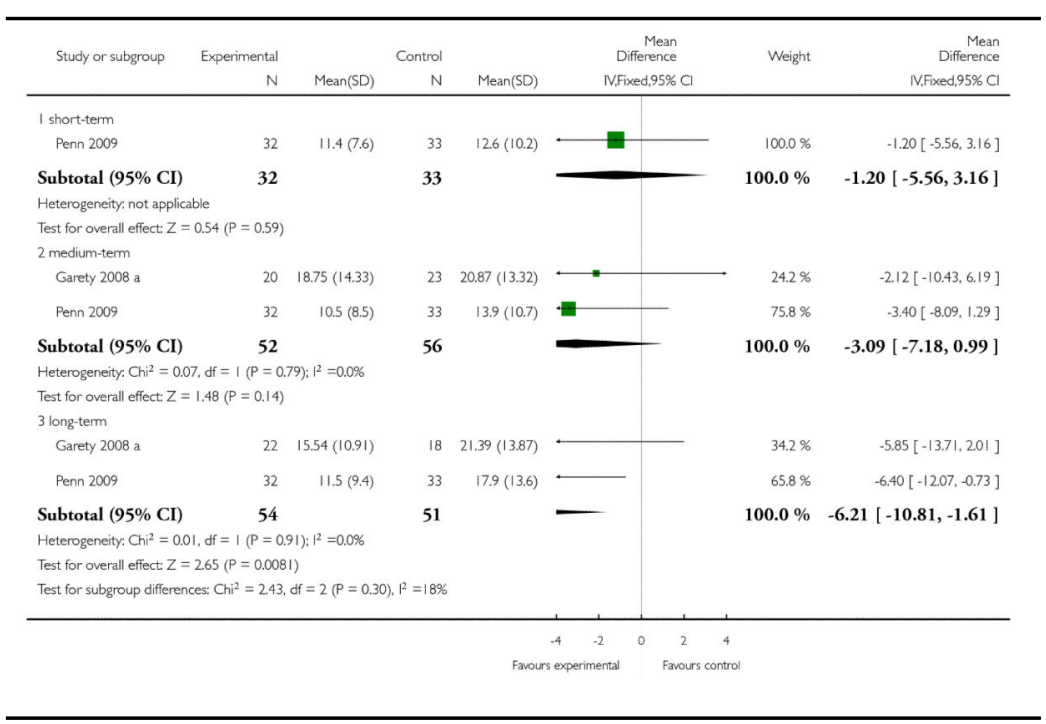


Analysis 1.14

Comparison 1 CBT versus ALL OTHER

PSYCHOLOGICAL THERAPIES, Outcome 14 Mental

state: $5 \mathrm{~g}$. Specific - average score - affective symptoms -

Anger/aggression (Novaco Anger Scale (high = poor))

Review: Cognitive behavioural therapy versus other psychosocial treatments for schizophrenia

Comparison: 1 CBT versus ALL OTHER PSYCHOLOGICAL THERAPIES

Outcome: 14 Mental state: $5 \mathrm{~g}$. Specific - average score - affective symptoms - Anger/ aggression (Novaco Anger Scale (high = poor))

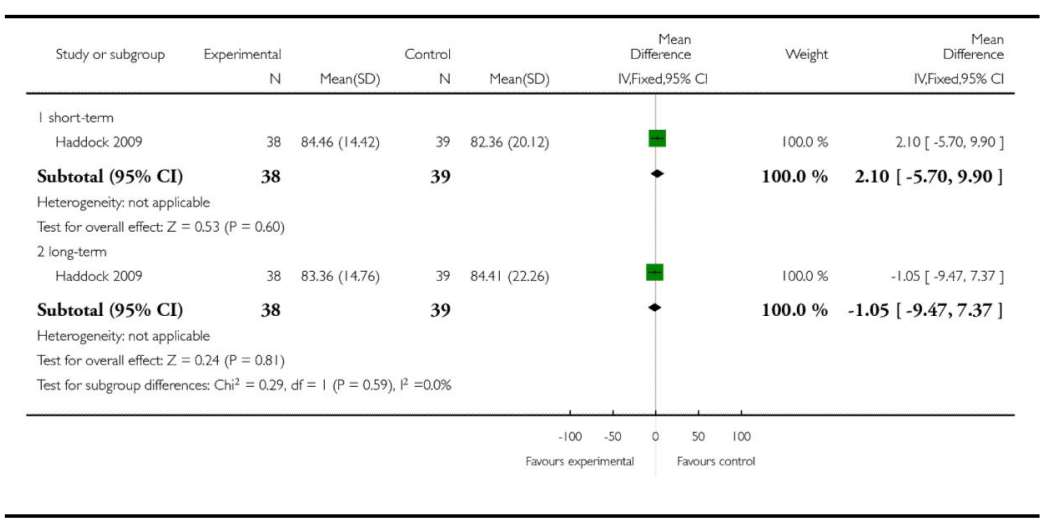


Analysis 1.15

Comparison 1 CBT versus ALL OTHER

PSYCHOLOGICAL THERAPIES, Outcome 15 Mental

state: $5 \mathrm{~d}$. Specific - average score - affective symptoms -

self esteem (Rosenberg Self Esteem Scale $($ high $=$ good $)$ )

Review: Cognitive behavioural therapy versus other psychosocial treatments for schizophrenia

Comparison: 1 CBT versus ALL OTHER PSYCHOLOGICAL THERAPIES

Outcome: 15 Mental state: $5 \mathrm{~d}$. Specific - average score - affective symptoms - self esteem $($ Rosenberg Self Esteem Scale $($ high $=$ good $))$

\begin{tabular}{|c|c|c|c|c|c|c|c|c|}
\hline Study or subgroup & $\begin{array}{r}\text { Experimental } \\
\mathrm{N}\end{array}$ & \multicolumn{3}{|c|}{ Control } & \multicolumn{2}{|c|}{$\begin{array}{c}\text { Mean } \\
\text { Difference } \\
\text { IV.Fixed,95\% Cl }\end{array}$} & Weight & $\begin{array}{r}\text { Mean } \\
\text { Difference } \\
\text { IV,Fixed,95\% CI }\end{array}$ \\
\hline \multicolumn{9}{|l|}{1 short-tem } \\
\hline Penn 2009 & 32 & $29.8(5.4)$ & 33 & $28.2(5)$ & & a & $100.0 \%$ & $1.60[-0.93,4.13]$ \\
\hline Subtotal $(95 \% \mathrm{CI})$ & 32 & & 33 & & & • & $100.0 \%$ & $1.60[-0.93,4.13]$ \\
\hline \multicolumn{9}{|c|}{ Heterogeneity, not applicable } \\
\hline \multicolumn{9}{|c|}{ Test for overal effect: $Z=1.24(P=0.22)$} \\
\hline \multicolumn{9}{|l|}{2 medium-term } \\
\hline Penn 2009 & 32 & $29.4(6)$ & 33 & $28.6(6.2)$ & & a & $100.0 \%$ & $0.80[-2.17,3.77]$ \\
\hline Subtotal $(95 \% \mathrm{CI})$ & 32 & & 33 & & & + & $100.0 \%$ & $0.80[-2.17,3.77]$ \\
\hline \multicolumn{9}{|l|}{ Heterogeneity not applicable } \\
\hline \multicolumn{9}{|c|}{ Test for overal effect: $Z=0.53(P=0.60)$} \\
\hline \multicolumn{9}{|l|}{3 long-term } \\
\hline Penn 2009 & 32 & $29.3(7.6)$ & 33 & $27.6(6.7)$ & & a & $100.0 \%$ & $1.70[-1.79,5.19]$ \\
\hline Subtotal $(95 \% \mathrm{CI})$ & 32 & & 33 & & & - & $100.0 \%$ & $1.70[-1.79,5.19]$ \\
\hline \multicolumn{9}{|c|}{ Heterogeneity not applicable } \\
\hline \multicolumn{9}{|c|}{ Test for overal effect: $Z=0.96(P=0.34)$} \\
\hline \multicolumn{9}{|c|}{ Test for subgroup differences: $C h i^{2}=0.21$, df $=2(P=0.90), 1^{2}=0.0 \%$} \\
\hline & & & & & -50 & $0 \quad 50$ & & \\
\hline
\end{tabular}


Analysis 1.16

Comparison 1 CBT versus ALL OTHER

PSYCHOLOGICAL THERAPIES, Outcome 16 Mental

state: 5e. Specific - average score - affective symptoms anxiety (Beck anxiety Inventory (high = poor))

Review: Cognitive behavioural therapy versus other psychosocial treatments for schizophrenia

Comparison: 1 CBT versus ALL OTHER PSYCHOLOGICAL THERAPIES

Outcome: 16 Mental state: 5e. Specific - average score - affective symptoms - anxiety (Beck anxiety Inventory (high $=$ poor $)$ )

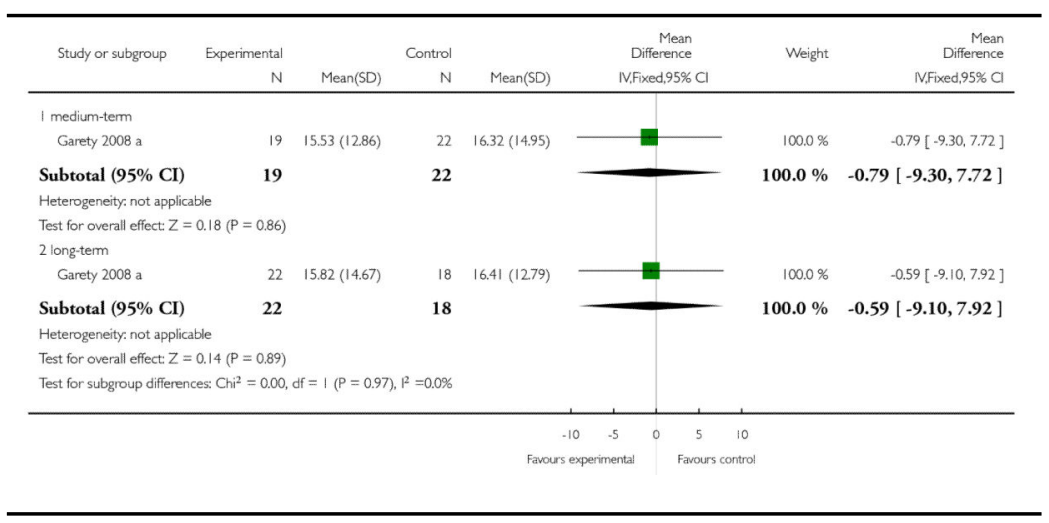


Analysis 1.17

Comparison 1 CBT versus ALL OTHER

PSYCHOLOGICAL THERAPIES, Outcome 17 Mental

state: 5f. Specific - average score - affective symptoms -

insight (Beck Cognitive Insight Scale (high = good))

Review: Cognitive behavioural therapy versus other psychosocial treatments for schizophrenia

Comparison: 1 CBT versus ALL OTHER PSYCHOLOGICAL THERAPIES

Outcome: 17 Mental state: 5f. Specific - average score - affective symptoms - insight (Beck Cognitive Insight Scale $($ high $=$ good $)$ )

\begin{tabular}{|c|c|c|c|c|c|c|c|c|}
\hline \multirow[t]{2}{*}{ Study or subgroup } & Experimental & \multicolumn{3}{|c|}{ Control } & \multicolumn{2}{|c|}{$\begin{array}{l}\text { Mean } \\
\text { Difference }\end{array}$} & \multirow[t]{2}{*}{ Weight } & \multirow{2}{*}{$\begin{array}{r}\text { Mean } \\
\text { Difference } \\
\text { IV.Fixed,95\% C }\end{array}$} \\
\hline & $\mathrm{N}$ & $\operatorname{Mean}(\mathrm{SD})$ & $\mathrm{N}$ & $\operatorname{Mean}(\mathrm{SD})$ & IV.Fixe & $\mathrm{d}, 95 \% \mathrm{Cl}$ & & \\
\hline \multicolumn{9}{|l|}{1 short-term } \\
\hline Penn 2009 & 32 & $6.7(6.3)$ & 33 & $6(5.8)$ & & $=$ & $100.0 \%$ & $0.70[-2.25,3.65]$ \\
\hline Subtotal $(95 \% \mathrm{CI})$ & 32 & & 33 & & & & $100.0 \%$ & $0.70[-2.25,3.65]$ \\
\hline \multicolumn{9}{|c|}{ Heterogeneity: not applicable } \\
\hline \multicolumn{9}{|c|}{ Test for overall effect: $Z=0.47(P=0.64)$} \\
\hline \multicolumn{9}{|l|}{2 medium-term } \\
\hline Penn 2009 & 32 & $4.2(6.6)$ & 33 & $4.7(5.4)$ & 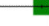 & & $100.0 \%$ & $-0.50[-3.44,2.44]$ \\
\hline Subtotal $(95 \% \mathrm{CI})$ & 32 & & 33 & & & & $100.0 \%$ & $-0.50[-3.44,2.44]$ \\
\hline \multicolumn{9}{|c|}{ Heterogeneity: not applicable } \\
\hline \multicolumn{9}{|c|}{ Test for overall effect: $Z=0.33(P=0.74)$} \\
\hline \multicolumn{9}{|l|}{3 long-term } \\
\hline Penn 2009 & 32 & $4.4(5.6)$ & 33 & $3.7(4.4)$ & & & $100.0 \%$ & $0.70[-1.75,3.15]$ \\
\hline Subtotal $(95 \% \mathrm{CI})$ & 32 & & 33 & & & & $100.0 \%$ & $0.70[-1.75,3.15]$ \\
\hline \multicolumn{9}{|c|}{ Heterogeneity: not applicable } \\
\hline \multicolumn{9}{|c|}{ Test for overall effect: $Z=0.56(P=0.58)$} \\
\hline \multicolumn{9}{|c|}{ Test for subgroup differences: $\mathrm{Ch}^{2}{ }^{2}=0.45, \mathrm{df}=2(\mathrm{P}=0.80), \mathrm{F}^{2}=0.0 \%$} \\
\hline & & & & & -2 & 2 & & \\
\hline & & & & & & Favours & & \\
\hline
\end{tabular}


Analysis 1.18

Comparison 1 CBT versus ALL OTHER

PSYCHOLOGICAL THERAPIES, Outcome 18 Mental

state: 5c. Specific - average score - affective symptoms depression (Montgomery-Asberg Depression Rating

Scale, high $=$ poor $)$

Review: Cognitive behavioural therapy versus other psychosocial treatments for schizophrenia

Comparison: 1 CBT versus ALL OTHER PSYCHOLOGICAL THERAPIES

Outcome: 18 Mental state: 5c. Specific - average score - affective symptoms - depression (Montgomery-Asberg Depression Rating Scale, high = poor)

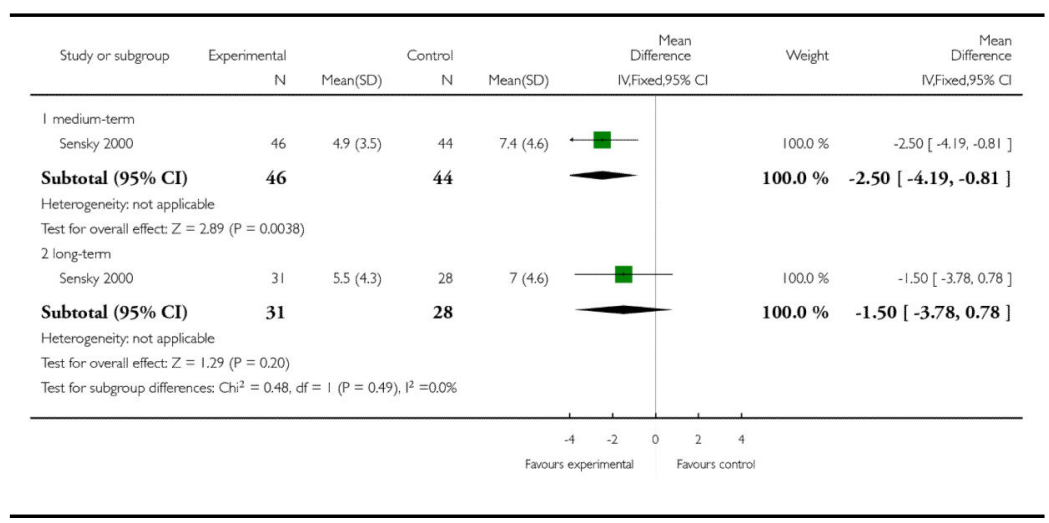




\section{Analysis 1.19}

Comparison 1 CBT versus ALL OTHER

PSYCHOLOGICAL THERAPIES, Outcome 19 Mental

state: 6a. Specific - average score - problem behaviours

$($ Novaco Provocation Inventory, high = poor)

Review: Cognitive behavioural therapy versus other psychosocial treatments for schizophrenia

Comparison: 1 CBT versus ALL OTHER PSYCHOLOGICAL THERAPIES

Outcome: 19 Mental state: 6a. Specific - average score - problem behaviours (Novaco

Provocation Inventory, high $=$ poor)

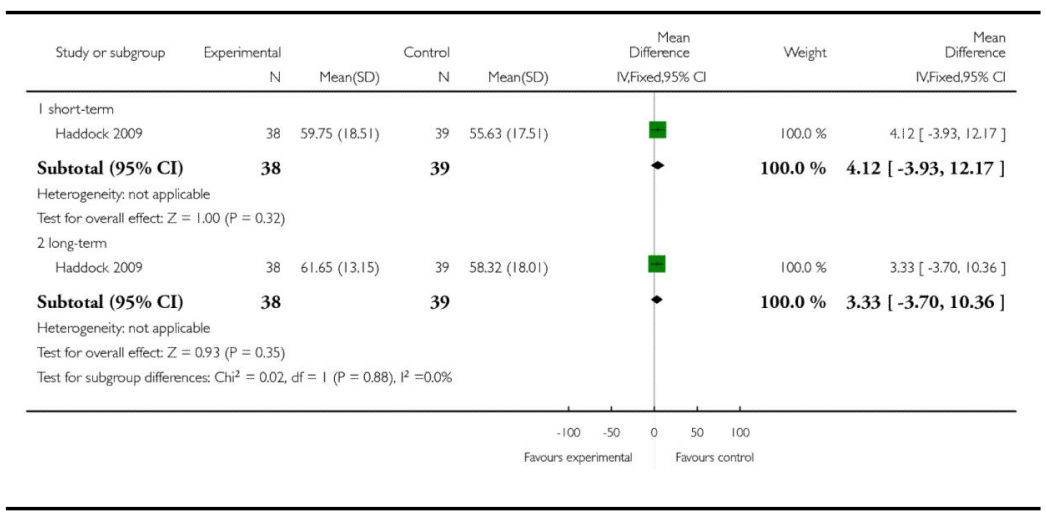

Analysis 1.20

Comparison 1 CBT versus ALL OTHER

PSYCHOLOGICAL THERAPIES, Outcome 20 Mental state: 6b. Specific - average score - problem behaviours (Ward Anger Rating Scale, high = poor)

Review: Cognitive behavioural therapy versus other psychosocial treatments for schizophrenia

Comparison: 1 CBT versus ALL OTHER PSYCHOLOGICAL THERAPIES

Outcome: 20 Mental state: 6b. Specific - average score - problem behaviours (Ward Anger Rating Scale, high = poor)

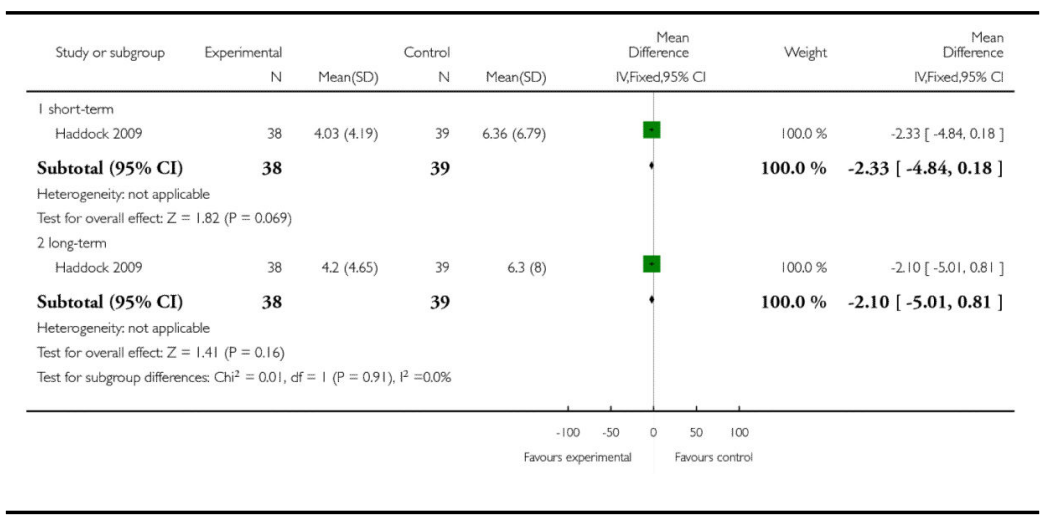


Analysis 1.21

Comparison 1 CBT versus ALL OTHER

PSYCHOLOGICAL THERAPIES, Outcome 21 Mental

state: 6c. Specific - average score - problem behaviours

(HCR-20 risk management, high poor) - long-term only

Review: Cognitive behavioural therapy versus other psychosocial treatments for schizophrenia

Comparison: 1 CBT versus ALL OTHER PSYCHOLOGICAL THERAPIES

Outcome: 21 Mental state: 6c. Specific - average score - problem behaviours (HCR-20 risk management, high poor) - long-term only

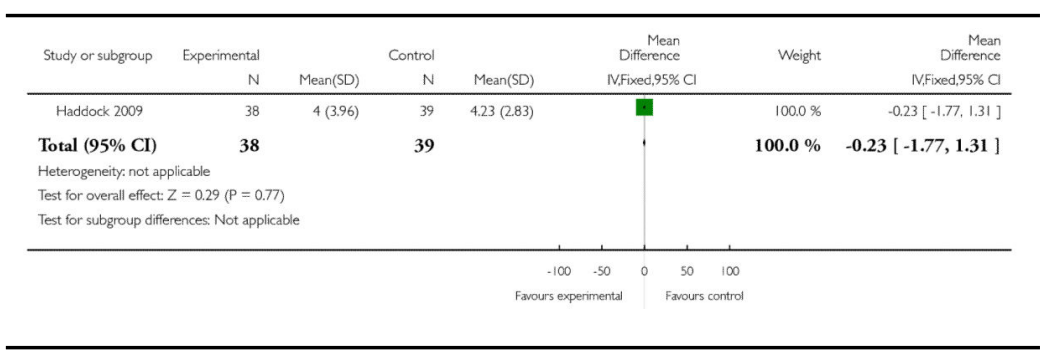

Analysis 1.22

Comparison 1 CBT versus ALL OTHER

PSYCHOLOGICAL THERAPIES, Outcome 22 Mental

state: 6d. Specific - average score - problem behaviour

$($ HCR - 20 clinical scale, high = poor $)$ - long-term only

Review: Cognitive behavioural therapy versus other psychosocial treatments for schizophrenia

Comparison: 1 CBT versus ALL OTHER PSYCHOLOGICAL THERAPIES

Outcome: 22 Mental state: 6d. Specific - average score - problem behaviour (HCR - 20 clinical scale, high = poor) - long-term only

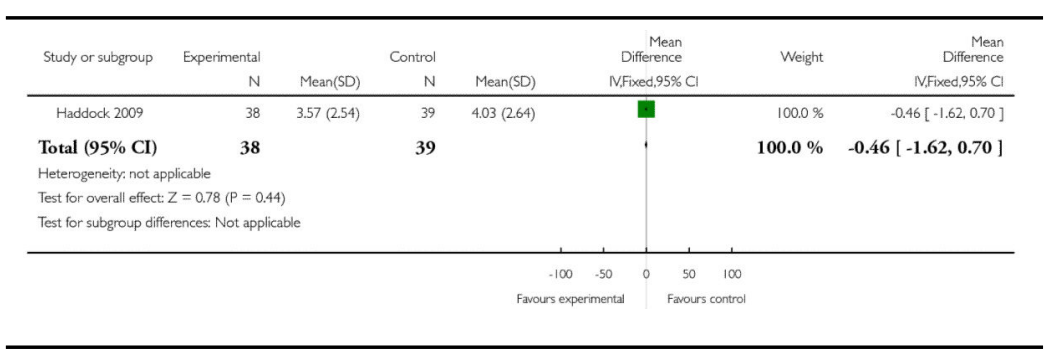


Analysis 1.23

Comparison 1 CBT versus ALL OTHER

PSYCHOLOGICAL THERAPIES, Outcome 23 Global state: 1. Relapse/rehospitalisation

Review: Cognitive behavioural therapy versus other psychosocial treatments for schizophrenia

Comparison: 1 CBT versus ALL OTHER PSYCHOLOGICAL THERAPIES

Outcome: 23 Global state: 1. Relapse/rehospitalisation

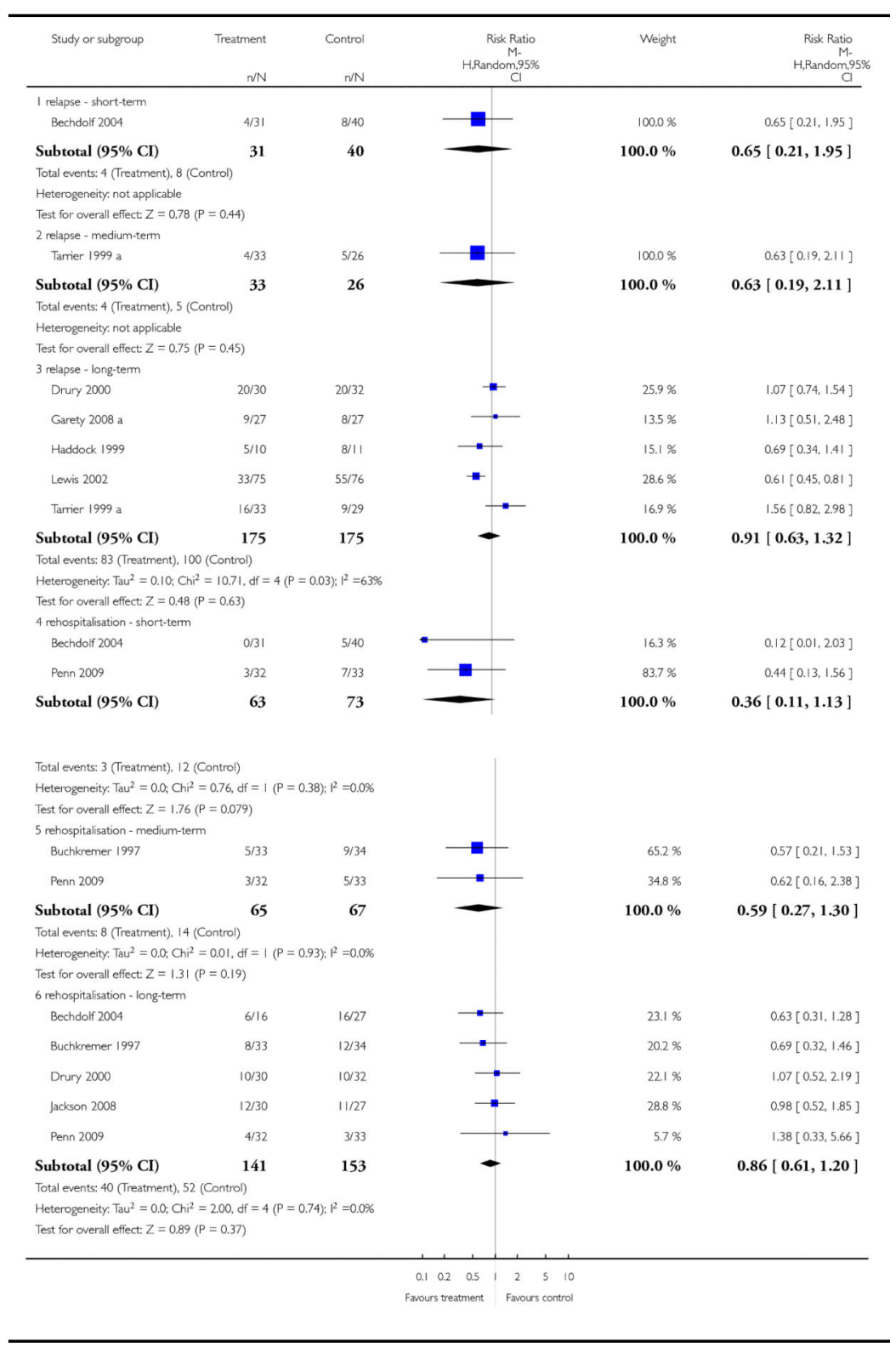


Analysis 1.24

Comparison 1 CBT versus ALL OTHER

PSYCHOLOGICAL THERAPIES, Outcome 24 Global

state: 2. Various outcomes

Review: Cognitive behavioural therapy versus other psychosocial treatments for schizophrenia

Comparison: 1 CBT versus ALL OTHER PSYCHOLOGICAL THERAPIES

Outcome: 24 Global state: 2. Various outcomes

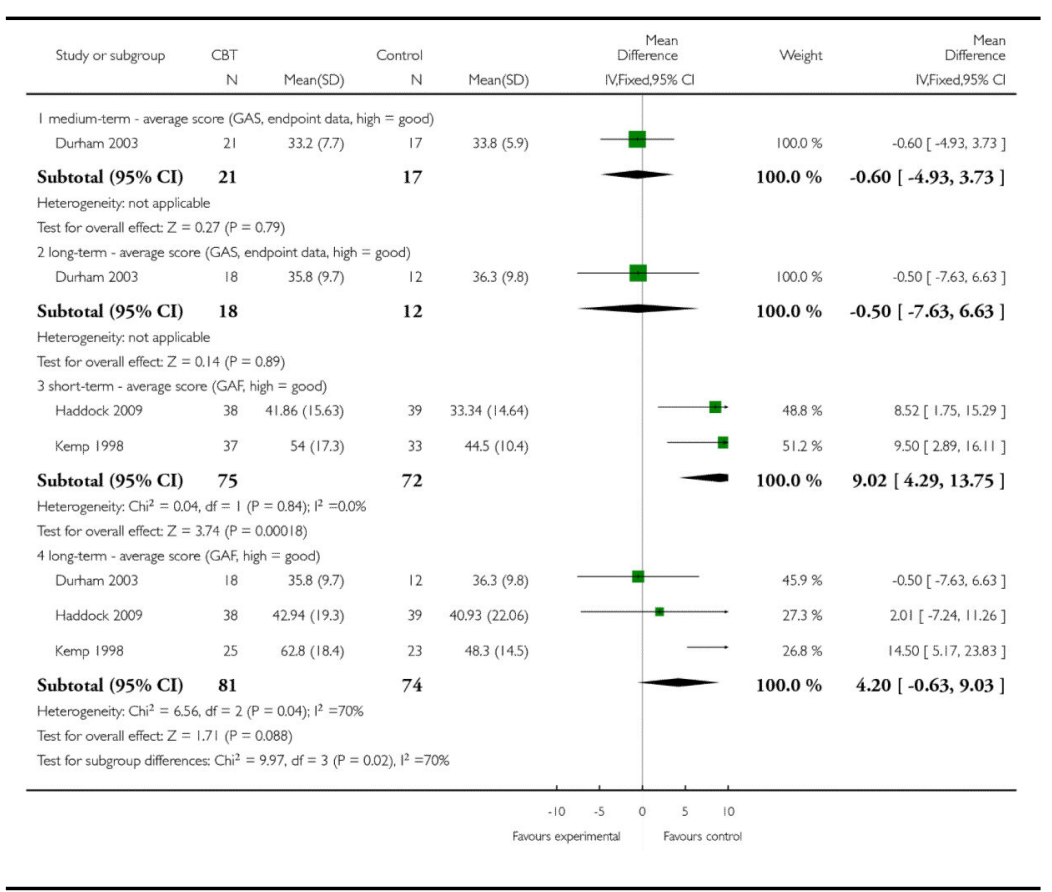


Analysis 1.25

Comparison 1 CBT versus ALL OTHER

PSYCHOLOGICAL THERAPIES, Outcome 25 Global state: 3a. Social functioning - average scores (Social

Functioning Scale, high $=$ good)

Review: Cognitive behavioural therapy versus other psychosocial treatments for schizophrenia

Comparison: 1 CBT versus ALL OTHER PSYCHOLOGICAL THERAPIES

Outcome: 25 Global state: 3a. Social functioning - average scores (Social Functioning Scale, high $=$ good)

\begin{tabular}{|c|c|c|c|c|c|c|c|c|}
\hline \multirow[t]{2}{*}{ Study or subgroup } & \multirow{2}{*}{$\begin{array}{r}\text { Experimental } \\
\mathrm{N}\end{array}$} & \multicolumn{3}{|c|}{ Control } & \multirow{2}{*}{\multicolumn{2}{|c|}{$\begin{array}{c}\text { Mean } \\
\text { Difference } \\
\text { IV,Fixed,95\% C }\end{array}$}} & \multirow[t]{2}{*}{ Weight } & \multirow{2}{*}{$\begin{array}{r}\text { Mean } \\
\text { Difference } \\
\text { NFixed,95\% Cl } \\
\end{array}$} \\
\hline & & $\operatorname{Mean}(S D)$ & $\mathrm{N}$ & $\operatorname{Mean}(\mathrm{SD})$ & & & & \\
\hline \multicolumn{9}{|l|}{ I short-term } \\
\hline Penn 2009 & 32 & $129.6(21.1)$ & 33 & $124.2(22.4)$ & & : & $100.0 \%$ & $5.40[-5.18,15.98]$ \\
\hline Subtotal $(95 \% \mathrm{CI})$ & 32 & & 33 & & & - & $100.0 \%$ & $5.40[-5.18,15.98]$ \\
\hline \multicolumn{9}{|l|}{ Heterogeneity, not appicable } \\
\hline \multicolumn{9}{|c|}{ Test for overall effect: $Z=1.00(P=0.32)$} \\
\hline \multicolumn{9}{|c|}{2 medium-term } \\
\hline Penn 2009 & 32 & $129.1(20.5)$ & 33 & $121.9(23.3)$ & & E & $100.0 \%$ & $7.20[-3.46,17.86]$ \\
\hline Subtotal $(95 \% \mathrm{CI})$ & 32 & & 33 & & & - & $100.0 \%$ & $7.20[-3.46,17.86]$ \\
\hline \multicolumn{9}{|c|}{ Heterogeneity, not applicable } \\
\hline \multicolumn{9}{|c|}{ Test for overal effect: $Z=1.32(P=0.19)$} \\
\hline \multicolumn{9}{|l|}{3 long-term } \\
\hline Penn 2009 & 32 & $128.5(28.5)$ & 33 & $119.7(24.2)$ & & 분 & $100.0 \%$ & $8.80[-4.07,21.67]$ \\
\hline Subtotal $(95 \% \mathrm{CI})$ & 32 & & 33 & & & - & $100.0 \%$ & $8.80[-4.07,21.67]$ \\
\hline \multicolumn{9}{|c|}{ Heterogeneity, not applicable } \\
\hline \multicolumn{9}{|c|}{ Test for overall effect: $Z=1.34(P=0.18)$} \\
\hline \multicolumn{9}{|c|}{ Test for subgroup differences: $\mathrm{Ch}^{2}=0.16$, df $=2(\mathbb{P}=0.92), 1^{2}=0.0 \%$} \\
\hline & & & & & .50 & $0 \quad 50$ & & \\
\hline & & & & Favour & immental & Favour: & & \\
\hline
\end{tabular}


Analysis 1.26

Comparison 1 CBT versus ALL OTHER

PSYCHOLOGICAL THERAPIES, Outcome 26 Global state: $3 b$. Social functioning - average scores (Social and Occupational Functioning Assessment Scale, high = good)

Review: Cognitive behavioural therapy versus other psychosocial treatments for schizophrenia Comparison: 1 CBT versus ALL OTHER PSYCHOLOGICAL THERAPIES

Outcome: 26 Global state: 3b. Social functioning - average scores (Social and Occupational Functioning Assessment Scale, high = good)

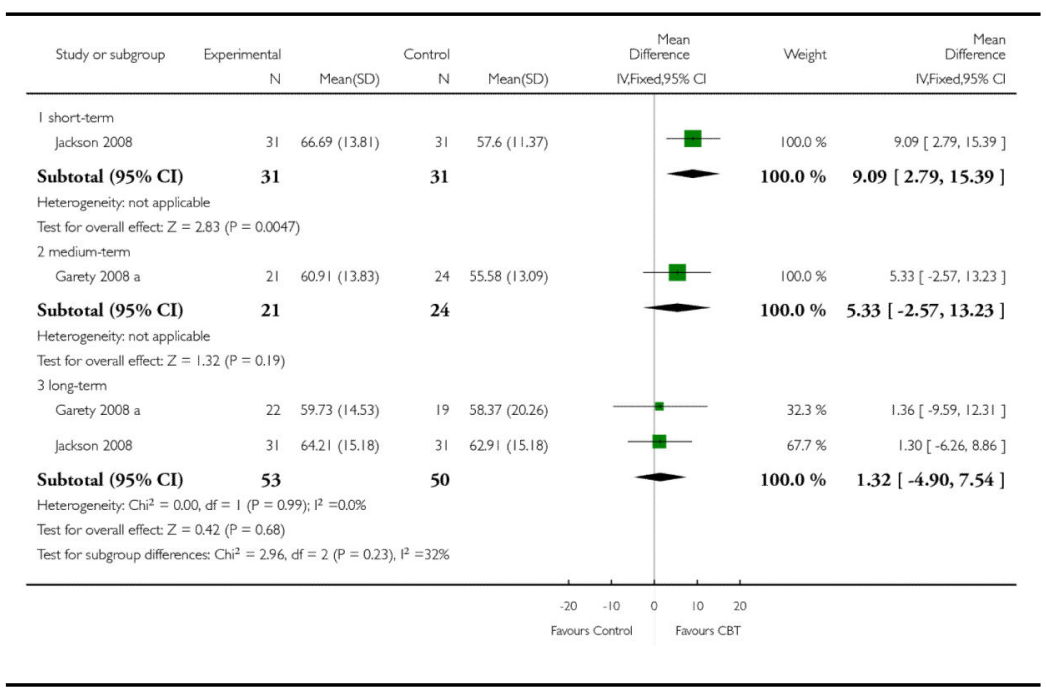


Analysis 1.27

Comparison 1 CBT versus ALL OTHER

PSYCHOLOGICAL THERAPIES, Outcome 27

Quality of life: Average score (EuroQOL, high = good) long-term only

Review: Cognitive behavioural therapy versus other psychosocial treatments for schizophrenia

Comparison: 1 CBT versus ALL OTHER PSYCHOLOGICAL THERAPIES

Outcome: 27 Quality of life: Average score (EuroQOL, high = good) - long-term only

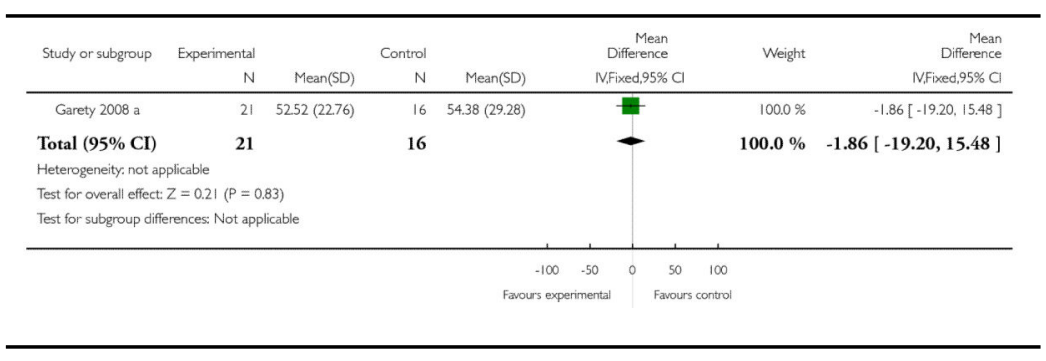

Analysis 1.28

Comparison 1 CBT versus ALL OTHER

PSYCHOLOGICAL THERAPIES, Outcome 28

Satisfaction with treatment: 1. Attitude to medication average score - short-term

Review: Cognitive behavioural therapy versus other psychosocial treatments for schizophrenia

Comparison: 1 CBT versus ALL OTHER PSYCHOLOGICAL THERAPIES

Outcome: 28 Satisfaction with treatment: 1 . Attitude to medication - average score - shortterm

\begin{tabular}{|c|c|c|c|c|c|c|c|c|}
\hline Study or subgroup & $\begin{array}{r}\text { CBT } \\
\mathrm{N} \\
\end{array}$ & \multicolumn{3}{|c|}{ Control } & \multicolumn{2}{|c|}{$\begin{array}{c}\text { Mean } \\
\text { Difference } \\
\text { iv.Fixed.95\% CI }\end{array}$} & Weight & $\begin{array}{r}\text { Mean } \\
\text { Difference } \\
\text { IVFixixd,95\% C }\end{array}$ \\
\hline \multicolumn{9}{|c|}{1 Attitude to Medication Questionnaire (high $=$ good) } \\
\hline Kemp 1998 & 39 & $19.4(3.7)$ & 35 & $14.9(6.1)$ & & 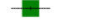 & $100.0 \%$ & $4.50[2.17,6.83]$ \\
\hline Subtotal $(95 \% \mathrm{CI})$ & 39 & & 35 & & & $\sim$ & $100.0 \%$ & $4.50[2.17,6.83]$ \\
\hline \multirow{2}{*}{\multicolumn{9}{|c|}{$\begin{array}{l}\text { Heterogeneity: not applicable } \\
\text { Test for overall effect: } Z=3.78 \text { ( } P=0.00015)\end{array}$}} \\
\hline & & & & & & & & \\
\hline \multicolumn{9}{|c|}{2 Drug Attitude Inventory (high $=$ good) } \\
\hline Kemp 1998 & 35 & $50.1(6.3)$ & 28 & $44.4(8.1)$ & & $\tau-$ & $100.0 \%$ & $5.70[2.05,9.35]$ \\
\hline Subtotal $(95 \% \mathrm{CI})$ & 35 & & 28 & & & $\sim$ & $100.0 \%$ & $5.70[2.05,9.35]$ \\
\hline \multicolumn{9}{|l|}{ Heterogeneity not applicable } \\
\hline \multirow{2}{*}{\multicolumn{9}{|c|}{$\begin{array}{l}\text { Test for overall effect: } Z=3.06(P=0.0022) \\
\text { Test for subgroup differences: } C \text { hi }{ }^{2}=0.29 . \mathrm{df}=1(P=0.59) \cdot \mathrm{H}^{2}=0.0 \%\end{array}$}} \\
\hline \multicolumn{7}{|c|}{ Test for subgroup differences: $C h i^{2}=0.29, \mathrm{df}=1(P=0.59), 1^{2}=0.0 \%$} & & \\
\hline & & & & & $\begin{array}{l}-10 \quad-5 \\
\text { Farours control }\end{array}$ & $\begin{array}{cc}5 & 10 \\
\text { Farours CBT }\end{array}$ & & \\
\hline
\end{tabular}


Analysis 1.29

Comparison 1 CBT versus ALL OTHER

PSYCHOLOGICAL THERAPIES, Outcome 29

Satisfaction with treatment: 2 . Leaving the study early

Review: Cognitive behavioural therapy versus other psychosocial treatments for schizophrenia

Comparison: 1 CBT versus ALL OTHER PSYCHOLOGICAL THERAPIES

Outcome: 29 Satisfaction with treatment: 2 . Leaving the study early

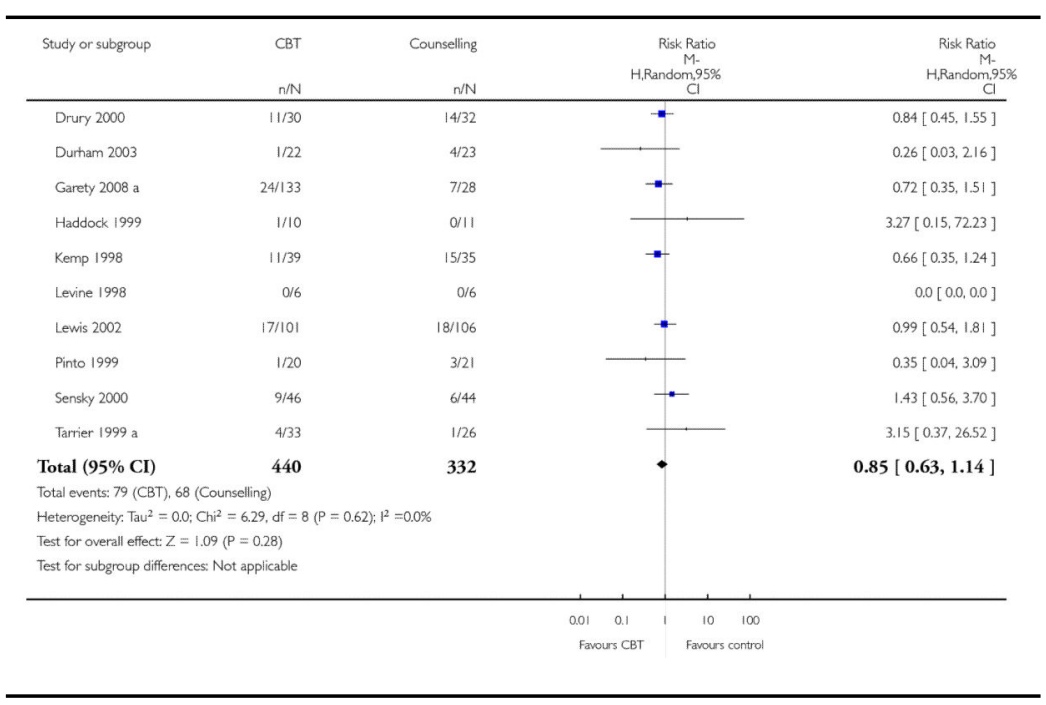

Analysis 2.1

Comparison 2 SUBGROUP 1: CBT versus "NONACTIVE" THERAPIES, Outcome 1 Adverse effect/ event: Death

Review: Cognitive behavioural therapy versus other psychosocial treatments for schizophrenia

Comparison: 2 SUBGROUP 1: CBT versus “NON-ACTIVE” THERAPIES

Outcome: 1 Adverse effect/event: Death

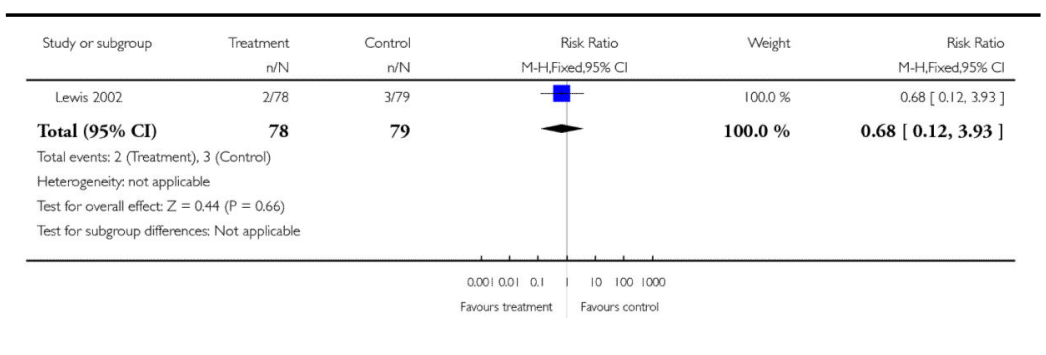




\section{Analysis 2.2}

Comparison 2 SUBGROUP 1: CBT versus "NON-

ACTIVE" THERAPIES, Outcome 2 Mental state: 1.

General - no important or reliable change

Review: Cognitive behavioural therapy versus other psychosocial treatments for schizophrenia

Comparison: 2 SUBGROUP 1: CBT versus "NON-ACTIVE” THERAPIES

Outcome: 2 Mental state: 1 . General - no important or reliable change

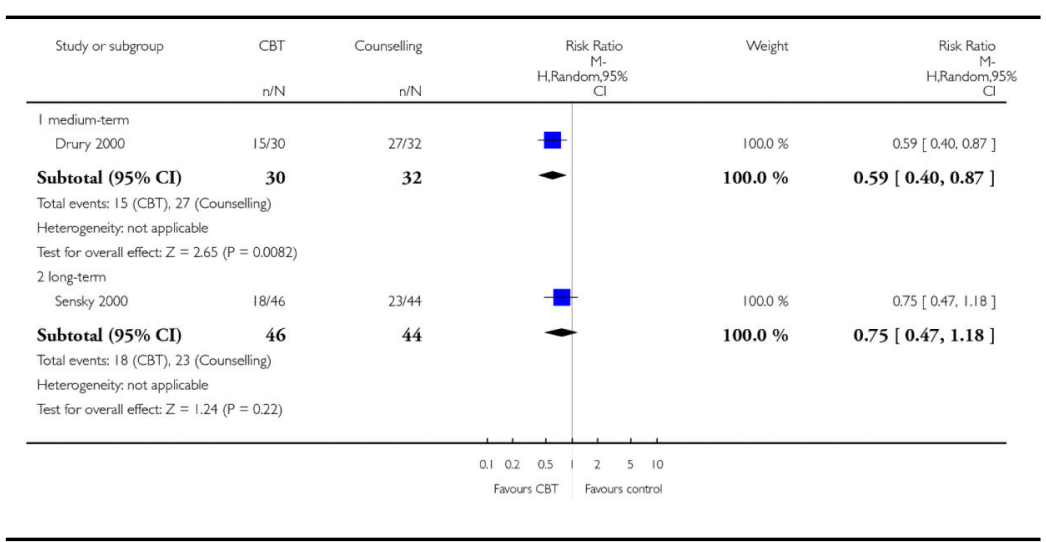

Analysis 2.3

Comparison 2 SUBGROUP 1: CBT versus "NON-

ACTIVE" THERAPIES, Outcome 3 Mental state: $2 a$.

General - average score - total $($ BPRS, high = poor)

Review: Cognitive behavioural therapy versus other psychosocial treatments for schizophrenia

Comparison: 2 SUBGROUP 1: CBT versus "NON-ACTIVE" THERAPIES

Outcome: 3 Mental state: $2 \mathrm{a}$. General - average score - total (BPRS, high = poor)

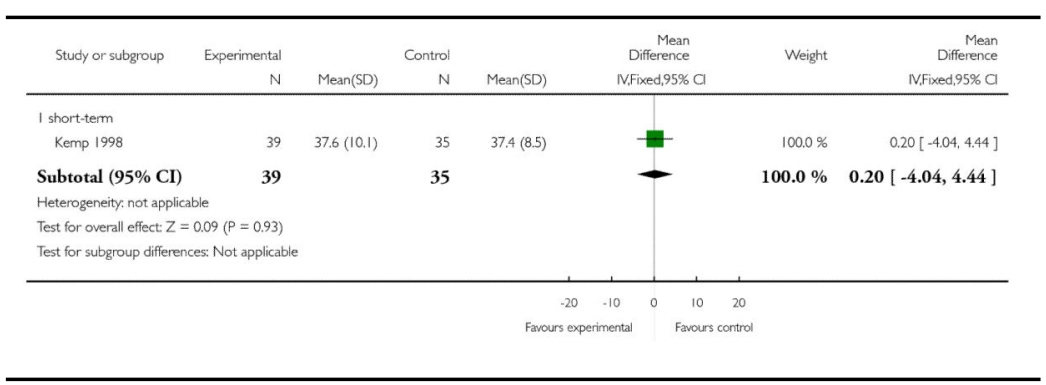


Analysis 2.4

Comparison 2 SUBGROUP 1: CBT versus "NON-

ACTIVE" THERAPIES, Outcome 4 Mental state: 2 b.

General - average score - total (PANSS, endpoint data, high $=$ poor $)$

Review: Cognitive behavioural therapy versus other psychosocial treatments for schizophrenia

Comparison: 2 SUBGROUP 1: CBT versus "NON-ACTIVE" THERAPIES

Outcome: 4 Mental state: 2b. General - average score - total (PANSS, endpoint data, high = poor)

\begin{tabular}{|c|c|c|c|c|c|c|c|}
\hline \multirow[t]{2}{*}{ Study or subgroup } & \multirow{2}{*}{$\begin{array}{r}\text { Treatment } \\
\mathrm{N}\end{array}$} & \multicolumn{3}{|c|}{ Control } & \multirow{2}{*}{$\begin{array}{c}\text { Mean } \\
\text { Difference } \\
\text { N.Fixed,95\% C }\end{array}$} & \multirow[t]{2}{*}{ Weight } & \multirow{2}{*}{$\begin{array}{r}\text { Mean } \\
\text { Dfference } \\
\text { IV.Fixed, } 95 \% \text { CI }\end{array}$} \\
\hline & & $\operatorname{Mean}(\mathrm{SD})$ & $\mathrm{N}$ & $\operatorname{Mean}(\mathrm{SD})$ & & & \\
\hline \multicolumn{8}{|l|}{ I short-term } \\
\hline Lewis 2002 & 78 & $61.73(19.69)$ & 7I & $59.96(16.39)$ & - & $100.0 \%$ & $1.77[-4.03,7.57]$ \\
\hline Subtotal $(95 \% \mathrm{CI})$ & 78 & & 71 & & & $100.0 \%$ & $1.77[-4.03,7.57]$ \\
\hline \multicolumn{8}{|l|}{ Heterogeneity: not applicable } \\
\hline \multicolumn{8}{|c|}{ Test for overall effect: $Z=0.60(P=0.55)$} \\
\hline \multicolumn{8}{|c|}{2 long-term } \\
\hline Haddock 2009 & 38 & $53.97(20.27)$ & 39 & $57.73(16.31)$ & $=$ & $17.3 \%$ & $-3.76[-11.99,4.47]$ \\
\hline Lewis 2002 - Liverpool & 26 & $53.7(13.3)$ & 23 & $53(14.6)$ & - & $19.0 \%$ & $0.70[-7.16,8.56]$ \\
\hline Lewis 2002 - Manchester & 25 & $71.2(15.8)$ & 30 & $76.6(21.7)$ & 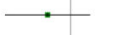 & $11.9 \%$ & $-5.40[-15.33,4.53]$ \\
\hline Lewis 2002 - Nottingham & 24 & $51.5(7.5)$ & 26 & $51.4(9.6)$ & $\rightarrow$ & $51.8 \%$ & $0.10[-4.66,4.86]$ \\
\hline Subtotal $(95 \% \mathrm{CI})$ & 113 & & 118 & & - & $100.0 \%$ & $-1.11[-4.53,2.32]$ \\
\hline \multirow{2}{*}{\multicolumn{8}{|c|}{$\begin{array}{l}\text { Heterogencity: } \mathrm{Ch}^{2}=1.57, \mathrm{df}=3(P=0.67) ; 1^{2}=0.0 \% \\
\text { Test for overall effect: } Z=0.63(P=0.53)\end{array}$}} \\
\hline & & & & & & & \\
\hline \multicolumn{8}{|c|}{$\begin{array}{ccccc}-20 & -10 & 0 & 10 & 20 \\
\text { Favours teatment } & & \text { Facours control }\end{array}$} \\
\hline
\end{tabular}


Analysis 2.5

Comparison 2 SUBGROUP 1: CBT versus "NON-

ACTIVE" THERAPIES, Outcome 5 Mental state: 3a.

Specific - average score - positive symptoms - overall

(PANSS, endpoint data, high = poor)

Review: Cognitive behavioural therapy versus other psychosocial treatments for schizophrenia

Comparison: 2 SUBGROUP 1: CBT versus “NON-ACTIVE” THERAPIES

Outcome: 5 Mental state: 3 a. Specific - average score - positive symptoms - overall (PANSS, endpoint data, high $=$ poor $)$

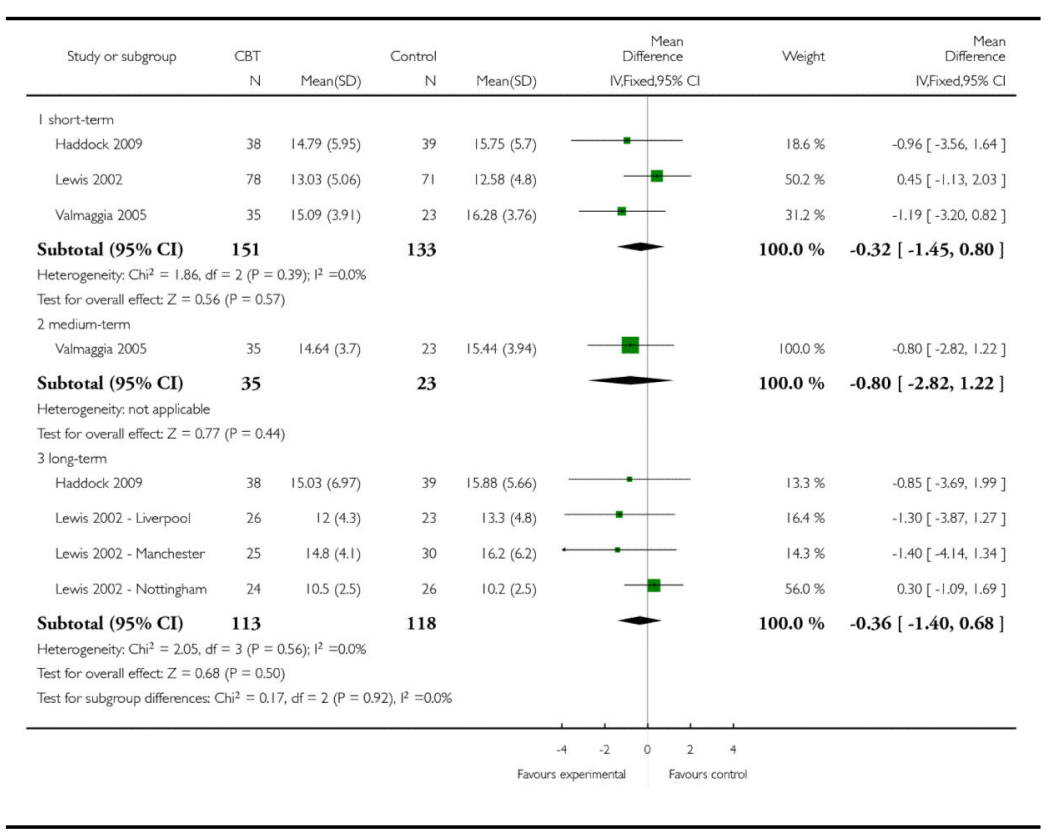


Analysis 2.6

Comparison 2 SUBGROUP 1: CBT versus "NON-

ACTIVE" THERAPIES, Outcome 6 Mental state: $3 \mathrm{~b}$.

Specific - average score - positive symptoms -

hallucinations (Psychotic Symptom Rating Scale, high = poor)

Review: Cognitive behavioural therapy versus other psychosocial treatments for schizophrenia

Comparison: 2 SUBGROUP 1: CBT versus "NON-ACTIVE" THERAPIES

Outcome: 6 Mental state: 3 b. Specific - average score - positive symptoms - hallucinations (Psychotic Symptom Rating Scale, high = poor)

\begin{tabular}{|c|c|c|c|c|c|c|c|c|}
\hline \multirow[t]{2}{*}{ Study or subgroup } & \multirow{2}{*}{$\begin{array}{r}\text { Experimental } \\
N\end{array}$} & \multicolumn{3}{|c|}{ Control } & \multirow{2}{*}{\multicolumn{2}{|c|}{$\begin{array}{c}\text { Mean } \\
\text { Difference } \\
\text { IV.Fixed,95\% C }\end{array}$}} & \multirow[t]{2}{*}{ Weight } & \multirow{2}{*}{$\begin{array}{r}\text { Mean } \\
\text { Difference } \\
\text { IV.Fixed,95\% Cl }\end{array}$} \\
\hline & & $\operatorname{Mean}(S D)$ & $\mathrm{N}$ & $\operatorname{Mean}(S D)$ & & & & \\
\hline \multicolumn{9}{|l|}{ I short-term } \\
\hline Haddock 2009 & 38 & $9.74(13.92)$ & 39 & $11.38(15.13)$ & & 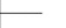 & $31.3 \%$ & $-1.64[-8.13,4.85]$ \\
\hline Lewis 2002 & 47 & $6.15(10.31)$ & 41 & $6.41(10.61)$ & & & $68.7 \%$ & $-0.26[-4.65,4.13]$ \\
\hline Subtotal $(95 \% \mathrm{CI})$ & 85 & & 80 & & & & $100.0 \%$ & $-0.69[-4.33,2.94]$ \\
\hline \multicolumn{9}{|c|}{ Heterogeneity: $C i^{2}=0.12$, of $=1(P=0.73) ; 1^{2}=0.0 \%$} \\
\hline \multicolumn{9}{|c|}{ Test for overall effect: $Z=0.37(P=0.71)$} \\
\hline \multicolumn{9}{|l|}{2 long-term } \\
\hline Haddock 2009 & 38 & $9.36(12.72)$ & 39 & 10.38 (16.63) & & & $30.2 \%$ & $-1.02[-7.62,5.58]$ \\
\hline Lewis 2002 - Liverpool & & $0.0001(0.00001)$ & 11 & $9.5(14.4)$ & $=$ & & $18.2 \%$ & $-9.50[-18.01,-0.99]$ \\
\hline Lewis 2002 - Manchester & 15 & $7.1(12.5)$ & 20 & $14.2(16.2)$ & $\longleftarrow$ & - & $14.5 \%$ & $-7.10[-16.61,241]$ \\
\hline Lewis 2002 - Nottingham & 14 & $4.4(8.9)$ & 15 & $2.7(7.3)$ & & $\mp$ & $37.2 \%$ & $1.70[-4.25,7.65]$ \\
\hline Subtotal $(95 \% \mathrm{CI})$ & 78 & & 85 & & & & $100.0 \%$ & $-2.43[-6.06,1.19]$ \\
\hline \multirow{3}{*}{\multicolumn{9}{|c|}{$\begin{array}{l}\text { Heterogeneity: } C \mathrm{Ch}^{2}=5.61, \mathrm{df}=3(\mathrm{P}=0.13) ; 1^{2}=46 \% \\
\text { Test for overall effect } Z=1.32(\mathrm{P}=0.19) \\
\text { Test for subgroup differences: } C \mathrm{Ch}^{2}=0.44, \mathrm{df}=1(\mathrm{P}=0\end{array}$}} \\
\hline & & & & & & & & \\
\hline & & & & & & & & \\
\hline & & & & & $.10 \quad .5$ & 5 & 10 & \\
\hline
\end{tabular}


Analysis 2.7

Comparison 2 SUBGROUP 1: CBT versus "NON-

ACTIVE" THERAPIES, Outcome 7 Mental state: 3c.

Specific - average score - positive symptoms - delusions

(Psychotic Symptom Rating Scale, high = poor)

Review: Cognitive behavioural therapy versus other psychosocial treatments for schizophrenia

Comparison: 2 SUBGROUP 1: CBT versus “NON-ACTIVE” THERAPIES

Outcome: 7 Mental state: 3c. Specific - average score - positive symptoms - delusions (Psychotic Symptom Rating Scale, high = poor)

\begin{tabular}{|c|c|c|c|c|c|c|c|c|}
\hline Study or subgroup & $\begin{array}{r}\text { Experimental } \\
\mathrm{N}\end{array}$ & \multicolumn{3}{|c|}{ Control } & \multicolumn{2}{|c|}{$\begin{array}{c}\text { Mean } \\
\text { Difference } \\
\text { IVFFixed,95\% C }\end{array}$} & Weight & $\begin{array}{r}\text { Mear } \\
\text { Difference } \\
\text { IV Fixed,95\% C }\end{array}$ \\
\hline \multicolumn{9}{|l|}{ I short-term } \\
\hline Haddock 2009 & 38 & $4.9(6.55)$ & 39 & $11.04(6.7)$ & $\leftarrow$ & & $40.0 \%$ & $-6.14[-9.10,-3.18]$ \\
\hline Lewis 2002 & 74 & $6.95(7.66)$ & 67 & $6.13(6.98)$ & & \pm & $60.0 \%$ & $0.82[-1.60,3.24]$ \\
\hline Subtotal $(95 \% \mathrm{CI})$ & 112 & & 106 & & & & $100.0 \%$ & $-1.96[-3.84,-0.09]$ \\
\hline \multicolumn{9}{|c|}{ Heterogeneity: $\mathrm{Ch}^{2}=12.75, \mathrm{df}=1(\mathrm{P}=0.00036) ;{ }^{2}=92 \%$} \\
\hline \multicolumn{9}{|c|}{ Test for overall effect: $Z=2.06(P=0.040)$} \\
\hline \multicolumn{9}{|l|}{2 long-term } \\
\hline Haddock 2009 & 38 & $7.6(8.25)$ & 39 & $8.38(8.03)$ & $\longmapsto$ & & $23.9 \%$ & $-0.78[-4.42,2.86]$ \\
\hline Lewis 2002 - Liverpool & 24 & $3.5(6)$ & 23 & $5.9(7.3)$ & " & - & $21.5 \%$ & $-2.40[-6.23,1.43]$ \\
\hline Lewis 2002 - Manchester & 25 & $8.9(6.9)$ & 27 & $9.2(8.1)$ & & & $19.0 \%$ & $-0.30[-4,38,3.78]$ \\
\hline Lewis 2002 - Nottingham & 23 & $5.5(5.3)$ & 25 & $6.4(5.2)$ & \pm & & $35.7 \%$ & $-0.90[-3.87,2.07]$ \\
\hline Subtotal $(95 \% \mathrm{CI})$ & 110 & & 114 & & & & $100.0 \%$ & $-1.08[-2.86,0.70]$ \\
\hline \multirow{2}{*}{\multicolumn{9}{|c|}{ Heterogeneity: $\mathrm{Ch}^{2}=0.64$, of $=3(\mathrm{P}=0.89) ;\left.\right|^{2}=0.0 \%$}} \\
\hline \multicolumn{8}{|c|}{ Test for overall effect: $Z=1.19(P=0.23)$} & \\
\hline \multicolumn{9}{|c|}{ Test for subgroup differences: $C \mathrm{i}^{2}=0.45, \mathrm{df}=1(\mathrm{P}=0.50), \mathrm{I}^{2}=0.0 \%$} \\
\hline & & & & & $-4 \quad-2$ & 2 & 4 & \\
\hline
\end{tabular}


Analysis 2.8

Comparison 2 SUBGROUP 1: CBT versus "NON-

ACTIVE" THERAPIES, Outcome 8 Mental state: 4 a.

Specific - average score - negative symptoms - overall

(PANSS, endpoint data, high = poor)

Review: Cognitive behavioural therapy versus other psychosocial treatments for schizophrenia

Comparison: 2 SUBGROUP 1: CBT versus “NON-ACTIVE” THERAPIES

Outcome: 8 Mental state: 4a. Specific - average score - negative symptoms - overall (PANSS, endpoint data, high $=$ poor $)$

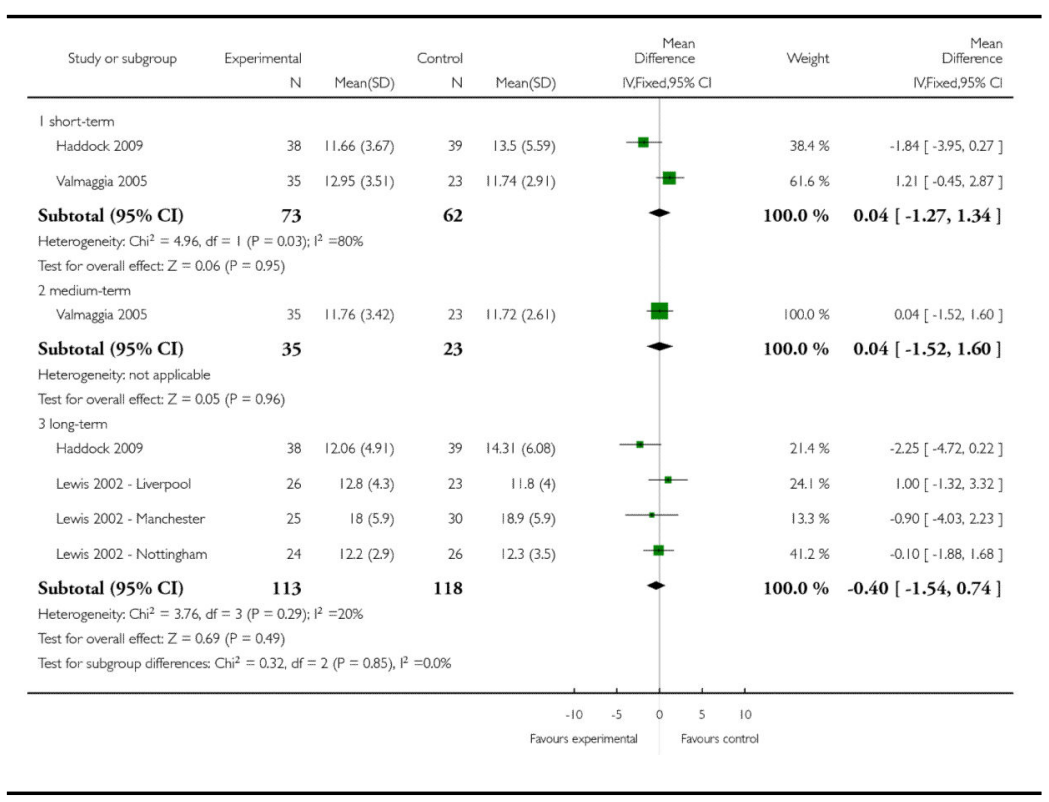


Analysis 2.9

Comparison 2 SUBGROUP 1: CBT versus "NON-

ACTIVE" THERAPIES, Outcome 9 Mental state: $4 \mathrm{~b}$.

Specific - average score - negative symptoms - overall

$($ SANS, high $=$ good $)$

Review: Cognitive behavioural therapy versus other psychosocial treatments for schizophrenia

Comparison: 2 SUBGROUP 1: CBT versus "NON-ACTIVE" THERAPIES

Outcome: 9 Mental state: 4b. Specific - average score - negative symptoms - overall (SANS, high $=$ good)

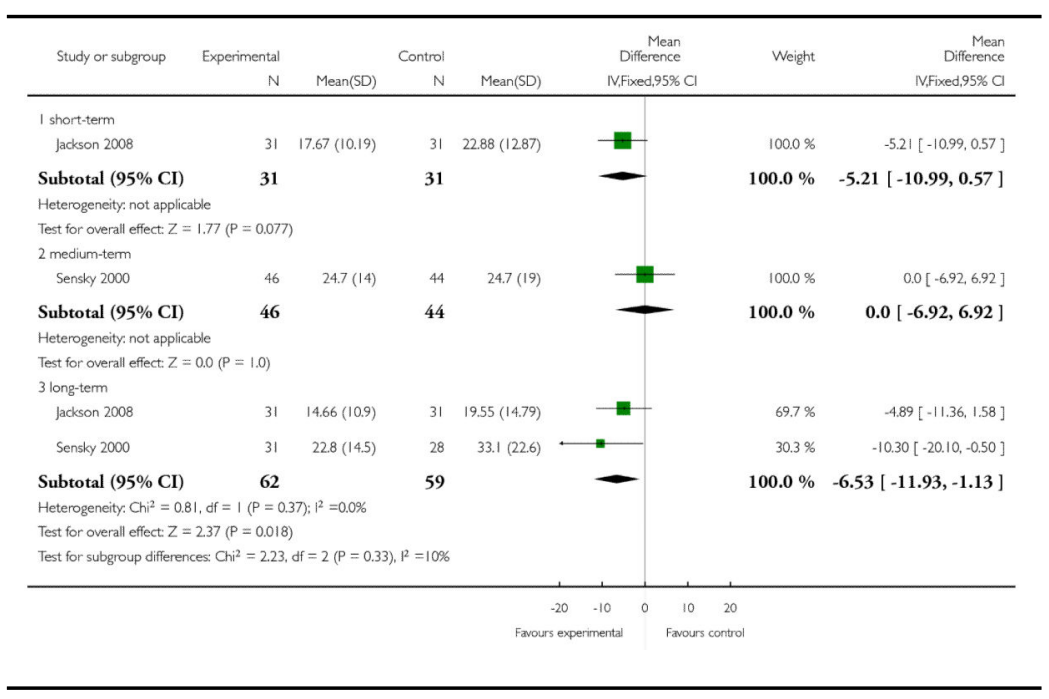


Analysis 2.10

Comparison 2 SUBGROUP 1: CBT versus "NON-

ACTIVE” THERAPIES, Outcome 10 Mental state: 5a.

Specific - average score - affective symptoms (PANSS

General symptoms, endpoint data, high $=$ poor)

Review: Cognitive behavioural therapy versus other psychosocial treatments for schizophrenia

Comparison: 2 SUBGROUP 1: CBT versus "NON-ACTIVE” THERAPIES

Outcome: 10 Mental state: 5a. Specific - average score - affective symptoms (PANSS

General symptoms, endpoint data, high $=$ poor)

\begin{tabular}{|c|c|c|c|c|c|c|c|}
\hline \multirow[t]{2}{*}{ Study or subgroup } & \multirow{2}{*}{$\begin{array}{r}\text { Experimental } \\
\mathrm{N}\end{array}$} & \multicolumn{3}{|c|}{ Control } & \multirow{2}{*}{$\begin{array}{c}\text { Mean } \\
\text { Difference } \\
\text { IV.Fixed,95\% Cl }\end{array}$} & \multirow[t]{2}{*}{ Weight } & \multirow{2}{*}{$\begin{array}{r}\text { Mean } \\
\text { Difference } \\
\text { N.Fixed,95\% Cl }\end{array}$} \\
\hline & & $\operatorname{Mean}(S D)$ & $\mathrm{N}$ & $\operatorname{Mean}(S D)$ & & & \\
\hline \multicolumn{8}{|l|}{ I short-term } \\
\hline Haddock 2009 & 38 & $28.45(6.52)$ & 39 & $29.5(7.84)$ & $\longrightarrow$ & $50.7 \%$ & $-1.05[-4.27,2.17]$ \\
\hline Valmaggia 2005 & 35 & $30.4(6.28)$ & 23 & $29.58(6.16)$ & $\rightarrow-$ & $49.3 \%$ & $0.82[-2.45,4.09]$ \\
\hline Subtotal $(95 \% \mathrm{CI})$ & 73 & & 62 & & 2 & $100.0 \%$ & $-0.13[-2.42,2.16]$ \\
\hline \multicolumn{8}{|c|}{ Heterogeneity: $\mathrm{Ch}^{2}=0.64, \mathrm{df}=1(P=0.42): 1^{2}=0.0 \%$} \\
\hline \multicolumn{8}{|c|}{ Test for overall effect: $Z=0.11(P=0.91)$} \\
\hline \multicolumn{8}{|l|}{2 medium-term } \\
\hline Valmaggia 2005 & 35 & $29.74(6.34)$ & 23 & $29.62(4.65)$ & & $100.0 \%$ & $0.12[-2.71,2.95]$ \\
\hline Subtotal $(95 \% \mathrm{CI})$ & 35 & & 23 & & & $100.0 \%$ & $0.12[-2.71,2.95]$ \\
\hline \multicolumn{8}{|l|}{ Heterogeneity. not applicable } \\
\hline \multicolumn{8}{|c|}{ Test for overall effect $Z=0.08(P=0.93)$} \\
\hline \multicolumn{8}{|l|}{3 long-term } \\
\hline Haddock 2009 & 38 & $26.88(10.46)$ & 39 & $28.81(9.56)$ & $\Rightarrow$ & $15.7 \%$ & $-1.93[-6.41,2.55]$ \\
\hline Lewis 2002 - Liverpool & 26 & $28.9(6.9)$ & 23 & $27.9(7.4)$ & & $19.4 \%$ & $1.00[-3.02,5.02]$ \\
\hline Lewis 2002 - Manchester & 25 & $38.3(10.8)$ & 30 & $41.5(12.2)$ & & $8.5 \%$ & $-3.20[-9.28,2.88]$ \\
\hline Lewis 2002 - Nottingham & 24 & $28.8(3.8)$ & 26 & $28.9(4.7)$ & $=$ & $56.4 \%$ & $-0.10[-2.46,2.26]$ \\
\hline Subtotal $(95 \% \mathrm{CI})$ & 113 & & 118 & & - & $100.0 \%$ & $-0.44[-2.21,1.34]$ \\
\hline \multicolumn{8}{|c|}{ Heterogeneity: $C \mathrm{i}^{2}=1.79, \mathrm{df}=3(\mathrm{P}=0.62) ; 1^{2}=0.0 \%$} \\
\hline \multicolumn{8}{|c|}{ Test for overall effect: $Z=0.48(P=0.63)$} \\
\hline \multicolumn{8}{|c|}{ Test for subgroup differences: $C h^{2}=0.12, \mathrm{df}=2(P=0.94), \mathrm{I}^{2}=0.0 \%$} \\
\hline & & & & & -5 & & \\
\hline
\end{tabular}


Analysis 2.11

Comparison 2 SUBGROUP 1: CBT versus "NON-

ACTIVE" THERAPIES, Outcome 11 Mental state: 5 b.

Specific - average score - affective symptoms -

depression (Montgomery-Asberg Depression Rating

Scale, high $=$ poor $)$

Review: Cognitive behavioural therapy versus other psychosocial treatments for schizophrenia

Comparison: 2 SUBGROUP 1: CBT versus "NON-ACTIVE” THERAPIES

Outcome: 11 Mental state: 5b. Specific - average score - affective symptoms - depression (Montgomery-Asberg Depression Rating Scale, high = poor)

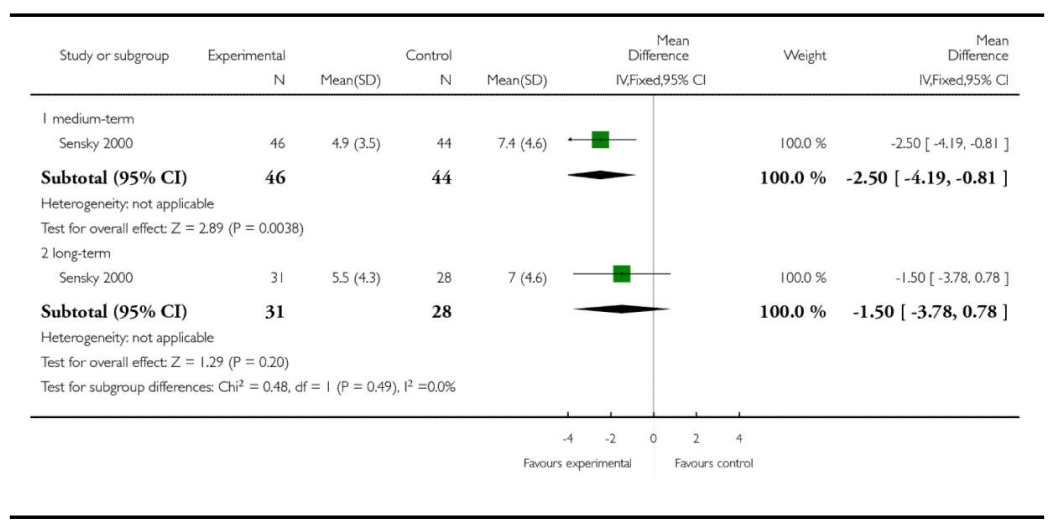


Analysis 2.12

Comparison 2 SUBGROUP 1: CBT versus "NON-

ACTIVE" THERAPIES, Outcome 12 Mental state: 5c.

Specific - average score - affective symptoms - Anger/

aggression (Novaco Anger Scale, high = poor)

Review: Cognitive behavioural therapy versus other psychosocial treatments for schizophrenia

Comparison: 2 SUBGROUP 1: CBT versus "NON-ACTIVE" THERAPIES

Outcome: 12 Mental state: 5c. Specific - average score - affective symptoms - Anger/ aggression (Novaco Anger Scale, high = poor)

\begin{tabular}{|c|c|c|c|c|c|c|c|c|}
\hline \multirow[t]{2}{*}{ Study or subgroup } & \multirow{2}{*}{$\begin{array}{r}\text { Experimental } \\
\mathrm{N}\end{array}$} & \multicolumn{3}{|c|}{ Control } & \multirow{2}{*}{\multicolumn{2}{|c|}{$\begin{array}{c}\text { Mean } \\
\text { Difference } \\
\text { IV.Fixed,95\% CI }\end{array}$}} & \multirow[t]{2}{*}{ Weight } & \multirow{2}{*}{$\begin{array}{r}\text { Mear } \\
\text { Difference } \\
\text { IV.Fixed,95\% C }\end{array}$} \\
\hline & & $\operatorname{Mean}(\mathrm{SD})$ & $\mathrm{N}$ & $\operatorname{Mcan}(\mathrm{SD})$ & & & & \\
\hline \multicolumn{9}{|l|}{ I short-term } \\
\hline Haddock 2009 & 38 & $84.46(14.42)$ & 39 & $82.36(20.12)$ & & 풀 & $100.0 \%$ & $2.10[-5.70,9.90]$ \\
\hline Subtotal $(95 \% \mathrm{CI})$ & 38 & & 39 & & & - & $100.0 \%$ & $2.10[-5.70,9.90]$ \\
\hline \multicolumn{9}{|c|}{ Heterogeneity, not applicable } \\
\hline \multicolumn{9}{|c|}{ Test for overall effect: $Z=0.53(P=0.60)$} \\
\hline \multicolumn{9}{|c|}{2 long-term } \\
\hline Haddock 2009 & 38 & $83.36(14.76)$ & 39 & $84.4 !(22.26)$ & & $\mathbf{m}$ & $100.0 \%$ & $-1.05[-9.47,7.37]$ \\
\hline Subtotal $(95 \% \mathrm{CI})$ & 38 & & 39 & & & - & $100.0 \%$ & $-1.05[-9.47,7.37]$ \\
\hline \multicolumn{9}{|c|}{ Heterogeneity. not applicable } \\
\hline \multicolumn{9}{|c|}{ Test for overall effect: $Z=0.24(P=0.81)$} \\
\hline \multicolumn{9}{|c|}{ Test for subgroup differences: $C h i^{2}=0.29, \mathrm{df}=\mid(P=0.59) \cdot 1^{2}=0.0 \%$} \\
\hline & & & & & .50 & $0 \quad 50$ & & \\
\hline & & & & Favou & rimental & Favours & & \\
\hline
\end{tabular}

Analysis 2.13

Comparison 2 SUBGROUP 1: CBT versus "NON-

ACTIVE" THERAPIES, Outcome 13 Mental state: 6a.

Specific - average score - problem behaviours (Novaco

Provocation Inventory, high = poor)

Review: Cognitive behavioural therapy versus other psychosocial treatments for schizophrenia

Comparison: 2 SUBGROUP 1: CBT versus “NON-ACTIVE” THERAPIES

Outcome: 13 Mental state: 6a. Specific - average score - problem behaviours (Novaco

Provocation Inventory, high $=$ poor)

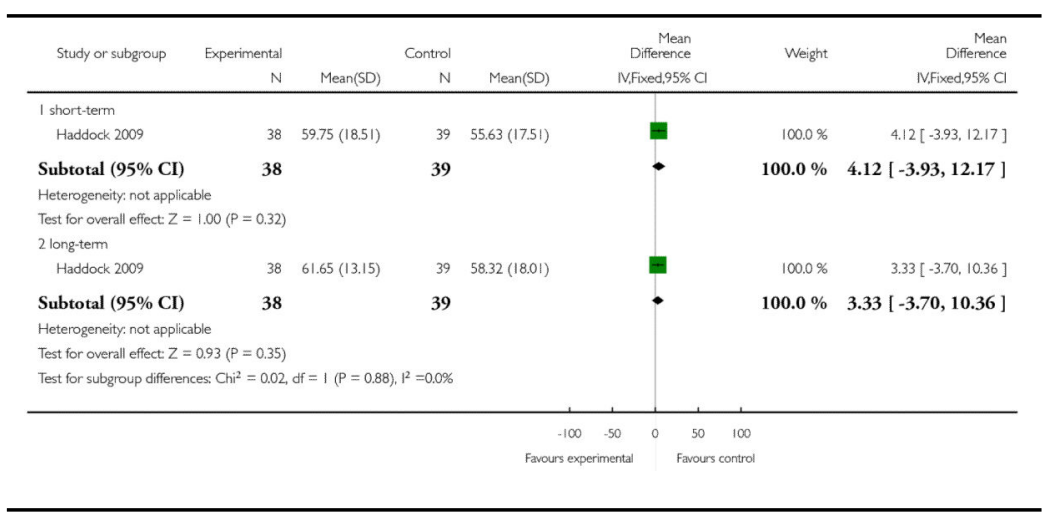


Analysis 2.14

Comparison 2 SUBGROUP 1: CBT versus "NON-

ACTIVE" THERAPIES, Outcome 14 Mental state: 6c. Specific - average score - problem behaviours (Ward Anger Rating Scale, high = poor)

Review: Cognitive behavioural therapy versus other psychosocial treatments for schizophrenia

Comparison: 2 SUBGROUP 1: CBT versus "NON-ACTIVE" THERAPIES

Outcome: 14 Mental state: 6c. Specific - average score - problem behaviours (Ward Anger Rating Scale, high = poor)

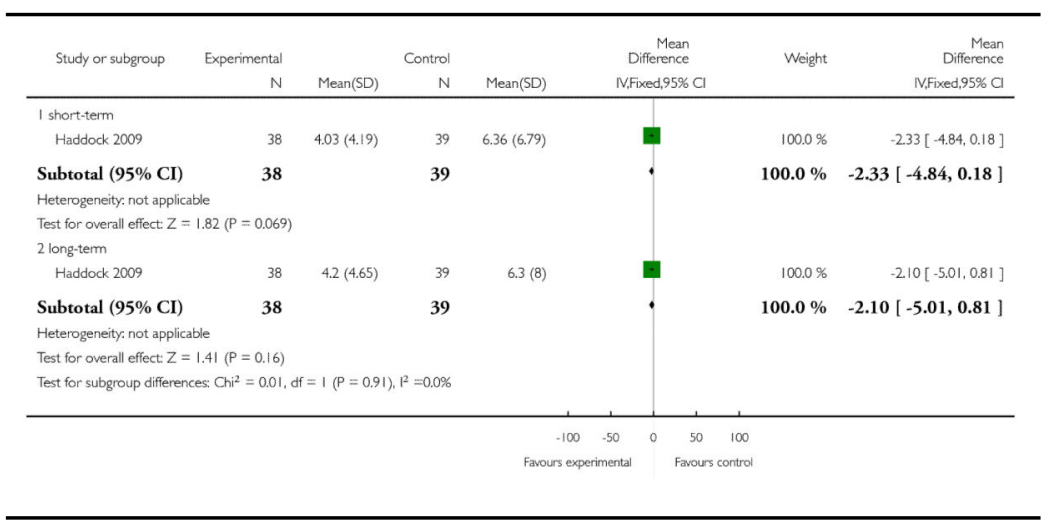

Analysis 2.15

Comparison 2 SUBGROUP 1: CBT versus "NON-

ACTIVE" THERAPIES, Outcome 15 Mental state: 6d.

Specific - average score - problem behaviour (HCR - 20

clinical scale, high $=$ poor $)$ - long-term only

Review: Cognitive behavioural therapy versus other psychosocial treatments for schizophrenia

Comparison: 2 SUBGROUP 1: CBT versus "NON-ACTIVE" THERAPIES

Outcome: 15 Mental state: 6d. Specific - average score - problem behaviour (HCR - 20

clinical scale, high = poor) - long-term only

\begin{tabular}{|c|c|c|c|c|c|c|c|c|}
\hline \multirow[t]{2}{*}{ Study or subgroup } & \multirow{2}{*}{$\begin{array}{r}\text { Experimental } \\
\mathrm{N}\end{array}$} & \multicolumn{3}{|c|}{ Control } & \multicolumn{2}{|c|}{$\begin{array}{l}\text { Mean } \\
\text { Difference }\end{array}$} & \multirow[t]{2}{*}{ Weight } & \multirow{2}{*}{$\begin{array}{r}\text { Mean } \\
\text { Difference } \\
\text { |VFFixed,95\% CI }\end{array}$} \\
\hline & & $\operatorname{Mean}(\mathrm{SD})$ & $\mathrm{N}$ & $\operatorname{Mean}(\mathrm{SD})$ & & (Fixed,95\% Cl & & \\
\hline Haddock 2009 & 38 & $3.57(2.54)$ & 39 & $4.03(264)$ & & 둠- & $100.0 \%$ & $-0.46[-1.62,0.70]$ \\
\hline Total $(95 \% \mathrm{CI})$ & 38 & & 39 & & & & $100.0 \%$ & $-0.46[-1.62,0.70]$ \\
\hline \multicolumn{9}{|c|}{ Heterogeneity: not applicable } \\
\hline \multicolumn{9}{|c|}{ Test for overall effect: $Z=0.78(P=0.44)$} \\
\hline \multicolumn{9}{|c|}{ Test for subgroup differences: Not applicable } \\
\hline & & & & Favour & -2 & 02 & & \\
\hline
\end{tabular}


Analysis 2.16

Comparison 2 SUBGROUP 1: CBT versus "NON-

ACTIVE" THERAPIES, Outcome 16 Mental state: $6 \mathrm{e}$. Specific - average score - problem behaviours (HCR-20 risk management, high poor) - long-term only

Review: Cognitive behavioural therapy versus other psychosocial treatments for schizophrenia

Comparison: 2 SUBGROUP 1: CBT versus "NON-ACTIVE" THERAPIES

Outcome: 16 Mental state: 6e. Specific - average score - problem behaviours (HCR-20 risk management, high poor) - long-term only

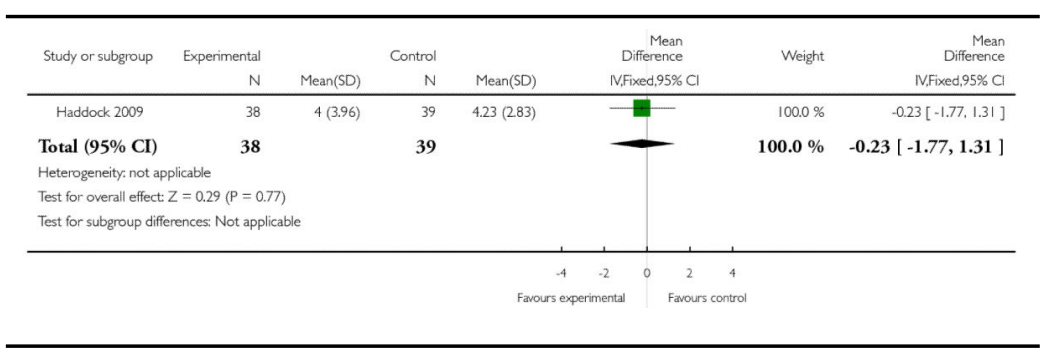

Analysis 2.17

Comparison 2 SUBGROUP 1: CBT versus "NON-

ACTIVE" THERAPIES, Outcome 17 Global state: 1.

Relapse - long-term only

Review: Cognitive behavioural therapy versus other psychosocial treatments for schizophrenia

Comparison: 2 SUBGROUP 1: CBT versus “NON-ACTIVE” THERAPIES

Outcome: 17 Global state: 1 . Relapse - long-term only

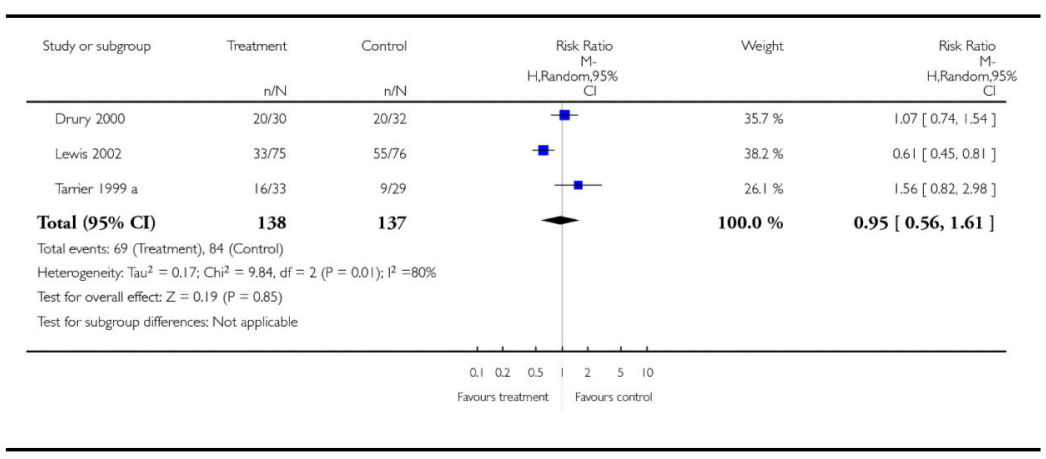




\section{Analysis 2.18}

Comparison 2 SUBGROUP 1: CBT versus "NON-

ACTIVE" THERAPIES, Outcome 18 Global state: 2.

Rehospitalisation - long-term only

Review: Cognitive behavioural therapy versus other psychosocial treatments for schizophrenia

Comparison: 2 SUBGROUP 1: CBT versus "NON-ACTIVE" THERAPIES

Outcome: 18 Global state: 2. Rehospitalisation - long-term only

\begin{tabular}{|c|c|c|c|c|c|c|}
\hline Study or subgroup & $\begin{array}{l}C B T \\
n / N\end{array}$ & $\begin{array}{r}\text { Control } \\
\pi / N\end{array}$ & \multicolumn{2}{|c|}{$\begin{array}{c}\text { Risk Ratio } \\
\text { M-H,Fixed,95\% C }\end{array}$} & Weight & $\begin{array}{r}\text { Risk Ratio } \\
\text { M-H,Fixed,95\% C }\end{array}$ \\
\hline Drury 2000 & $10 / 30$ & $10 / 32$ & & $\Rightarrow$ & $45.5 \%$ & $1.07[0.52 .2 .19]$ \\
\hline Jackson 2008 & $12 / 30$ & 11/27 & & \# & $54.5 \%$ & $0.98[0.52,1.85]$ \\
\hline Total $(95 \% \mathrm{CI})$ & 60 & 59 & & - & $100.0 \%$ & $1.02[0.63,1.64]$ \\
\hline \multicolumn{7}{|c|}{ Total events: 22 (CBT). 21 (Control) } \\
\hline \multicolumn{7}{|c|}{ Heterogeneity. $\mathrm{Ch}^{2}=0.03, \mathrm{df}=1(\mathrm{P}=0.87) ; 1^{2}=0.0 \%$} \\
\hline \multicolumn{7}{|c|}{ Test for overall effect: $Z=0.08(P=0.93)$} \\
\hline \multicolumn{7}{|c|}{ Test for subgroup differences: Not applicable } \\
\hline & & & $0.005 \quad 0.1$ & 110 & & \\
\hline & & & Favours experimental & Favours & & \\
\hline
\end{tabular}

Analysis 2.19

Comparison 2 SUBGROUP 1: CBT versus "NON-

ACTIVE" THERAPIES, Outcome 19 Global state: 3. Average score $($ GAF , high $=$ good $)$

Review: Cognitive behavioural therapy versus other psychosocial treatments for schizophrenia

Comparison: 2 SUBGROUP 1: CBT versus "NON-ACTIVE" THERAPIES

Outcome: 19 Global state: 3 . Average score $(\mathrm{GAF}$, high = good $)$

\begin{tabular}{|c|c|c|c|c|c|c|c|c|}
\hline \multirow[t]{2}{*}{ Study or subgroup } & \multirow{2}{*}{$\begin{array}{r}\text { Experimental } \\
\mathrm{N}\end{array}$} & \multicolumn{3}{|c|}{ Control } & \multirow{2}{*}{\multicolumn{2}{|c|}{$\begin{array}{c}\text { Mean } \\
\text { Difference } \\
\text { IV.Fixed,95\% Cl }\end{array}$}} & \multirow[t]{2}{*}{ Weight } & \multirow{2}{*}{$\begin{array}{r}\text { Mean } \\
\text { Difference } \\
\text { N,Fixed,95\% Cl }\end{array}$} \\
\hline & & $\operatorname{Mean}(\mathrm{SD})$ & $\mathrm{N}$ & $\operatorname{Mean}(S D)$ & & & & \\
\hline \multicolumn{9}{|l|}{ I short-term } \\
\hline Haddock 2009 & 38 & $41.86(15.63)$ & 39 & $33.34(14.64)$ & & $\mp$ & $48.8 \%$ & $8.52[1.75,15.29]$ \\
\hline Kemp 1998 & 37 & $54(17.3)$ & 33 & $44.5(10.4)$ & & $=-$ & $51.2 \%$ & $9.50[2.89,16.11]$ \\
\hline Subtotal $(95 \% \mathrm{CI})$ & 75 & & 72 & & & - & $100.0 \%$ & $9.02[4.29,13.75]$ \\
\hline \multicolumn{9}{|c|}{ Heterogeneity: $\mathrm{Ch}^{2}=0.04, \mathrm{df}=\mathrm{I}(\mathrm{P}=0.84) ; \mathrm{I}^{2}=0.0 \%$} \\
\hline \multicolumn{9}{|c|}{ Test for overall effect: $Z=3.74(P=0.00018)$} \\
\hline \multicolumn{9}{|l|}{2 long-term } \\
\hline Durham 2003 & 18 & $35.8(9.7)$ & 12 & $36.3(9.8)$ & & & $45.9 \%$ & $-0.50[-7.63,6.63]$ \\
\hline Haddock 2009 & 38 & $42.94(19.3)$ & 39 & $40.93(22.06)$ & & "- & $27.3 \%$ & $201[-7.24,11.26]$ \\
\hline Kemp 1998 & 25 & $62.8(18.4)$ & 23 & $48.3(14.5)$ & & $\longrightarrow$ & $26.8 \%$ & $14.50[5.17,23.83]$ \\
\hline Subtotal $(95 \% \mathrm{CI})$ & 81 & & 74 & & & - & $100.0 \%$ & $4.20[-0.63,9.03]$ \\
\hline \multicolumn{9}{|c|}{ Heterogeneity: $\mathrm{Ch}^{2}=6.56, \mathrm{df}=2(\mathrm{P}=0.04): \mathrm{I}^{2}=70 \%$} \\
\hline \multicolumn{9}{|c|}{ Test for overall effect: $Z=1.71(P=0.088)$} \\
\hline \multicolumn{9}{|c|}{ Test for subgroup differences: $\mathrm{Chi}^{2}=1.95, \mathrm{df}=1(\mathrm{P}=0.16), \mathrm{I}^{2}=49 \%$} \\
\hline & & & & & $\begin{array}{ll}-20 & -10 \\
\text { Favours control }\end{array}$ & $\begin{array}{lrr}0 & 10 & 20 \\
& \text { Favours CBT }\end{array}$ & & \\
\hline
\end{tabular}


Analysis 2.20

Comparison 2 SUBGROUP 1: CBT versus "NON-

ACTIVE" THERAPIES, Outcome 20 Global state: 4.

Social functioning - average scores (Social and

Occupational Functioning Assessment Scale, high = good)

Review: Cognitive behavioural therapy versus other psychosocial treatments for schizophrenia

Comparison: 2 SUBGROUP 1: CBT versus "NON-ACTIVE" THERAPIES

Outcome: 20 Global state: 4. Social functioning - average scores (Social and Occupational Functioning Assessment Scale, high = good)

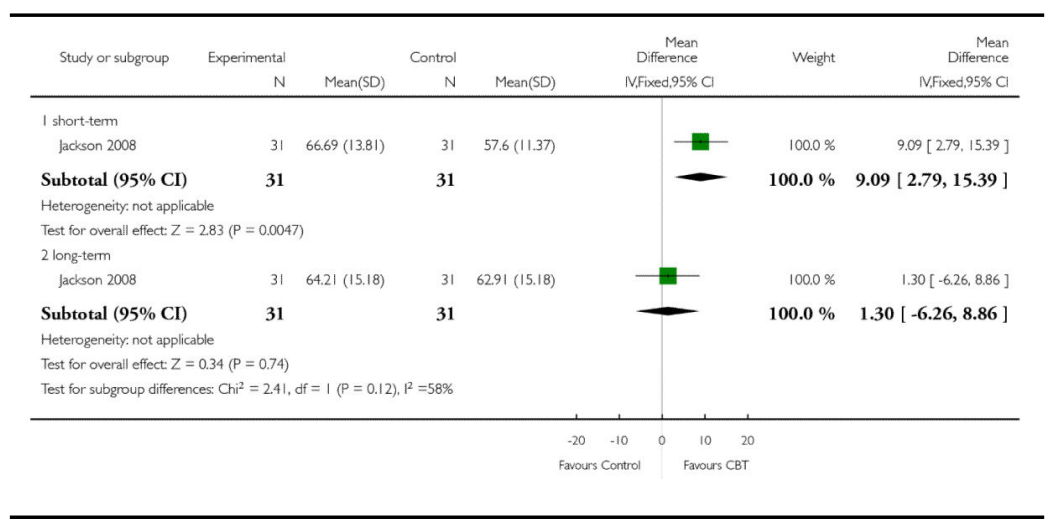


Analysis 2.21

Comparison 2 SUBGROUP 1: CBT versus "NON-

ACTIVE" THERAPIES, Outcome 21 Satisfaction with treatment: 1. Attitude to medication - average score short-term

Review: Cognitive behavioural therapy versus other psychosocial treatments for schizophrenia

Comparison: 2 SUBGROUP 1: CBT versus "NON-ACTIVE" THERAPIES

Outcome: 21 Satisfaction with treatment: 1 . Attitude to medication - average score - shortterm

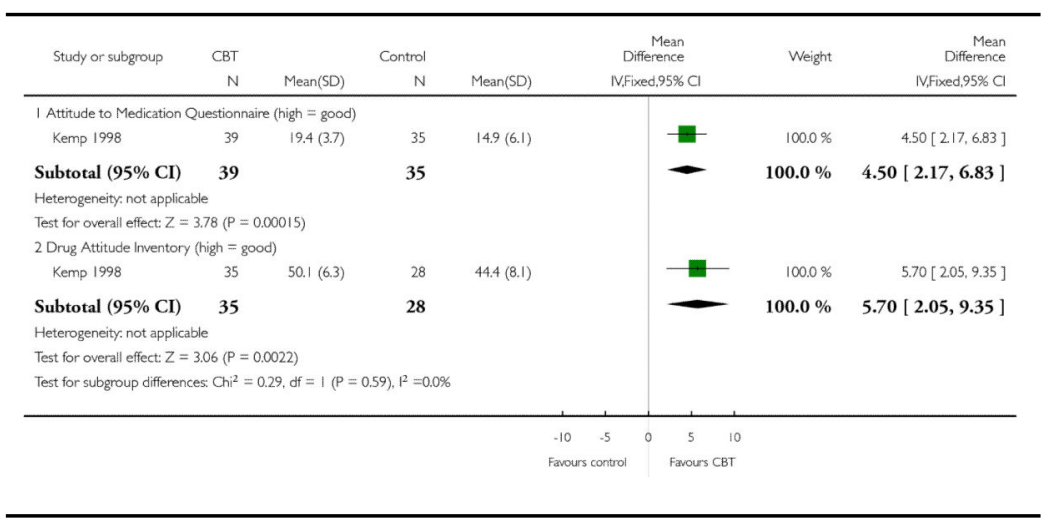

Analysis 2.22

Comparison 2 SUBGROUP 1: CBT versus "NON-

ACTIVE" THERAPIES, Outcome 22 Satisfaction with treatment: 2 . Leaving the study early

Review: Cognitive behavioural therapy versus other psychosocial treatments for schizophrenia

Comparison: 2 SUBGROUP 1: CBT versus "NON-ACTIVE" THERAPIES

Outcome: 22 Satisfaction with treatment: 2 . Leaving the study early

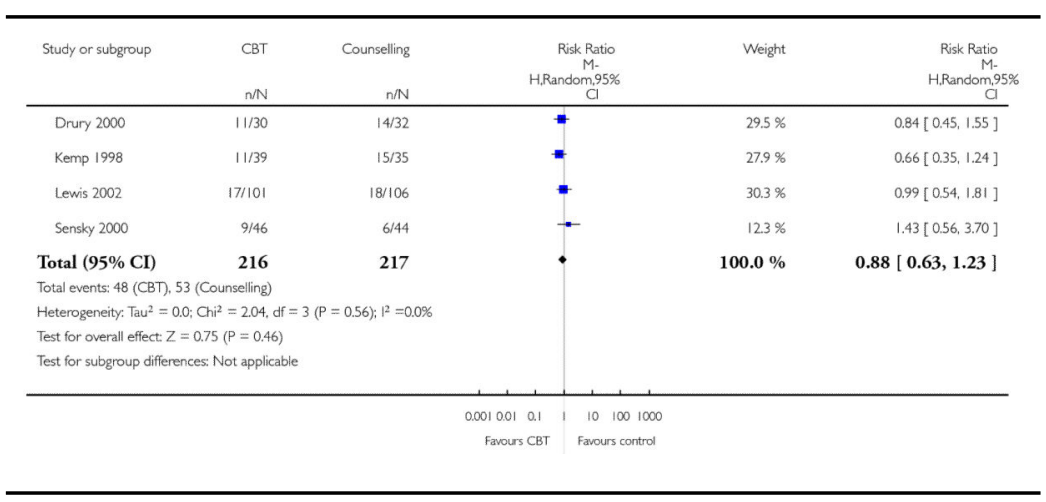


Analysis 3.3

Comparison 3 SUBGROUP 2: CBT versus "ACTIVE" PSYCHOLOGICAL THERAPIES, Outcome 3 Mental state: 1. No important or reliable change

Review: Cognitive behavioural therapy versus other psychosocial treatments for schizophrenia

Comparison: 3 SUBGROUP 2: CBT versus “ACTIVE” PSYCHOLOGICAL THERAPIES Outcome: 3 Mental state: 1 . No important or reliable change

\begin{tabular}{|c|c|c|c|c|c|}
\hline Study or subgroup & CBT & $\begin{array}{r}\text { Counselling } \\
n / N \\
\end{array}$ & $\begin{array}{r}\text { Risk Ratio } \\
\text { M- } \\
\text { H.Random.95\% } \\
\mathrm{CI}\end{array}$ & Weight & $\begin{array}{l}\text { Risk Ratio } \\
\text { M. } \\
\text { H.Random.95\% } \\
\text { C }\end{array}$ \\
\hline \multicolumn{6}{|l|}{1 shortterm } \\
\hline Bechdolf 2004 & $29 / 31$ & $35 / 40$ & $=$ & $60.9 \%$ & $1.07[0.92,1.24]$ \\
\hline Cather 2005 & 6/15 & $9 / 13$ & $=$ & $39.1 \%$ & $0.58[0.28,1.18]$ \\
\hline Subtotal $(95 \% \mathrm{CI})$ & 46 & 53 & - & $100.0 \%$ & $0.84[0.40,1.75]$ \\
\hline \multicolumn{6}{|c|}{ Total events: 35 (CBT), 44 (Counselling) } \\
\hline \multicolumn{6}{|c|}{ Heterogeneity, Tau ${ }^{2}=0.22 ; \mathrm{Ch}^{2}=4.21, \mathrm{df}=1(\mathrm{P}=0.04) ; \mathrm{P}^{2}=76 \%$} \\
\hline \multicolumn{6}{|c|}{ Test for overall effect: $Z=0.46(P=0.64)$} \\
\hline \multicolumn{6}{|l|}{2 medium-term } \\
\hline Durham 2003 & $18 / 22$ & 1719 & $=$ & $57.6 \%$ & $0.91[0.71,1.17]$ \\
\hline Tarrier $1999 \mathrm{a}$ & $22 / 33$ & $22 / 26$ & \pm & $42.4 \%$ & $0.79[0.59,1.05]$ \\
\hline Subtotal $(95 \% \mathrm{CI})$ & 55 & 45 & - & $100.0 \%$ & $0.86[0.71,1.04]$ \\
\hline \multicolumn{6}{|c|}{ Total events; 40 (CBT), 39 (Counselling) } \\
\hline \multicolumn{6}{|c|}{ Heterogeneity $\mathrm{Tau}^{2}=0.0 ; \mathrm{Chi}^{2}=0.62, \mathrm{df}=1(P=0.43) ; 1^{2}=0.0 \%$} \\
\hline \multicolumn{6}{|c|}{ Test for overall effect: $Z=1.57(P=0.12)$} \\
\hline \multicolumn{6}{|l|}{3 long-term } \\
\hline Durham 2003 & $15 / 22$ & $16 / 19$ & - & $27.0 \%$ & $0.81[0.57,1.14]$ \\
\hline Garety 2008 a & $8 / 27$ & $9 / 27$ & $\rightarrow$ & $5.2 \%$ & $0.89[0.40,1.96]$ \\
\hline Tarrier 1999 a & $28 / 33$ & 22226 & $=$ & $67.8 \%$ & $1.00[0.81,1.25]$ \\
\hline Subtotal $(95 \% \mathrm{CI})$ & 82 & 72 & - & $100.0 \%$ & $0.94[0.79,1.13]$ \\
\hline \multirow{3}{*}{\multicolumn{6}{|c|}{$\begin{array}{l}\text { Total events: } 51 \text { (CBT), } 47 \text { (Counselling) } \\
\text { Heterogeneity. Tau }=0.0 ; \mathrm{Ch}^{2}=1.15 \text {, of }=2(P=0.56) ; 1^{2}=0.0 \% \\
\text { Test for overall effect: } Z=0.67(P=0.50)\end{array}$}} \\
\hline & & & & & \\
\hline & & & & & \\
\hline & & & 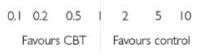 & & \\
\hline
\end{tabular}


Analysis 3.4

Comparison 3 SUBGROUP 2: CBT versus "ACTIVE" PSYCHOLOGICAL THERAPIES, Outcome 4 Mental state: 2a. General - average score - total (BPRS, high = poor)

Review: Cognitive behavioural therapy versus other psychosocial treatments for schizophrenia

Comparison: 3 SUBGROUP 2: CBT versus “ACTIVE” PSYCHOLOGICAL THERAPIES Outcome: 4 Mental state: 2a. General - average score - total (BPRS, high = poor)

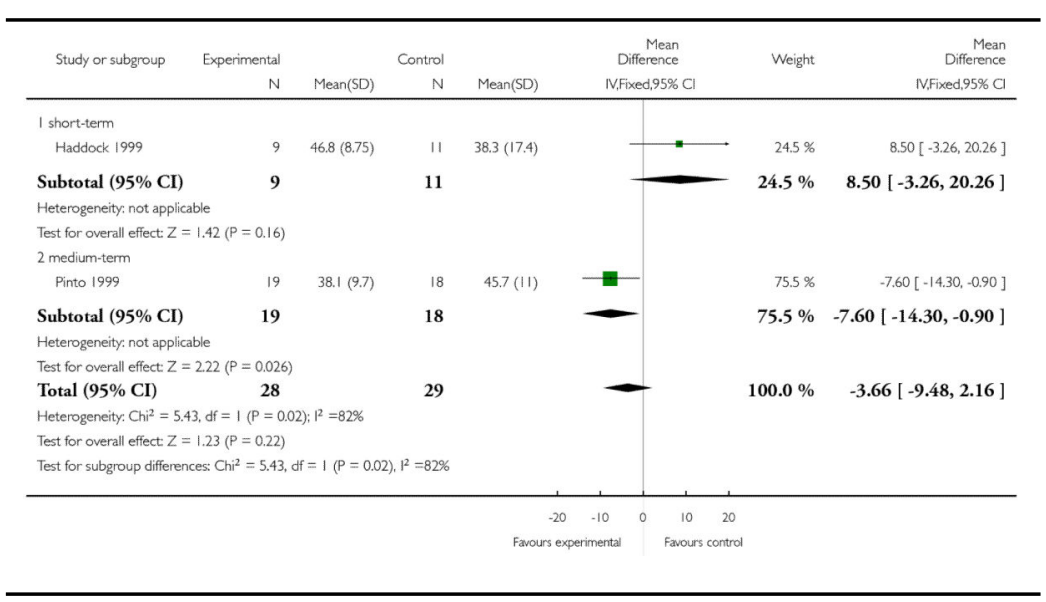


Analysis 3.5

Comparison 3 SUBGROUP 2: CBT versus "ACTIVE" PSYCHOLOGICAL THERAPIES, Outcome 5 Mental state: 2b. General - average score - total (PANSS, endpoint data, high $=$ poor)

Review: Cognitive behavioural therapy versus other psychosocial treatments for schizophrenia

Comparison: 3 SUBGROUP 2: CBT versus “ACTIVE” PSYCHOLOGICAL THERAPIES Outcome: 5 Mental state: 2b. General - average score - total (PANSS, endpoint data, high = poor)

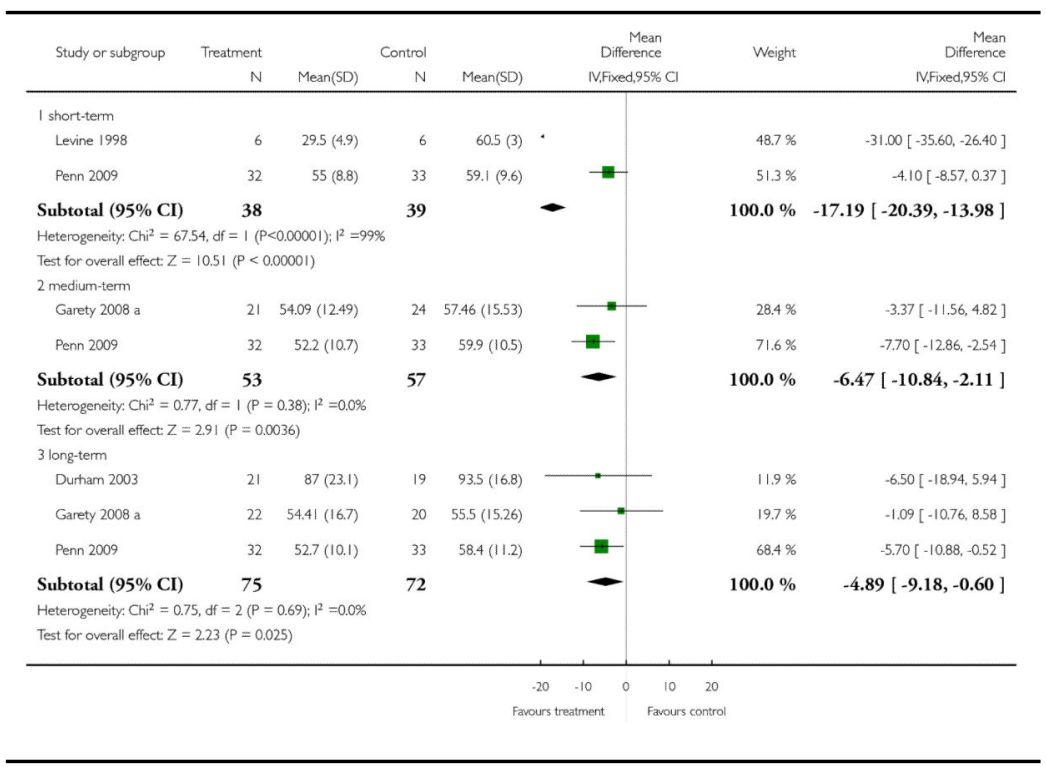


Analysis 3.6

Comparison 3 SUBGROUP 2: CBT versus "ACTIVE" PSYCHOLOGICAL THERAPIES, Outcome 6 Mental state: 3a. Specific - average score - positive symptoms overall $($ PANSS, endpoint data,high $=$ poor $)$

Review: Cognitive behavioural therapy versus other psychosocial treatments for schizophrenia

Comparison: 3 SUBGROUP 2: CBT versus “ACTIVE" PSYCHOLOGICAL THERAPIES Outcome: 6 Mental state: 3 a. Specific - average score - positive symptoms - overall (PANSS, endpoint data, high $=$ poor $)$

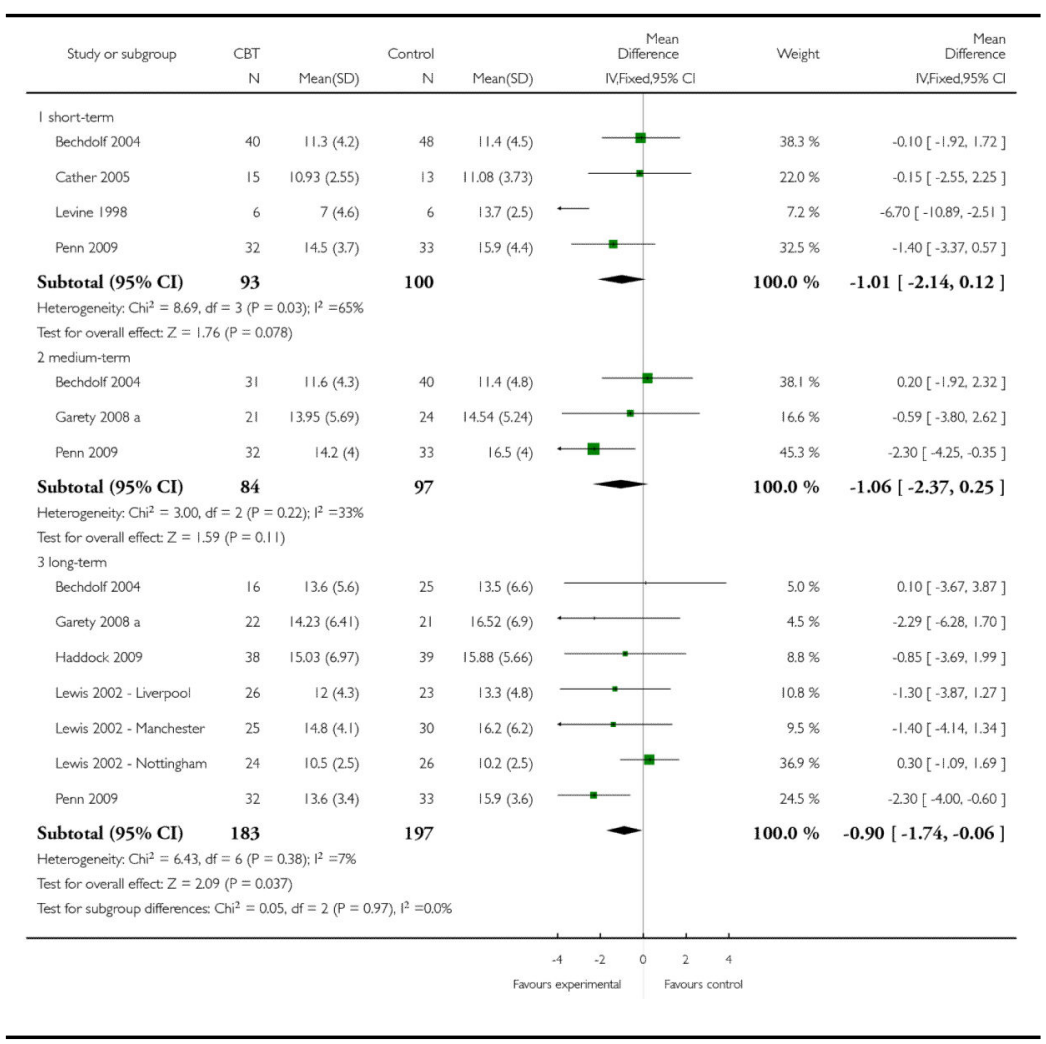


Analysis 3.7

Comparison 3 SUBGROUP 2: CBT versus "ACTIVE" PSYCHOLOGICAL THERAPIES, Outcome 7 Mental state: $3 b$. Specific - average score - positive symptoms hallucinations (Psychotic Symptom Rating Scale, high = poor)

Review: Cognitive behavioural therapy versus other psychosocial treatments for schizophrenia

Comparison: 3 SUBGROUP 2: CBT versus “ACTIVE” PSYCHOLOGICAL THERAPIES Outcome: 7 Mental state: 3 b. Specific - average score - positive symptoms - hallucinations (Psychotic Symptom Rating Scale, high = poor)

\begin{tabular}{|c|c|c|c|c|c|c|c|}
\hline \multirow[t]{2}{*}{ Study or subgroup } & \multirow{2}{*}{$\begin{array}{r}\text { Experimental } \\
\mathrm{N}\end{array}$} & \multicolumn{3}{|c|}{ Control } & \multirow{2}{*}{$\begin{array}{c}\text { Mean } \\
\text { Difiference } \\
\text { IV.Fixed,95\% Cl }\end{array}$} & \multirow[t]{2}{*}{ Weight } & \multirow{2}{*}{$\begin{array}{r}\text { Mean } \\
\text { Dfference } \\
\text { AV.Fixed,95\% CI }\end{array}$} \\
\hline & & $\operatorname{Mean}(S D)$ & $\mathrm{N}$ & $\operatorname{Mean}(S D)$ & & & \\
\hline \multicolumn{8}{|l|}{ I short-term } \\
\hline Cather 2005 & 15 & $18.11(11.36)$ & 13 & $20.52(12.57)$ & $\cdot$ & $5.1 \%$ & $-2.41[-11.34,6.52]$ \\
\hline Penn 2009 & 32 & $25.4(7.4)$ & 33 & $26.3(6.8)$ & & $34.2 \%$ & $-0.90[-4.36,2.56]$ \\
\hline Subtotal $(95 \% \mathrm{CI})$ & 47 & & 46 & & & $39.4 \%$ & $-1.10[-4.32,2.13]$ \\
\hline \multicolumn{8}{|c|}{ Heterogeneity: $\mathrm{Ch}^{2}=0.10, \mathrm{dr}=1(P=0.76) ; 1^{2}=0.0 \%$} \\
\hline \multicolumn{8}{|c|}{ Test for overall effect $Z=0.67(P=0.50)$} \\
\hline \multicolumn{8}{|l|}{2 medium-term } \\
\hline Durham 2003 & 21 & $17.9(13.2)$ & 19 & $20.6(123)$ & 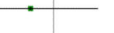 & $6.6 \%$ & $-2.70[-10.60,5.20]$ \\
\hline Penn 2009 & 32 & $25.6(6.9)$ & 33 & $25.7(8.4)$ & & $29.4 \%$ & $-0.10[-3.83,3.63]$ \\
\hline Subtotal $(95 \% \mathrm{CI})$ & 53 & & 52 & & & $35.9 \%$ & $-0.57[-3.95,2.80]$ \\
\hline \multicolumn{8}{|c|}{ Heterogeneity: $C h^{2}=0.34$, df $=\mid(P=0.56) ; 1^{2}=0.0 \%$} \\
\hline \multicolumn{8}{|c|}{ Test for overal effect $Z=0.33(P=0.74)$} \\
\hline \multicolumn{8}{|l|}{3 long-term } \\
\hline Durham 2003 & 20 & $18.5(12.8)$ & 19 & $18(12.2)$ & & $6.6 \%$ & $0.50[-7.35,8.35]$ \\
\hline Penn 2009 & 32 & $23(9.6)$ & 33 & $23(10)$ & & $18.0 \%$ & $0.0[-4.76,4.76]$ \\
\hline Subtotal $(95 \% \mathrm{CI})$ & 52 & & 52 & & - & $24.7 \%$ & $0.13[-3.94,4.21]$ \\
\hline \multicolumn{8}{|c|}{ Heterogeneity: $\mathrm{Ch}^{2}=0.01, \mathrm{df}=1(\mathrm{P}=0.91) ; 1^{2}=0.0 \%$} \\
\hline \multicolumn{8}{|c|}{ Test for overall effect: $Z=0.06(P=0.95)$} \\
\hline Total $(95 \% \mathrm{CI})$ & 152 & & 150 & & - & $100.0 \%$ & $-0.60[-2.63,1.42]$ \\
\hline \multicolumn{8}{|c|}{ Heterogeneity: $C \mathrm{Ch}^{2}=0.66, \mathrm{df}=5(P=0.98) ; 1^{2}=0.0 \%$} \\
\hline \multicolumn{8}{|c|}{ Test for overall effect: $Z=0.59(P=0.56)$} \\
\hline \multicolumn{8}{|c|}{ Test for subgroup differences: $\mathrm{Ch}^{2}=0.22, \mathrm{df}=2(P=0.90), \mathrm{I}^{2}=0.0 \%$} \\
\hline & & & & & $\begin{array}{lll}-5 & 0 & 5 \\
\text { mental } & & \text { Favour }\end{array}$ & & \\
\hline
\end{tabular}


Analysis 3.8

Comparison 3 SUBGROUP 2: CBT versus "ACTIVE" PSYCHOLOGICAL THERAPIES, Outcome 8 Mental state: 3c. Specific - average acore - positive symptoms delusions (Psychotic Symptom Rating Scale, high = poor)

Review: Cognitive behavioural therapy versus other psychosocial treatments for schizophrenia

Comparison: 3 SUBGROUP 2: CBT versus “ACTIVE” PSYCHOLOGICAL THERAPIES Outcome: 8 Mental state: $3 c$. Specific - average acore - positive symptoms - delusions (Psychotic Symptom Rating Scale, high = poor)

\begin{tabular}{|c|c|c|c|c|c|c|c|c|}
\hline \multirow{3}{*}{$\begin{array}{l}\text { Study or subgroup } \\
\text { I short-term }\end{array}$} & \multirow{2}{*}{$\begin{array}{r}\text { Experimental } \\
\mathrm{N} \\
\end{array}$} & \multicolumn{3}{|c|}{ Control } & \multicolumn{2}{|c|}{$\begin{array}{c}\text { Mean } \\
\text { Difference }\end{array}$} & \multirow[t]{2}{*}{ Weight } & \multirow{2}{*}{$\begin{array}{r}\text { Mean } \\
\text { Difference } \\
\text { IV,Fixed,95\% Cl }\end{array}$} \\
\hline & & $\operatorname{Mean}(S D)$ & $\mathrm{N}$ & $\operatorname{Mean}(\mathrm{SD})$ & \multicolumn{2}{|c|}{ IV,Fixed,95\% Cl } & & \\
\hline & & & & & & & & \\
\hline Cather 2005 & 15 & $10.69(6.49)$ & 13 & $10.15(7.48)$ & & & $7.9 \%$ & $0.54[-4.69,5.77]$ \\
\hline Penn 2009 & 32 & $8.6(7)$ & 33 & $10(6.3)$ & 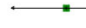 & & $20.7 \%$ & $-1.40[-4.64,1.84]$ \\
\hline Subtotal $(95 \% \mathrm{CI})$ & 47 & & 46 & & & & $28.6 \%$ & $-0.86[-3.62,1.89]$ \\
\hline \multicolumn{9}{|c|}{ Heterogeneity: Chi ${ }^{2}=0.38, \mathrm{df}=1(P=0.54): 1^{2}=0.0 \%$} \\
\hline \multirow{2}{*}{\multicolumn{9}{|c|}{$\begin{array}{l}\text { Test for overal effect: } Z=0.61(P=0.54) \\
2 \text { medium-term }\end{array}$}} \\
\hline & & & & & & 2 medium-term & & \\
\hline Durham 2003 & 22 & $13.3(5.4)$ & 19 & $11.8(6.2)$ & & " & $16.9 \%$ & $1.50[-2.09,5.09]$ \\
\hline Penn 2009 & 32 & $8(7.7)$ & 33 & $10.4(5.9)$ & & - & $19.4 \%$ & $-2.40[-5.74,0.94]$ \\
\hline Subtotal $(95 \% \mathrm{CI})$ & 54 & & 52 & & & & $36.3 \%$ & $-0.59[-3.03,1.86]$ \\
\hline \multicolumn{9}{|c|}{ Heterogeneity: $C h i^{2}=2.43, \mathrm{df}=1(P=0.12) ; 1^{2}=59 \%$} \\
\hline \multicolumn{9}{|c|}{ Test for overal effect: $Z=0.47(P=0.64)$} \\
\hline \multicolumn{9}{|l|}{3 long-term } \\
\hline Durham 2003 & 21 & $11.1(5.8)$ & 19 & $9.7(6.1)$ & & & $15.9 \%$ & $1.40[-230,5.10]$ \\
\hline Penn 2009 & 32 & $6.9(7)$ & 33 & $9(6.8)$ & & - & $19.3 \%$ & $-2.10[-5.46,1.26]$ \\
\hline Subtotal $(95 \% \mathrm{CI})$ & 53 & & 52 & & & & $35.1 \%$ & $-0.52[-3.00,1.97]$ \\
\hline \multicolumn{9}{|c|}{ Heterogeneity: $C \mathrm{i}^{2}=1.89, \mathrm{df}=1\langle\mathrm{P}=0.17\rangle: 1^{2}=47 \%$} \\
\hline \multicolumn{9}{|c|}{ Test for overal effect: $Z=0.41(P=0.68)$} \\
\hline Total $(95 \% \mathrm{CI})$ & 154 & & 150 & & & & $100.0 \%$ & $-0.64[-2.11,0.83]$ \\
\hline \multicolumn{9}{|c|}{ Heterogeneity: $C \mathrm{Ch}^{2}=4.74, \mathrm{df}=5(\mathrm{P}=0.45): \mathrm{I}^{2}=0.0 \%$} \\
\hline \multicolumn{9}{|c|}{ Test for overal effect: $Z=0.85(P=0.39)$} \\
\hline \multicolumn{9}{|c|}{ Test for subgroup differences: $\mathrm{Ch}^{2}=0.04, \mathrm{df}=2(\mathrm{P}=0.98), 1^{2}=0.0 \%$} \\
\hline & & & & & $-4 \quad-2$ & 2 & 4 & \\
\hline & & & & & Is experimental & & & \\
\hline
\end{tabular}


Analysis 3.9

Comparison 3 SUBGROUP 2: CBT versus "ACTIVE" PSYCHOLOGICAL THERAPIES, Outcome 9 Mental state: 4a. Specific - average score - negative symptoms overall PANSS, endpoint data,high = poor)

Review: Cognitive behavioural therapy versus other psychosocial treatments for schizophrenia

Comparison: 3 SUBGROUP 2: CBT versus “ACTIVE” PSYCHOLOGICAL THERAPIES Outcome: 9 Mental state: 4a. Specific - average score - negative symptoms - overall (PANSS, endpoint data, high $=$ poor $)$

\begin{tabular}{|c|c|c|c|c|c|c|c|}
\hline \multirow[t]{2}{*}{ Study or subgroup } & \multirow{2}{*}{$\begin{array}{r}\text { Experimental } \\
\mathrm{N}\end{array}$} & \multicolumn{3}{|c|}{ Control } & \multirow{2}{*}{$\begin{array}{c}\text { Mean } \\
\text { Difference } \\
\text { IV.Fixed.95\% CI }\end{array}$} & \multirow[t]{2}{*}{ Weight } & \multirow{2}{*}{$\begin{array}{r}\text { Mean } \\
\text { Difference } \\
\text { IV.Fixed,95\% CI } \\
\end{array}$} \\
\hline & & $\operatorname{Mean}(\mathrm{SD})$ & $\mathrm{N}$ & $\operatorname{Mean(SD)}$ & & & \\
\hline \multicolumn{8}{|l|}{ I short:term } \\
\hline Bechdolf 2004 & 40 & $13.9(4.5)$ & 48 & 13.1 (5.2) & , & $29.4 \%$ & $0.80[-1.23,283]$ \\
\hline Cather 2005 & 15 & $14.87(4.97)$ & 13 & $14.92(5.72)$ & & $7.5 \%$ & $-0.05[-4.05,3.95]$ \\
\hline Levine 1998 & 6 & $7.8(4)$ & 6 & $15(1.5)$ & $\hookrightarrow$ & $10.3 \%$ & $-7.20[-10.62,-3.78]$ \\
\hline Penn 2009 & 32 & $13.5(3.3)$ & 33 & $13.4(2.9)$ & $\Rightarrow$ & $528 \%$ & $0.10[-1.41,1.61]$ \\
\hline Subtotal $(95 \% \mathrm{CI})$ & 93 & & 100 & & - & $100.0 \%$ & $-0.46[-1.56,0.64]$ \\
\hline \multicolumn{8}{|c|}{ Heterogeneity: $C h^{2}=16.99$, of $=3(P=0.00071) ; 1^{2}=82 \%$} \\
\hline \multicolumn{8}{|c|}{ Test for overall effect: $Z=0.82(P=0.41)$} \\
\hline \multicolumn{8}{|l|}{2 medium-term } \\
\hline Bechdolf 2004 & 31 & $12.5(4.01)$ & 40 & $13(6.1)$ & & $31.3 \%$ & $-0.50[-2.86,1.86]$ \\
\hline Garety 2008 a & 21 & $12.33(4.94)$ & 24 & $13.38(5.81)$ & $\rightarrow$ & $17.7 \%$ & $-1.05[-4.19,209]$ \\
\hline Penn 2009 & 32 & $12.4(3.9)$ & 33 & $127(3.7)$ & 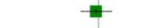 & $51.0 \%$ & $-0.30[-2.15,1.55]$ \\
\hline Subtotal $(95 \% \mathrm{CI})$ & 84 & & 97 & & - & $100.0 \%$ & $-0.50[-1.82,0.83]$ \\
\hline \multicolumn{8}{|c|}{ Heterogeneity: $C \mathrm{~h}^{2}=0.16$, ff $=2(\mathrm{P}=0.92) ; 1^{2}=0.0 \%$} \\
\hline \multicolumn{8}{|c|}{ Test for overall effect: $Z=0.73(P=0.46)$} \\
\hline \multicolumn{8}{|l|}{3 long-term } \\
\hline Bechdolf 2004 & 16 & $13.7(5)$ & 25 & $14.5(6.31)$ & $=$ & $24.0 \%$ & $-0.80[-4.28,2.68]$ \\
\hline Garety 2008 a & 22 & $12.18(4.38)$ & 21 & $12.95(8.09)$ & 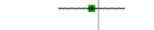 & $19.0 \%$ & $-0.77[-4.68,3.14]$ \\
\hline Penn 2009 & 32 & $12.9(4.4)$ & 33 & $13.2(4.9)$ & $=$ & $56.9 \%$ & $-0.30[-2.56,1.96]$ \\
\hline Subtotal $(95 \% \mathrm{CI})$ & 70 & & 79 & & - & $100.0 \%$ & $-0.51[-2.22,1.20]$ \\
\hline \multicolumn{8}{|c|}{ Heterogeneity: $C h^{2}=0.08$, df $=2(P=0.96) ; 1^{2}=0.0 \%$} \\
\hline \multicolumn{8}{|c|}{ Test for overall effect: $Z=0.59(P=0.56)$} \\
\hline \multicolumn{8}{|c|}{ Test for subgroup differences: $C h^{2}=0.00$, df $=2(P=1.00), 1^{2}=0.0 \%$} \\
\hline & & & & & -10 & & \\
\hline
\end{tabular}


Analysis 3.10

Comparison 3 SUBGROUP 2: CBT versus "ACTIVE" PSYCHOLOGICAL THERAPIES, Outcome 10 Mental state: $4 \mathrm{~b}$. Specific - average score - negative symptoms overall $($ SANS, high $=$ good $)$

Review: Cognitive behavioural therapy versus other psychosocial treatments for schizophrenia

Comparison: 3 SUBGROUP 2: CBT versus “ACTIVE” PSYCHOLOGICAL THERAPIES Outcome: 10 Mental state: $4 \mathrm{~b}$. Specific - average score - negative symptoms - overall $($ SANS, high $=$ good $)$

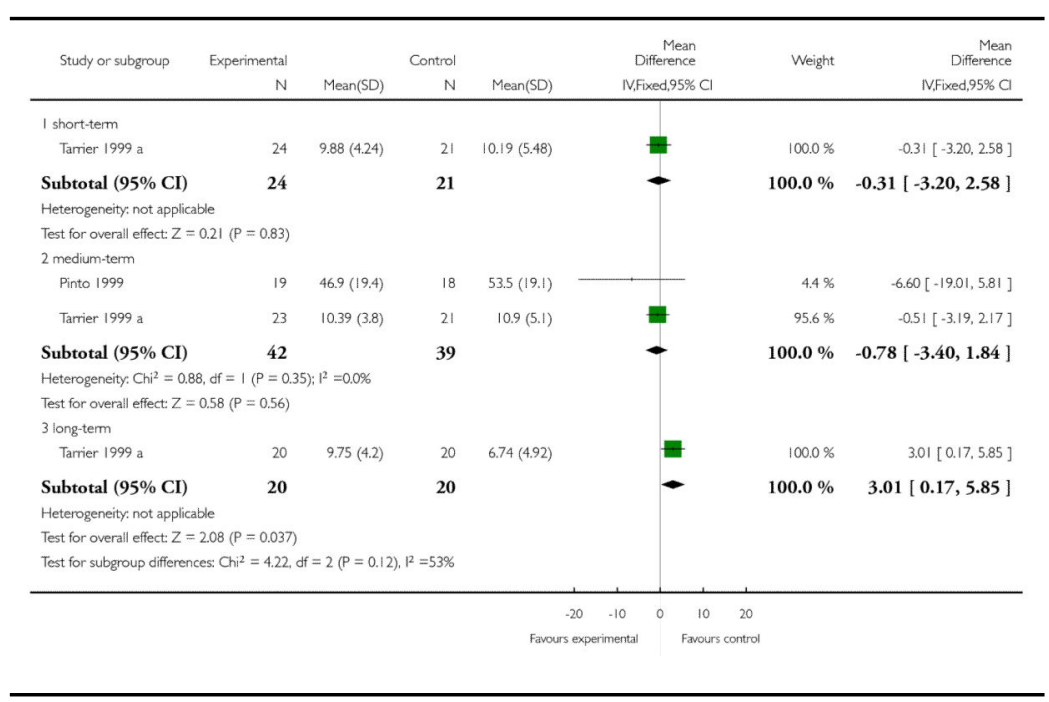


Analysis 3.11

Comparison 3 SUBGROUP 2: CBT versus "ACTIVE" PSYCHOLOGICAL THERAPIES, Outcome 11 Mental state: 5a. Specific - average score - affective symptoms

(PANSS General symptoms,endpoint data, high = poor)

Review: Cognitive behavioural therapy versus other psychosocial treatments for schizophrenia

Comparison: 3 SUBGROUP 2: CBT versus “ACTIVE” PSYCHOLOGICAL THERAPIES Outcome: 11 Mental state: 5a. Specific - average score - affective symptoms (PANSS General symptoms, endpoint data, high = poor)

\begin{tabular}{|c|c|c|c|c|c|c|c|c|}
\hline \multirow[t]{2}{*}{ Study or subgroup } & \multirow{2}{*}{$\begin{array}{r}\text { Experimental } \\
\mathrm{N}\end{array}$} & \multicolumn{3}{|c|}{ Control } & \multirow{2}{*}{\multicolumn{2}{|c|}{$\begin{array}{c}\text { Mean } \\
\text { Difference } \\
\text { IV.Fixed.95\% CI }\end{array}$}} & \multirow[t]{2}{*}{ Weight } & \multirow{2}{*}{$\begin{array}{r}\text { Mean } \\
\text { Difference } \\
\text { IVFFixed,95\% C } \\
\end{array}$} \\
\hline & & $\operatorname{Mean}(\mathrm{SD})$ & $\mathrm{N}$ & $\operatorname{Mean(SD)}$ & & & & \\
\hline \multicolumn{9}{|l|}{ I short-term } \\
\hline Bechdolf 2004 & 40 & $28(9.2)$ & 48 & $25(6.2)$ & & $=-$ & $40.1 \%$ & $3.00[-0.35,6.35]$ \\
\hline Penn 2009 & 32 & $27(4.9)$ & 33 & $29(6.3)$ & - & & $59.9 \%$ & $-200[-4.74,0.74]$ \\
\hline Subtotal $(95 \% \mathrm{CI})$ & 72 & & 81 & & & & $100.0 \%$ & $0.01[-2.11,2.13]$ \\
\hline \multicolumn{9}{|c|}{ Heterogeneity: $C h i^{2}=5.13, d f=\mid(P=0.02) ; 1^{2}=81 \%$} \\
\hline \multicolumn{9}{|c|}{ Test for overall effect: $Z=0.00(P=1.0)$} \\
\hline \multicolumn{9}{|l|}{2 medium-term } \\
\hline Bechdolf 2004 & 31 & $28.5(8.8)$ & 40 & $26(6.9)$ & & $=$ & $28.8 \%$ & $2.50[-1.26,6.26]$ \\
\hline Durham 2003 & 22 & $96.2(17.7)$ & 19 & $95.2(16.2)$ & & & $3.8 \%$ & $1.00[-9.38,11.38]$ \\
\hline Garety 2008 a & 21 & $27.81(6.76)$ & 24 & $29.54(7.6)$ & $\longrightarrow$ & - & $23.2 \%$ & $-1.73[-5.93,247]$ \\
\hline Penn 2009 & 32 & $25.6(5.3)$ & 33 & $30(7.1)$ & $=$ & & $44.2 \%$ & $-4.40[-7.44,-1.36]$ \\
\hline Subtotal $(95 \% \mathrm{CI})$ & 106 & & 116 & & & & $100.0 \%$ & $-1.59[-3.61,0.43]$ \\
\hline \multicolumn{9}{|c|}{ Heterogeneity: $\mathrm{Ch}^{2}=8.06, \mathrm{df}=3(\mathrm{P}=0.04): \mathrm{I}^{2}=63 \%$} \\
\hline \multicolumn{9}{|c|}{ Test for overall effect: $Z=1.54(P=0.12)$} \\
\hline \multicolumn{9}{|l|}{3 longterm } \\
\hline Bechdolf 2004 & 16 & $28.1(6.3)$ & 25 & $26.4(6.9)$ & & $=$ & $23.8 \%$ & $1.70[-2.40,5.80]$ \\
\hline Durham 2003 & 21 & $87(23.1)$ & 149 & $93.5(16.8)$ & & - & $3.8 \%$ & $-6.50[-16.74,3.74]$ \\
\hline Garety 2008 a & 22 & $28(8.42)$ & 20 & $28.25(6.56)$ & . & - & $19.5 \%$ & $-0.25[-4.79,4.29]$ \\
\hline Penn 2009 & 32 & $26(5.1)$ & 33 & $29.6(6.2)$ & 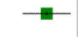 & & $52.9 \%$ & $-3.60[-6.36,-0.84]$ \\
\hline Subtotal $(95 \% \mathrm{CI})$ & 91 & & 227 & & $\longrightarrow$ & & $100.0 \%$ & $-1.80[-3.80,0.21]$ \\
\hline \multicolumn{9}{|c|}{ Heterogeneity: $C \mathrm{~h}^{2}=5.69, \mathrm{df}=3(\mathrm{P}=0.13) ; 1^{2}=47 \%$} \\
\hline \multicolumn{9}{|c|}{ Test for overall effect: $Z=1.76(P=0.079)$} \\
\hline \multicolumn{9}{|c|}{ Test for subgroup differences: $C h^{2}=1.72, d f=2(P=0.42), 1^{2}=0.0 \%$} \\
\hline & & & & & $\begin{array}{c}-5 \\
\text { xperimental }\end{array}$ & $\begin{array}{cc}5 & 10 \\
\text { Favours control }\end{array}$ & & \\
\hline
\end{tabular}


Analysis 3.12

Comparison 3 SUBGROUP 2: CBT versus "ACTIVE" PSYCHOLOGICAL THERAPIES, Outcome 12 Mental state: $5 \mathrm{~b}$. Specific - average score - affective symptoms depression (Beck Depression Inventory, high = poor)

Review: Cognitive behavioural therapy versus other psychosocial treatments for schizophrenia

Comparison: 3 SUBGROUP 2: CBT versus “ACTIVE” PSYCHOLOGICAL THERAPIES Outcome: 12 Mental state: 5b. Specific - average score - affective symptoms - depression (Beck Depression Inventory, high = poor)

\begin{tabular}{|c|c|c|c|c|c|c|c|c|}
\hline \multirow[t]{2}{*}{ Study or subgroup } & \multirow{2}{*}{$\begin{array}{r}\text { Experimental } \\
\mathrm{N}\end{array}$} & \multicolumn{3}{|c|}{ Control } & \multicolumn{2}{|c|}{$\begin{array}{c}\text { Mean } \\
\text { Difference }\end{array}$} & \multirow[t]{2}{*}{ Weight } & \multirow{2}{*}{$\begin{array}{r}\text { Mean } \\
\text { Difference } \\
\text { IVFixed,95\% C }\end{array}$} \\
\hline & & $\operatorname{Mean}(S D)$ & $\mathrm{N}$ & $\operatorname{Mean}(S D)$ & & ed, $95 \% \mathrm{Cl}$ & & \\
\hline \multicolumn{9}{|l|}{ I short-term } \\
\hline Penn 2009 & 32 & $11.4(7.6)$ & 33 & $12.6(10.2)$ & $=$ & & $32.9 \%$ & $-1.20[-5.56,3.16]$ \\
\hline Subtotal $(95 \% \mathrm{CI})$ & 32 & & 33 & & & & $32.9 \%$ & $-1.20[-5.56,3.16]$ \\
\hline \multicolumn{9}{|c|}{ Heterogeneity, not applicable } \\
\hline \multicolumn{9}{|c|}{ Test for overal effect: $Z=0.54(P=0.59)$} \\
\hline \multicolumn{9}{|l|}{2 medium-term } \\
\hline Garety 2008 a & 20 & $18.75(14.33)$ & 23 & $20.87(13.32)$ & & & $9.1 \%$ & $-2.2[-10.43,6.19]$ \\
\hline Penn 2009 & 32 & $10.5(8.5)$ & 33 & $13.9(10.7)$ & 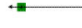 & & $28.5 \%$ & $-3.40[-8.09,1.29]$ \\
\hline Subtotal $(95 \% \mathrm{CI})$ & 52 & & 56 & & & & $37.5 \%$ & $-3.09[-7.18,0.99]$ \\
\hline \multicolumn{9}{|c|}{ Heterogeneity; $C \mathrm{Ch}^{2}=0.07, \mathrm{df}=1 \quad(\mathrm{P}=0.79) ; \mathrm{I}^{2}=0.0 \%$} \\
\hline \multicolumn{9}{|c|}{ Test for overall effect: $Z=1.48(P=0.14)$} \\
\hline \multicolumn{9}{|l|}{3 long-term } \\
\hline Garety 2008 a & 22 & $15.54(10.91)$ & 18 & $21.39(13.87)$ & & & $10.1 \%$ & $-5.85[-13.71,2.01]$ \\
\hline Penn 2009 & 32 & $11.5(9.4)$ & 33 & $17.9(13.6)$ & & & $19.5 \%$ & $-6.40[-1207,-0.73]$ \\
\hline Subtotal $(95 \% \mathrm{CI})$ & 54 & & 51 & & - & & $29.6 \%$ & $-6.21[-10.81,-1.61]$ \\
\hline \multicolumn{9}{|c|}{ Heterogeneity, $C \mathrm{i}^{2}=0.01, \mathrm{df}=1(P=0.91): 1^{2}=0.0 \%$} \\
\hline \multicolumn{9}{|c|}{ Test for overall effect: $Z=2.65(P=0.0081)$} \\
\hline Total $(95 \% \mathrm{CI})$ & 138 & & 140 & & & & $100.0 \%$ & $-3.39[-5.90,-0.89]$ \\
\hline \multicolumn{9}{|c|}{ Heterogeneity $: \mathrm{Ch}^{2}=2.52, \mathrm{df}=4(\mathrm{P}=0.64): 1^{2}=0.0 \%$} \\
\hline \multicolumn{9}{|c|}{ Test for overall effect: $Z=2.66(P=0.0079)$} \\
\hline \multicolumn{9}{|c|}{ Test for subgroup differences: $\mathrm{Ch}^{2}=2.43, \mathrm{df}=2(\mathrm{P}=0.30), \mathrm{f}^{2}=18 \%$} \\
\hline & & & & & $-4 \quad-2$ & 0 & 4 & \\
\hline & & & & Farours & sexperimental & Favours c & & \\
\hline
\end{tabular}


Analysis 3.13

Comparison 3 SUBGROUP 2: CBT versus "ACTIVE" PSYCHOLOGICAL THERAPIES, Outcome 13 Mental state: 5c. Specific - average score - affective symptoms self esteem (Rosenberg Self Esteem Scale (high = good))

Review: Cognitive behavioural therapy versus other psychosocial treatments for schizophrenia

Comparison: 3 SUBGROUP 2: CBT versus “ACTIVE” PSYCHOLOGICAL THERAPIES Outcome: 13 Mental state: $5 \mathrm{c}$. Specific - average score - affective symptoms - self esteem $($ Rosenberg Self Esteem Scale $($ high $=$ good)

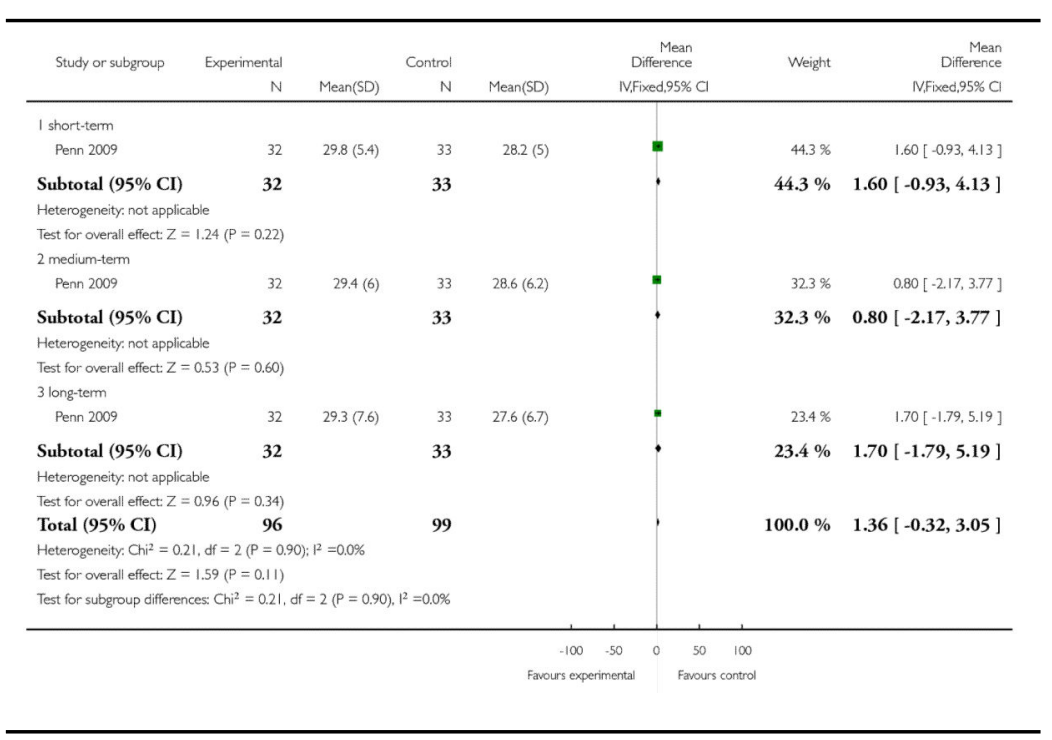


Analysis 3.14

Comparison 3 SUBGROUP 2: CBT versus "ACTIVE" PSYCHOLOGICAL THERAPIES, Outcome 14 Mental state: $5 \mathrm{~d}$. Specific - average score - affective symptoms anxiety (Beck anxiety Inventory (high = poor))

Review: Cognitive behavioural therapy versus other psychosocial treatments for schizophrenia

Comparison: 3 SUBGROUP 2: CBT versus “ACTIVE” PSYCHOLOGICAL THERAPIES Outcome: 14 Mental state: 5d. Specific - average score - affective symptoms - anxiety (Beck anxiety Inventory (high = poor))

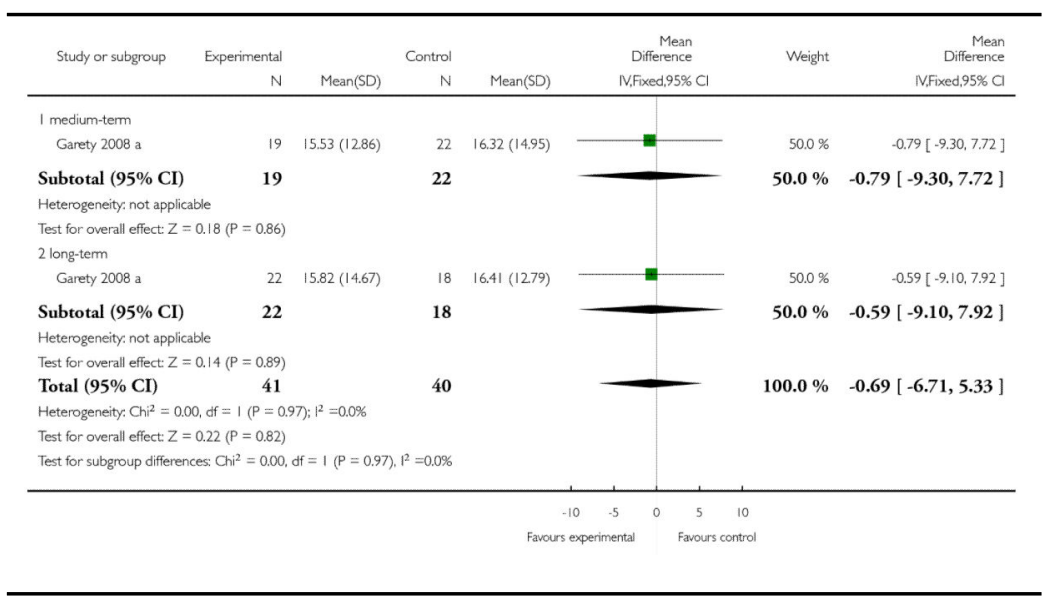


Analysis 3.15

Comparison 3 SUBGROUP 2: CBT versus "ACTIVE" PSYCHOLOGICAL THERAPIES, Outcome 15 Mental State: 5e. Specific - average score - affective symptoms insight (Beck Cognitive Insight Scale (high = good))

Review: Cognitive behavioural therapy versus other psychosocial treatments for schizophrenia

Comparison: 3 SUBGROUP 2: CBT versus “ACTIVE” PSYCHOLOGICAL THERAPIES

Outcome: 15 Mental State: 5e. Specific - average score - affective symptoms - insight (Beck Cognitive Insight Scale (high = good))

\begin{tabular}{|c|c|c|c|c|c|c|c|c|}
\hline \multirow{3}{*}{$\begin{array}{l}\text { Study or subgroup } \\
\begin{array}{l}\text { I short-term } \\
\text { Penn } 2009\end{array}\end{array}$} & \multirow{3}{*}{$\begin{array}{r}\text { Experimental } \\
\mathrm{N} \\
32\end{array}$} & \multirow{2}{*}{\multicolumn{2}{|c|}{$\begin{array}{lr} & \text { Control } \\
\text { Mean(SD) } & \mathrm{N} \\
\end{array}$}} & \multirow[t]{2}{*}{$\operatorname{Mean}(S D)$} & \multicolumn{2}{|c|}{$\begin{array}{c}\text { Mean } \\
\text { Difference } \\
\text { N.Fixed,95\% CI }\end{array}$} & Weight & $\begin{array}{r}\text { Mean } \\
\text { Difference } \\
\text { |V.Fixed,95\% C } \\
\end{array}$ \\
\hline & & & & & & & & \\
\hline & & $6.7(6.3)$ & 33 & $6(5.8)$ & & " & $29.0 \%$ & $0.70[-225,3.65]$ \\
\hline Subtotal $(95 \% \mathrm{CI})$ & 32 & & 33 & & & & $29.0 \%$ & $0.70[-2.25,3.65]$ \\
\hline \multicolumn{9}{|l|}{ Heterogeneity: not applicable } \\
\hline \multicolumn{9}{|c|}{ Test for overall effect: $Z=0.47(P=0.64)$} \\
\hline \multicolumn{9}{|l|}{2 medium-term } \\
\hline Penn 2009 & 32 & $4.2(6.6)$ & 33 & $4.7(5.4)$ & & & $29.2 \%$ & $-0.50[-3.44,2.44]$ \\
\hline Subtotal $(95 \% \mathrm{CI})$ & 32 & & 33 & & & & $29.2 \%$ & $-0.50[-3.44,2.44]$ \\
\hline \multicolumn{9}{|l|}{ Heterogeneity: not applicable } \\
\hline \multicolumn{9}{|c|}{ Test for overall effect: $Z=0.33(P=0.74)$} \\
\hline \multicolumn{9}{|l|}{3 long-term } \\
\hline Penn 2009 & 32 & $4.4(5.6)$ & 33 & $3.7(4.4)$ & & & $41.8 \%$ & $0.70[-1.75,3.15]$ \\
\hline Subtotal $(95 \% \mathrm{CI})$ & 32 & & 33 & & & & $41.8 \%$ & $0.70[-1.75,3.15]$ \\
\hline \multicolumn{9}{|c|}{ Heterogeneity. not applicable } \\
\hline \multicolumn{9}{|c|}{ Test for overall effect: $Z=0.56(P=0.58)$} \\
\hline Total $(95 \% \mathrm{CI})$ & 96 & & 99 & & & & $100.0 \%$ & $0.35[-1.24,1.94]$ \\
\hline \multicolumn{9}{|c|}{ Heterogeneity: $C h i^{2}=0.45$, of $=2(P=0.80) ; 1^{2}=0.0 \%$} \\
\hline \multicolumn{9}{|c|}{ Test for overall effect: $Z=0.43(P=0.67)$} \\
\hline \multicolumn{9}{|c|}{ Test for subgroup differences: $C \mathrm{~h}^{2}=0.45, \mathrm{df}=2(\mathrm{P}=0.80), \mathrm{I}^{2}=0.0 \%$} \\
\hline & & & & & -2 & 2 & & \\
\hline
\end{tabular}


Analysis 3.16

Comparison 3 SUBGROUP 2: CBT versus "ACTIVE" PSYCHOLOGICAL THERAPIES, Outcome 16 Global state: 1. Relapse

Review: Cognitive behavioural therapy versus other psychosocial treatments for schizophrenia

Comparison: 3 SUBGROUP 2: CBT versus “ACTIVE” PSYCHOLOGICAL THERAPIES Outcome: 16 Global state: 1 . Relapse

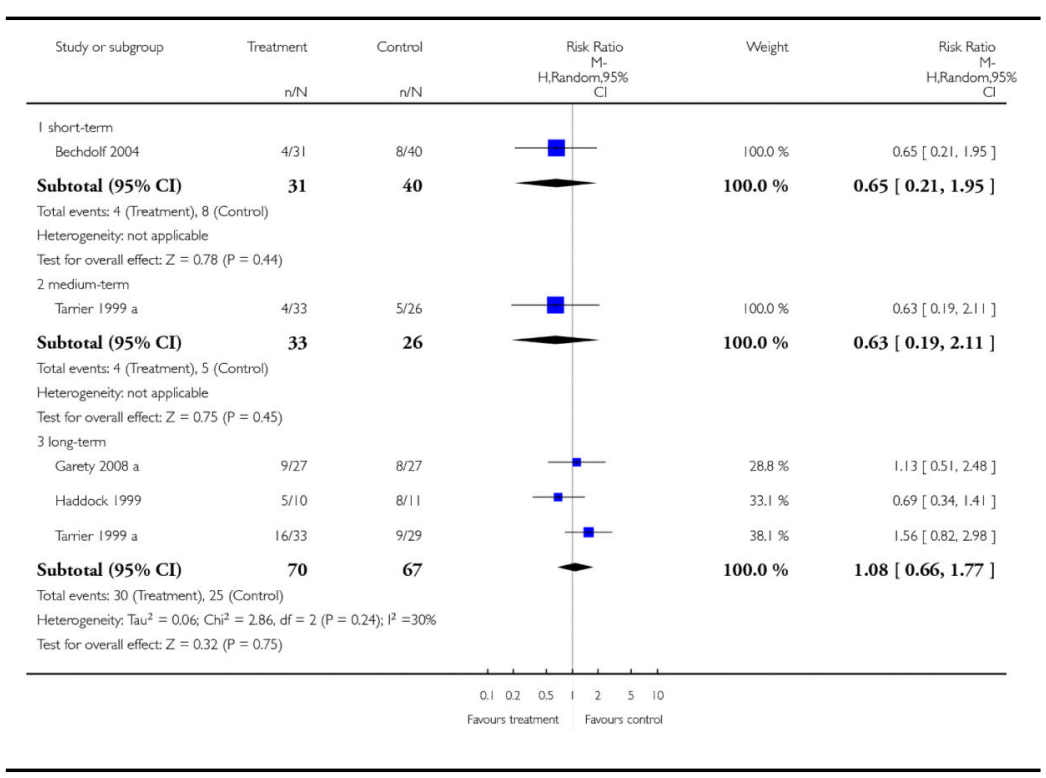


Analysis 3.17

Comparison 3 SUBGROUP 2: CBT versus "ACTIVE" PSYCHOLOGICAL THERAPIES, Outcome 17 Global state: 2. Rehospitalisation

Review: Cognitive behavioural therapy versus other psychosocial treatments for schizophrenia

Comparison: 3 SUBGROUP 2: CBT versus “ACTIVE” PSYCHOLOGICAL THERAPIES Outcome: 17 Global state: 2. Rehospitalisation

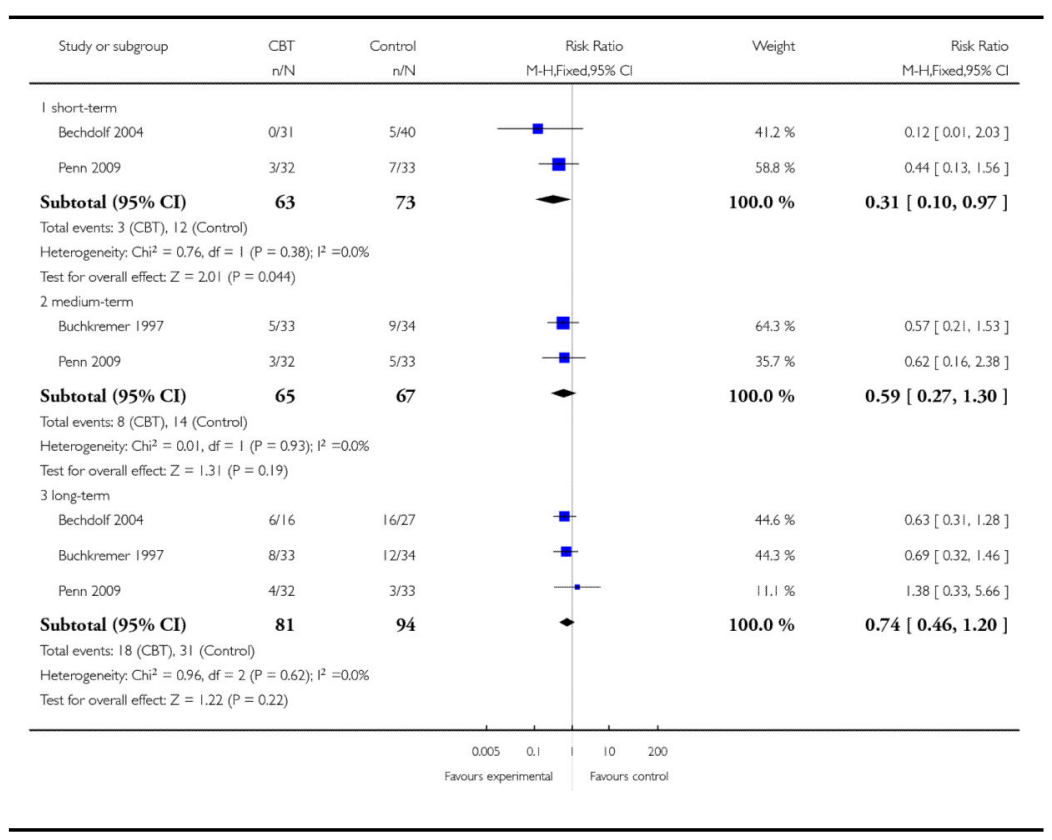


Analysis 3.18

Comparison 3 SUBGROUP 2: CBT versus "ACTIVE" PSYCHOLOGICAL THERAPIES, Outcome 18 Global state: 3a. Average score (GAS, endpoint data, high = good)

Review: Cognitive behavioural therapy versus other psychosocial treatments for schizophrenia

Comparison: 3 SUBGROUP 2: CBT versus “ACTIVE” PSYCHOLOGICAL THERAPIES Outcome: 18 Global state: $3 \mathrm{a}$. Average score (GAS, endpoint data, high = good)

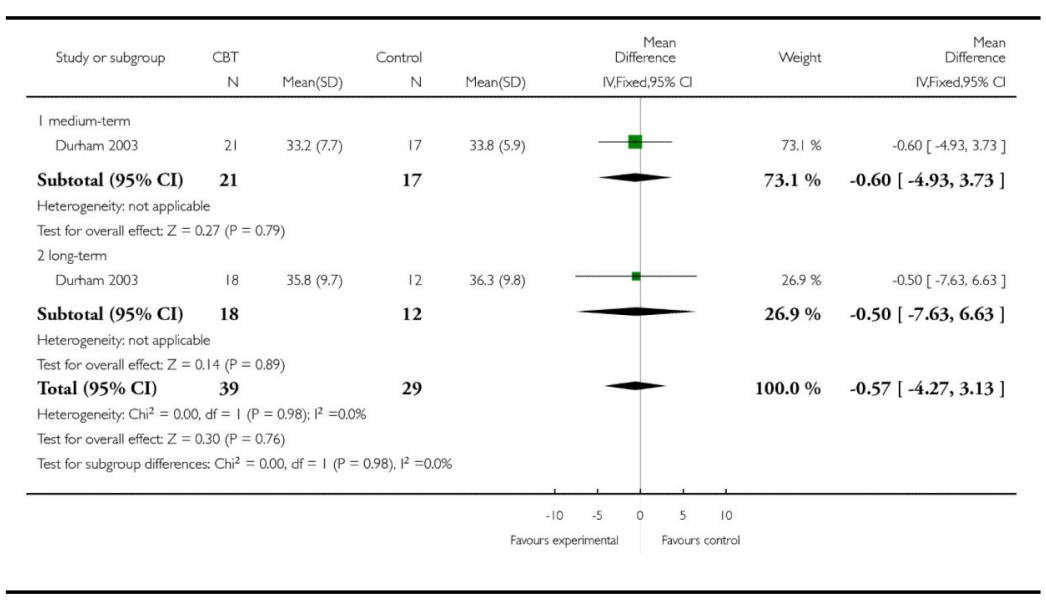

Analysis 3.19

Comparison 3 SUBGROUP 2: CBT versus "ACTIVE" PSYCHOLOGICAL THERAPIES, Outcome 19 Global state: 3b. Average score $(\mathrm{GAF}$, high $=$ good $)$

Review: Cognitive behavioural therapy versus other psychosocial treatments for schizophrenia

Comparison: 3 SUBGROUP 2: CBT versus “ACTIVE” PSYCHOLOGICAL THERAPIES Outcome: 19 Global state: $3 \mathrm{~b}$. Average score $(\mathrm{GAF}$, high = good)

\begin{tabular}{|c|c|c|c|c|c|c|c|c|}
\hline Study or subgroup & $\begin{array}{r}\text { Experimental } \\
\mathrm{N}\end{array}$ & \multicolumn{3}{|c|}{ Control } & \multicolumn{2}{|c|}{$\begin{array}{c}\text { Mean } \\
\text { Difference } \\
\text { IV,Fixed,95\% CI }\end{array}$} & Weight & 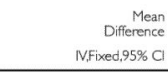 \\
\hline \multicolumn{9}{|l|}{1 short-term } \\
\hline Haddock 2009 & 38 & $41.86(15.63)$ & 39 & $33.34(14.64)$ & & 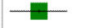 & $100.0 \%$ & $8.52[1.75,15.29]$ \\
\hline Subtotal $(95 \% \mathrm{CI})$ & 38 & & 39 & & & - & $100.0 \%$ & $8.52[1.75,15.29]$ \\
\hline \multicolumn{9}{|c|}{ Heterogeneity not applicable } \\
\hline \multicolumn{9}{|c|}{ Test for overall effect: $Z=2.47(P=0.014)$} \\
\hline \multicolumn{9}{|l|}{2 longterm } \\
\hline Durham 2003 & 18 & $35.8(9.7)$ & 12 & $36.3(9.8)$ & - & & $100.0 \%$ & $-0.50[-7.63,6.63]$ \\
\hline Subtotal $(95 \% \mathrm{CI})$ & 18 & & 12 & & & - & $100.0 \%$ & $-0.50[-7.63,6.63]$ \\
\hline \multicolumn{9}{|c|}{ Heterogeneity not applicable } \\
\hline \multicolumn{9}{|c|}{ Test for overal effect: $Z=0.14(P=0.89)$} \\
\hline \multicolumn{9}{|c|}{ Test for subgroup differences: $\mathrm{Ch}^{2}=3.23 \mathrm{df}=1(\mathrm{P}=0.07), 1^{2}=69 \%$} \\
\hline & & & & & $-20 \quad-10$ & $10 \quad 20$ & & \\
\hline & & & & & Favours control & Favours CBT & & \\
\hline
\end{tabular}


Analysis 3.20

Comparison 3 SUBGROUP 2: CBT versus "ACTIVE" PSYCHOLOGICAL THERAPIES, Outcome 20 Global state: 4a. Social Functioning Scale (high $=$ good)

Review: Cognitive behavioural therapy versus other psychosocial treatments for schizophrenia

Comparison: 3 SUBGROUP 2: CBT versus “ACTIVE” PSYCHOLOGICAL THERAPIES Outcome: 20 Global state: 4a. Social Functioning Scale (high = good)

\begin{tabular}{|c|c|c|c|c|c|c|c|c|}
\hline Study or subgroup & $\begin{array}{r}\text { Experimental } \\
\mathrm{N}\end{array}$ & \multicolumn{3}{|c|}{ Control } & \multicolumn{2}{|c|}{$\begin{array}{c}\text { Mean } \\
\text { Difference } \\
\text { IV,fixed,95\% C }\end{array}$} & Weight & $\begin{array}{r}\text { Mean } \\
\text { Difference } \\
\text { M.Fixed,95\% C } \\
\end{array}$ \\
\hline \multicolumn{9}{|l|}{ I short-term } \\
\hline Penn 2009 & 32 & $129.6(21.1)$ & 33 & $124.2(22.4)$ & & $\#$ & $37.6 \%$ & $5.40[-5.18,15.98]$ \\
\hline Subtotal $(95 \% \mathrm{CI})$ & 32 & & 33 & & & - & $37.6 \%$ & $5.40[-5.18,15.98]$ \\
\hline \multicolumn{9}{|c|}{ Heterogeneity not applicable } \\
\hline \multicolumn{9}{|c|}{ Test for overall effect: $Z=1.00(P=0.32)$} \\
\hline \multicolumn{9}{|l|}{2 medium-term } \\
\hline Penn 2009 & 32 & $129.1(20.5)$ & 33 & $121.9(23.3)$ & & 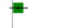 & $37.0 \%$ & $7.20[-3.46,17.86]$ \\
\hline Subtotal $(95 \% \mathrm{CI})$ & 32 & & 33 & & & - & $37.0 \%$ & $7.20[-3.46,17.86]$ \\
\hline \multicolumn{9}{|c|}{ Heterogeneity, not applicable } \\
\hline \multicolumn{9}{|c|}{ Test for overall effect: $Z=1.32(P=0.19)$} \\
\hline \multicolumn{9}{|l|}{3 long-term } \\
\hline Penn 2009 & 32 & $128.5(28.5)$ & 33 & $119.7(24.2)$ & & $\mp$ & $25.4 \%$ & $8.80[-4.07,21.67]$ \\
\hline Subtotal $(95 \% \mathrm{CI})$ & 32 & & 33 & & & - & $25.4 \%$ & $8.80[-4.07,21.67]$ \\
\hline \multicolumn{9}{|c|}{ Heterogeneity, not applicable } \\
\hline \multicolumn{9}{|c|}{ Test for overall effect: $Z=1.34(P=0.18)$} \\
\hline Total $(95 \% \mathrm{CI})$ & 96 & & 99 & & & - & $100.0 \%$ & $6.93[0.44,13.41]$ \\
\hline \multicolumn{9}{|c|}{ Heterogeneity; $\mathrm{Ch}^{2}{ }^{2}=0.16, \mathrm{df}=2(\mathrm{P}=0.92) ; 1^{2}=0.0 \%$} \\
\hline \multicolumn{9}{|c|}{ Test for overall effect: $Z=2.09(P=0.036)$} \\
\hline \multicolumn{9}{|c|}{ Test for subgroup differences: $\mathrm{Ch}^{2}=0.16, \mathrm{df}=2(P=0.92), 1^{2}=0.0 \%$} \\
\hline & & & & & .50 & 50 & & \\
\hline & & & & Fave & rimental & Favours & & \\
\hline
\end{tabular}


Analysis 3.21

Comparison 3 SUBGROUP 2: CBT versus "ACTIVE"

PSYCHOLOGICAL THERAPIES, Outcome 21 Global state 4b. Social and Occupational Functioning

Assessment Scale $($ high $=$ good $)$

Review: Cognitive behavioural therapy versus other psychosocial treatments for schizophrenia

Comparison: 3 SUBGROUP 2: CBT versus “ACTIVE” PSYCHOLOGICAL THERAPIES Outcome: 21 Global state 4b. Social and Occupational Functioning Assessment Scale (high $=$ good)

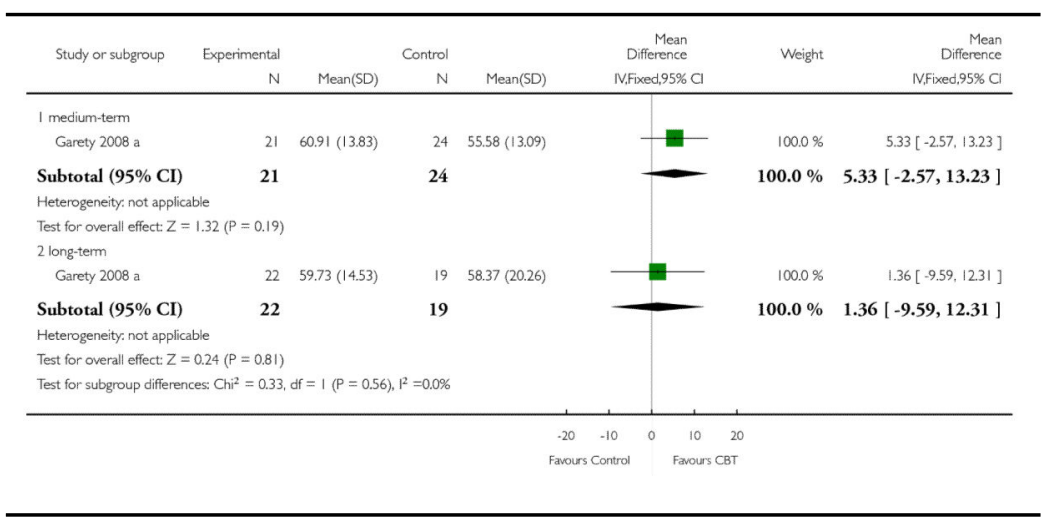

Analysis 3.22

Comparison 3 SUBGROUP 2: CBT versus "ACTIVE" PSYCHOLOGICAL THERAPIES, Outcome 22

Quality of Life: EuroQOL $($ high $=$ good $)$

Review: Cognitive behavioural therapy versus other psychosocial treatments for schizophrenia

Comparison: 3 SUBGROUP 2: CBT versus “ACTIVE” PSYCHOLOGICAL THERAPIES Outcome: 22 Quality of Life: EuroQOL (high = good)

\begin{tabular}{|c|c|c|c|c|c|c|c|c|}
\hline Study or subgroup & $\begin{array}{r}\text { Experimental } \\
\mathrm{N}\end{array}$ & \multicolumn{3}{|c|}{ Control } & \multicolumn{2}{|c|}{$\begin{array}{r}\text { Mean } \\
\text { Difference }\end{array}$} & Weight & $\begin{array}{r}\text { Mear } \\
\text { Difference } \\
\text { N.Fixed,95\% C }\end{array}$ \\
\hline \multicolumn{9}{|l|}{ I long-tem } \\
\hline Garety 2008 a & 21 & $52.52(22.76)$ & 16 & $54.38(29.28)$ & & & $100.0 \%$ & $-1.86[-19.20,15.48]$ \\
\hline Total $(95 \% \mathrm{CI})$ & 21 & & 16 & & & & $100.0 \%$ & $-1.86[-19.20,15.48]$ \\
\hline \multicolumn{9}{|c|}{ Heterogeneity. not applicable } \\
\hline \multicolumn{9}{|c|}{ Test for overall effect: $Z=0.21(P=0.83)$} \\
\hline \multicolumn{9}{|c|}{ Test for subgroup differences: Not applicable } \\
\hline \multirow{2}{*}{\multicolumn{9}{|c|}{$\begin{array}{ccccc}-100 & -50 & 0 & 50 & 100 \\
\text { Favours experimental } & & 50 & 100 \text { Fars control }\end{array}$}} \\
\hline & & & & Favou & & & & \\
\hline
\end{tabular}


Analysis 3.23

Comparison 3 SUBGROUP 2: CBT versus "ACTIVE" PSYCHOLOGICAL THERAPIES, Outcome 23

Satisfaction with treatment: 1 . Leaving the study early

Review: Cognitive behavioural therapy versus other psychosocial treatments for schizophrenia

Comparison: 3 SUBGROUP 2: CBT versus “ACTIVE” PSYCHOLOGICAL THERAPIES

Outcome: 23 Satisfaction with treatment: 1.Leaving study early

\begin{tabular}{|c|c|c|c|c|}
\hline Study or subgroup & $\begin{array}{l}\mathrm{CBT} \\
\mathrm{n} / \mathrm{N}\end{array}$ & $\begin{array}{r}\text { Counselling } \\
n / N\end{array}$ & $\begin{array}{r}\text { Risk Ratio } \\
M- \\
\text { H.Random,95\% } \\
C\end{array}$ & $\begin{array}{c}\text { Risk Ratio } \\
\text { M- } \\
\text { H.Random.95\% } \\
\text { C. }\end{array}$ \\
\hline Durham 2003 & 1/22 & $4 / 23$ & $\longrightarrow$ & $0.26[0.03,2.16]$ \\
\hline Garety 2008 a & $24 / 133$ & $7 / 28$ & 불 & $0.72[0.35,1.51]$ \\
\hline Haddock 1999 & 1/10 & o/11 & - & $3.27[0.15,72.23]$ \\
\hline Levine 1998 & $0 / 6$ & $0 / 6$ & & $0.0[0.0,0.0]$ \\
\hline Pinto 1999 & 1/20 & $3 / 21$ & $\because$ & $0.35[0.04,3.09]$ \\
\hline Tarrier 1999 a & $4 / 33$ & 1/26 & $\longrightarrow$ & $3.15[0.37,26.52]$ \\
\hline Total $(95 \% \mathrm{CI})$ & 224 & 115 & - & $0.75[0.40,1.43]$ \\
\hline \multicolumn{5}{|c|}{$\begin{array}{l}\text { Total events: } 31 \text { (CBT), } 15 \text { (Counselling) } \\
\text { Heterngeneity Tau }{ }^{2}=0.01 ; C \mathrm{Ch}^{2}=4.06, \mathrm{df}=4(\mathrm{P}=0.40) ; 1^{2}=2 \% \\
\text { Test for overall effect: } Z=0.87 \text { ( } P=0.38) \\
\text { Test for subgroup differences: Not applicable }\end{array}$} \\
\hline & & & 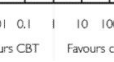 & \\
\hline
\end{tabular}

\section{FEEDBACK}

\section{Twitter comment, 11 November 2012}

\section{Summary}

A twitter comment posted re Sensky trial data http://topsy.com/twitter/clinpsych.11? nohidden $=1 \&$ offset $=60 \&$ om $=$ aaaaaa $\&$ page $=7$

\section{Reply}

Authors have amended review in response to this twitter.

Contributors

Twitter comment: Paul Hutton.

Author responding: Chris Jones.

\section{WHAT'S NEW}

Last assessed as up-to-date: 8 March 2010. 


\begin{tabular}{lll}
\hline Date & Event & Description \\
\hline 20 March 2014 & Amended & $\begin{array}{l}\text { Title changed to Cognitive Behavioural Therapy versus other psychosocial treatments } \\
\text { for schizophrenia }\end{array}$ \\
\hline
\end{tabular}

\section{HISTORY}

Protocol first published: Issue 9, 2010

Review first published: Issue 4, 2012

\begin{tabular}{lll}
\hline Date & Event & Description \\
\hline 2 April 2013 & Amended & $\begin{array}{l}\text { Outcomes from paper Turkington 2008 added to Sensky 2000. Also see Feedback } \\
\text { section. }\end{array}$ \\
\hline 17 April 2012 & Amended & Reference correction (Birchwood 2006). \\
\hline
\end{tabular}

\section{DIFFERENCES BETWEEN PROTOCOL AND REVIEW}

The original protocol has been substantially reformatted to make it more clear but the content has not been substantively changed.

\section{SUMMARY OF FINDINGS FOR THE MAIN COMPARISON}

Cognitive behavioural therapy compared with other psychosocial therapies for schizophrenia

Patient or population: patients with schizophrenia

Settings: in either community or hospital settings

Intervention: Cognitive behavioural therapy

Comparison: other psychosocial therapies 


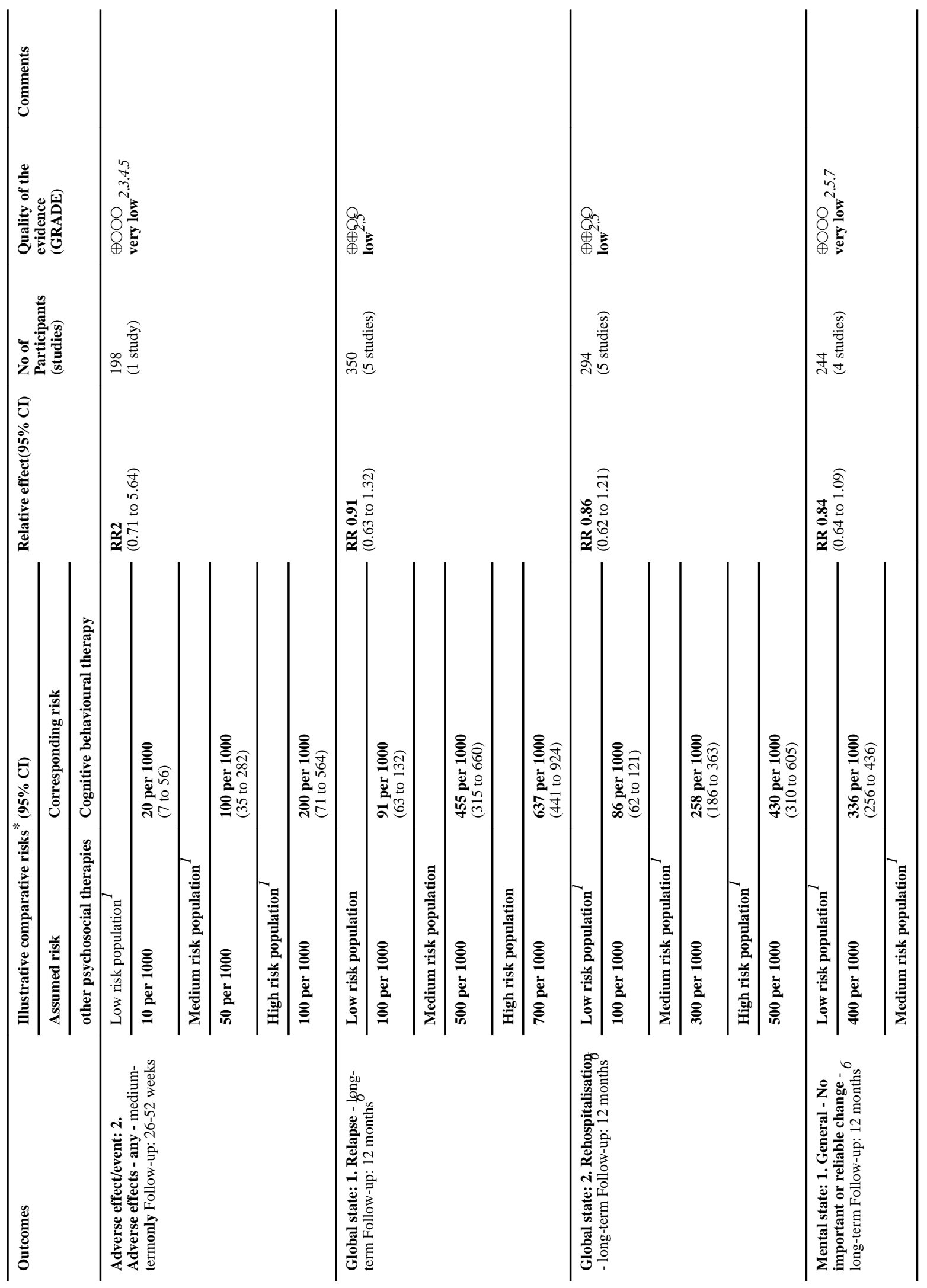




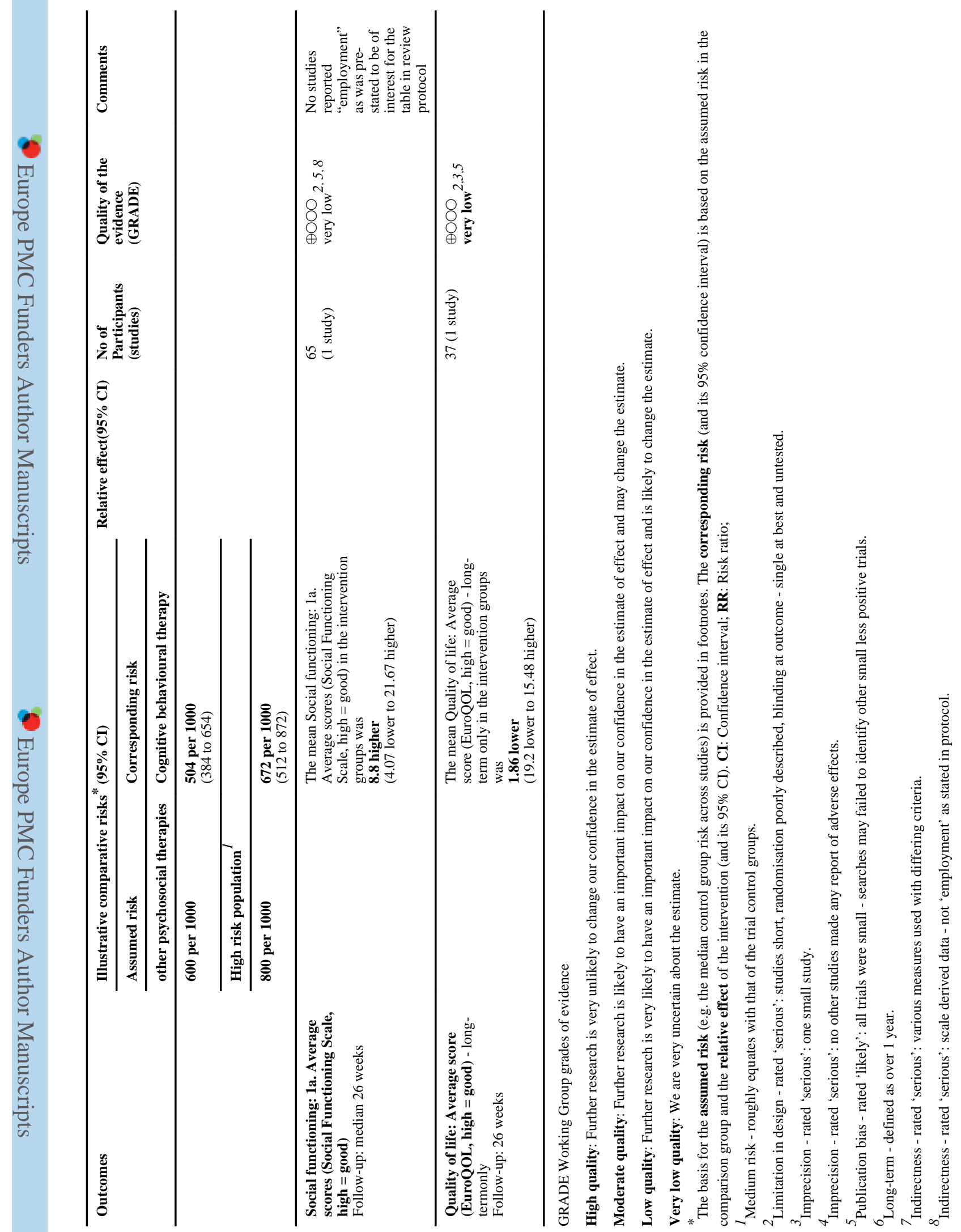




\section{References to studies included in this review}

Bechdolf 2004 \{published data only . Bechdolf A, Knost B, Kuntermann C, Schiller S, Klosterkotter J, Hambrecht M, Pukrop R. A randomized comparison of group cognitivebehavioural therapy and group psychoeducation in patients with schizophrenia. Acta Psychiatrica Scandinavica. 2004; 110(1):21-8. [PubMed: 15180776]

Bechdolf A, Kohn D, Knost B, Pukrop R, Klosterkotter J. A randomized comparison of group cognitive-behavioural therapy and group psychoeducation in acute patients with schizophrenia: outcome at 24 months. Acta Psychiatrica Scandinavica. 2005; 112(3):172-9.

Buchkremer 1997 \{published data only\} . Buchkremer G, Klingberg S, Holle R, Schulze Monking H, Hornung W. Psychoeducational psychotherapy for schizophrenic patients and their key relatives or caregivers: Results of a two year follow-up. Acta Psychiatrica Scandinavica. 1997; 96:483-91. [PubMed: 9421346]

Klingberg S, Buchkremer G, Holle R, Monking H, Hornung W. Differential therapy effects of psychoeducational psychotherapy for schizophrenic patients - results of 2-year follow-up. European Archives of Psychiatry and Clinical Neuroscience. 1999; 249:66-72. [PubMed: 10369152]

Cather 2005 \{published data only\} . Cather C, Penn D, Otto MW, Yovel I, Mueser KT, Goff DC A pilot study of functional cognitive behavioral therapy (fCBT) for schizophrenia. Schizophrenia Research. 2005; 74(23):201-9. [PubMed: 15722000]

Drury 2000 \{published data only . Drury V, Birchwood M, Cochrane R. Cognitive therapy and recovery from acute psychosis: A controlled trial. British Journal of Psychiatry. 2000; 177:8-14. [PubMed: 10945081]

Drury V, Brichwood M, Cochrane R, Macmillan F. Cognitive therapy and recovery from acute psychosis: A controlled trial. I. Impact on psychotic symptoms. British Journal of Psychiatry. 1996; 169:593-601. [PubMed: 8932888]

Drury V, Brichwood M, Cochrane R, Macmillan F. Cognitive therapy and recovery from acute psychosis: A controlled trial. II. Impact on recovery time. British Journal of Psychiatry. 1996; 169:602-7. [PubMed: 8932889]

Durham 2003 \{published data only\} . Durham RC, Guthrie M, Morton RV, Reid DA, Treliving LR, Fowler D, MacDonald RR. Tayside-Fife clinical trial of cognitive-behavioural therapy for medication-resistant psychotic symptoms. British Journal of Psychiatry. 2003; 182:303-11. [PubMed: 12668405]

Garety 2008 a \{published data only\} . Garety PA, Fowler DG, Freeman D, Bebbington P, Dunn G, Kuipers E. Cognitive-behavioural therapy and family intervention for relapse prevention and symptom reduction in psychosis: randomised controlled trial. British Journal of Psychiatry. 2008; 192(6):412-23. [PubMed: 18515890]

Haddock 1999 \{published data only\} . Haddock G, Tarrier N, Morrison AP, Hopkins R, Drake R, Lewis S. A pilot study evaluating the effectiveness of individual inpatient cognitive-behavioural therapy in early psychosis. Social Psychiatry and Psychiatric Epidemiology. 1999; 34(5):254-8. [PubMed: 10396167]

Haddock 2009 \{published data only . Haddock G, Barrowclough C, Shaw JJ, Dunn G, Novaco RW, Tarrier N. Cognitive-behavioural therapy v. social activity therapy for people with psychosis and a history of violence: randomised controlled trial. British Journal of Psychiatry. 2009; 194(2):152-7. [PubMed: 19182178]

Jackson 2008 \{published data only\} . Bendall S, Jackson HJ, Killackey E, Allott K, Johnson T, Harrigan S, Gleeson J, McGorry PD. The credibility and acceptability of befriending as a control therapy in a randomized controlled trial of cognitive behaviour therapy for acute first episode psychosis. Behavioural and Cognitive Psychotherapy. 2006; 34:277-91.

Jackson HJ, McGorry PD, Killackey E, Bendall S, Allott K, Dudgeon P, Gleeson J, Johnson T, Harrigan S. Acute-phase and 1-year follow-up results of a randomized controlled trial of CBT versus befriending for first-episode psychosis: the ACE project. Psychological Medicine. 2008; 38(5):725-35. [PubMed: 18005494]

Kemp 1998 \{published data only\} . Kemp R, Hayward P, Applewhaite G, Everitt B, David A. Compliance therapy in psychotic patients: a randomised controlled trial. BMJ. 1996; 312:345-9. [PubMed: 8611831] 
Kemp R, Kirov G, Everitt B, Hayward P, David A. Randomised controlled trial of compliance therapy. British Journal of Psychiatry. 1998; 172:413-9. [PubMed: 9747403]

Klingberg 2009 \{published data only\} . Klingberg S, Wittorf A, Herrlich J, Wiedemann G, Meisner C, Buchkremer G, Frommann N, Wölwer W. Cognitive behavioural treatment of negative symptoms in schizophrenia patients: study design of the TONES study, feasibility and safety of treatment. European Archives of Psychiatry and Clinical Neuroscience. 2009; 259(Suppl 2):149-54.

Levine 1998 \{published data only\} . Levine J, Barak Y, Granek I. Cognitive group therapy for paranoid schizophrenics: Applying cognitive dissonance. Journal of Cognitive Psychotherapy. 1998; 12(1):3-12.

Lewis 2002 \{published data only\} . Lewis S, Tarrier N, Haddock G, Bentall R, Kinderman P, Kingdon D, Siddle R, Drake R, Everitt J, Leadley K, Benn A, Grazebrook K, Haley C, Akhtar S, Davies L, Palmer S, Faragher B, Dunn G. Randomised controlled trial of cognitive-behavioural therapy in early schizophrenia: Acute-phase outcomes. British Journal of Psychiatry. 2002; 181(S43):S91-7.

Tarrier N, Lewis S, Haddock G, Bentall R, Drake R, Kinderman P, Kingdon D, Siddle R, Everitt J, Leadley K, Benn A, Grazebrook K, Haley C, Akhtar S, Davies L, Palmer S, Dunn G. Cognitivebehavioural therapy in first-episode and early schizophrenia. British Journal of Psychiatry. 2004; 184:231-9. [PubMed: 14990521]

Lewis 2002 - Liverpool \{published data only\} . Lewis S, Tarrier N, Haddock G, Bentall R, Kinderman P, Kingdon D, Siddle R, Drake R, Everitt J, Leadley K, Benn A, Grazebrook K, Haley C, Akhtar S, Davies L, Palmer S, Faragher B, Dunn G. Randomised controlled trial of cognitive-behavioural therapy in early schizophrenia: acute-phase outcomes. British Journal of Psychiatry. 2002; 181(S43):S91-7.

Tarrier N, Lewis S, Haddock G, Bentall R, Drake R, Kinderman P, Kingdon D, Siddle R, Everitt J, Leadley K, Benn A, Grazebrook K, Haley C, Akhtar S, Davies L, Palmer S, Dunn G. Cognitivebehavioural therapy in first-episode and early schizophrenia. British Journal of Psychiatry. 2004; 184:231-9. [PubMed: 14990521]

Lewis 2002 - Manchester \{published data only\} . Lewis S, Tarrier N, Haddock G, Bentall R, Kinderman P, Kingdon D, Siddle R, Drake R, Everitt J, Leadley K, Benn A, Grazebrook K, Haley C, Akhtar S, Davies L, Palmer S, Faragher B, Dunn G. Randomised controlled trial of cognitive-behavioural therapy in early schizophrenia: Acute-phase outcomes. British Journal of Psychiatry. 2002; 181(S43):S91-7.

Tarrier N, Lewis S, Haddock G, Bentall R, Drake R, Kinderman P, Kingdon D, Siddle R, Everitt J, Leadley K, Benn A, Grazebrook K, Haley C, Akhtar S, Davies L, Palmer S, Dunn G. Cognitivebehavioural therapy in first-episode and early schizophrenia. British Journal of Psychiatry. 2004; 184:231-9. [PubMed: 14990521]

Lewis 2002 - Nottingham \{published data only\} . Lewis S, Tarrier N, Haddock G, Bentall R, Kinderman P, Kingdon D, Siddle R, Drake R, Everitt J, Leadley K, Benn A, Grazebrook K, Haley C, Akhtar S, Davies L, Palmer S, Faragher B, Dunn G. Randomised controlled trial of cognitive-behavioural therapy in early schizophrenia: Acute-phase outcomes. British Journal of Psychiatry. 2002; 181(S43):S91-7.

Tarrier N, Lewis S, Haddock G, Bentall R, Drake R, Kinderman P, Kingdon D, Siddle R, Everitt J, Leadley K, Benn A, Grazebrook K, Haley C, Akhtar S, Davies L, Palmer S, Dunn G. Cognitivebehavioural therapy in first-episode and early schizophrenia. British Journal of Psychiatry. 2004; 184:231-9. [PubMed: 14990521]

O’Donnell 2003 \{published data only\} . O’Donnell C, Donohoe G, Sharkey L, Owens N, Migone M, Harries R, Kinsella A, Larkin C, O'Callaghan E. Compliance therapy: A randomised controlled trial in schizophrenia. BMJ. 2003; 327(7419):834. [PubMed: 14551096]

Penn 2009 \{published data only\} . Penn DL, Meyer PS, Evans E, Wirth RJ, Cai K, Burchinal M. A randomized controlled trial of group cognitive-behavioral therapy vs. enhanced supportive therapy for auditory hallucinations. Schizophrenia Research. 2009; 109:52-9. [PubMed: 19176275] 
Pinto 1999 \{published data only\} . Pinto A, LaPia S, Mennella R, Giorgio D, DeSimone L. Cognitive-behavioural therapy and clozapine for clients with treatment refactory schizophrena. Psychiatric Services. 1999; 50(7):901-4. [PubMed: 10402608]

Sensky 2000 \{published data only . *Sensky T, Turkington D, Kingdon D, Scott J, Scott J, Siddle $\mathrm{R}, \mathrm{O}$-Carroll M, Barnes T. A randomized controlled trial of cognitive-behavioural therapy for persistent symptoms in schizophrenia resistant to medication. Archives of General Psychiatry. 2000; 57:165-72. [PubMed: 10665619]

Turkington D, Sensky T, Scott J, Barnes T, Nur U, Siddle R, Hammond K, Samarasekara N, Kingdon D. A randomized controlled trial of cognitive-behavior therapy forpersistent symptoms in schizophrenia: A five-year follow-up. Schizophrenia Research. 2008; 98:1-7. [PubMed: 17936590]

Tarrier 1999 a $\quad$ published data only\} . Tarrier N, Beckett R, Harwood S, Baker A, Yusupoff L, Ugarteburu I. A trial of two cognitive-behavioural methods of treating drug-resistant residual psychotic symptoms in schizophrenic patients: 1. outcome. British Journal of Psychiatry. 1993; 162:524-32. [PubMed: 8481745]

Tarrier N, Kinney C, McCarthy E, Humphreys L, Wittkowski A, Morris J. Two-year follow-up of cognitive--behavioral therapy and supportive counselling in the treatment of persistent symptoms in chronic schizophrenia. Journal of Consulting and Clinical Psychology. 2000; 68(5):917-22. [PubMed: 11068978]

Tarrier N, Wittkowski A, Kinney C, McCarthy E, Morris J, Humpherys L. Durability of the effects of cognitive-behavioural therapy in the treatment of chronic schizophrenia: 12-month follow-up. British Journal of Psychiatry. 1999; 174:500-4. [PubMed: 10616627]

Tarrier N, Yusupoff L, Kinney C, McCarthy E, Gledhill A, Haddock G, Morris J. Randomised controlled trial of intensive cognitive behavioural therapy for patients with chronic schizophrenia. BMJ. 1998; 317:303-7. [PubMed: 9685273]

Turkington 2000 \{published data only\} . Turkington D, Kingdon D. Cognitive-behavioural techniques for general psychiatrists in the management of patients with psychoses. British Journal of Psychiatry. 2000; 177:101-6. [PubMed: 11026947]

Valmaggia 2005 \{published data only\} . Valmaggia LR, Gaag MVD, Tarrier N, Pijnenborg M, Slooff CJ. Cognitive-behavioural therapy for refractory psychotic symptoms of schizophrenia resistant to atypical antipsychotic medication. Randomised controlled trial. British Journal of Psychiatry. 2005; 186:324-30. [PubMed: 15802690]

\section{References to studies excluded from this review}

Anzai 2002 \{published data only\} . Anzai N, Yoneda S, Kumagai N, Nakamura Y, Ikebuchi E, Liberman R. Training persons with schizophrenia in illness self-management: A randomised controlled trial in Japan. Psychiatric Services. 2002; 53(5):545-7. [PubMed: 11986501]

Arlow 1997 \{published data only\} . Arlow PB, Moran ME, Bermanzohn PC, Stronger R, Siris SG. Cognitive-behavioural treatment of panic attacks in chronic schizophrenia. Journal of Psychotherapy Practice and Research. 1997; 6:145-50. [PubMed: 9071665]

Bach 2002 \{published data only\} . Bach P, Hayes SC. The use of acceptance and commitment therapy to prevent the rehospitalization of psychotic patients: A randomized controlled trial. Journal of Consulting and Clinical Psychology. 2002; 70(5):1129-39. [PubMed: 12362963]

Barrowclough 2001 \{published data only\} . Barrowclough C, Haddock G, Tarrier N, Lewis SW, Moring J, O’Brien R, Schofield N, McGovern J. Randomized controlled trial of motivational interviewing, cognitive behavior therapy, and family intervention for patients with comorbid schizophrenia and substance use disorders. American Journal of Psychiatry. 2001; 158(10):170613. [PubMed: 11579006]

Haddock G, Barrowclough C, Tarrier N, Moring J, O’Brien R, Schofield N, Quinn J, Palmer S, Davies L, Lowens I, McGovern J, Lewis S. Cognitive-behavioural therapy and motivational intervention for schizophrenia and substance misuse. 18-month outcomes of a randomised controlled trial. British Journal of Psychiatry. 2003; 183:418-26. [PubMed: 14594917]

Barrowclough 2006 \{published data only\} . Barrowclough C, Haddock G, Lobban F, Jones S, Siddle R, Roberts C, Gregg L. Group cognitive-behavioural therapy for schizophrenia. 
Randomised controlled trial. British Journal of Psychiatry. 2006; 189:527-32. [PubMed: 17139037]

Bechdolf 2005b \{published data only\} . Bechdolf A, Veith V, Schwarzer D, Schormann M, Stamm E, Janssen B, Berning J. Cognitive-behavioral therapy in the pre-psychotic phase: an exploratory study. Psychiatry Research. 2005; 136(2-3):251-5. [PubMed: 16122813]

Bellucci 2002 \{published data only\} . Bellucci DM, Galberman K, Haslam N. Computer assisted cognitive rehabilitation reduces negative symptoms in the severely mentally ill. Schizophrenia Research. 2002; 59:225-32. [PubMed: 12414079]

Bouchaud 1996 \{published data only\} . Bouchaud S, Vallieres A, Roy M, Maziade M. Cognitive restructuring in the treatment of psychotic symptoms in schizophrenia: A critical analysis. Behavior Therapy. 1996; 27:257-77.

Bradshaw 1993 \{published data only\} . Bradshaw W. Coping-skills, training versus a problemsolving approach with schizophrenic patients. Hospital and Community Psychiatry. 1993; 44(5): 491-500.

Bradshaw 2000 \{published data only . Bradshaw W. Integrating cognitive-behavioral psychotherapy for persons with schizophrenia into a psychiatric rehabilitation program: results of a three year trial. Community Mental Health Journal. 2000; 36(5):491-500. [PubMed: 10994682]

Buchanan 1992 \{published data only\} . Buchanan A. A two year prospective study of treatment compliance in patients with schizophrenia. Psychological Medicine. 1992; 22(3):787-97. [PubMed: 1357703]

Castle 2002 \{published data only\} . Castle, D.; Nathan, P.; Kingser, P.; Halprin, S.; Drummand, P.; Jeffreys, L. Treating social anxiety in schizophrenia: a group based cognitive behaviour therapy approach; Proceedings of the 155th Annual Meeting of the American Psychiatric Association; Philadelphia, Pennsylvania, USA. 2002 May 18-23; 2002.

Chadwick 1994 \{published data only\}. Chadwick P, Birchwood M. The omnipotence of voices: A cognitive approach to auditory hallucinations. British Journal of Psychiatry. 1994; 164:190-201. [PubMed: 8173822]

Chadwick P, Lowe C. A cognitive approach to measuring and modifying delusions. Behavioural Research Therapy. 1994; 32(3):355-67.

Claghorn 1974 \{published data only\} . Clagthorn JL, Johnstone EE, Cook TH, Itschner L. Group therapy and maintenance treatment of schizophrenics. Archives of General Psychiatry. 1974; 31:361-5. [PubMed: 4606594]

Daniels 1998 \{published data only\} . Daniels L. A group cognitive-behavioural and processoriented approach to treating the social impairment and negative symptoms associated with chronic mental illness. Journal of Psychotherapy Practice and Research. 1998; 7:167-76. [PubMed: 9527960]

Drake 1993 \{published data only . Drake RE, Bebout RR, Roach JP. A research evaluation of social network case management for homeless persons with dual disorders. Social Network Research. 1993; 1:83-98.

Edwards 2003 \{published data only . Edwards J, Wong L, Bernett P, Harrigan SM, McGorry PD, Wade D, Murphy B, Drew L, Albiston D. Enduring positive symptoms in first episode psychosis: A randomised controlled trial of clozapine and CBT. International Congress on Schizophrenia Research. 2003; 60:321.

England 2007 \{published data only\} . England M. Efficacy of cognitive nursing intervention for voice hearing. Perspectives in Psychiatric Care. 2007; 42(2):69-76. [PubMed: 17388849]

England M. Significance of cognitive intervention for voice hearers. Perspectives in Psychiatric Care. 2008; 44(1):40-7. [PubMed: 18177277]

Evins 2001 \{published data only\} . Evins AE, Mays VK, Rigotti NA, Tisdale T, Cather C, Goff D. A pilot trial of bupropion added to cognitive behavioural therapy for smoking cessation in schizophrenia. Nicotine \& Tobacco Research. 2001; 3:397-403. [PubMed: 11694208]

Fritze 1988 \{published data only\} . Fritze J, Forthner B, Schmitt B, Thaler U. Cognitive training adjunctive to pharmacotherapy in schizophrenia and depression: A pilot study on the lateralization hypothesis of schizophrenia and depression and on cognitive therapy as adjunctive to pharmacotherapy. Neuropsychobiology. 1988; 19:45-50. [PubMed: 3185895] 
Garety 1994 \{published data only . Garety PA, Kuiper L, Fowler D, Chamberlin F, Dunn G. Cognitive behavioural therapy for drug-resistant psychosis. British Journal of Medical Psychology. 1994; 67:259-71. [PubMed: 7803318]

Garety 1998 \{published data only\} . Garety P, Fowler D, Kuipers E, Freeman D, Dunn G, Bebbington P, Jones S. London East-Anglia randomised controlled trial of cognitive behavioural therapy for psychosis: II. Predictors of outcome. British Journal of Psychiatry. 1994; 171:420-6. [PubMed: 9463599]

Kuipers E, Fowler D, Garety P, Chisholm D, Freeman D, Dunn G, Bebbington P, Hadley C. London East-Anglia randomised control trial of cognitive behavioural therapy for psychosis III: Follow-up and economic evaluation at 18 months. British Journal of Psychiatry. 1998; 173:61-8. [PubMed: 9850205]

Kuipers E, Garety P, Fowler D, Dunn G, Freeman D, Bebbington P, Hadley C. London East-Anglia randomised controlled trial of cognitive behavioural therapy for psychosis: I. Effects of the treatment phase. British Journal of Psychiatry. 1997; 171:319-27. [PubMed: 9373419]

Gaudiano 2006 \{published data only\} . Gaudiano BA, Herbert JD. Acute treatment of inpatients with psychotic symptoms using acceptance and commitment therapy: pilot results. Behaviour Research and Therapy. 2006; 44(3):415-37. [PubMed: 15893293]

Granholm 2005 \{published data only\} . Granholm E, McQuaid JR, McClure FS, Auslander LA, Perivoliotis D, Pedrelli P, Patterson T, Jeste DV. A randomized, controlled trial of cognitive behavioral social skills training for middle-aged and older outpatients with chronic schizophrenia. American Journal of Psychiatry. 2005; 162(3):520-9. [PubMed: 15741469]

Granholm E, McQuaid JR, McClure FS, Link PC, Perivoliotis D, Gottlieb JD, Patterson TL, Jeste DV. Randomized controlled trial of cognitive behavioral social skills training for older people with schizophrenia: 12-month follow-up. Journal of Clinical Psychiatry. 2007; 68(5):730-7. [PubMed: 17503982]

Gumley 2003 \{published data only\} . Gumley A, O’Grady M, McNay L, Rilley J, Power K, Norrie J. Early intervention for relapse in schizophrenia: Results of a twelve month randomized controlled trial of cognitive behavioural therapy. Psychological Medicine. 2003; 33:419-31. [PubMed: 12701663]

Haldun 2002 \{published data only\} . Haldun, S.; Mehmet, S.; Perhan, G.; Ilkten, C.; Besti, U. Optimal treatment of schizophrenia. Proceedings of the 12th World Congress of Psychiatry; Yokohama, Japan. 2002 Aug 24-29; 2002.

Hartman 1983 \{published data only\} . Hartman LM, Cashman FE. Cognitive-behavioral and psychopharmacological treatment of delusional symptoms: A preliminary report. Behavioural Psychotherapy. 1983; 11:50-61.

Hayward 1995 \{published data only\} . Hayward P, Chan N, Kemp R, Youle S, David A. Medication self-management: A preliminary report on an intervention to improve medication compliance. Journal of Mental Health. 1995; 4:511-7.

Hertz 2000 \{published data only\} . Herz MI, Lamberti JS, Mintz J, Scott R, O’Dell SP, McCartan L, Nix G. A program for relapse prevention in schizophrenia: A controlled study. Archives of General Psychiatry. 2000; 57(3):277-83. [PubMed: 10711914]

Hodel 1994 \{published data only\}. Hodel B, Brenner HD. Cognitive therapy with schizophrenic patients: Conceptual basis, present state, future directions. Acta Psychiatrica Scandinavica. 1994; 90S:108-15. [PubMed: 7879632]

Hogarty 1991 \{published data only\} . Hogarty GE, Anderson CM, Reiss DF, Kornblith SJ, Greenwald DP, Ulrich RF, Carter M, The Environmental-Personal Indicators in the Course of Schizophenia (EPICS) Research Group. Family psychoeducation, social skills training, and maintenance chemotherapy in the aftercare treatment of schizophrenia: II two year effects of a controlled study on relapse and adjustment. Archives of General Psychiatry. 1991; 48:340-7. [PubMed: 1672589]

Hogarty 1997 \{published data only\} . Hogarty G, Cornblith S, Greenwald D, DiBarry A, Cooley S, Ulrich R, Carter M, Flesher S. Three-year trials of personal therapy among schizophrenic patients living with or independent of family. I: Description of study and effects on relapse rates.

American Journal of Psychiatry. 1997; 154(11):1504-13. [PubMed: 9356557] 
Hogarty G, Greenwald D, Ulrich R, Cornblith S, DiBarry A, Cooley S, Carter M, Flesher S. Threeyear trials of personal therapy among schizophrenic patients living with or independent of family. II: Effects on adjustment of patients. American Journal of Psychiatry. 1997; 154(11):1514-24. [PubMed: 9356558]

Hogarty 2004 \{published data only\} . Hogarty GE, Flesher S, Ulrich R, Carter M, Greenwald D, Pogue-Geile M, Kechavan M, Cooley S, DiBarry AL, Garrett A, Parepally H, Zoretich R. Cognitive enhancement therapy for schizophrenia: Effects of a 2-year randomized trial on cognition and behavior. Archives of General Psychiatry. 2004; 61(9):866-76. [PubMed: 15351765]

Jackson 1998 \{published data only\} . Jackson H, McGorry P, Edwards J, Hulbert C, Henry L, Francey S, Maude D, Cocks J, Power P, Harrigan S, Dudgeon P. Cognitively oriented psychotherapy for early psychosis (COPE): Priminary results. British Journal of Psychiatry. 1998; 172(Suppl 33):93-100.

Jackson 2001 \{published data only\} . Jackson, C. Promoting personal recovery from psychosis: A randomised control trial in first episode schizophrenia. National Research Register; 2001.

Kemp 1996b \{published data only\} . Kemp R, David A. Compliance therapy: An intervention targeting insight and treatment adherence in psychotic patients. Behavioural and Cognitive Psychotherapy. 1996; 24:331-50.

Kingdon 1991 \{published data only\} . Kingdon D, Turkington D. The use of cognitive behavior therapy with a normalizing rationale in schizophrenia. Journal of Nervous and Mental Disease. 1991; 179(4):207-11. [PubMed: 2007891]

Kuipers 1996 \{published data only\} . Kuipers E. The management of difficult to treat patients with schizophrenia, using non-drug therapies. British Journal of Psychiatry. 1996; 169:41-51.

Kuipers 2004 \{published data only\} . Kuipers E, Holloway F, Rabe-Hesketh S, Tennakoon L. An RCT of early intervention in psychosis: Croydon outreach and assertive support team (COAST). Social Psychiatry and Psychiatric Epidemiology. 2004; 39(5):358-63. [PubMed: 15133591]

Lecompte 1996 \{published data only\} . Lecompte D, Pelc I. A cognitive-behavioral program to improve compliance with medication in patients with schizophrenia. International Journal of Mental Health. 1996; 25(1):51-6.

Lysaker 2009 \{published data only\} . Lysaker PH, Davis LW, Bryson GJ, Bell MD. Effects of cognitive behavioral therapy on work outcomes in vocational rehabilitation for participants with schizophrenia spectrum disorders. Schizophrenia Research. 2009; 107:186-91. [PubMed: 19046856]

MacPherson 1996 \{published data only\} . MacPherson R, Jerrom B, Hughes A. A controlled study of education about drug treatment of schizophrenia. British Journal of Psychiatry. 1996; 168:709-17. [PubMed: 8773813]

May 1984 \{published data only\} . May PRA. A step forward in research on psychotherapy of schizophrenia. Schizophrenia Bulletin. 1984; 10:604-7. [PubMed: 6393324]

McGorry 2002 \{published data only . McGorry P, Yung A, Phillips L, Yuen H, Francey S, Cosgrave E, Germano D, Bravin J, McDonald T, Blair A, Adlard S, Jackson H. Randomised controlled trial of interventions designed to reduce the risk of progression to first-episode psychosis in a clinical sample with subthreshold symptoms. Archives of General Psychiatry. 2002; 59:921-8. [PubMed: 12365879]

Morrison 2002 \{published data only . Morrison AP, Bentall RP, French P, Walford L, Kilcommons A, Knight A, Kreutz M, Lewis SW. Randomised controlled trial of early detection and cognitive therapy for preventing transition to psychosis in high-risk individuals. British Journal of Psychiatry. 2002; 181(43):78-84.

Olbrich 1990 \{published data only\} . Olbrich R, Mussgay L. Reducton of schizophrenic deficits by cognitive training: An evaluative study. European Archives of Psychiatry and Neurological Sciences. 1990; 239:366-9. [PubMed: 2144236]

Perris 1992 \{published data only\} . Perris C. A cognitive-behavioral treatment program for patients with a schizophrenic disorders. New Directions for Mental Health Services. 1992; 53:21-32. [PubMed: 1579116] 
Rector 2003 \{published data only\} . Rector NA, Seeman MV, Segal ZV. Cognitive therapy for schizophrenia: A preliminary randomized controlled trial. Schizophrenia Research. 2003; 63:111. [PubMed: 12892853]

Roder 2002 \{published data only\} . Roder V, Brenner HD, Muller D, Lachler M, Zorn P, Reisch T, Bosch J, Bridler R, Christen C, Jaspen E, Schmidl F, Schwemmer V. Development of specific social skills training programmes for schizophrenia patients: Results of a multicentre study. Acta Psychiatrica Scandinavica. 2002; 105:363-71. [PubMed: 11942943]

Sellwood 2001 \{published data only . Sellwood W, Barrowclough C, Tarrier N, Quinn J, Mainwaring J, Lewis S. Needs-based cognitive-behavioural family intervention for carers of patients suffering from schizophrenia: 12-month follow-up. Acta Psychiatrica Scandinavica. 2001; 104(5):346-55. [PubMed: 11722315]

Sellwood W, Wittkowski A, Tarrier N, Barrowclough C. Needs-based cognitive-behavioural family intervention for patients suffering from schizophrenia: 5-year follow-up of a randomized controlled effectiveness trial. Acta Psychiatrica Scandinavica. 2007; 116(6):447-52. [PubMed: 17961200]

Shon 2002 \{published data only\} . Shon K, Park S. Medication and Sympton management education program for the rehabilitation of psychiatric patients in Korea: The effects of promoting schedule on self-efficacy theory. Yonsei Medical Journal. 2002; 43(5):579-89. [PubMed: 12402370]

Spaulding 1992 \{published data only\}. Spaulding WD. Design prerequisites for research on cognitive therapy for schizophrenia. Schizophrenia Bulletin. 1992; 18:139-42.

Startup 1998 \{unpublished data only\} . Startup, M.; Jackson, M. A controlled trial of cognitive behaviour therapy for schizophrenia and related disorders. Wales Office of Research and Development for Health and Social Care; 2003. Grant number: RC012

Wales Office of Research and Development for Heatlh and Social Care. A controlled trial of cognitive behaviour therapy for schizophrenia and related disorders. 2001. http://dialspace.dial.pipex.com/ word/

Startup 2006 \{published data only\} . Startup M, Jackson MC, Startup S. Insight and recovery from acute psychotic episodes: The effects of cognitive behavior therapy and premature termination of treatment. Journal of Nervous and Mental Disorders. 2006; 194(10):740-5.

Tarrier 1993 b \{published data only\} . Tarrier N, Beckett R, Harwood S, Baker A, Yusupoff L, Ugarteburu I. A trial of two cognitive behavioural methods of treating drug-resistant residual psychotic symptoms in schizophrenic patients: I. Outcome. British Journal of Psychiatry. 1993; 162:524-32. [PubMed: 8481745]

Tarrier N, Sharpe L, Beckett R, Harwood S, Baker A, Yusopoff L. A trial of two cognitive behavioural methods of treating drug resistant residual psychotic symptoms in schizophrenic patients: II. Treatment specific changes in coping and problem solving skills. Social Psychiatry and Psychiatric Epidemiology. 1993; 28:5-10. [PubMed: 8096654]

Turkington 2002 \{published data only . Turkington D, Kingdon D, Turner T. Effectiveness of a brief cognitive-behavioural therapy intervention in the treatment of schizophrenia. British Journal of Psychiatry. 2002; 180:523-7. [PubMed: 12042231]

Turkington 2006 \{published data only\} . Turkington D, Kingdon D, Rathod S, Hammond K, Pelton J, Mehta R. Outcomes of an effectiveness trial of cognitive-behavioural intervention by mental health nurses in schizophrenia. British Journal of Psychiatry. 2006; 189:36-40. [PubMed: 16816304]

Van Der Gaag 2003 \{published data only\} . Van Der Gaag M, Kern RS, Van Den Bosch RJ, Liberman RP. A controlled trial of cognitive remediation in schizophrenia. Schizophrenia Bulletin. 2003; 28:167-76. [PubMed: 12047016]

Velligan 2002 \{published data only\} . Velligan DI, Prihoda TJ, Ritch JL, Maples M, Bow-Thomas $\mathrm{CC}$, Dassori A. A randomized single blind pilot study of compensatory strategies in schizophrenia out-patients. Schizophrenia Bulletin. 2002; 28(2):283-92. [PubMed: 12693434]

Wirshing 1992 \{published data only\} . Eckman TA, Wirshing WC, Marder SR, Liberman RP, Johnston-Cronk K, Zimmerman K, Mintz J. Technique for training schizophrenic patients in illness self-management: a controlled trial. American Journal of Psychiatry. 1992; 149:1549-55. [PubMed: 1384364] 
Wirshing WC, Marder SR, Eckman T, Liberman RP, Mintz J. Acquisition and retention of skills training methods in chronic schizophrenic outpatients. Psychopharmacology Bulletin. 1992; 28:241-5. [PubMed: 1480726]

Wykes 2002 \{published data only\} . Wykes, T. The effectiveness of cognitive remediation therapy (CRT) for patients with schizophrenia. National Research Register; 2002.

Wykes 2003 \{published data only\} . Wykes T, Thompson N, Green N, Surgaldze S, Hayward P. Changing voices: A randomised control trial of group cognitive behavioural treatment. Schizophrenia Research. 2003; 60:331.

Wykes T, Thompson N, Hyward P. Changing voices: A randomised control trial of group cognitive treatment. Schizophrenia Research. 2002; 53(Suppl 1):12.

\section{References to studies awaiting assessment}

NCT00980252 \{published data only\} . NCT00980252. Medication adherence in schizophrenia: Development of a CBT-based intervention. 2009. http://www.clinicaltrials.gov/show/ NCT00980252

Wu Ningqiang 2008 \{published data only\} . Wu N, Wang Q, Kong L. A controlled study of cognitive behaviour therapy in chronic schizophrenia. Journal of Clinical Psychosomatic Diseases. 2008; 14(3):206.

\section{Additional references}

Alford 1994 . Alford BA, Beck AT. Cognitive therapy of delusional beliefs. Behaviour Research and Therapy. 1994; 32:369-80. [PubMed: 8192636]

Altman 1996 . Altman DG, Bland JM. Detecting skewness from summary information. BMJ. 1996; 313:1200. [PubMed: 8916759]

Andreasen 1984 . Andreasen, NC. Scale for the Assessment of Negative Symptoms (SANS). University of Iowa; 1984.

APA 1995 . American Psychiatric Association. Diagnostic and Statistical Manual of Mental Disorders. 4th Edition. American Psychiatric Assoication; 1995.

Asberg 1978 . Asberg M, Montgomery S, Perris C, Shalling D, Sedvall G. A comprehensive psychopathological rating scale. Acta Psychiatrica Scandinavicia Supplementum. 1978; 271:527.

Beck 1961 . Beck AT, Ward CH, Mendelson M, Mock J, Erbaugh J. An inventory for measuring depression. Archives General Psychiatry. 1961; 4:561-71.

Beck 1988 . Beck AT, Epstein N, Brown G, Steer RA. An inventory for measuring clinical anxiety: Psychometric properties. Journal of Consulting and Clinical Psychology. 1988; 56(6):893-97. [PubMed: 3204199]

Beck 2004 . Beck AT, Baruch E, Balter JM, Steer RA, Warman DM. A new instrument for measuring insight: the Beck cognitive insight scale. Schizophrenia Research. 2004; 68(2):31930. [PubMed: 15099613]

Beck 2005 . Beck AT. The current state of cognitive therapy. Archives of General Psychiatry. 2005; 62:953-9. [PubMed: 16143727]

Begg 1996 . Begg C, Cho M, Eastwood S, Horton R, Moher D, Olkin I, Pitkin R, Rennie D, Schulz KF, Simel D, Stroup DF. Improving the quality of randomized controlled trials. The CONSORT statement. JAMA. 1996; 276:637-9. [PubMed: 8773637]

Birchwood 1990 . Birchwood M, Smith J, Cochrane R, Wetton C, Copestake S. The social functioning scale: the development and validation of a new scale of social adjustment for use in family intervention programmes with schizophenic patients. British Journal of Psychiatry. 1990; 157:853-9. [PubMed: 2289094]

Birchwood 2006 . Birchwood M, Trower P. The future of cognitive-behavioural therapy for psychosis: not a quasi-neuroleptic. British Journal of Psychiatry. 2006; 188:107-8. [PubMed: 16449695] 
Bird 2006 . Bird. We need to talk: The case of psychological therapy in the NHS. 2006 www.scmh.org.uk/pdfs/we.need.to.talk.pdf.

Bland 1997 . Bland JM. Statistics notes. Trials randomised in clusters. BMJ. 1997; 315:600. [PubMed: 9302962]

Boissel 1999 . Boissel JP, Cucherat M, Li W, Chatellier G, Gueyffier F, Buyse M, Boutitie F, Nony P, Haugh M, Mignot G. The problem of therapeutic efficacy indices. 3. Comparison of the indices and their use. Therapie. 1999; 54(4):405-11. [PubMed: 10667106]

Brambilla 2000 . Brambilla S, Pioli R. Development, reliability and acceptability of a new version of the DSM-IV social and occupational functioning assessment scale (SOFAS) to assess routine social funtioning. Acta Psychiatrica Scandinavica. 2000; 101:323-9. [PubMed: 10782554]

Brazier 1993 . Brazier J, Jones N, Kind P. Testing the validity of the EuroQol and comparing it with the SF-36 health survey questionnaire. Quality of Life Research. 1993; 2:169-80. [PubMed: 8401453]

Chadwick 2000 . Chadwick P, Lees S, Birchwood M. The revised beliefs about voices questionnaire (BAVQ-R). British Journal of Psychiatry. 2000; 177(3):229-32. [PubMed: 11040883]

Christison 1991 . Christison GW, Kirch DG, Wyatt RJ. When symptoms persist: choosing among alternative somatic symptoms for schizophrenia. Schizophrenia Bulletin. 1991; 17:217-45. [PubMed: 1679252]

Davis 1977 . Davis JM, Casper R. Antipsycotic drugs: Clinical pharmacology and therapeutic use. Drugs. 1977; 14:260-82. [PubMed: 21069]

Deeks 2000 . Deeks, J. Issues in the selection for meta-analyses of binary data; Proceedings of the 8th International Cochrane Colloquium; Cape Town, South Africa. 2000 Oct 25-28th; 2000.

Divine 1992 . Divine GW, Brown JT, Frazier LM. The unit of analysis error in studies about physicians' patient care behavior. Journal of General Internal Medicine. 1992; 7(6):623-9. [PubMed: 1453246]

Donner 2002 . Donner A, Klar N. Issues in the meta-analysis of cluster randomized trials. Statistics in Medicine. 2002; 21:2971-80. [PubMed: 12325113]

Drake 1986 . Drake RE, Cotton PG. Depression, hopelessness and suicide in chronic schizophrenia. British Journal of Psychiatry. 1986; 148:554. [PubMed: 3779226]

Egger 1997 . Egger M, Davey-Smith G, Schneider M, Minder C. Bias in meta-analysis detected by a simple graphical test. BMJ. 1997; 315:629-34. [PubMed: 9310563]

Elbourne 2002 . Elbourne D, Altman DG, Higgins JPT, Curtina F, Worthingtond HV, Vaile A. Meta-analyses involving cross-over trials: Methodological issues. International Journal of Epidemiology. 2002; 31(1):140-9. [PubMed: 11914310]

Endicott 1976 . Endicott J, Spitzer R, Fleiss J, Cohen CJ. The global assessment scale. A procedure to measuring overall severity of psychiatric disturbance. Archives of General Psychiatry. 1976; 33:766-71. [PubMed: 938196]

Furukawa 2006 . Furukawa TA, Barbui C, Cipriani A, Brambilla P, Watanabe N. Imputing missing standard deviations in meta-analyses can provide accurate results. Journal of Clinical Epidemiology. 2006; 59(7):7-10. [PubMed: 16360555]

Garety 2008 . Garety PA, Fowler DG, Freeman D, Bebbington P, Dunn G, Kuipers E. Cognitivebehavioural therapy and family intervention for relapse prevention and symptom reduction in psychosis: Randomised controlled trial. British Journal of Psychiatry. 2008; 192:412-23. [PubMed: 18515890]

Gulliford 1999 . Gulliford MC. Components of variance and intraclass correlations for the design of community-based surveys and intervention studies: Data from the Health Survey for England 1994. American Journal of Epidemiology. 1999; 149:876-83. [PubMed: 10221325]

Haddock 1999b . Haddock G, McCarron J, Tarrier N, Faragher EB. Scales to measure dimensions of hallucinations and delusions: The psychotic symptom rating scales (PSYRATS). Psychological Medicine. 1999; 29(4):879-89. [PubMed: 10473315]

Higgins 2003 . Higgins JP, Thompson SG, Deeks JJ, Altman DG. Measuring inconsistency in metaanalyses. BMJ. 2003; 327:557-60. [PubMed: 12958120] 
Higgins 2009 . Higgins, JPT.; Green, S., editors. Cochrane Handbook for Systematic Reviews of Interventions Version 5.0.2. updated September 2009Available from www.cochranehandbook.org

Jones 2004 . Jones C, Cormac I, Mota J, Campbell C. Cognitive Behaviour Therapy for schizophrenia. Cochrane Database of Systematic Reviews. 2004; (2) DOI: 10.1002/14651858.CD000524.pub2.

Jones 2009a . Jones C, Cormac I, Campbell C, Meaden A, Hacker D, Irving CB. Cognitive behaviour therapy versus specific pharmacological treatments for schizophrenia. Cochrane Database of Systematic Reviews. 2009; (3) DOI: 10.1002/14651858.CD007965.

Jones 2009b . Jones C, Campbell C, Cormac I, Hacker D, Meaden A, Irving CB. Cognitive behaviour therapy versus standard care for schizophrenia. Cochrane Database of Systematic Reviews. 2009; (3) DOI: 10.1002/14651858.CD007964.

Kay 1987 . Kay SR, Fiszbein A, Opler LA. The positive and negative syndrome scale (PANSS) for schizophrenia. Schizophrenia Bulletin. 1987; 13:261-76. [PubMed: 3616518]

Leucht 2005a . Leucht S, Kane JM, Kissling W, Hamann J, Etschel E, Engel R. What does the PANSS mean? Schizophrenia Research. 2005; 79:231-8. [PubMed: 15982856]

Leucht 2005b . Leucht S, Kane JM, Kissling W, Hamann J, Etschel E, Engel R. Clinical implications of Brief Psychiatric Rating Scale Scores. British Journal of Psychiatry. 2005; 187:366-71. [PubMed: 16199797]

Marshall 2000 . Marshall M, Lockwood A, Adams C, Bradley C, Joy C, Fenton M. Unpublished rating scales - a major source of bias in randomised controlled trials of treatments for schizophrenia? British Journal of Psychiatry. 2000; 176:249-52. [PubMed: 10755072]

McKenna 2007 . McKenna, PJ. Schizophrenia and Related Syndromes. 2nd Edition. Routledge; London: 2007.

Meltzer 1992 . Meltzer HY. Treatment of the neuroleptic-nonresponsive schizophrenic patient. Schizophrenia Bulletin. 1992; 18:515-42. [PubMed: 1357741]

MHA 1983 . Mental Health Act. Department of Health; 1983.

Moher 2001 . Moher D, Schulz KF, Altman D. The CONSORT statement: Revised recommendations for improving the quality of reports of parallel-group randomized trials. JAMA. 2001; 285:1987-91. [PubMed: 11308435]

Montgomery 1979 . Montgomery S, Asberg M. A new depression scale designed to be sensitive to change. British Journal of Psychiatry. 1979; 154:382-9. [PubMed: 444788]

NICE 2002 . National Collaborating Centre for Mental Health. Schizophrenia: Core interventions in the treatment and management of schizophrenia in primary and secondary care. National Institute for Clinical Excellence; 2002.

NICE 2009 . National Collaborating Centre for Mental Health. Core interventions in the treatment and management of schizophrenia in primary and secondary care (update). National Institute for Clinical Excellence; 2009.

Novaco 2003 . Novaco, R. The novaco anger scale and provocation inventory. Western Psychological Association; 2003.

Overall 1962 . Overall J, Gorham D. The brief psychiattric rating scale. Psychological Reports. 1962; 10:799-812.

Pilling 2002 . Pilling S, Bebbington P, Kuipers E, Garety P, Geddes J, Martindale B, Orbach G, Morgan C. Psychological treatments in schizophrenia: II. Meta-analysesof randomized controlled trials of social skills training andcognitive remediation. Psychological Medicine. 2002; 32:783791. [PubMed: 12171373]

Rosenberg 1965 . Rosenberg, M. Society and the Adolescent Self Image. Princeton University Press; 1965. The measurement of self-esteem; p. 297-307.

Tarrier 1993 . Tarrier N, Beckett R, Harwood S, Baker A, Yusupoff L, Ugarteburu I. A trial of two cognitive-behavioural methods of treating drug-resistant residual psychotic symptoms in schizophrenic patients: I. Outcome. British Journal of Psychiatry. 1993; 162:524-32. [PubMed: 8481745] 
Trower 2004 . Trower P, Birchwood M, Meaden A, Bryne S, Nelson A, Ross K. Cognitive therapy for command hallucinations: randomised controlled trial. The British Journal of Psychiatry. 2004; 184:312-320. [PubMed: 15056575]

Turkington 2004 . Turkington D, Dudley R, Warman DM, Beck AT. Cognitive-behavioral therapy for schizophrenia: A review. Journal of Psychiatric Practice. 2004; 10(1):5-16. [PubMed: 15334983]

Ukoumunne 1999 . Ukoumunne OC, Gulliford MC, Chinn S, Sterne JAC, Burney PGJ. Methods for evaluating area-wide and organistation-based intervention in health and health care: A systematic review. Health Technology Assessment. 1999; 3(5):1-75.

Webster 1997 . Webster, CD.; Douglas, KS.; Eaves, D.; Hart, SD. HCR-20: Assessing Risk for Violence. 2nd Edition. Simon Fraser University; 1997.

WHO 1973 . Report of the International Pilot Study of Schizophrenia. World Health Organization; [accessed 1 November 2009]

Wykes 2004 . Wykes T. Psychological treatment for voices in psychosis. Cognitive Neuropsychiatry. 2004; 9:25-41. [PubMed: 16571573]

Xia 2009 . Xia J, Adams CE, Bhagat N, Bhagat V, Bhoopathi P, El-Sayeh H, Pinfold V, Takriti Y. Losing participants before the trial ends erodes credibility of findings. Psychiatric Bulletin. 2009; 33:254-7.

* Indicates the major publication for the study 


\section{PLAIN LANGUAGE SUMMARY}

\section{Cognitive behaviour therapy versus other psychosocial treatments for schizophrenia}

Cognitive behavioural therapy (CBT) is a talking therapy first mentioned in 1952 but only became recommended as a routine treatment in 2002. CBT encourages people to openly discuss their beliefs, emotions and experiences with a therapist (individually or in a group), as well as participate in assessing their symptoms, emotional distress and behaviour. Such discussion is thought to help develop ways of challenging, coping and managing unhelpful thoughts and problem behaviour. People with schizophrenia may have difficulties with concentration, attention and motivation. The capacity to think, feel pleasure, talk openly and act also may be reduced. All of which can mean making friends, living independently and finding employment are sometimes hard. The idea of CBT is to help with these problems by coming up with 'real world' coping strategies and problem solving skills.

Relatively little is known about the effects of CBT when compared with other psychological or talking therapies (such as supportive therapy, psycho-education, group, relaxation and family therapy) in helping people with schizophrenia. This review found that research in this area was often small scale and of limited quality. The majority of therapists (65\%) met the review's standard of being qualified (but this was not a complete finding as most studies did not take into account appropriate training and the qualification of therapists).

In the main, no difference in overall effectiveness was found between CBT and other talking therapies. Relapses (people with schizophrenia becoming unwell again) and rehospitalisation (the need to go back into hospital) were not reduced. CBT was not any better at improving mental state compared to other talking therapies and CBT was no better or worse in managing the symptoms of schizophrenia, both in terms of managing positive symptoms (such as hearing voices or seeing things) and negative symptoms (not feeling emotions, inactivity which leads to weight gain).

No difference was found for leaving the study early or continuing treatment for CBT compared with other therapies, although the overall number of people who left the study early was relatively low compared to drug trials meaning that CBT and other talking therapies may better at retaining and keeping people with schizophrenia in treatment. No advantage for CBT was recorded with regard to death by natural causes or suicide, coping with anxiety, building self-esteem, developing insight or helping with anger or problem behaviours such as violence. Few studies reported the effect CBT had on quality of life and in developing better social or work skills.

The review, however, suggests that there might be some longer term advantage in CBT for dealing with emotions and distressing feelings. Some initial findings indicated that CBT may be of greater benefit to people with depression and managing its symptoms.

This Plain Language Summary was written by a consumer Benjamin Gray, Service User and Service User Expert, Rethink Mental Illness. ben.gray@ rethink.org 


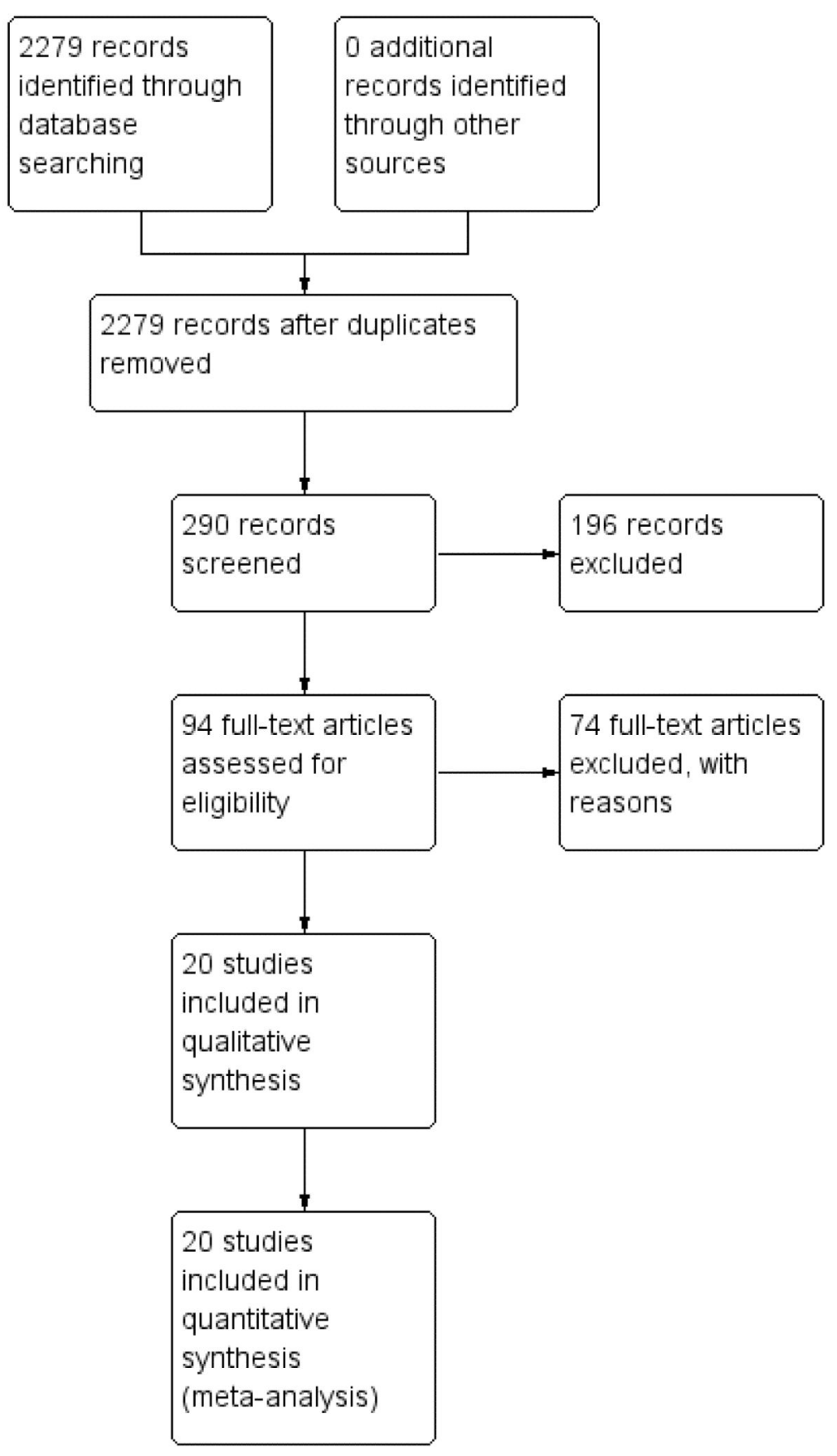

Figure 1. Study flow diagram 


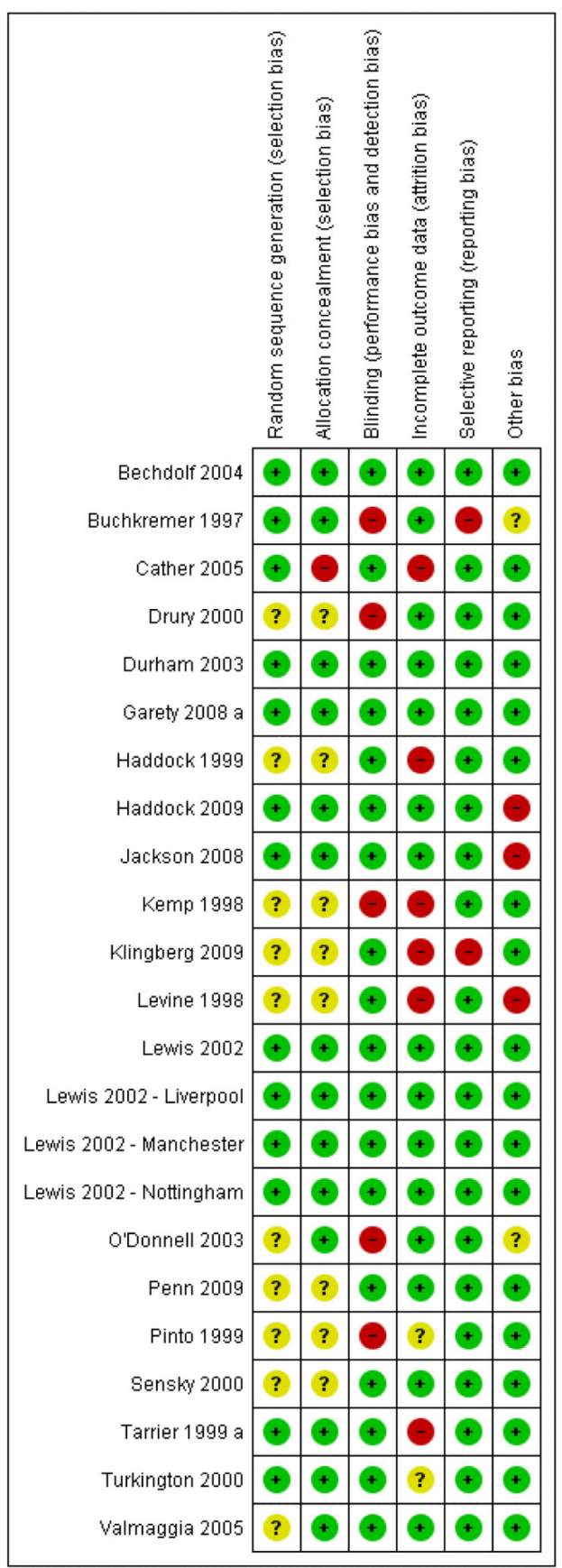

Figure 2. Risk of bias summary: review authors' judgements about each risk of bias item for each included study 


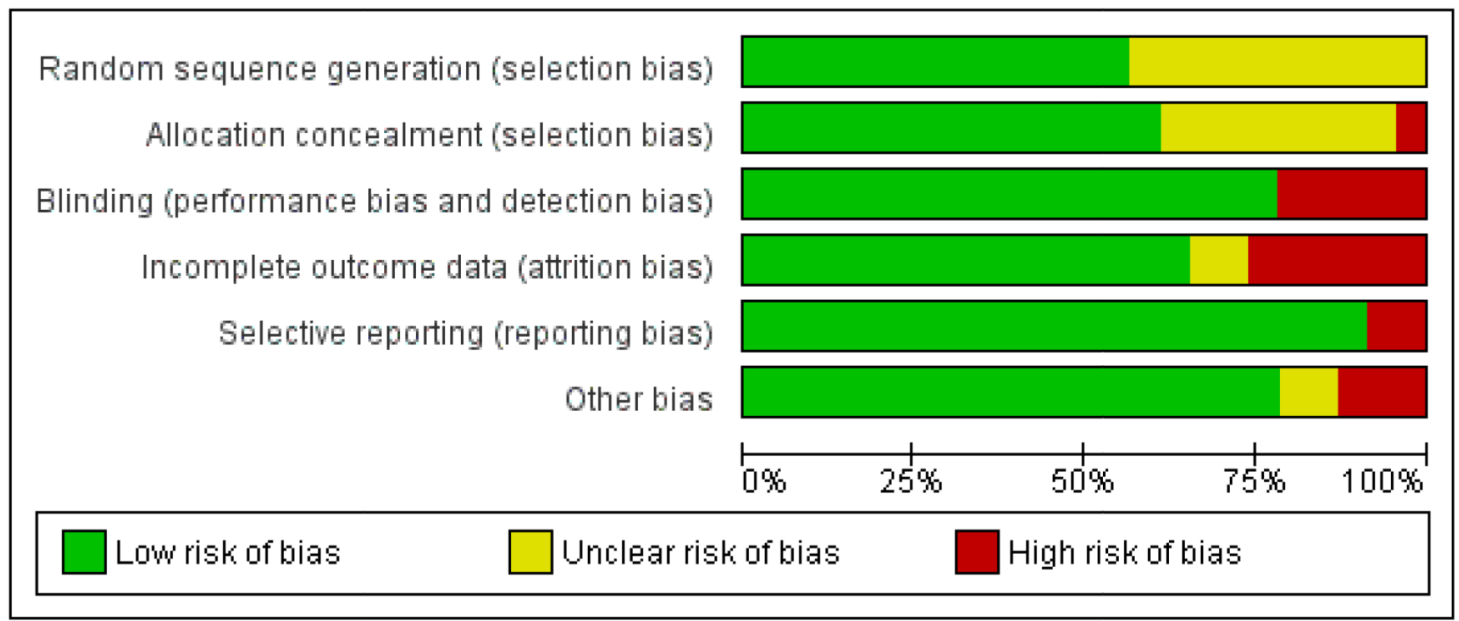

Figure 3. Risk of bias graph: review authors' judgements about each risk of bias item presented as percentages across all included studies 


\section{Table 1}

\section{Outcome categories}

\begin{tabular}{|c|c|}
\hline Category & Description \\
\hline General functioning & These relate to meaningful changes in symptomatology and general clinical condition, recovery and well-being \\
\hline Mental state & $\begin{array}{l}\text { These refer to presence or absence of symptoms of psychosis as well as continuous measures relating to } \\
\text { characteristics of such symptoms (e.g. preoccupation; conviction; frequency; duration; intensity, loudness; } \\
\text { perceived interference with daily living) and insight. Measures of general affect (e.g. anxiety, depression, shame, } \\
\text { hopelessness, anger; self-esteem) and symptom-related affect measures (e.g. voice-related distress; delusional } \\
\text { distress) are also considered. The presence or frequency of problematic behaviours (suicide attempts; deliberate } \\
\text { self-harm; violence to others, etc) and functional and adaptive behaviours (e.g. increased coping strategies) are } \\
\text { included }\end{array}$ \\
\hline Adverse outcomes & $\begin{array}{l}\text { All health interventions have the capacity for unintended and unwanted side effects. To date there has been a } \\
\text { paucity of studies that have attempted to identify adverse effects of psychological therapies. Such outcomes might } \\
\text { include dependency, increased distress, increased family dysfunction and disengagement from mental health } \\
\text { services }\end{array}$ \\
\hline Service utilisation & $\begin{array}{l}\text { The measurement of service utilisation and functional outcomes may convey important information regarding } \\
\text { health economic benefits, as well as provide indirect markers of personal independence. Such outcomes might } \\
\text { include number of acute hospital /inpatient respite days, number of acute hospital admissions or equivalent (e.g. } \\
\text { Home treatment/crisis team intervention; respite admissions), changes in legal status (MHA 1983), changes in } \\
\text { level of care (including accommodation type and intensity of service (Assertive Outreach Team versus } \\
\text { Community Mental Health Team)) }\end{array}$ \\
\hline Functional outcomes & $\begin{array}{l}\text { These outcomes might include changes in employment, occupational and educational status, level of received } \\
\text { benefits or social welfare, perceived quality of life and level of social functioning }\end{array}$ \\
\hline Pharmacological treatment & $\begin{array}{l}\text { These outcomes would include alterations in the degree of compliance with the prescribed medication regimen, as } \\
\text { well as alterations to the prescribed medication including changes in type of medication and prescribed dosage. } \\
\text { Unwanted side effects will also be assessed }\end{array}$ \\
\hline Economic outcomes & $\begin{array}{l}\text { These outcomes would include both the direct costs of CBT (e.g., costs relating to the provision of therapy) and } \\
\text { the indirect costs of CBT (e.g., reduction in medication, reduction in relapse, etc) }\end{array}$ \\
\hline
\end{tabular}




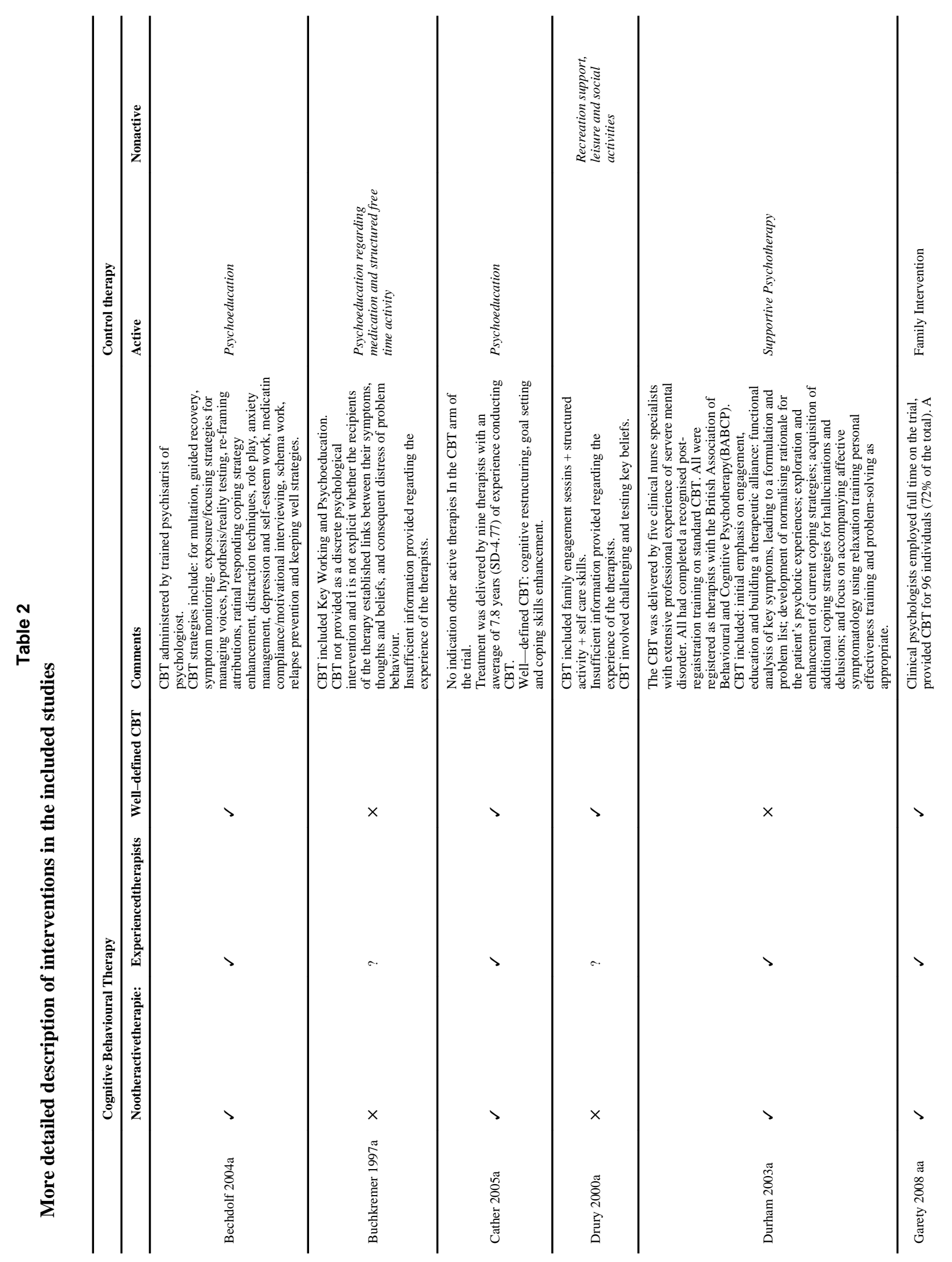




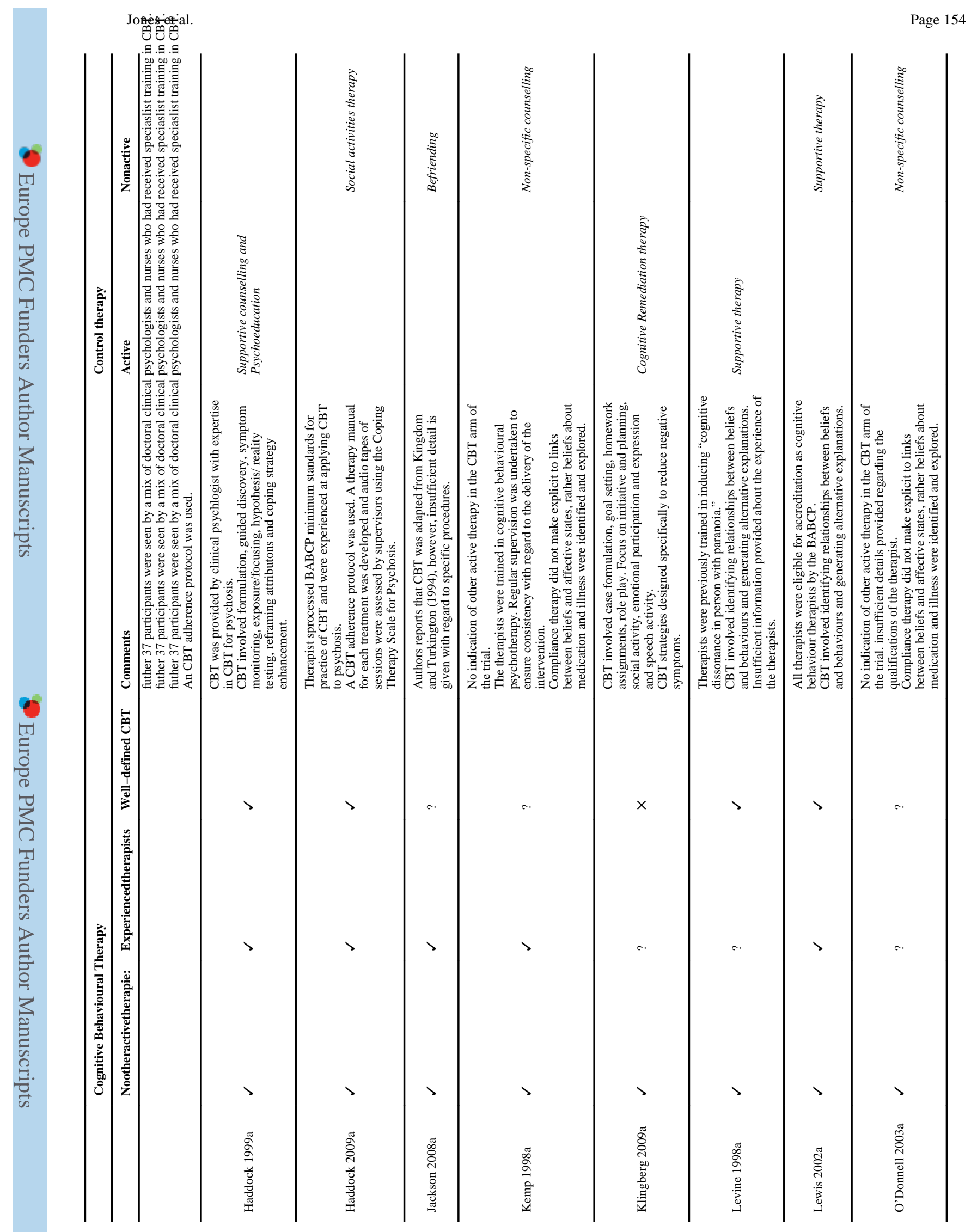

Cochrane Database Syst Rev. Author manuscript; available in PMC 2014 September 15. 
Jones et al.

Page 155

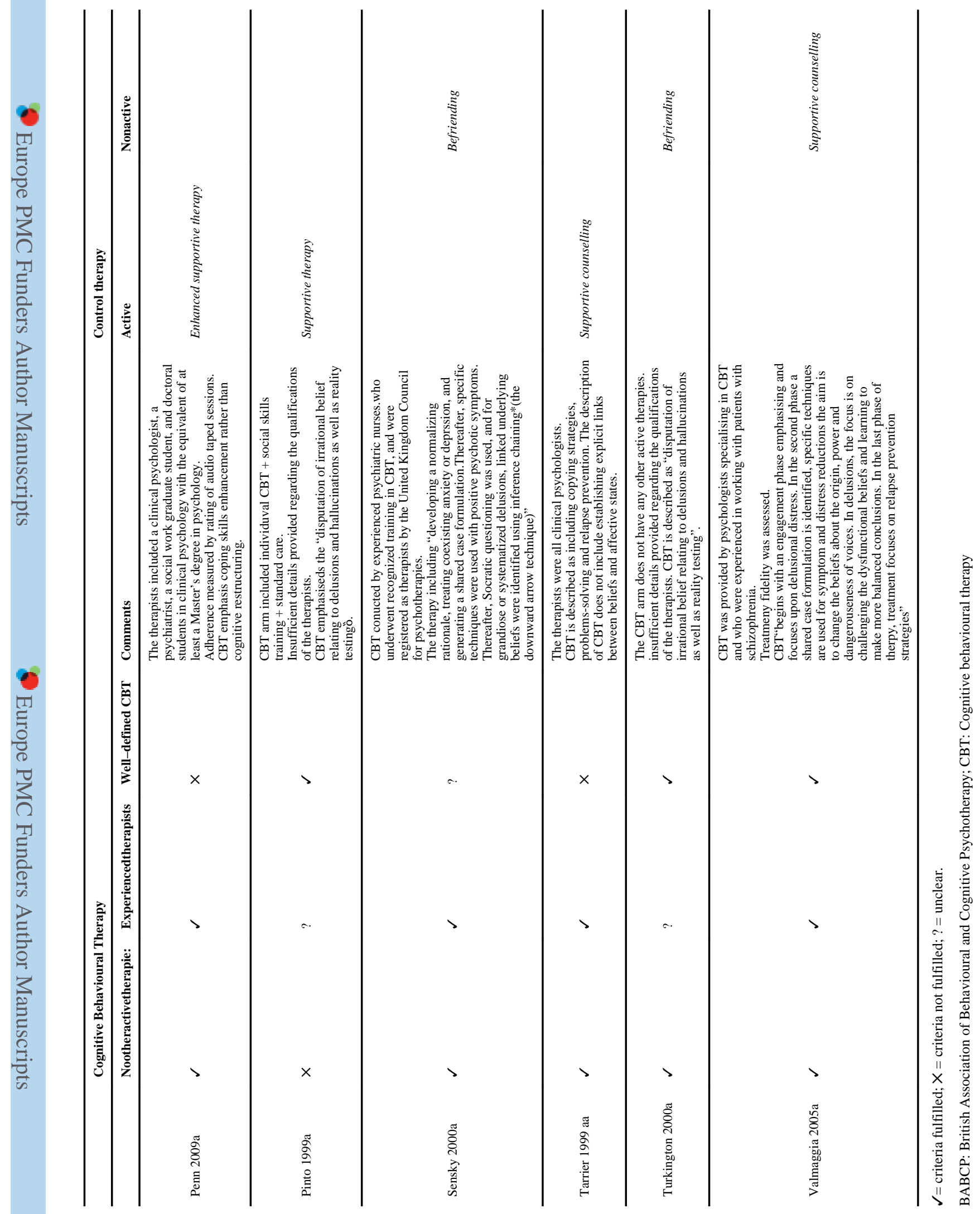

Cochrane Database Syst Rev. Author manuscript; available in PMC 2014 September 15. 